UNIVERSIDADE DE SÃO PAULO

INSTITUTO DE GEOCIÊNCIAS

\title{
ORIGEM E HIDROQUÍMICA DO NITRATO NAS ÁGUAS SUBTERRÂNEAS DO AQÜÍFERO ADAMANTINA EM URÂNIA, SP
}

\author{
FABIANA ALVES CAGNON
}

Orientador: Prof. Dr. Ricardo César Aoki Hirata

DISSERTAÇÃO DE MESTRADO

COMISSÃO JULGADORA

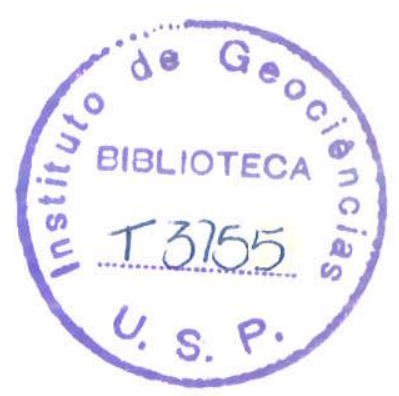

Nome

Presidente: Prof. Dr. Ricardo César Aoki Hirata

Examinadores: Prof. Dr. Ivo Karmann

Dr. Rodrigo César de Araújo Cunha

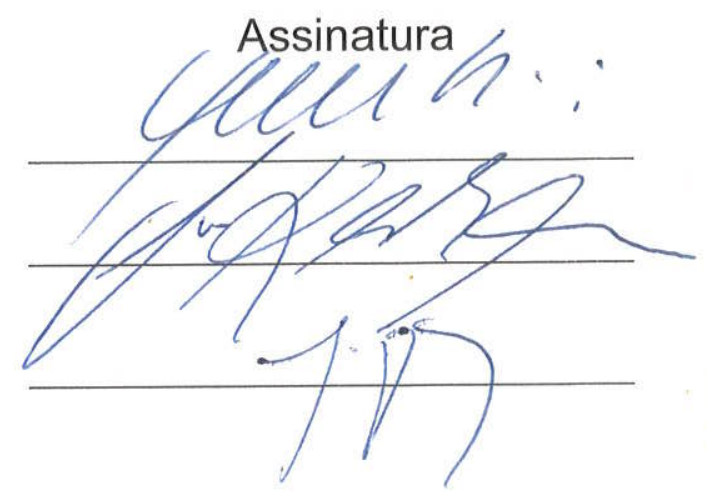

SÃO PAULO

2003 


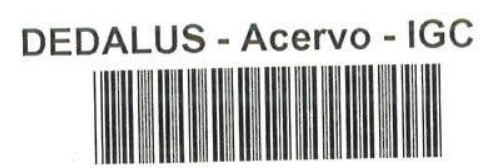

30900012039

UNIVERSIDADE DE SÃO PAULO

INSTITUTO DE GEOCIÊNCIAS

\section{ORIGEM E HIDROQUIIMICA DO NITRATO NAS ÁGUAS DO AQUÍFERO ADAMANTINA EM URÂNIA, SP}

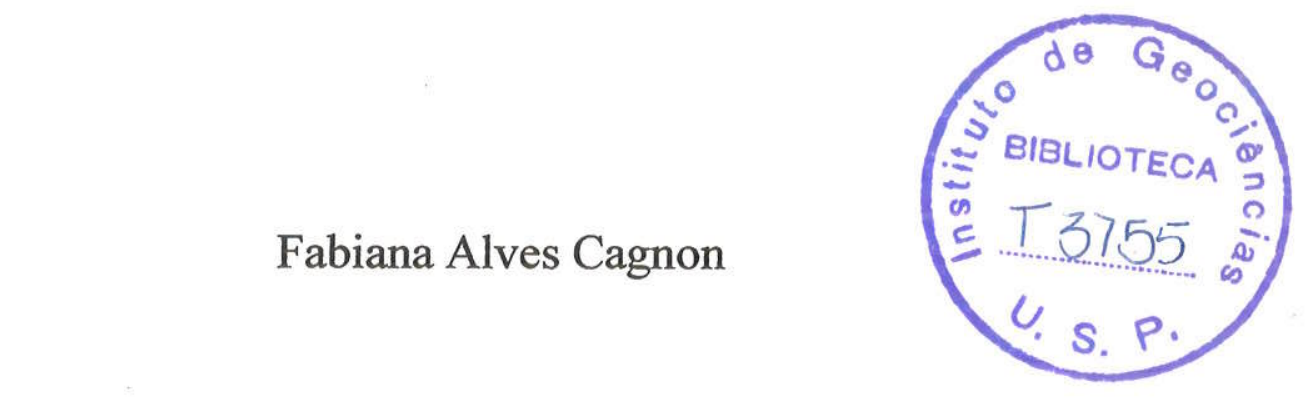

Orientador: Prof. Dr. Ricardo César Aoki Hirata

\section{DISSERTAÇÃO DE MESTRADO}

Programa de Pós - Graduação em Geologia Sedimentar e Ambiental

SÃO PAULO

2003 
É inevitável que, quanto mais ambicioso é o trabalho, mais imperfeita seja a sua execução...mas isso não quer dizer que ele só deva ser apresentado quando não houver mais nenhuma esperança de melhorá-lo. Friedrich Hayek

(The Construction of Liberty) 


\section{AGRADECIMENTOS}

Esta dissertação é o resultado da ajuda valiosa de entidades e pessoas às quais desejo manifestar minha profunda gratidão.

Ao Prof. Dr. Ricardo César Aoki Hirata pela orientação segura durante todas as etapas da elaboração deste trabalho, pela amizade, incentivo, paciência e ainda pelo exemplo de profissionalismo e dedicação à pesquisa;

Ao Curso de Pós-Graduação do Instituto de Geociências da Universidade de São Paulo por toda infraestrutura colocada à disposição;

Ao Centro de Aperfeiçoamento de Professores do Ensino Superior - CAPES pelo auxílio financeiro por meio de bolsa de mestrado;

À Fundação de Amparo à Pesquisa do Estado de São Paulo - FAPESP, pelo auxilio financeiro (Processo $n^{\circ} 00 / 10345-5$ );

À ERM BRASIL Ltda., pelo auxílio e constante incentivo durante todas as etapas desta pesquisa;

Aos colegas do Laboratório de Modelos Físicos (LAMO), Reginaldo, Marta, Claudia, Luiz, Alessandro, Gláucia, Angélica, Fabíola, Zeca, Alexandra, Lalas, Liliana, Marika, Cristiano e Douglas pela amizade e pelos debates, críticas e sugestões sempre valiosos;

Aos colegas da ERM BRASIL Ltda., em especial ao Eugênio, Yanko, Aldérico, Ferlin, Ricardo, Reginaldo, Susanne, Pedro, Maurício, Diego, Paulo, Jorge, Juliana, Alaine, Vanessa, Sasha, Rosi, Valéria, Cris, Kelly, Nil, Rodrigo, Paulo e Enrico pela ajuda, amizade, paciência e incentivo constantes;

Aos amigos do IPT, Zé Luíz Albuquerque, Cris, Ana, Kátia, Duda, Aluísio, Luís Celso e Zeno pelas valiosas sugestões, incentivo e amizade.

Aos meus pais e à minha irmã Valéria; pela confiança, constante incentivo e pelo amor que me dedicam hoje e sempre;

Ao Seu Zé e a Dona Lalá pelo amor e confiança;

Em especial ao Zé, companheiro de trabalho e amigo de todos as horas. Pela felicidade de tê-lo ao meu lado, vivendo os sonhos e me ajudando a torná-los realidade; $e$

A todas as pessoas que direta ou indiretamente contribuíram de alguma maneira para que este trabalho pudesse ser realizado. 


\section{SUMÁRIO}

Agradecimentos

iii

Lista de figuras

vii

Lista de tabelas

ix

Lista de quadros

ix

Lista de anexos

$x$

Lista de fotografias

$x i$

Resumo

xii

Abstract

xiii

1 Introdução

2 Objetivos

3 Revisão Bibliográfica

3.1 Nitrogênio: Aspectos Fundamentais

3.1.1 O Ciclo do Nitrogênio

3.1.2 Nitrificação

3.1.3 Relação do Ciclo do Nitrogênio com os Solos e as Águas Subterrâneas

3.2 Fontes de Contaminação por Compostos Nitrogenados das Águas Subterrâneas

3.3 Riscos à Saúde Humana

3.4 Isótopos de Nitrogênio

3.4.1 Identificação de Fontes Potenciais de Contaminação 
4 Área de Estudo

$\begin{array}{lll}4.1 & \text { Localização e Vias de Acesso } & 20\end{array}$

4.2 Histórico de Uso e Ocupação do Solo e Aspectos Socioeconômicos 20

4.3 Aspectos Fisiográficos $\quad 23$

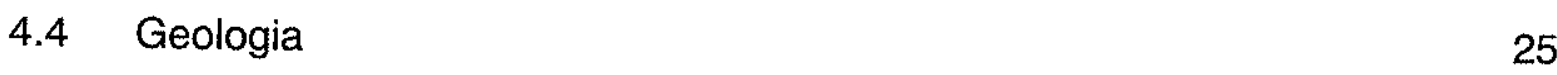

$\begin{array}{lll}4.5 & \text { Hidrogeologia } & 26\end{array}$

$5 \quad$ Materiais e Métodos 29

5.1 Cadastro de Poços Cacimbas e Tubulares 30

5.2 Cadastro de Fontes Potenciais de Contaminação 30

5.3 Levantamento Planialtimétrico 31

5.4 Determinação das Condições de Fluxo e Parâmetros Hidrogeológicos 31

5.5 Coleta de Amostras de Água Subterrânea e Realização de Análises Físico-Químicas

5.6 Análise dos Resultados 38

$\begin{array}{lll}\text { 5.6.1 Análise Estatística } & 38\end{array}$

5.6.2 Classificação e Evolução Hidroquímica das Águas Subterrâneas 40

6 Apresentação e Discussão dos Resultados 42

6.1 Controle de Qualidade 42

6.2 Cadastro de Poços Cacimbas e Tubulares 44

6.3 Fontes Potenciais de Contaminação 48

6.4 Hidrogeologia Local 56

6.5 Classificação e Evolução Hidroquímica das Águas Subterrâneas 62

6.6 Contaminação das Águas Subterrâneas por Nitrato - Distribuição Espacial e Temporal

6.7 Série Nitrogenada 
$\begin{array}{lll}6.8 & \text { Análises Isotópicas } & 79\end{array}$

7 Conclusões $\quad 81$

8 Recomendações $\quad 84$

9 Referências Bibliográficas $\quad 86$ 


\section{LISTA DE FIGURAS}

Figura 3.1 - O ciclo do nitrogênio (CANTER, 1997).

Figura 3.2 - Principais fontes e caminhos do nitrogênio em subsuperfície (FREEZE \& CHERRY, 1979).

Figura 3.3 - Intervalos da razão ${ }^{15} \mathrm{~N}$ presente nos diferentes materiais (AMBERGER \& SCHMIDT, 1987 apud CLARK \& FRITZ, 1997; BÖTTCHER et al., 1990; LÉTOLLE, 1980 apud CLARK \& FRITZ, 1997).

Figura 4.1 - Localização da área de estudo

Figura 6.1 - Percentuais de erros analíticos obtidos versus número de amostras analisadas

Figura 6.2 - Localização de poços

Figura 6.3 - Área urbana do município de Urânia nos anos de 1962, 1971, 1985,1997 e 2001.

Figura 6.4 - Fontes potenciais de contaminação

Figura 6.5 - Cota dos Níveis de Água Estáticos em Poços Cacimbas (m)

Figura 6.6 - Potenciométrico - outubro/2001

Figura 6.7 - Diagramas de Piper - (A) abril/00, (B) agosto/01, (C) fevereiro/01, (D) agosto/01 e (E) setembro/01

Figura 6.8 - Histogramas: (A) concentração de nitrato na zona rasa (abril/00),

(B) valores de condutividade elétrica na zona intermediária (junho/99) e (C) concentração de cloreto na zona intermediária (agosto/01)

Figura 6.9 - Gráfico de correlação da concentração de nitrato (mg/L) - set/01 com as profundidades dos níveis de água $(\mathrm{m})$ - out/01

Figura 6.10 - Isoconcentração de nitrato (mg/L), zonas rasa e intermediária, estação úmida

Figura 6.11 - Isoconcentração de nitrato (mg/L), zonas rasa e intermediária, estação seca 
Figura 6.12 - Isoconcentração de cloreto (mg/L), zonas rasa e intermediária, estação úmida

Figura 6.13 - Isoconcentração de cloreto $(\mathrm{mg} / \mathrm{L})$, zonas rasa e intermediária, estação seca

Figura 6.14 - Correlação nitrato $\times$ cloreto, nitrato $x$ condutividade elétrica e nitrato $\times$ sódio.

Figura 6.15 - Gráficos das concentrações de nitrato, cloreto e condutividade elétrica, no período de junho de 1998 a setembro de 2001

Figura 6.16 - Gráfico de correlação da concentração de nitrato $(\mathrm{mg} / \mathrm{L})$ com $15 \mathrm{~N}(\%)$. 


\section{LISTA DE TABELAS}

Tabela 6.1 - Percentuais de erros abaixo de 10\% e média das condutividades elétricas para cada campanha - resultados obtidos em laboratório e no campo

Tabela 6.2 - Sumário dos Parâmetros Hidrogeológicos para o Aqüífero Adamantina

\section{LISTA DE QUADROS}

Quadro 3.1 - Relação entre as espécies de nitrogênio e seus respectivos estados de oxidação (STUMM \& MORGAN,1996).

Quadro 4.1 - População de Urânia desde 1970 a 2000 e projeção para 2010

Quadro 5.1 - Faixas de leitura dos parâmetros medidos com RQFLEX-Plus

Quadro 5.2 - Programa de amostragem das águas subterrâneas

Quadro 5.3 - Relação dos parâmetros analisados em laboratório e respectivos métodos analíticos

Quadro 5.4 - Limites de detecção obtidos para cada parâmetros

Quadro 5.5 - Sumário dos dados utilizados na confecção dos diagramas

Quadro 6.1 - Cadastro das fontes potenciais de contaminação - fossas

Quadro 6.2 - Cadastro das fontes potenciais de contaminação - área agrícola 


\section{LISTA DE ANEXOS}

Anexo 1 - Sumário dos resultados analíticos das amostras de água subterrânea

Anexo 2 - Cálculos dos percentuais de erros obtidos com o balanço iônico resultados obtidos em laboratório

Anexo 3 - Cálculos dos percentuais de erros obtidos com o balanço iônico resultados obtidos no campo (cloreto e nitrato)

Anexo 4 - Resultados analíticos e cálculo dos percentuais de erros para as amostras em duplicata

Anexo 5 - Cadastros de poços cacimbas e tubulares

Anexo 6 - Medidas dos níveis de água e carga hidráulica nos meses de. agosto, setembro e outubro de 2001

Anexo 7 - Diagramas de Pearson - zona rasa

Anexo 8 - Diagramas de Pearson - zona intermediária

Anexo 9 - Sumário dos intervalos de concentração, médias aritméticas, desvios padrão, coeficiente de variação (CV's) e número de amostras utilizadas nos cálculos para os compostos nitrato, cloreto, $\mathrm{pH}$, Eh e amônio 


\section{LISTA DE FOTOGRAFIAS}

Foto 1 - Medição do nível de água em poço cacimba.

Foto 2 - Levantamento topográfico de poço cacimba, utilizando GPS.

Foto 3 - Bomba elétrica de superfície instalada em poços tubular.

Foto 4 - Poço tubular - PT-30.

Foto 5 - Poço tubular PT-29 em área de mata nativa.

Foto 6 - Poço tubular PT-28 em área agrícola.

Foto 7 - Coleta de água no poço tubular PT-32. 


\section{RESUMO}

CAGNON, F.A. (2001) Origem e Hidroquímica do Nitrato nas Águas do Aqüifero Adamantina em Urânia, SP. São Paulo, 148 p. Dissertação (Mestrado) - Instituto de Geociências, Universidade de São Paulo.

O proposto deste estudo é a determinação da origem e o entendimento do comportamento geoquímico do nitrato no Aqüífero Adamantina, em Urânia, noroeste do Estado de São Paulo. As principais atividades desenvolvidas foram a elaboração de um cadastro de poços e de fontes potenciais de contaminação e a realização de análises físico-químicas (no campo e em laboratório) e isotópicas (nitrogênio) das águas subterrâneas.

O Aqüífero Adamantina, na área urbana do município de Urânia, encontra-se extensivamente contaminado por nitrato e poluído por cloreto e amônio. A fonte de contaminação é do tipo antrópica, multipontual, proveniente de sistema de saneamento in situ do tipo fossas negras.

As maiores concentrações de nitrato foram identificadas na zona rasa (ZR) do aqüífero (até $21 \mathrm{~m}$ de profundidade). Estas distribuem-se na forma de "ilhas" circulares. Foram observadas variações temporais destas concentrações quando comparadas às estações seca e úmida.

$\mathrm{Na}$ ZR distinguem-se águas bicarbonatas nitratadas cálcicas, secundariamente bicarbonatadas nitratadas sódicas e cloro-nitratadas cálcicas. As águas de profundidade intermediária (ZI), de 57 a $104 \mathrm{~m}$ de profundidade, são bicarbonatadas cálcicas e bicarbonatadas nitratadas cálcicas. Na zona profunda (ZP), até $160 \mathrm{~m}$ de profundidade, as águas são bicarbonatadas sódicas. Estas evoluem, da ZR para ZI, acompanhando o fluxo subterrâneo, da recarga para a descarga, junto às principais drenagens que cortam a área, com diminuição das concentrações de nitrato, cloreto e sódio. Predomina nas zonas rasa e intermediária um ambiente hidroquímico oxidante. 


\section{ABSTRACT}

CAGNON, F.A. (2001) Origin and Chemistry of Nitrate in Groundwater of the Adamantina Aquifer in Urânia, SP. São Paulo, 148 p. Dissertation (Masters Degree Course) - Geosciences Institute, University of São Paulo.

This study has been conducted with a view to determining the origin and understanding the geochemical behavior of nitrate in the Adamantina Aquifer in Urânia, located in the northwest of the state of São Paulo. The main activities developed included a survey of wells and potential sources of contamination, as well as physical-chemical analyses (in the field and the laboratory) and isotopic (nitrogen) analyses of groundwater.

In the urban area of the municipality of Urânia, the Adamantina Aquifer is found to be extensively contaminated by nitrate and polluted with chloride and ammonia. The source of this contamination is anthropic and multi-point in nature, caused by the in-situ sanitation system (cesspit).

The highest concentrations of nitrate were detected in the shallow zone (ZR) of the aquifer (until $21 \mathrm{~m}$ depth). These concentrations are distributed in the form of circular "islands". Seasonal variations in these concentrations were observed when making a comparison between the rainy and dry seasons of the year.

In the $\mathrm{ZR}$, there are found to be calcium-nitrate-bicarbonate waters and, to a lesser extent, sodium-nitrate-bicarbonate and calcium-chloride-nitrate waters. Groundwater of intermediate depth (ZI), from 57 to $104 \mathrm{~m}$ depth, is calciumbicarbonate and calcium-nitrate-bicarbonate. In the deep zone (ZP), until $160 \mathrm{~m}$ depth, sodium-bicarbonate waters are to be found. These waters evolve from the $\mathrm{ZR}$ to the $\mathrm{Zl}$, in a manner that accompanies groundwater flow, from the recharge zone to the discharge zone, joined to the main drains that cross the area, with a fall in concentrations of nitrate, chloride and sodium. An oxidizing hydrochemical environment predominates in the shallow and intermediate zones. 
O nitrato é um dos poluentes de ocorrência mais freqüente nas águas subterrâneas. Em concentrações superiores a $10 \mathrm{mg} / \mathrm{L}-\mathrm{N}$ ou $45 \mathrm{mg} / \mathrm{L}-\mathrm{NO}_{3}{ }^{-}$, pode causar metahemoglobinemia e câncer (Portaria 1.469, de dezembro de 2000, do Ministério da Saúde). Entre as fontes antrópicas deste contaminante, destacamse o uso de fertilizantes orgânicos e inorgânicos em lavouras, a criação de animais, os sistemas de saneamento in situ (fossas sépticas ou negras) e o desmatamento de áreas de vegetação natural. Em urbanizações providas de esgoto sanitário, rupturas nas tubulações podem contribuir como focos locais de poluição.

A despeito da grande importância assinalada, estudos específicos da contaminação de nitrato, por saneamento ou atividades agrícolas, são ainda bastante restritos no Brasil, sobretudo quando o tema é enfocado com um alto grau de detalhamento. A necessidade de definir a origem do nitrato, para que seja possivel buscar novas formas de amenização do problema, levou à apresentação desta dissertação.

Altos teores de nitrato, muitas vezes excedendo os valores de potabilidade, têm sido detectados em poços tubulares pouco profundos e em cacimbas na cidade de Urânia, noroeste do Estado de São Paulo (HIRATA, 2000a; BERTOLO \& HIRATA, 2000; GUTIERREZ, 1999). Na estação experimental que monitora o comportamento hidrogeoquímico da zona não-saturada, foram também detectadas altas concentrações de nitrato em lisímetros (BERTOLO \& HIRATA, 2000; BERTOLO, 2001). Estes estudos, entretanto, não determinaram a origem da contaminação, mas acredita-se que provenham de fossas sépticas ou negras e/ou do uso incorreto de fertilizantes nitrogenados. A cidade conta hoje com boa cobertura das redes de água e esgoto, gerenciadas pela Sabesp (Companhia de Saneamento Básico do Estado de São Paulo), porém grande parte desta ainda utiliza sistema de saneamento do tipo misto, caracterizado pelo uso de fossas negras, e poços cacimbas e tubulares para a captação de água, muitas vezes utilizada como fonte de água potável. Soma-se, a isto o fato de que em décadas passadas a presença de fossas sépticas e negras era bastante comum. 
Segundo HIRATA (2000a), teores anômalos de nitrato foram detectados em $85 \%$ das amostras de poços cacimbas e em $30 \%$ dos poços tubulares que se concentram na zona de recarga do aqüífero, sendo evidente a presença de contaminação por nitrato nas águas rasas.

A contaminação de aqüiferos por nitrato não se restringe à Urânia, visto que - processo histórico de ocupação territorial foi muito parecido ao que experimentaram os vários municípios onde o problema também ocorre. Embora não exista um levantamento sistemático da situação paulista, acredita-se que várias dezenas de cidades estejam convivendo com o problema (CAMPOS et al., 1994), incluindo grandes centros como São José do Rio Preto (BARCHA, 1980), Bauru (HIRATA, 2000b), Marília, Presidente Prudente, Jaú, Ribeirão Preto, entre outros.

Muitos dos relatos deste tipo de contaminação descrevem ainda o problema como superficial, não atingindo os poços mais profundos. Uma das questões que se coloca é qual será a evolução do problema e se poderá haver comprometimento de porções mais profundas do aqüifero. É importante lembrar que, em vários locais contaminados, o sistema de saneamento por meio da coleta do efluente doméstico já havia sido implementado há algumas décadas, e a agricultura já havia sido substituida por outras atividades. Entretanto, a persistência do contaminante está fazendo com que o problema evolua e, dependendo de sua intensidade, pode atingir porções profundas do aqüifero.

Os resultados apresentados nesta dissertação fazem parte de um projeto de auxílio à pesquisa intitulado "A Origem do Nitrato e a Evolução do Impacto nas Águas do Aqüifero Adamantina no Município de Urânia (SP)" que contou com o apoio financeiro da Fundação de Amparo à Pesquisa do Estado de São Paulo (FAPESP/ Processo 00/10345-5). 


\section{OBJETIVOS}

São objetivos desta pesquisa:

determinar a origem do nitrato na água subterrânea do Aquífero Adamantina no município de Urânia; e

$>$ aprofundar o entendimento do comportamento geoquímico do nitrato na zona saturada.

\section{REVISÃO BIBLIOGRÁFICA}

A revisão bibliográfica foi desenvolvida com base nas principais publicações referentes aos temas desta pesquisa.

\subsection{Nitrogênio: Aspectos Fundamentais}

$O$ nitrato pode ser expresso como nitrogênio-nitrato $\left(\mathrm{NO}_{3}-\mathrm{N}\right)$ ou nitrato $\left(\mathrm{NO}_{3}{ }^{-}\right)$. Existem quatro aspectos fundamentais para o entendimento do nitrato nas águas subterrâneas. $O$ primeiro deles diz respeito ao ciclo do nitrogênio e suas propriedades químicas e microbiológicas; o segundo compreende o ciclo do nitrogênio e sua relação com o solo e a água subterrânea; o terceiro está associado às fontes contaminantes e o quarto estuda a relação entre excessivas concentrações de nitrato nas águas subterrâneas e os riscos à saúde humana.

\subsubsection{O Ciclo do Nitrogênio}

O movimento e a transformação dos compostos nitrogenados na biosfera podem ser caracterizados com o ciclo do nitrogênio (Figura 3.1). 


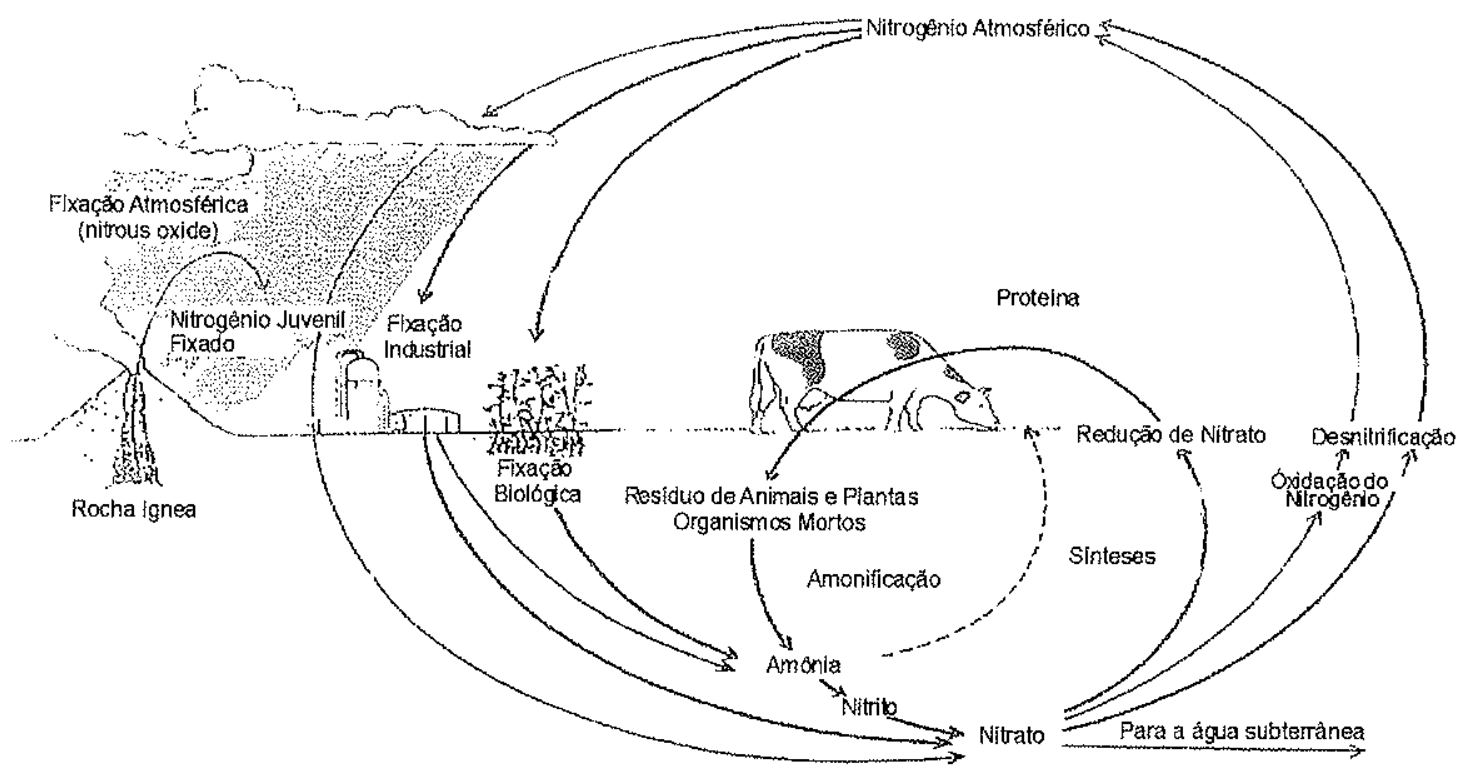

Figura 3.1 - O ciclo do nitrogênio (CANTER, 1997).

O nitrogênio na forma de nitrato é um dos mais problemáticos e difundidos contaminantes dentre $O$ vasto número de potenciais contaminantes das águas subterrâneas (KEENEY,1986 apud CANTER,1997). Ele é considerado o principal constituinte da atmosfera, com aproximadamente $78 \%$ em volume, e pode ocorrer na natureza de muitas formas. É um elemento biologicamente ativo e participa de uma infinidade de reações que são importantes para a vida, e que afetam a qualidade da água.

O nitrogênio atmosférico pode combinar com o hidrogênio ou oxigênio antes de ser assimilado pelas plantas. As plantas, por sua vez, são consumidas por animais. A intervenção humana, por meio de processos de fixação do nitrogênio industrial e do cultivo em larga escala de legumes, exerce papel preponderante na mudança deste ciclo. A quantidade de nitrogênio fixada anualmente por estes dois mecanismos excede em mais de $10 \%$ a quantidade de nitrogênio fixada pelo ecossistema terrestre anterior ao advento da agricultura (USEPA, 1994).

O nitrogênio ocorre na natureza em sete estados de oxidação, variando desde $-3\left(\mathrm{NH}_{3}\right)$, na forma mais reduzida, até $+5\left(\mathrm{NO}_{3}{ }^{-}\right)$, mais oxidada (Quadro 3.1). 
Quadro 3.1 - Relação entre as espécies de nitrogênio e seus respectivos estados de oxidação (STUMM \& MORGAN, 1996).

\begin{tabular}{|c|c|c|}
\hline Espécie & Estado de Oxidação & Fonte \\
\hline $\mathrm{NO}_{3}^{-}$ & +5 & $\begin{array}{c}\text { Fertilizantes, efluentes domésticos e } \\
\text { industriais. }\end{array}$ \\
\hline $\mathrm{NO}_{2}(\mathrm{~g})$ & +4 & Combustiveis fósseis. \\
\hline $\mathrm{NO}_{2}^{-}$ & +3 & $\begin{array}{l}\text { Fase intermediária da nitrificação e } \\
\text { desnitrificacão. }\end{array}$ \\
\hline $\mathrm{NO}(\mathrm{g})$ & +2 & Combustiveis fósseis. \\
\hline $\mathrm{N}_{2} \mathrm{O}(\mathrm{g})$ & +1 & $\begin{array}{l}\text { Combustiveis fósseis (fase intermediária } \\
\text { da nitrificação). }\end{array}$ \\
\hline $\mathrm{N}_{2}(\mathrm{~g})$ & 0 & $\begin{array}{c}\text { Fertilizantes, atividade biológica e } \\
\text { atmosfera. }\end{array}$ \\
\hline $\mathrm{NH}_{4}^{+}, \mathrm{NH}_{3}(\mathrm{~g})$ & -3 & $\begin{array}{l}\text { Fertilizantes, excrementos de animais, } \\
\text { efluentes domésticos e industriais. }\end{array}$ \\
\hline
\end{tabular}

Os solos, oceanos, lagos, a atmosfera e a atividade biológica constituem as principais fontes naturais de nitrogênio no planeta. A transferência deste elemento para os diferentes ecossistemas é contínua.

Os mecanismos de transporte primariamente responsáveis pelo movimento do nitrogênio no meio ambiente incluem precipitação, sedimentação em sistemas aquáticos, vento, movimento das águas subterrâneas e superficiais e volatilização. Estes mecanismos são controlados pela: temperatura, $\mathrm{pH}$, flora microbiológica, potencial de oxidação e redução e a disponibilidade no substrato de nutrientes e oxigênio. Apesar de mecanismos de transporte e transformação serem tipicamente considerados como processos individuais, é importante reconhecer que estes compreendem uma dinâmica contínua e muitas vezes não é possivel distinguir os limites que governam a transformação de formas específicas de nitrogênio (USEPA, 1994).

O nitrogênio orgânico pode ser incorporado aos animais, por meio da alimentação, ou propiciar à formação de nitrogênio amoniacal (amônio e amônia). O nitrogênio amoniacal pode seguir destinos diferentes no solo, como a geração 
de formas mais oxidadas, transferência para outros ecossistemas ou, até mesmo, troca catiônica entre os argilominerais e matéria orgânica, propiciando sua fixação no solo (NOMMIK \& VAHTRAS, 1982). Desta forma, a transformação dos compostos nitrogenados pode ocorrer por meio de diferentes mecanismos, os quais incluem fixação, amonificação, sínteses, desnitrificação e nitrificação.

A fixação refere-se à incorporação do nitrogênio inerte e gasoso em compostos químicos, os quais podem ser utilizados pelas plantas e animais. A morte, seguida da decomposição de animais e vegetais, leva à formação de nitrogênio amoniacal na forma de amônio ou amônia (amonificação), pela ação de bactérias de acordo com as reações (1) e (2):

$$
\begin{aligned}
0,5 \mathrm{~N}_{2}(\mathrm{~g})+1,5 \mathrm{H}_{2}(\mathrm{~g})+\mathrm{H}^{+}\left(10^{-7} \mathrm{M}\right) \Leftrightarrow \mathrm{NH}_{4}^{+} \\
0,5 \mathrm{~N}_{2}(\mathrm{~g})+0,75 \mathrm{CH}_{2} \mathrm{O}+0,75 \mathrm{H}_{2} \mathrm{O}+\mathrm{H}^{+}\left(10^{-7} \mathrm{M}\right) \Leftrightarrow 0,75 \mathrm{CO}_{2}+\mathrm{NH}_{4}^{+}
\end{aligned}
$$

Os argilominerais presentes no solo podem fixar o amônio por meio de processos de troca catiônica, ilustrados segundo a reação (3):

$$
\mathrm{RK}^{+}+\mathrm{NH}_{4}^{+} \Leftrightarrow \mathrm{RNH}_{4}^{+}+\mathrm{K}^{+}
$$

$\mathrm{O}$ amônio que não é adsorvido é, então, convertido a nitrito $\left(\mathrm{NO}_{2}{ }^{-}\right) \mathrm{e}$, posteriormente, oxidado a nitrato $\left(\mathrm{NO}_{3}{ }^{-}\right)$.

Síntese ou assimilação está relacionada aos mecanismos bioquímicos que usam compostos de amônio ou nitrato para formar a proteína de plantas e outros compostos nitrogenados.

\subsubsection{Nitrificação}

Segundo USEPA (1994), a nitrificação é a oxidação biológica do ín amônio $\left(\mathrm{NH}_{4}{ }^{+}\right)$. Isto sucede em dois estágios: na primeira etapa, forma-se o nitrito e, num segundo estágio, o nitrato.

O nitrito ocorre geralmente em pequenas quantidades, sendo muito baixa a sua concentração no solo. Este composto é posteriormente oxidado a nitrato $\left(\mathrm{NO}_{3}{ }^{-}\right)$por intermédio de bactérias. Este processo ocorre em meio aeróbio em lagos, mares, solos e águas subterrâneas. Segundo SCHMIDT (1982), os 
principais fatores controladores desse processo são $\circ \mathrm{pH}$, temperatura, Eh e os conteúdos de $\mathrm{O}_{2}$ e $\mathrm{CO}_{2}$.

O processo de nitrificação ocorre por meio das reações (4) e (5) (LEWIS et al., 1988):

$$
\begin{aligned}
2 \mathrm{NH}_{4}{ }^{+}+2 \mathrm{OH}^{-}+3 \mathrm{O}_{2}{ }^{-} & =2 \mathrm{NO}_{2}^{-}+2 \mathrm{H}^{+}+4 \mathrm{H}_{2} \mathrm{O} \\
2 \mathrm{NO}_{2}^{-}+\mathrm{O}_{2} & =2 \mathrm{NO}_{3}^{-}{ }^{-}(5)
\end{aligned}
$$

FREEZE \& CHERRY (1979) definem nitrificação como um processo aeróbio por meio do qual ocorre a degradação de substâncias orgânicas nitrogenadas por intermédio de bactérias. As bactérias que degradam 0 amônio são as nitrossomonas (reação 4), em condiçōes de $\mathrm{pH}=7$ e $\mathrm{pE}>6$, com ganho ou perda de energia, e as que degradam o nitrito, as nitrobactérias (reação 5), ambas organismos quimiolitrofos aeróbios.

O processo de nitrificação depende não só da quantidade de oxigênio, mas também de matéria orgânica disponiveis no solo, correndo então normalmente nas zonas não-saturada e saturada rasa, onde tais condições são satisfeitas.

$O$ processo inverso, onde o nitrato $\left(\mathrm{NO}_{3}{ }^{-}\right)$é reduzido a nitrito e posteriormente a gás nitrogênio $\left(\mathrm{N}_{2}\right)$ ou, em menor quantidade, a $\mathrm{N}_{2} \mathrm{O}, \mathrm{NO}$ e $\mathrm{NO}_{2}{ }^{-}$, é denominado desnitrificação.

\subsubsection{Relação do Ciclo do Nitrogênio com os Solos e as Águas Subterrâneas}

Segundo CANTER (1997), a presença de nitrato nas águas subterrâneas em altas concentrações é normalmente o resultado da lixiviação do nitrogênio presente na zona não-saturada e a transformação deste para nitrato, tanto na zona saturada como na não-saturada. O nitrogênio pode ocorrer na zona nãosaturada naturalmente ou ser introduzido por meio de atividades antrópicas (FREEZE \& CHERRY, 1979).

A Figura 3.2 apresenta as principais fontes e caminhos do nitrogênio em subsuperfície. 


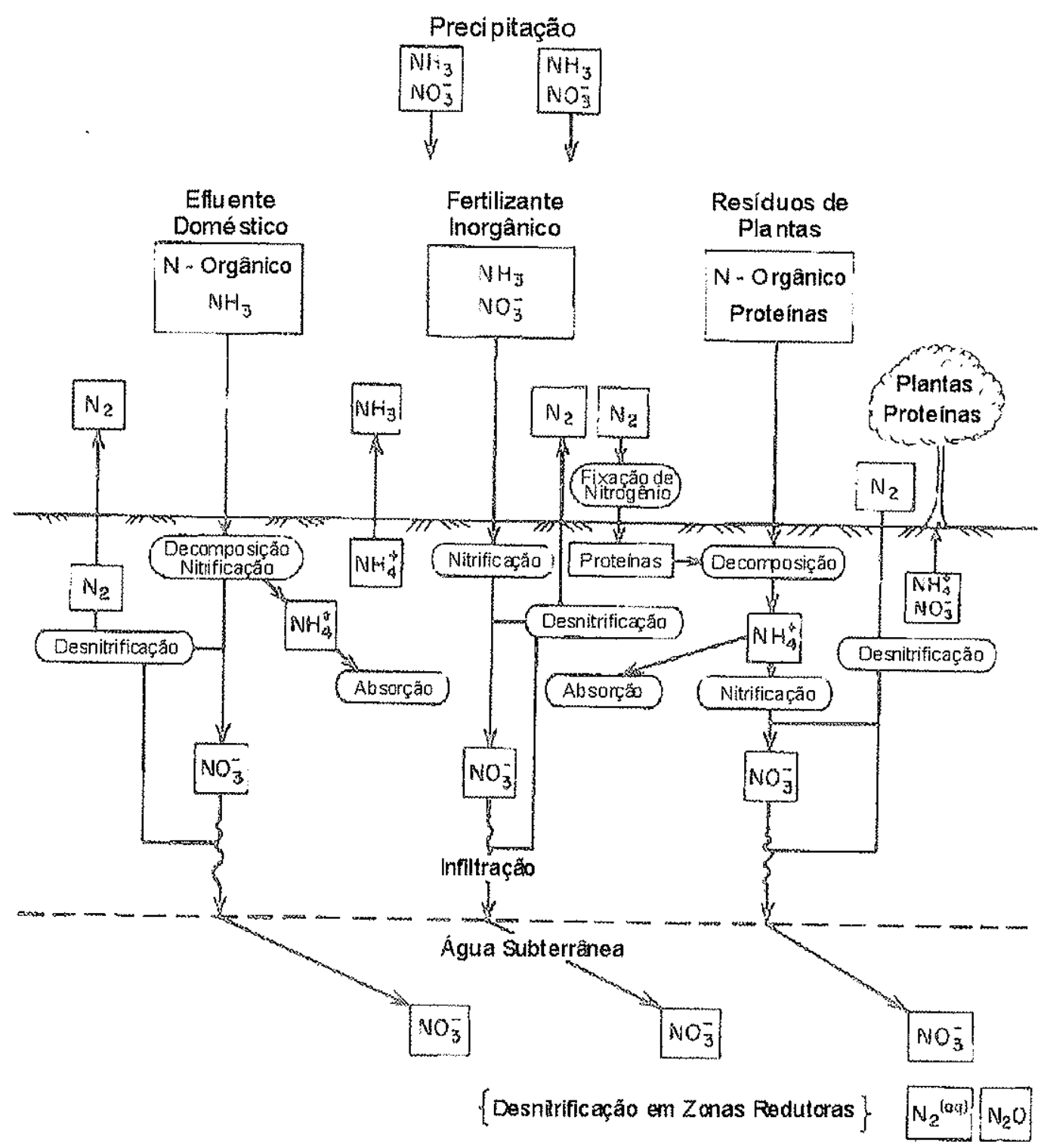

Figura 3.2 - Principais fontes e caminhos do nitrogênio em subsuperfície (FREEZE \& CHERRY, 1979).

O nitrogênio presente no solo pode ocorrer nas formas orgânica e inorgânica. A fixação deste elemento no solo, feita principalmente por meio da ação biológica, diminui com a profundidade. Algumas bactérias presentes nas raizes de leguminosas e as algas azuis são capazes de fixar o nitrogênio e assimilá-lo como nitrogênio orgânico (APPELO \& POSTMA, 1993; STUMM \& MORGAN, 1996). Adicionalmente, a fixação do nitrogênio por bactérias converte o gás nitrogênio em formas disponiveis para a vida vegetal.

Processos químicos ou microbiológicos podem influenciar o movimento de diversas formas de nitrogênio em subsuperficie. Os processos de nitrificação $e$ 
desnitrificação são aqueles ao longo dos quais fenômenos microbiológicos (degradação de compostos nitrogenados pelas bactérias), abióticos (modificação nas condições de oxidação do meio) e hidrodinâmicos (dispersão mecânica) influenciam as concentrações de nitrato nas águas subterrâneas.

Usualmente mais de $90 \%$ do nitrogênio presente nos solos é orgânico, da mesma forma que aquele presente nas plantas e nos animais ou em húmus originados da decomposição de resíduos de plantas e animais (USEPA, 1994).

As concentrações de nitrato são normalmente baixas porque este composto é utilizado em sínteses, mecanismos bioquímicos que consomem nitrato para formar a proteína de plantas e outros compostos, lixiviado pela infiltração de água ou, muitas vezes, consumido em processos de desnitrificação que ocorrem abaixo da camada superficial e aeróbia do solo. Entretanto, sínteses e desnitrificação normalmente não removem naturalmente todo o nitrato adicionado ao solo por fertilizantes ou por efluentes domésticos. Desta forma, o excedente de nitrato que pode atingir as águas subterrâneas é motivo de grande preocupação no que diz respeito à qualidade destas águas, em muitas áreas dos Estados Unidos e também em muitos países (USEPA, 1994).

Segundo FERREIRA (1999), ambientes redutores causam a desnitrificação, processo que envolve bactérias facultativas heterotróficas, no qual o nitrato é reduzido a óxido de nitrogênio ou nitrogênio molecular segundo a reação 6 :

$$
\mathrm{CH}_{2} \mathrm{O}+4 / 5 \mathrm{NO}_{3}{ }^{-} \Rightarrow 2 / 5 \mathrm{~N}_{2}(\mathrm{~g})+\mathrm{HCO}_{3}^{-}+1 / 5 \mathrm{H}^{+}+2 / 5 \mathrm{H}_{2} \mathrm{O}
$$

sendo $(\mathrm{g})$ forma gasosa ou dissolvida e $\mathrm{CH}_{2} \mathrm{O}$, a matéria orgânica.

Segundo FOSTER \& HIRATA (1988), a lixiviação do nitrato para as águas subterrâneas representa um sério problema de contaminação, especialmente em zonas densamente povoadas, e o único mecanismo para reduzir a concentração de nitrato é diluindo-o no fluxo regional das águas subterrâneas. Para isso, seria necessário dispor de áreas relativamente extensas, a fim de manter as concentrações abaixo de $10 \mathrm{mg} / \mathrm{L}$ de nitrogênio-nitrato (CANTER et al., 1987; FOSTER \& HIRATA, 1988). Segundo FERREIRA (1999), as duas formas de maior interesse no que diz respeito à poluição das águas subterrâneas são: 0 nitrato e o amônio. 
HIRATA (2000b) e FERREIRA (1999) afirmam, porém, que diluição não é o único mecanismo capaz de reduzir as concentrações de nitrato nas águas subterrâneas. Processos de desnitrificação também são de extrema importância para a remoção ou diminuição das concentrações de nitrato nas águas.

FREEZE \& CHERRY (1979) também destacam a diluição na diminuição da concentração de nitrato quando dizem que "...em águas oxidantes, o nitrato é a forma mais estável do nitrogênio dissolvido. Neste ambiente onde a estabilidade é alta, o principal mecanismo de atenuação do contaminante é a diluição hidráulica, que ocorrerá ao longo do seu transporte."

Em áreas providas de sistemas de saneamento in situ com tanques sépticos, ocorre rápida nitrificação de amônio, em condições aeróbias, nos campos de infiltração. Nestas áreas, o amônio é facilmente convertido a nitrato, onde permanece solúvel e é facilmente transportado para a água subterrânea.

Segundo CANTER \& KNOX (1988), o nitrato também pode provir diretamente do sistema de infiltração de efluentes domésticos (fossas sépticas ou negras) só que em pequenas quantidades, devido às condições anaeróbias presentes. Como o nitrato possui carga negativa, não é atraído pelas partículas do solo em condições naturais de $\mathrm{pH}$, ou seja, não é adsorvido, sendo por isso mais móvel que o amônio, tanto na zona saturada, como na zona não-saturada.

$O$ transporte e o comportamento do amônio em subsuperfície podem envolver: adsorção, troca catiônica, incorporação em biomassa microbiana ou liberação à atmosfera em forma de gás.

\subsection{Fontes de Contaminação por Compostos Nitrogenados das Águas Subterrâneas}

As fontes e causas para a contaminação das águas subterrâneas são inúmeras e tão diversas quanto as atividades do homem. Um grande número de métodos de classificação de fontes tem sido desenvolvido, porém nenhum deles foi ainda adotado em escala mundial. A classificação de fontes pela origem tem sido a mais utilizada nas últimas décadas (ZAPOROZEC \& MILLER, 2000 apud UNESCO, 2001).

Uma classificação baseada no caráter da fonte normalmente se refere à distinção de fontes pontual, linear e difusa. As fontes pontuais de contaminação 
são aquelas que podem ser relacionadas a um ponto especifico, restrita a uma área de dimensões conhecidas. Fontes linear ou difusa espalham contaminantes sob grandes distâncias ou áreas (ZAPOROZEC \& MILLER, 2000 apud UNESCO 2001). Esta última constitui tema de extrema relevância devido à dificuldade para a sua caracterização, pois se associa a grandes áreas, exigindo numerosos pontos de monitoramento (IPT, 2000). São exemplos de fontes de poluição difusas o saneamento in situ e as atividades agrícolas (IPT, 2000; FREEZE \& CHERRY, 1979).

Segundo KEENEY (1986; 1989 apud CANTER, 1997), as fontes de contaminação por nitrato nas águas subterrâneas podem ser classificadas em: 1) naturais; 2) residuos animais e 3) agricultura. Destas, ressaltam-se as áreas destinadas à criação de animais, onde se utiliza excremento animal na fertilização do solo, e áreas agrícolas que usam fertilizantes inorgânicos em excesso (KEENEY, 1989; CANTER et al., 1987). Sistemas de saneamento, que incluem tanques sépticos e aterros, são também importantes fontes de contaminação.

Desde a Segunda Grande Guerra Mundial, houve um aumento do uso de fertilizantes nitrogenados em cultivos agrícolas em todo o mundo (FOSTER \& CHILTON, 1996; FREEZY \& CHERRY, 1979). A aplicação de fertilizantes nitrogenados é responsável por extensas áreas contaminadas na Europa, especialmente na Inglaterra, Espanha e França.

Fontes näo-pontuais de contaminação por nitrato nas águas subterrâneas, provenientes de atividades agrícolas, é uma preocupação global crescente. A contaminação ocorre com a utilização excessiva de fertilizantes sintéticos, ou seja, mais do que a planta requer (EXNER \& SPADING, 1994).

O Brasil é um dos 15 maiores consumidores de agroquímicos do mundo, sendo o Estado de São Paulo o maior consumidor brasileiro. Apesar da crescente preocupação dos hidrogeólogos a cerca da qualidade das águas subterrâneas e a sua relação com as práticas agrícolas, poucos estudos têm sido desenvolvidos no Brasil (HIRATA \& JAHNEL, 1998 apud CANDELA \& AURELI, 1998).

A preocupação a respeito da contaminação das águas subterrâneas em áreas agrícolas não decorre apenas por causa da utilização de fertilizantes sintéticos. A difundida aplicação de resíduo animal no processo de fertilização do 
solo constitui uma fonte potencial de contaminação por nitrogênio das águas em grandes regiões dos Estados Unidos e de outros paises (KARR et al., 2002).

De acordo com USEPA (1977, apud FREEZY \& CHERRY, 1979), sistemas sépticos para disposição de efluentes domésticos do tipo fossas são as principais e mais freqüentes fontes de contaminação dos solos e das águas subterrâneas dos Estados Unidos. Segundo ARAVENA et al. (1993), estes sistemas, muitas vezes localizados sobre aqüíferos não-confinados, os quais são utilizados como fontes de abastecimento de água, constituem uma das mais numerosas fontes de contaminação de aqüif́ros rasos. A expansão da malha urbana para áreas rurais ao redor das cidades, não supridas por sistemas de coleta de efluentes, tem criado uma incrivel demanda para utilização de fossas.

Plumas contaminantes geradas por sistemas de saneamento in situ são descritas por vários autores em diversas situações hidrogeológicas (WOODWARD et al., 1961; WALKER et al., 1973; VIRARAGHAVAN \& WARNOCK, 1976; STARR \& SAWHNEY, 1980; FOSTER et al., 1987; ROBERTSON \& CHERRY, 1992; FERREIRA \& HIRATA, 1993; HIRATA, 2000c e VARNIER, 2001). O número de casos de contaminação por sistemas de fossas sépticas fez com que PATTERSON et al. (1971, apud LEWIS et al., 1982) recomendassem o não uso destes sistemas em áreas densamente povoadas. $O$ problema do nitrato, associado aos sistemas de saneamento in situ, tem restringido a instalação de vilas para populações de baixa renda na Bolívia, financiadas pelo Banco Mundial (Jennifer Sara, do programa PNUMA/Banco Mundial, comunicação pessoal).

De acordo com HIRATA (2000 apud TEIXEIRA et al., 2000), os efluentes domésticos municipais possuem elevadas concentrações de carbono orgânico, cloreto, nitrogênio, sódio, magnésio, sulfato e alguns metais incluindo ferro, zinco e cobre, além de concentraçōes variadas de microorganismos patogênicos. Destes compostos, os que apresentam os maiores riscos à água subterrânea são o nitrogênio e os microrganismos patogênicos.

O nitrogênio em fossas sépticas encontra-se cerca de $75 \%$ na forma amoniacal, e 25\%, na forma orgânica, ou seja, o amônio é a forma predominante de nitrogênio que penetra em subsuperfície. Ele pode ser descarregado diretamente da fossa ou ser transformado a amônio por meio da conversão do 
nitrogênio orgânico, dentro do sistema de disposição de efluentes (CANTER \& KNOX, 1988).

ROBERTSON et al. (1991), por meio de uma rede de monitoramento de água subterrânea, investigaram os impactos causados por dois sistemas sépticos adjacentes à duas casas, localizados sobre aqüiferos rasos, arenosos e nãoconfinados, em duas planícies da província de Ontário no Canadá. Dentre os principais resultados destes estudos, tem-se que o sódio foi caracterizado como o melhor indicador de impacto, visto que o valor de fundo (background) encontrado para os íns cloreto e nitrato foi considerado relativamente alto, como resultado de práticas agrícolas. Nas duas áreas estudadas, a configuração das plumas demonstrou que o transporte destas por advecção é rápido em contrapartida a uma ineficiente dispersão e atenuação da pluma por dispersão. Observou-se também a ocorrência de um processo de desnitrificação associado aos sedimentos do leito do rio, ricos em carbono orgânico. As plumas das duas áreas foram caracterizadas, comparativamente aos valores de background, por meio dos baixos niveis de oxigênio dissolvido e $\mathrm{pH}$ e as altas concentrações de nitrato.

VARNIER (2001) desenvolveu estudos de detalhe sobre o impacto de fossas sépticas em aqüiferos rasos. Os resultados destes trabalhos mostraram uma zonificação em três áreas, segundo o tipo de ambiente geoquímico e a disponibilidade de nitrogênio. Em uma zona mais próxima à fossa, nota-se que o ambiente é mais redutor, com predominância de nitrogênio amoniacal e carbono orgânico dissolvido. Na segunda zona, há a presença de amônio e nitrato e na terceira, maior disponibilidade de oxigênio dissolvido, próximo à saturação, e predominância de nitrato.

\subsection{Riscos à Saúde Humana}

Uma das maiores preocupações relacionadas ao uso da água subterrânea com excessivas concentrações de nitrato está relacionada aos efeitos que podem causar à saúde humana. O mais importante efeito está relacionado à perda da capacidade de transporte/transferência do oxigênio no sangue, a metahemoglobinemia. 
O Ministério da Saúde, por meio da Portaria 1.469 de dezembro de 2000 , considera que uma água é não - potável ou imprópria para o consumo quando as concentrações de nitrato excedem $45 \mathrm{mg} / \mathrm{L}$ de $\mathrm{NO}_{3}$.

A metahemoglobinemia (cianose infantil) é uma doença que afeta principalmente os bebês menores de três meses. A toxicidade está associada à redução do nitrato a nitrito. Esta reação ocorre na saliva de pessoas de qualquer idade e no trato gastrointestinal de bebês durante os seus três primeiros meses de vida. $O$ íon nitrito que se forma, oxida o ferro nas moléculas de hemoglobina, transformando-o de ferroso $\left(\mathrm{Fe}^{2+}\right)$ a férrico $\left(\mathrm{Fe}^{3+}\right)$. A metahemoglobina produzida torna o sangue incapaz de fixar, de maneira reversível, o oxigênio, o que resulta em uma anoxia que pode levar à morte. Os efeitos da metahemoglobinemia, entretanto, são rapidamente reversiveis e não são acumulativos (BURT et al., 1993; CANTER, 1997).

Adicionalmente, outra preocupação relacionada à saúde pública é que muitos estudos mostraram que a ingestão de nitrito pode resultar em cânceres de muitos órgãos. $O$ nitrito, e indiretamente o nitrato, pode reagir com amidas para formar nitrosaminas e nitrosamidas. Estudos comprovaram que a maioria destes compostos pode ser cancerigena a um grande número de espécies animais e muitos deles são considerados mutagênicos. A abundante ingestão de nitrato pode contribuir ao surgimento de câncer gástrico. Atualmente não existem estudos que comprovem a existência de uma relação direta entre a elevada ingestão de nitrato e algum tipo de câncer no homem (FRASER et al., 1980 apud FERREIRA, 1999).

Excesso de nitrato na água subterrânea tem também causado problemas em ruminantes. As ovelhas e o gado são seriamente afetados por nitrato desde o nascimento até a vida adulta. Animais monogástricos, tais como cavalos, galinhas e porcos, são também candidatos a problemas de saúde (CANTER, 1997).

Sintomas do envenenamento por nitrato-nitrito no gado incluem cianoses, perda respiratória, aceleração dos batimentos cardíacos, modo de andar cambaleante, urina freqüente e colapsos. Em casos mais severos, podem ocorrer convulsões, coma e morte em algumas horas.

$\mathrm{Na}$ forma de amônio, o nitrogênio tem efeitos tóxicos à vida aquática e contribui para a demanda de oxigênio. Alguns manuais para a vida aquática 
limitam as concentrações de nitrogênio orgânico e inorgânico em $1 \mathrm{mg} / \mathrm{L}$. (FRASER et al., 1980 apud FERREIRA, 1999).

\subsection{Isótopos de Nitrogênio}

As variaçōes isotópicas impõem às águas assinaturas as quais as identificam. Esta assinatura pode ser utilizada no entendimento de problemas hidrogeológicos como, por exemplo, na identificação de áreas de recarga e idade da água, nos estudos de fenômenos de mistura de diferentes águas e em processos de interaçăo água-rocha e água-gás $e$, ainda, no entendimento da origem do nitrato presente nas águas subterrâneas, por meio da análise isotópica do nitrogênio.

\subsubsection{Identificação de Fontes Potenciais de Contaminação}

$O$ nitrogênio apresenta oito isótopos que variam de ${ }^{12} \mathrm{~N}$ até ${ }^{19} \mathrm{~N}$, sendo $\circ{ }^{14} \mathrm{~N}$ e $\circ{ }^{15} \mathrm{~N}$ os mais estáveis. ${ }^{14} \mathrm{~N}$ representa $99,63 \%$ do nitrogênio disponivel na atmosfera e o ${ }^{15} \mathrm{~N}, 0,37 \%$ (CLARK \& FRITZ, 1997). Segundo EXNER \& SPADING (1994), variações nas concentrações desses dois isótopos estáveis podem ser valiosas ferramentas para uma avaliação semi-quantitativa da origem do nitrato nas águas subterrâneas.

De acordo com RIVERS et al. (1996), a abundância relativa entre os isótopos ${ }^{15} \mathrm{~N}$ e ${ }^{14} \mathrm{~N}$ é medida em relação ao nitrogênio atmosférico, de acordo com a fórmula:

$$
{ }^{15} \mathrm{~N}=\left(R_{\mathrm{sp}} / R_{\mathrm{std}}-1\right){ }^{\star} 1000
$$

em que $R_{\text {spl }}={ }^{15} \mathrm{~N} /{ }^{14} \mathrm{~N}$ é a razão da amostra e $R_{\text {std }}={ }^{15} \mathrm{~N} /{ }^{14} \mathrm{~N}$, a razão do ar. Os resultados são apresentados em partes por mil (\%o). Se ${ }^{15} \mathrm{~N}$ é positivo, isto significa que a amostra é isotopicamente pesada e, se ocorre o inverso, ou seja, se ${ }^{15} \mathrm{~N}$ é negativo, a amostra é isotopicamente leve.

Entende-se por fracionamento isotópico a troca de isótopos entre duas moléculas ou fases que estão participando de uma reação. Os processos de fracionamento, tanto cinéticos como termodinâmicos, são relevantes para a determinação da origem do nitrogênio no aqüifero e subsidiam os estudos 
hidrogeológicos que utilizam a razão ${ }^{15} \mathrm{~N}$ (KREITLER, 1975; MARIOTTI \& LETOLLE, 1977 apud CLARK \& FRITZ, 1997; FLIPSE \& BONNER, 1985 apud CLARK \& FRITZ, 1997). Segundo vários autores, essa razão isotópica permite distinguir a origem do nitrato em aqǘferos, uma vez que os fertilizantes nitrogenados inorgânicos são mais pobres nessa relação que os excrementos de animais.

Os principais processos que afetam a composição isotópica do nitrogênio nas águas subterrâneas são volatilização, mineralização, desnitrificação e mistura de águas de diferentes origens (MARIOTTI et al., 1988; KENDALL, 1998).

Segundo AMBERGER \& SCHMIDT (1987 apud CLARK \& FRITZ, 1997); BÖTTCHER et al. (1990) e LÉTOLLE (1980 apud CLARK \& FRITZ, 1997), a Figura 3.3 apresenta diversos intervalos da razão ${ }^{15} \mathrm{~N}$. Estas razões baseiam-se nas diferentes composições isotópicas que caracterizam o nitrogênio de várias origens.

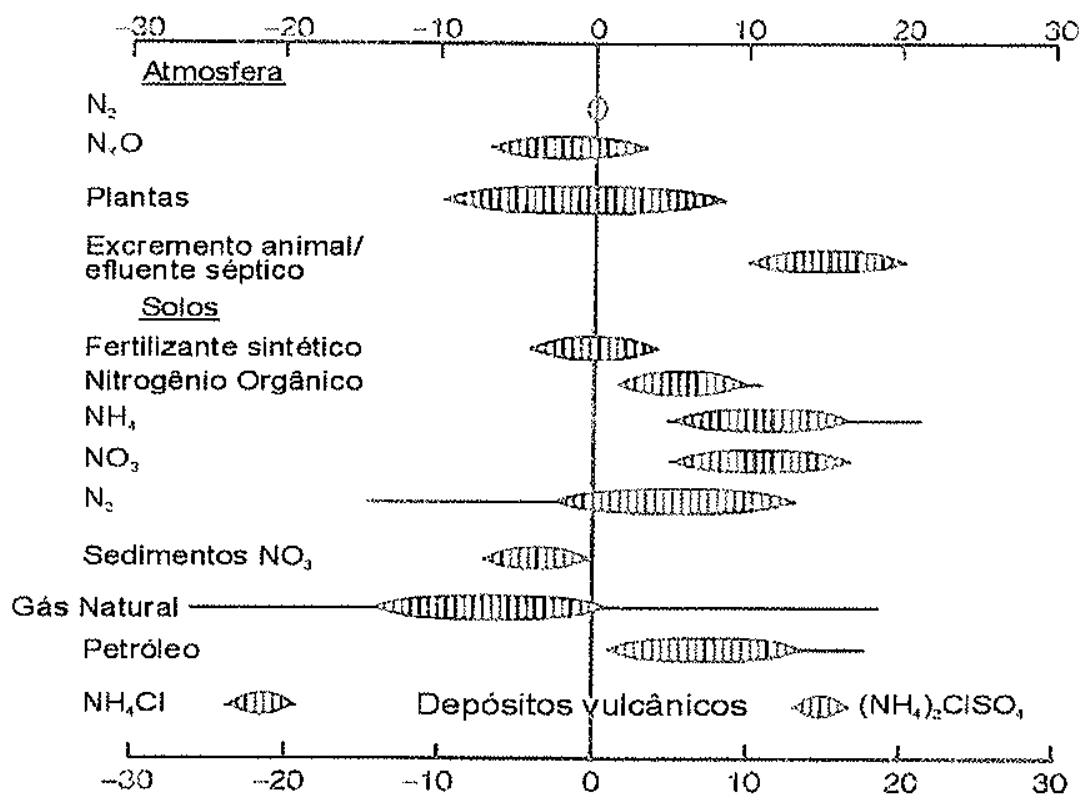

Figura 3.3 - Intervalos da razão ${ }^{15} \mathrm{~N}$ presente nos diferentes materiais (AMBERGER \& SCHMIDT, 1987 apud CLARK \& FRITZ, 1997; BÖTTCHER et al., 1990; LÉTOLLE, 1980 apud CLARK \& FRITZ, 1997). 
Para HEATON (1986), os valores de ${ }^{15} \mathrm{~N}$ encontram-se entre $-2 \%_{0}$ e $+4 \%_{0}$ para fertilizantes comerciais; entre $+3 \%_{\circ} e+8 \%_{0}$, para solos ricos em matéria orgânica e entre $+10 \%$ o $+20 \%$, para dejetos humanos e animais. Os dejetos, geralmente excretados como uréia, são convertidos a nitrato por meio dos processos de nitrificação. Isotopicamente o amônio escapa para a atmosfera durante este processo, deixando o nitrogênio remanescente enriquecido em ${ }^{15} \mathrm{~N}$. Da mesma forma, parte da amônia aplicada nos solos sofre volatilização propiciando também um enriquecimento em ${ }^{15} \mathrm{~N}$.

Segundo HEATON \& HUBNER (1986, apud KARR et al., 2002), processos físicos e bioquímicos induzem ao fracionamento isotópico, os quais produzem compostos nitrogenados com várias razões isotópicas. Fertilizantes inorgânicos são sintetizados a partir de nitrogênio atmosférico e geralmente têm ${ }^{15} \mathrm{~N}$ com um intervalo de aproximadamente $+4 \%$ a $-9 \%$. O nitrogênio derivado de fertilizantes é freqüentemente enriquecido em ${ }^{15} \mathrm{~N}$ durante sua passagem pelo solo. Isto é causado pela combinação de volatilização da amônia remineralizada microbiologicamente envolvendo perda de nitrogênio leve e desnitrificação parcial (BLACK \& WARING, 1979; HUBNER, 1986 apud KARR et al., 2002). O nitrato no solo geralmente ocorre em concentrações de ${ }^{15} \mathrm{~N}$ que variam de $+3 \%$ a $+8 \%$ 。 (HUBNER, 1986 apud KARR et al., 2002). O nitrato derivado de resíduo animal geralmente tem ${ }^{15} \mathrm{~N}$ entre $+10 \%$ e $+20 \%$ ou maior (GORMLLY \& SPALDING, 1979; KREITLER, 1975; WASSENAR, 1995; KARR et al., 2001 apud KARR et al. 2002).

KREITHER \& BROWNING (1983) descreveram o uso da razão ${ }^{15} \mathrm{~N}$, na identificação de fontes de contaminação por nitrato nas águas subterrâneas. Esses autores mediram razões isotópicas de nitrogênio de diferentes fontes e compararam com as razões destes isótopos presentes nas águas subterrâneas. Esta técnica identificou que a razão ${ }^{15} \mathrm{~N}$ presente no nitrato proveniente de solos cultivados sem fertilizantes varia de $+2 \%$ o $a+8 \%$, enquanto que, no nitrato resultante da decomposição animal, de $+10 \%$ a $+22 \%$.

A exemplo de KREITHER \& BROWNING (1983), os autores EXNER \& SPALDING (1994) também utilizaram a razão isotópica ${ }^{15} \mathrm{~N}$ para identificação da fonte de contaminação de nitrato nas águas subterrâneas de dois vales localizados nos Estados Unidos. Estes autores concluiram que as concentraçōes 
de ${ }^{15} \mathrm{~N}$, que variam de $+3,5 \%$ a $+5,9 \%$, indicam como fonte desta contaminação a aplicação de fertilizantes comerciais, e concentrações de ${ }^{15} \mathrm{~N}$ que oscilam de $+5,8 \%$ a $+8,8 \%$, uma mistura de duas fontes de contaminação: fertilizantes $e$ excremento animal.

A despeito das faixas de concentração de ${ }^{15} \mathrm{~N}$ obtidas por esses autores para nitrato de origens orgânica e inorgânica, RIVERS et al. (1996) definem outros intervalos. Segundo estes autores, o nitrogênio orgânico no solo é convertido a nitrato por meio de uma seqüência de processos de mineralização e nitrificação via amônio e nitrito. Este processo resulta em valores de ${ }^{15} \mathrm{~N}$ que variaram de $+4 \%$ o a $+9 \%$. Fertilizantes nitrogenados são isotopicamente empobrecidos em ${ }^{15} \mathrm{~N}$, o que resulta em valores de ${ }^{15} \mathrm{~N}$ que variaram de $-16 \%$ 。 a $-6 \%$. Estes autores salientam a necessidade de cautela na interpretação dos resultados das análises isotópicas, em função da faixa de sobreposição de intervalos variáveis de composições isotópicas de fontes potenciais e, ainda, do fracionamento isotópico decorrente de processos de transformação do nitrogênio.

RIVERS et al. (1996) estudaram a origem da contaminação por nitrato nas águas de um aqüifero arenoso não confinado localizado na Inglaterra. Os autores concluiram, a partir da análise de resultados das concentrações isotópicas ${ }^{15} \mathrm{~N}$, os quais variaram de $+4 \%_{0}$ a $+8 \%$, que o nitrato presente nos poços profundos deste aqüifero é proveniente de solo orgânico nitrogenado. Entretanto, todos os valores de concentração isotópica maiores que $+10 \%$ 。 são indicativos de resíduo animal ou de efluente doméstico.

GIRARD \& HILLAIRE-MARCEL (1997) estudaram a origem da contaminação por nitrato nas águas subterrâneas de um aqüifero pré-cambriano, fraturado, localizado na África. Comparando-se os resultados das concentrações de ${ }^{15} \mathrm{~N}$ das principais fontes de contaminação com os resultados das concentraçōes isotópicas obtidos para $\circ$ nitrogênio presente nas águas subterrâneas, os autores concluiram que o nitrato destas águas, cujas concentrações isotópicas oscilam entre $+12,8 \%$ o $a+17,1 \%$, é proveniente de fossas (cuja variação isotópica é de $+14,7 \%$ o a $+16,0 \%_{0}$ ).

O uso de isótopos, no entendimento de reações envolvendo o nitrogênio na hidrologia, ganhou especial atenção quando se tornou possivel fazer medições 
rotineiras de ${ }^{18} \mathrm{O}$ no nitrato (AMBERGER \& SCHMIDT, 1987 apud CLARK \& FRITZ, 1997).

A razão isotópica ${ }^{18} \mathrm{O} /{ }^{16} \mathrm{O}$, presente no nitrato, tem sido utilizada como ferramenta complementar na identificação da origem de nitrato (BÖTTCHER et al., 1990 apud CLARK, 1997).

Estudos experimentais têm mostrado que, no nitrato de origem biológica, apenas um oxigênio vem da atmosfera e os outros dois, da água (HOLLOCHER, 1984 apud CLARK \& FRITZ, 1997). Isto contrasta com o nitrato proveniente de fertilizantes sintéticos, os quais recebem oxigênio primariamente do ar atmosférico. Desta forma, como as duas fontes de oxigênio diferem significativamente, os nitratos de origem biológica e de fertilizantes sintéticos podem mostrar diferentes composições isotópicas.

Os autores ARAVENA et al. (1993) utilizaram as razões isotópicas ${ }^{15} \mathrm{~N} /{ }^{14} \mathrm{~N}$ e ${ }^{18} \mathrm{O}^{16} \mathrm{O}$, presentes no nitrato e na água respectivamente, no estudo da diferenciação de uma pluma de contaminação de nitrato proveniente de uma fossa séptica, em um aqüífero caracterizado por um elevado conteúdo de nitrato dentro e fora da pluma. Neste estudo, os autores delinearam previamente a pluma utilizando medições de concentração de sódio, visto que havia entre 10 a 20 vezes mais sódio em plumas provenientes de sistemas sépticos (ROBERTSON et al., 1991 apud ARAVENA et al., 1993).

Valores de ${ }^{15} \mathrm{~N}$ mostraram uma distinta separação isotópica entre o nitrato presente "dentro" e "fora" da pluma. Fora da pluma, as razões variavam de $+3,4 \%$ a $+6,2 \%$ e dentro da pluma, de $+8,1 \%$ a $+13,9 \%$, indicando que o nitrogênio da pluma deriva de uma fonte animal enriquecida por processos de volatização da amônia. Os resultados de ${ }^{18} \mathrm{O}$ presente no nitrato não apresentaram uma distinta separação entre o oxigênio "dentro" e "fora" da pluma, enquanto que os resultados de ${ }^{18} \mathrm{O}$ presente na água subterrânea, mostraram uma boa separação entre o oxigênio presente dentro $(-10,6 \%$ a $\pm 0,3 \%$ ) e fora da pluma $(-9,4 \%$ a $\pm 0,4 \%$. 


\section{4 ÁREA DE ESTUDO}

Uma descrição dos aspectos físicos da área de estudo, tais como localização geográfica, clima, geomorfologia, geologia e hidrogeologia, é apresentada a seguir.

\subsection{Localização e vias de acesso}

O município de Urânia localiza-se na região noroeste do Estado de São Paulo, possui área territorial de aproximadamente $208 \mathrm{~km}^{2}$ e população de 8.824 habitantes (SEADE, 2002).

A área de estudo abrange a zona urbana, perfazendo um total de aproximadamente $2,14 \mathrm{~km}^{2}$, entre as coordenadas UTM 7.760,140 e 7.762,300 $\mathrm{km}$ e 536,430 e $537,800 \mathrm{~km}$. Entretanto, alguns pontos de observação e coleta de amostras de água foram estabelecidos fora desta área, com o objetivo de utilizálos como valores de referência e de comparação. Desta forma, a área total onde foram coletados os dados perfaz um total de $18,9 \mathrm{~km}^{2}$, entre as coordenadas $7.760,000$ e $7.763,861 \mathrm{~km}$ e 534,500 e 539,386 km (Figura 4.1).

O município limita-se a norte com Santa Albertina e Paranapuã, a sul com São Francisco, a leste com Jales e a oeste com o município de Aspásia. Urânia dista aproximadamente $600 \mathrm{~km}$ da cidade de São Paulo. O acesso à área pode ser feito a partir da capital, pela Rodovia Anhangüera (SP 330) até a cidade de Limeira, ou pela Rodovia Bandeirantes, até a cidade de Campinas; seguindo pela Washington Luiz (SP 310), até Mirassol e, depois, pela Rodovia Euclides da Cunha (SP 320), até a cidade de Urânia.

\subsection{Histórico de Uso e Ocupação do Solo e Aspectos Socioeconômicos}

A cultura do café foi a grande responsável pelas transformações econômicas e sociais que se verificaram em todo o território paulista na década de 30 . A região de São José do Rio Preto, entre 1920 e 1935, apresentou grande aumento na produção de café e crescimento da população (IPT, 2000). 


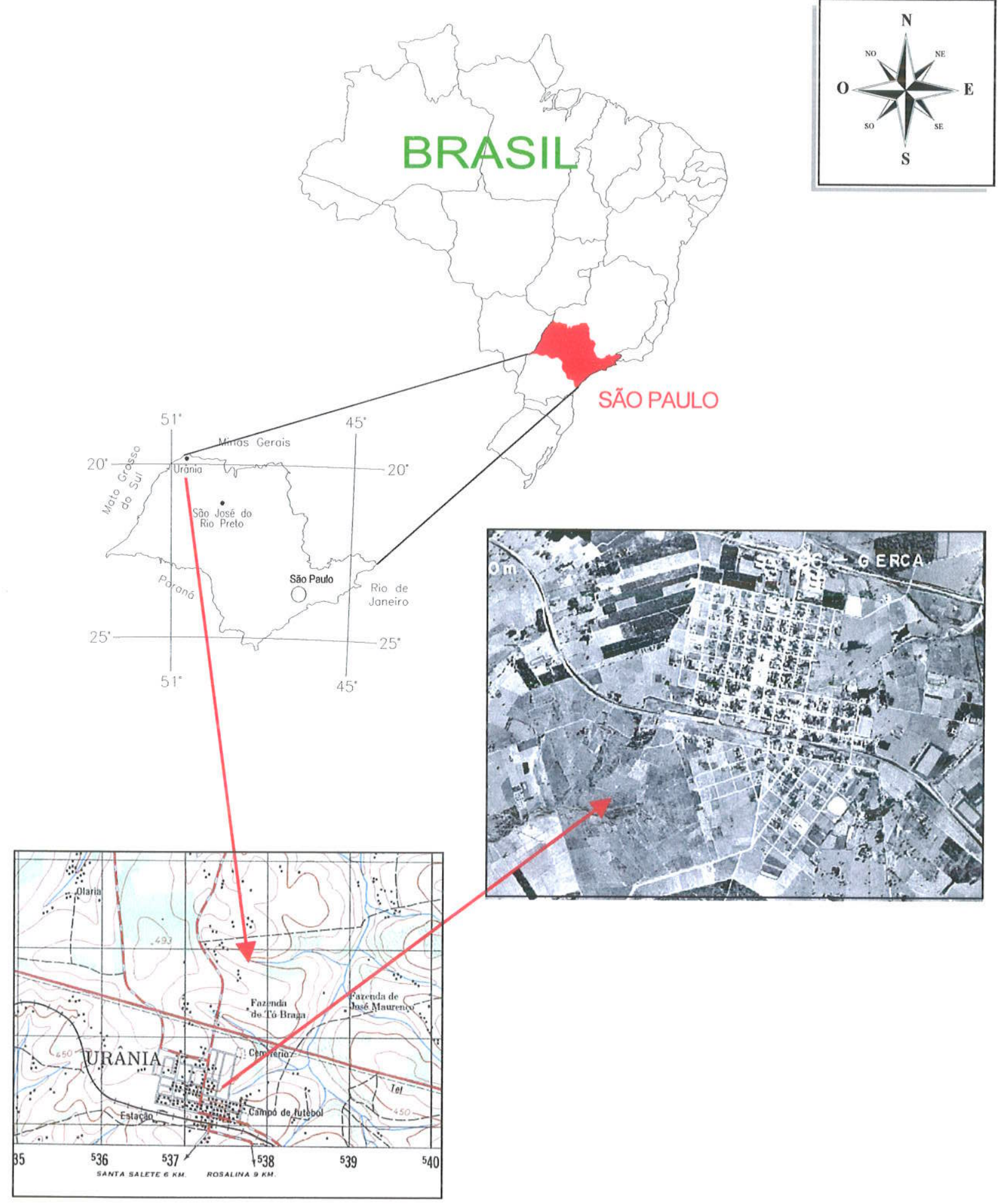

Figura 4.1 - Localização da área de estudos. 
Com a queda dos preços do café após 1929, áreas em pleno desenvolvimento foram afetadas. Na região de São José do Rio Preto, os rendimentos caíram e, nas zonas de cultivo mais antigo, onde a produção do café era baixa, ocorreu diversificação agrícola, com as culturas do algodão, cana-deaçúcar, produtos alimentares e a pecuária. Surgem as pequenas e médias propriedades e formam-se pequenos núcleos urbanos (IPT, 2000).

A partir da década de 40 , com o aumento no cultivo do algodão, veio a instalação da agroindústria correspondente. Entre 1949 e 1951, surgem a canade-açúcar e a laranja (IPT, 2000).

Em 1956, a região de Rio Preto possuía uma indústria pouco diversificada, predominando o ramo alimentar. Foi nesta época que se verificou intenso processo de urbanização nos principais municípios da região (IPT, 2000).

Em 30 de dezembro de 1953, foi criado o distrito de Urânia no município de Jales, por meio da Lei no 2.456 e, em 18 de fevereiro de 1959, este distrito foi transformado em município, por meio da lei no 5.285 (IGC, 1995).

A cidade surgiu em virtude da fertilidade do solo, para atender às necessidades da população radicada na lavoura. Atraída pelas riquezas que circulavam na região, a população cresceu e deu impulso à agricultura, marcada pela produção de café, milho, arroz e algodão. Paralelamente ao trato da terra, as grandes extensões livres acolheram os criadores de gado leiteiro e de corte (ALMODOVAR, 2000).

Desde 1950 até a década de 90, segundo informações verbais, predominou em Urânia a cultura do algodão, seguida pelo café e, em menor escala, milho, arroz e amendoim. A laranja e a uva começaram a ser plantadas nas décadas de 80 e 90, respectivamente. De acordo com ALMODOVAR (2000), em Urânia, fertilizantes a base de nitrogênio-fósforo-potássio (NPK) foram aplicados nas plantações de laranja.

Entre as principais atividades econômicas na cidade de Urânia em 2000, destacam-se a agricultura e a pecuária de pequeno porte. Há também pequenas indústrias, como a de beneficiamento de arroz e fábrica de móveis.

De acordo com PINO et al. (1997), do total da área agrícola do município, $19,7 \%$ são culturas anuais, perene e semiperene, $76 \%$, áreas com pastagem, $0,42 \%$, reflorestamento e $2 \%$, áreas de vegetação natural. Do total de área 
cultivada (anual, perene e semiperene), 75\% são braquiárias, $6 \%$ é utilizada para o cultivo de milho, $6 \%$ para o cultivo de laranja, $3 \%$, capim colonião, $2 \%$, café, $2 \%$, algodão e $3 \%$ para o cultivo de frutas, tais como limão, uva e manga.

A população de Urânia, no período de 1970 a 2000 está indicada no Quadro 4.1.

Quadro 4.1 - População de Urânia desde 1970 a 2000 e projeção para 2010.

\begin{tabular}{|l|c|c|c|c|c|c|c|c|c|c|c|c|}
\hline $\begin{array}{c}\text { Populaçäo } \\
\text { (hab.) }\end{array}$ & $\mathbf{1 9 7 0}$ & $\mathbf{1 9 8 0}$ & $\mathbf{1 9 9 0}$ & $\mathbf{1 9 9 1}$ & $\mathbf{1 9 9 2}$ & $\mathbf{1 9 9 3}$ & $\mathbf{1 9 9 4}$ & $\mathbf{1 9 9 5}$ & $\mathbf{1 9 9 6}$ & $\mathbf{1 9 9 7}$ & $\mathbf{2 0 0 0}$ & $\mathbf{2 0 1 0}$ \\
\hline Total & 16.829 & 13.510 & 12.280 & 12.149 & 12.082 & 10.095 & 10.060 & 10.012 & 9.979 & 8.587 & 8.824 & 7.858 \\
\hline Urbana & 5.134 & 6.498 & 7.561 & 7.620 & 7.715 & 6.734 & 6.818 & 6.894 & 6.980 & $\mathrm{Na}$ & 7.065 & $\mathrm{Na}$ \\
\hline Rural & 11.695 & 7.012 & 4.719 & 4.529 & 4.367 & 3.361 & 3.242 & 3.118 & 2.999 & $\mathrm{Na}$ & 1.759 & $\mathrm{Na}$ \\
\hline
\end{tabular}

Na: não informado

(Fonte: modificado de IPT, 2000)

O decréscimo no número total de habitantes está relacionado à fuga dos habitantes das pequenas cidades para os grandes centros urbanos e ainda a emancipação de dois novos municípios: Apásia, em 1993, e Santa Salete, em 1997, os quais anteriormente pertenciam à Urânia.

\subsection{Aspectos Fisiográficos}

De acordo com ROSS \& MOROZ (1997), o município de Urânia localiza-se em uma unidade geomorfológica denominada Planalto Ocidental Paulista, o qual abrange uma área de aproximadamente $50 \%$ do Estado de São Paulo. Este planalto corresponde, geologicamente, aos derrames basálticos que cobrem as unidades sedimentares do final do ciclo de deposição da Bacia do Paraná e às coberturas sedimentares que, por sua vez, foram depositadas na Bacia Bauru, acima desses basaltos.

Ainda segundo ROSS \& MOROZ (1997), dentro do Planalto Ocidental Paulista, são identificadas seis unidades geomorfológicas distintas, dentre estas aquela denominada de Planalto Centro - Ocidental, da qual faz parte a área de estudo. Esta unidade caracteriza-se pelo relevo monótono, levemente ondulado, de colinas amplas e baixas com topos convexos e aplanados. 
O sistema de drenagem é pouco denso e possui, como característica principal, o padrão paralelo, organizado na maior parte por rios conseqüentes (drenam no mesmo rumo do mergulho das camadas geológicas). Na cidade de Urânia, as altitudes variam de $400 \mathrm{~m}$ a $474 \mathrm{~m}$ acima do nivel do mar, com relevo de colinas (ROSS \& MOROZ, 1997).

De acordo com IGC-DAEE (1996 apud BERTOLO, 2001), o município de Urânia situa-se sobre os divisores hidrográficos dos rios São José dos Dourados, a sul (Unidade 18) e do Turvo/Grande, a norte (Unidade 15). É na cidade de Urânia que ocorrem algumas nascentes que fazem parte do Córrego da Porteira, tributário do Ribeirão da Ponte Pensa, que tem sentido oeste e deságua no Rio Paraná (Unidade 18); e as nascentes do Ribeirão Comprido, que têm sentido norte e deságuam no Córrego Cascavel, tributário do Rio Grande (Unidade 15).

Seus principais córregos são o Comprido e o Matadouro, os quais pertencem à Bacia do Rio Turvo, Sub-Bacia Cascavel/Cã-cã. Os principais córregos da Sub-Bacia Cascavel são o Ribeirão Cã-Cã e o Córrego Cascavel. A cidade de Urânia localiza-se nas cabeceiras dos rios formadores do Córrego Cascavel.

O Córrego Comprido, o único que corta a área urbana da cidade de Urânia e recebe todo o efluente coletado e tratado pelo município, é classificado como classe II, de acordo com o Decreto Estadual $n^{\circ} 8.468$ de 1976, que dispõe sobre a classificação das águas interiores. Os corpos de água classificados como classe II são aqueles que se destinam ao abastecimento doméstico, após tratamento convencional; à proteção das comunidades aquáticas; à recreação de contato primário (esqui aquático, natação e mergulho) e à irrigação de hortaliças e plantas frutiferas.

Segundo DAEE (1976), o clima da área de estudo pode ser definido como tropical úmido até subtropical úmido, segundo a classificação de Köppen (de 1948) de Aw até Cwa, com duas estações bem definidas: uma quente, com médias mensais acima de $20^{\circ} \mathrm{C}$ (outubro/março), verão, e outra com temperaturas abaixo de $19^{\circ} \mathrm{C}$ (abril/setembro), inverso.

Entre 1959 e 1999, a média anual de precipitação em Urânia foi de 1.271 $\mathrm{mm}$, com pico de $1.790 \mathrm{~mm}$. Os meses de dezembro, janeiro e fevereiro são predominantemente úmidos, com precipitação média de 1.960, 2.340 e $1.790 \mathrm{~mm}$, 
respectivamente. O potencial anual de evapotranspiração é de $2.200 \mathrm{~mm}$ (DAEE, 1976).

\subsection{Geologia}

Segundo IPT (1981), a região pesquisada está inserida na Bacia VulcanoSedimentar do Paraná, representada por uma complexa fossa tectônica encravada no escudo pré-cambriano. Esta bacia encontra-se preenchida por sedimentos continentais, alguns marinhos, e lavas basálticas da Formação Serra Geral. Na cidade de Urânia, afloram as rochas sedimentares da Formação Adamantina (Grupo Bauru), de idade cretácea superior (90 Ma a $65 \mathrm{Ma}$ ), que se depositam sobre os basaltos da Formação Serra Geral.

Anteriormente denominada de Formação Bauru, esta unidade foi elevada a Grupo Bauru, constituído pelas formações Caiuá, Santo Anastácio, Adamantina e Marilia, de acordo com a proposta de SOARES et al. (1980), em trabalho de revisão estratigráfica. 'Tal conceituação é bastante aceita, e adotada no Mapa Geológico do Estado de São Paulo, na escala 1:500.000 (IPT, 1981).

Posteriormente, foi proposta por FERNANDES (1992) e FERNANDES \& COIMBRA (1992) a designação de Bacia Bauru, para a unidade tectônica distinta da evolução da Bacia do Paraná para os sedimentos existentes sobre a extensa capa formada pelas rochas vulcânicas, embora a referência aos sedimentos existentes sobre as camadas de basaltos como Bacia Bauru já tenha sido utilizada anteriormente (FÚlFARO et al., 1982; IPT, 1989 apud IPT, 2000), mas não proposta formalmente.

A Formação Adamantina é a unidade de maior distribuição em superfície no Estado de São Paulo, aflorando extensivamente na região norte do Estado, na região da Bacia do Rio Turvo, onde se localiza a área de estudo. Nesta região, a Formação Adamantina assenta-se discordantemente sobre os basaltos da Formação Serra Geral (Grupo São Bento).

\section{Grupo São Bento - Formação Serra Geral}

Segundo RAPOSO (1992), a Formação Serra Geral é representada por um conjunto de derrames de lavas basálticas, de natureza variada, composta por termos ácidos e básicos. Estes derrames são formados por rochas de cor cinza- 
escuro a negra, afaníticas. ALMODOVAR (2000) descreveu e analisou amostras de calha de rochas basálticas em Urânia e classificou-as como melanocráticas, com textura fanerítica fina.

Segundo PALMÉR RIVERA (2002), o topo da superficie da Formação Serra Geral, na área de estudo, foi encontrada em altitudes que variaram de $307 \mathrm{~m}$ a $369 \mathrm{~m}$.

\section{Grupo Bauru - Formação Adamantina}

Segundo SOARES et al. (1979, apud SOARES et al., 1980), a Formação Adamantina foi depositada em um extenso sistema fluvial meandrante dominantemente pelítico a sul, gradando para psamítico a leste e norte. É formalmente proposta como denominação a um conjunto de fácies, cuja principal característica é a presença de bancos de arenitos, de granulação fina a muito fina, róseos a castanhos, portando estratificação cruzada e espessuras variando entre $2 \mathrm{~m}$ a $20 \mathrm{~m}$, alternados com bancos de lamitos, siltitos e arenitos lamíticos, de cor castanho - avermelhado a cinza - castanho, maciços ou com acamamento plano-paralelo grosso, freqüentemente com marcas de onda e micro-estratificaçäo cruzada.

FÚLFARO \& BARCELOS (1991) apontaram que a unidade é fossilifera e apresenta flora e fauna diversificadas. Seu conteúdo fossilifero indica idade do Cretáceo superior, o que é confirmado pela interdigitação desta unidade com a Formação Uberaba, no Triângulo Mineiro, contemporânea ao magmatismo alcalino daquela região.

Segundo GUTIERREZ (1999), os sedimentos da Formação Adamantina, na cidade de Urânia, são caracterizados por arenitos finos siltosos a muito argilosos, de cor marrom, com tonalidades de mais clara a escura e avermelhada. Os grãos são sub-arredondados e bem selecionados.

De acordo com PALMÉR RIVERA (2002), a espessura da Formação Adamantina na cidade de Urânia varia de $66 \mathrm{~m}$ a $165 \mathrm{~m}$.

\subsection{Hidrogeologia}

$\mathrm{Na}$ cidade de Urânia ocorrem duas unidades hidro-estratigráficas: o Aqüifero Adamantina (constituído pela Formação Adamantina) e o Aqüifero Serra Geral 
(constituído pela Formação Serra Geral). O Aqüifero Serra Geral é classificado como do tipo fraturado, livre, anisotrópico e heterogêneo. Localmente, o intemperismo da rocha pode caracterizar um sistema limitado do tipo poroso. Sua espessura média é de 150 m (ALMODOVAR, 1995).

O Aqüifero Adamantina é do tipo livre a semi confinado, apresenta-se lateralmente homogêneo e isotrópico e limita-se, na sua porção inferior, com os basaltos da Formação Serra Geral.

De acordo com BARCHA (1980), a porcentagem de silte-argila parece ser o fator preponderante no controle da permeabilidade do Grupo Bauru. Há sempre uma relação inversa entre ambas, de tal forma que as rochas mais permeáveis são aquelas onde a textura, sendo mais grossa, apresenta menores porcentagens desses clastos finos. A presença de cimento é outro importante fator controlador da permeabilidade.

Segundo BERTOLO (2001), o Aqüifero Adamantina possui extensão regional e tem comportamento livre a semi confinado. A recarga ocorre naturalmente pela infiltração da chuva, e as superficies potenciométricas são fortemente influenciadas pela geomorfologia da área, onde os divisores de água subterrâneas coincidem com os divisores das bacias hidrográficas. As linhas de fluxo convergem para os rios, tendo desta forma um caráter efluente.

Quanto ao comportamento hidráulico do Aqüífero Adamantina, ROCHA et al. (1982) concluíram que os valores médios de capacidade especifica, compreendidos no intervalo de 0,5 a $10 \mathrm{~m}^{3} / \mathrm{h} / \mathrm{m}$, ocorrem a sudeste do Estado de São Paulo, na região de Rancharia, onde há uma litofácie mais permeável da parte inferior da Formação Adamantina. Áreas com valores abaixo de $0,5 \mathrm{~m} 3 / \mathrm{h} / \mathrm{m}$ ocorrem a sudoeste do Estado, devido à pequena espessura saturada, e a norte, na margem esquerda do Rio Grande, onde a litofácie da Formação Adamantina é menos permeável.

Ainda conforme esses autores, os valores médios de transmissividade predominantes são da ordem de 30 a $50 \mathrm{~m}^{2} /$ dia e os valores de condutividade hidráulica média aparente entre de 0,1 a 1,0 $\mathrm{m} / \mathrm{dia}$.

Os poços tubulares de Urânia, Aspásia e Santa Salete mostram espessura saturada média de $100 \mathrm{~m}$, capacidade especifica de $0,24 \mathrm{~m}^{3} / \mathrm{h} / \mathrm{m}$ e transmissividade de $6,31 \mathrm{~m}^{2} /$ dia (HIRATA \& RODOLFI, 1993). De acordo com 
PALMÉR RIVERA (2002), este aqüifero, na cidade de Urânia, apresenta espessura que varia de $60 \mathrm{~m}$ a $120 \mathrm{~m}$.

Segundo HIRATA (2000a), na cidade de Urânia, os poços tubulares da Sabesp apresentam vazões de 0,7 a $18,0 \mathrm{~m}^{3} / \mathrm{h}$. As condutividades hidráulicas do local variam de $1 \times 10^{-7}$ a $1 \times 10^{-3} \mathrm{~m} / \mathrm{s}$, os gradientes hidráulicos de $1,30 \%$ a 3,42 $\%$, com espessuras de até $169 \mathrm{~m}$. O fluxo ocorre em direção nordeste e a velocidade média da água subterrânea é da ordem de $7 \times 10^{-2}$ a $3 \times 10^{-3} \mathrm{~m} / \mathrm{dia}$. De acordo com ALMODOVAR (2000), o aqüifero na cidade de Urânia pode ser considerado como livre, homogêneo $e$ isotrópico, cujos níveis de água apresentam pouca variação entre os períodos seco e chuvoso.

No estudo da bacia do Rio São José dos Dourados, realizado por MEZZALIRA et al. (1979), foram efetuadas análises de ${ }^{18} \mathrm{O}, \mathrm{D}, \mathrm{P}, \mathrm{Cl}, \mathrm{Mg}^{2+}, \mathrm{NH}_{4}{ }^{+}$ e $\mathrm{NO}_{3}{ }^{-}$. $\mathrm{A}$ conclusão destes autores foi de que as águas não apresentaram fortes sinais de evaporação durante a recarga, o que indica um sistema de infiltração rápida de alta condutividade hidráulica.

Um dos primeiros estudos sobre a hidroquímica do Sistema Aqüifero Bauru no Estado de São Paulo foi realizado por TALTASSE (1968). O autor distinguiu duas fácies hidrogeoquímicas para os arenitos cretácicos do Bauru: águas bicarbonatadas cálcicas e águas bicarbonatadas magnesianas.

Segundo DAEE (1974), na região de São José do Rio Preto, distinguem-se dois grupos hidrogeoquímicos em terrenos do Grupo Bauru: as águas bicarbonatadas cálcio-magnesianas e as águas bicarbonatadas cálcicas. Assim como DAEE (1974), ROCHA et al. (1982) e CAMPOS (1987) sugeriram um zoneamento hidrogeoquímico do Sistema Aqüifero Bauru. Dois domínios são indicados por esses autores: águas bicarbonatadas cálcicas e águas bicarbonatadas cálcio-magnesianas.

DAEE (1976 e 1979), estudando a região de Bauru, São José do Rio Preto, Araçatuba, Presidente Prudente e Marilia, identificou dois grupos hidrogeoquímicos principais: as águas bicarbonatadas cálcicas secundariamente magnesianas ou sódicas, para as águas pertencentes ao Bauru Superior, e as águas bicarbonatadas sódicas, secundariamente cálcicas, refletindo enriquecimento em sódio, proveniente de aqüiferos mais profundos. 
De acordo com ALMODOVAR (2000), as águas subterrâneas do município de Urânia podem ser classificadas em três zonas hidroquímicas: profunda (ZP) e intermediária ( $\mathrm{ZI})$, onde predomina a família das bicarbonatadas cálcicas ou magnesianas, e rasa $(Z R)$, onde predominam as cloro-nitratadas cálcicas ou magnesianas, secundariamente cloretadas sódicas. De acordo com a autora, as águas dos poços profundos não apresentam concentrações anômalas de nitrato, o $\mathrm{pH}$ aumenta da ZR para ZP e o Eh, cloreto, potássio, nitrato e sulfato diminuem de ZR para ZP.

\section{MATERIAIS E MÉTODOS}

Algumas hipóteses foram formuladas para explicar a origem do nitrato detectado nas águas subterrâneas na cidade de Urânia. Este trabalho respondeu a esta indagação, bem como permitiu avanço no entendimento das características geoquímicas do nitrato presente nestas águas.

Para tanto, as seguintes etapas de trabalho foram desenvolvidas:

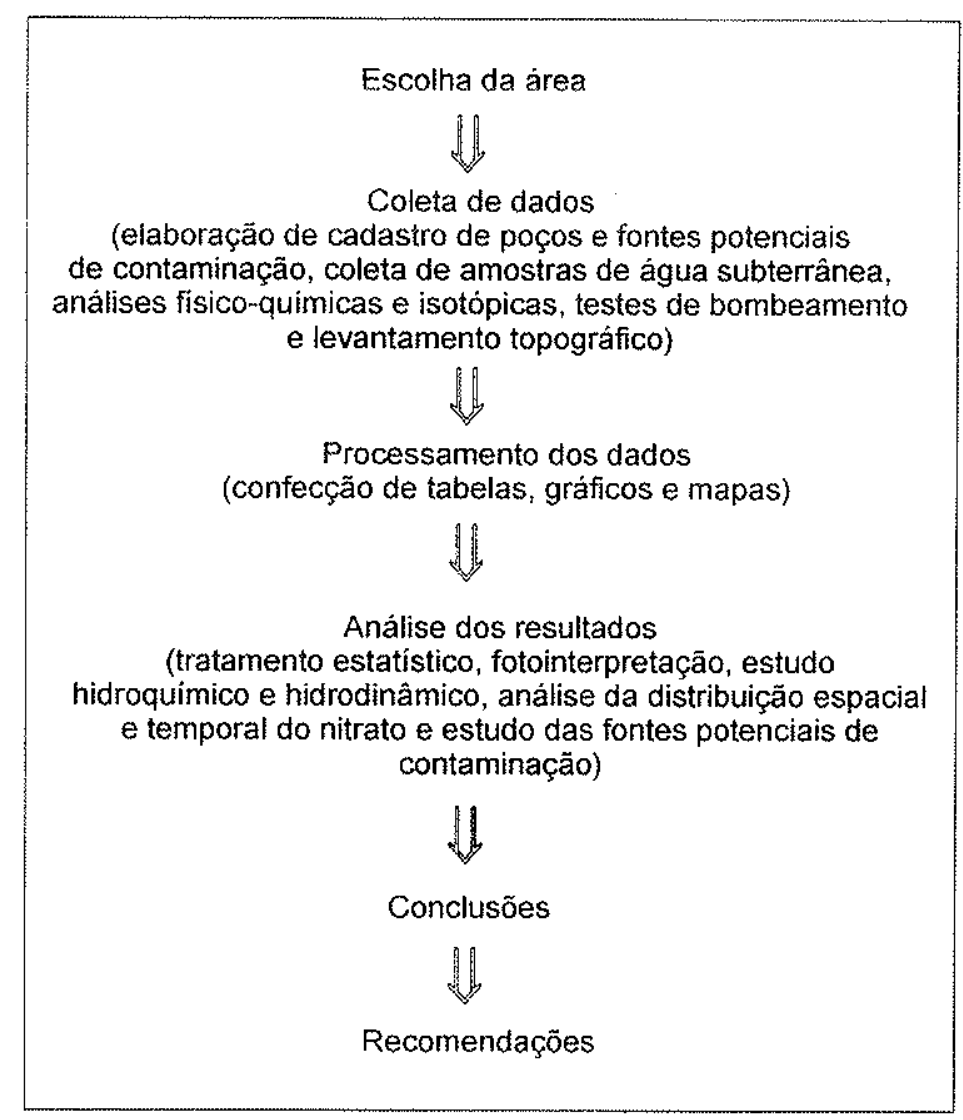




\subsection{Cadastro de Poços Cacimbas e Tubulares}

O cadastro de poços cacimbas e tubulares existentes, elaborado por ALMODOVAR (2000), foi ampliado por meio da aquisição de novos dados. Esta atividade, que teve como objetivo cadastrar no mínimo um poço a cada $200 \mathrm{~m}$, reuniu informações sobre as características hidráulicas, construtivas e os principais usos da água extraída a partir destes poços. Foram também cadastrados poços ao redor da área de estudo, na zona rural da cidade de Urânia.

\subsection{Cadastro de Fontes Potenciais de Contaminação}

Um cadastro das principais fontes de contaminação de nitrato foi elaborado para a área de estudo. Foram consideradas como principais fontes de contaminação sistemas de saneamento in situ (fossas) e atividades agrícolas, com utilização de fertilizantes orgânicos e/ou inorgânicos.

Este levantamento foi realizado por meio de:

- entrevistas com moradores e profissionais da prefeitura e da Sabesp;

- consulta ao banco de dados da Secretaria Municipal de Saúde; e

- estudo do histórico do uso e ocupação do solo por meio de fotografias aéreas, imagem de satélite e verificação de campo da área de estudo e arredores. Foram utilizadas as seguintes fotografias aéreas e imagem de radar:

a) fotografias $n^{\circ s} 2853,2854$ e 2875, de 1962, na escala 1:27.000, levantamento do Instituto Agronômico/Secretaria da Agricultura do Estado de São Paulo;

b) fotografias $n^{\text {os }} 34581$ e 34582 de 1965 , na escala 1:60.000, levantamento USAF;

c) fotografias $n^{0 s} 610,611,665$ e 666 de 1971, na escala 1:25.000, levantamento IBC-GERCA;

d) fotografias $\mathrm{n}^{\text {os }} 21,22$ e 23 de 1985, na escala 1:35.000, levantamento SEP/CAR/IGC - Votuporanga - Fernandópolis; e

e) imagem de satélite Landsat-5, cena 222/074, de 22/06/1997, composição das bandas 3,4 e 5 . 
- verificação, com o auxilio de técnicos da Sabesp, de mapas da rede de esgoto no município, de modo a localizar áreas sem saneamento básico e com presença potencial de fossas sépticas e ou negras, e

- levantamento de fossas localizadas ao redor dos poços monitorados, num raio de $200 \mathrm{~m}$ a partir do poço.

\subsection{Levantamento Planialtimétrico}

A base topográfica utilizada nesta pesquisa foi elaborada por meio das folhas topográficas Santa Albertina (SF-22-D-1-2) e Jales (SF-22-D-1-4), escala 1:50.000 com curvas de nível com eqüidistância de 10 m (IGGSP 1965 e 1966) e para a área urbana, do mapa topográfico com escala 1:2.000 e curvas de nível com eqüidistância de 5 m (URÂNIA, 1988).

O levantamento planialtimétrico dos poços monitorados, nos quais foram feitas medidas de profundidade do nível de água, foi realizado utilizando-se um equipamento de localização geográfica, do tipo GPS (Global Position System), da marca Trimble, modelo PRO-XR12. O programa Pathfinder Office foi utilizado para a correção diferencial dos dados registrados por antena localizada no escritório da empresa Santiago \& Cintra, em São Paulo, com precisão de 0,5 $\mathrm{m}$ a $1,0 \mathrm{~m}$ (para a altitude, coordenada " $\mathrm{z}$ ) e de $0,05 \mathrm{~m}$ a $0,10 \mathrm{~m}$ (para as coordenadas " $x$ " $e$ " $y$ "). Este levantamento teve como objetivos possibilitar o cálculo das cargas hidráulicas nestes poços.

\subsection{Determinação das Condições de Fluxo e de Parâmetros Hidrogeológicos}

As cargas hidráulicas dos poços monitorados foram calculadas subtraindose os valores de cota do terreno dos níveis de água estáticos medidos, utilizando um medidor elétrico de nível de água, nos dias 15/08/01, 19/09/01 e 25/10/01.

Mapas potenciométricos foram confeccionados com os valores de carga hidráulica calculados para os meses de agosto, setembro e outubro de 2001, sendo possível determinar a direção preferencial de fluxo da água subterrânea no aqüífero, o gradiente hidráulico e a velocidade de fluxo da água, calculada utilizando-se a equação de Darcy. Apenas o mapa confeccionado para o mês de 
outubro de 2001 é apresentado nesta dissertação pois todos são muito semelhantes.

O valor da condutividade hidráulica foi obtido por meio de dois ensaios de bombeamento nos poços tubulares PT-23A e PT-26, num período de $48 \mathrm{~h}$. Testes de recuperação também foram efetuados imediatamente após os testes de rebaixamento. Antes do início, as bombas instaladas nos poços foram desligadas por um período mínimo de $24 \mathrm{~h}$. Os níveis de água foram medidos com uma freqüência sugerida por BRASSINGTON (1998).

Os resultados de rebaixamento e recuperação versus tempo foram analisados utilizando-se o programa Aquifer Test da Waterloo Hydrogelogic Inc, versão 2.5, solução de Neuman.

\subsection{Coleta de Amostras de Água Subterrânea e Realização de Análises Físico - Químicas}

Um total de 208 amostras de água foram coletadas em 41 poços cacimbas e 28 poços tubulares. Foram feitas quatro campanhas de coleta de amostras de água subterrânea, distribuídas ao longo das quatro estações de um ano hidrogeológico. Uma quinta campanha de amostragem foi realizada e teve como objetivo a coleta de dados isotópicos.

$\mathrm{Na}$ primeira campanha foram coletadas 55 amostras para a realização de análises químicas. Definiu-se um grupo de 31 amostras (PC-02, PC-04, PC-06, PC-08, PC-23, PC-24, PC-25, PC-26, PC-27, PC-29, PC-30, PC-32, PC-33, PC34, PC-35, PC-38, PC-41, PC-42, PC-43, PT-02, PT-11, PT-12, PT-16, РT-18, PT-19, PT-22, PT-23, PT-25, PT-27, PT-28 e PT-29) a ser coletado é analisado nas três campanhas seguintes. Este grupo de amostras, que incluiu poços cacimbas e tubulares, foi definido com base nos seguintes critérios:

- distribuição espacial das amostras de forma a obter-se um conjunto de dados representativos de toda a área de estudo e permitir o entendimento do comportamento do nitrato, ao longo do ciclo hidrogeológico;

- concentração anômala de nitrato nos poços da área urbana;

- localização geográfica de acordo com o uso e a ocupação atual do solo. Foram selecionados poços representativos de cada uma das seguintes áreas previamente caracterizadas como: área urbana sob influência de 
fossas, área agrícola e área de mata nativa. Para isso, foram coletadas amostras ao redor da área de estudo, na zona rural da cidade de Urânia; e - recursos financeiros e tempo disponíveis para a realização das coletas e das análises químicas.

A caracterização físico-química da água subterrânea foi baseada na medição dos parâmetros: nitrato, nitrito, amônio, cloreto, ferro, alcalinidade, pH, Eh, condutividade elétrica e oxigênio dissolvido, medidos no campo a partir de equipamentos portáteis. Um mínimo de $20 \%$ destas amostras foram enviadas ao laboratório para análise dos íons maiores e menores e amônia. Na quinta campanha, foram ainda coletadas amostras para análise de nitrogênio orgânico e carbono orgânico dissolvido (COD).

As coletas foram realizadas utilizando-se as próprias bombas elétricas instaladas nos poços, após a remoção de água estagnada durante 5 minutos (purga). Alguns poços que não dispunham de bombas foram amostrados com amostradores de aço inoxidável.

Após a coleta, as amostras foram filtradas por meio de membranas de acetato celulose de $0,45 \mu \mathrm{m}$, acondicionadas em frascos descartáveis de polietileno de $200 \mathrm{~mL}$. Estes frascos foram preservados da seguinte forma: um deles foi mantido sob congelamento e os outros três com o $\mathrm{pH}<2$ pela adição, de $\mathrm{H}_{2} \mathrm{SO}_{4}$ e $\mathrm{HNO}_{3}$ com concentração 1:1 e mantidos a uma temperatura não superior a $4^{\circ} \mathrm{C}$ (CETESB, 1988). As amostras coletadas para análise de COD foram acondicionadas em frascos de vidro âmbar e mantidas a uma temperatura não superior a $4^{\circ} \mathrm{C}$ e as amostras destinadas à análise de nitrogênio orgânico, em frascos de polietileno, preservadas com $\mathrm{H}_{2} \mathrm{SO}_{4}$ e mantidas a uma temperatura não superior a $4^{\circ} \mathrm{C}$.

Todo o material não descartável, utilizado durante a amostragem, foi previamente lavado com água corrente e detergente neutro e enxaguados com ácido muriático e posteriormente, com água destilada (CETESB, 1988).

$\mathrm{Na}$ quinta campanha de monitoramento, realizada em setembro de 2001, foram coletadas 12 amostras de água para a realização de análise de ${ }^{15} \mathrm{~N}$. Após a coleta, estas amostras foram diluídas, de modo que a concentração de nitrato não ultrapassasse $5 \mathrm{mg} / \mathrm{L}$ como nitrogênio, filtradas manualmente, utilizando-se membranas de acetato celulose de $0,20 \mu \mathrm{m}$ e posteriormente filtradas, por 
gravidade (gotejamento), em tubos descartáveis de polietileno (tipo "ampolas"), também utilizados para o acondicionamento destas amostras, os quais continham resinas reativas que adsorvem o nitrato. Estes tubos foram ainda "lavados" três vezes com água deionizada, preenchidos com esta água, para que não ocorresse o ressecamento da resina, e mantidos sob congelamento para envio ao laboratório.

O programa de amostragem, que inclui a data de amostragem, os poços amostrados e os parâmetros analisados, pode ser observado no Quadro 5.2, a seguir.

Os parâmetros monitorados no campo e os equipamentos utilizados foram:

Alcalinidade total e parcial: dosagens de $\mathrm{CO}_{3}{ }^{2-}$ e $\mathrm{HCO}_{3}{ }^{-}$por titulação, de acordo com o procedimento recomendado pela APHA (1995), com o emprego de soluções de ácido sulfúrico $\left(\mathrm{H}_{2} \mathrm{SO}_{4}\right)$ 0,1045N (ago/00), 0,1053N (fev/01), 0,047N (ago/01) e 0,0112N (set/2001), padronizados em laboratório com $\mathrm{Na}_{2} \mathrm{CO}_{3}$ e, indicador misto para a determinação do ponto de viragem.

Condutividade elétrica: condutivímetro LF330/Set da WTW.

Eh/pH e temperatura: medidor 330/Set 1 da WTW. O medidor de Eh utilizado possui um eletrodo de cloreto de mercúrio e não de hidrogênio e, por este motivo, nas medidas de Eh acrescentou-se $250 \mathrm{mV}$ para correção.

Oxigênio dissolvido: oxímetro OXI330/Set da WTW.

As concentrações de nitrato, nitrito, amônio, ferro e cloreto foram medidas no campo utilizando-se o equipamento portátil RQFLEX-Plus da MERCK, por meio do método reflectométrico e de acordo com os procedimentos descritos por HANKE (1998). O Quadro 5.1 abaixo apresenta as faixas de leitura obtidas para cada um destes parâmetros.

Quadiro 5.1 - Faixas de leitura dos parâmetros medidos com RQFLEX-Plus.

\begin{tabular}{|c|c|}
\hline Parámetro & Faixa de Leitura (mg/L) \\
\hline Nitrato & $3,0-90,0$ (exceto set/01: 5,0-225,0) \\
\hline Nitrito & $0,5-25,0$ \\
\hline Amônio & $0,2-7,0$ \\
\hline Ferro & $0,2-20,0$ \\
\hline Cloreto & $2,0-50,0$ \\
\hline
\end{tabular}


Quadro 5.2 - Programa de amostragem das águas subterrâneas.

\begin{tabular}{|c|c|c|c|c|}
\hline $\begin{array}{c}\text { Data da } \\
\text { amostragem }\end{array}$ & Poços & $\begin{array}{c}\text { Tipo/quantidade } \\
\text { de poços } \\
\text { amostrados }\end{array}$ & $\begin{array}{l}\text { Parâmetros } \\
\text { analisados in situ }\end{array}$ & $\begin{array}{c}\text { Parâmetros analisados em } \\
\text { laboratório }\end{array}$ \\
\hline $\begin{array}{l}1^{a} \text { campanha: } \\
10 / 04 \mathrm{a} \\
12 / 04 / 2000\end{array}$ & $\begin{array}{l}\text { PC-02, PC-04, PC-06, PC-07, PC-08, PC-10, PC-11, PC-12, } \\
\text { PC-16, PC-18, PC-19, PC-21, PC-22, PC-23, PC-24, PC-25, } \\
\text { PC-26, PC-27, PC-29, PC-30, PC-31, PC-32, PC-33, PC-34, } \\
\text { PC-35, PC-36, PC-37, PC-38, PC-39, PC-40, PC-41, PC-42, } \\
\text { PC-43, PT-01, PT-02, PT.05, PT-08, PT-10, PT-11, PT-12, } \\
\text { PT-13, PT-14, PT-16, PT-18, PT-19, PT-21, PT-22, PT-23, } \\
\text { PT-24, PT-25, PT-26, PT-27, PT-28, PT-29 e PT-31. }\end{array}$ & $\begin{array}{l}33 \text { poços } \\
\text { cacimbase } \\
22 \text { poços } \\
\text { tubulares }\end{array}$ & $\begin{array}{l}\mathrm{pH} \text {, Eh, condutividade } \\
\text { elétrica, temperatura, } \\
\text { cloreto, nitrato, } \\
\text { amônio, nitrito e } \\
\text { alcalinidade. }\end{array}$ & $\begin{array}{l}\text { Série nitrogenada: } \mathrm{NO}_{3}{ }^{-} \text {e } \mathrm{NO}_{2}{ }^{-} \\
\text {lons maiores e menores: } \mathrm{Ca}^{2+}, \\
\mathrm{Mg}^{2+}, \mathrm{Na}^{+}, \mathrm{K}^{+}, \mathrm{SO}_{4}{ }^{2-}, \mathrm{F}^{-}, \mathrm{PO}_{4}^{2-}, \mathrm{Br}^{-}, \\
\mathrm{Cl}^{-}, \mathrm{Zn}^{-}, \mathrm{Sr}^{2+}, \mathrm{Ba}^{2+}, \mathrm{Fe}^{\text {total }}, \mathrm{Mn}^{+}, \mathrm{Al}^{+}, \\
\mathrm{Cr}^{\text {total }}, \mathrm{Pb}^{+}, \mathrm{Cu}^{+}, \mathrm{Ni}^{+} \text {e } \mathrm{Ag}^{+} \text {. }\end{array}$ \\
\hline $\begin{array}{l}2^{a} \text { campanha: } \\
29 / 08 \text { a } \\
06 / 09 / 2000\end{array}$ & $\begin{array}{l}\text { PC-02, PC-04, PC-06, PC-06, PC-17, PC-23, PC-24, PC-25, } \\
\text { PC-26, PC-27, PC-28, PC-29, PC-30, PC-32, PC-33, PC-34, } \\
\text { PC-35, PC-38, PC-41, PC-42, PC-43, PC-44, PC-45, PC-46, } \\
\text { PT-02, PT-07, PT-11, PT-12, PT-16, PT-18, PT-19, PT-21, } \\
\text { PT-22, PT-23, PT-25, PT-27, PT-28, PT-29, PT-30, PT-32, } \\
\text { PT-33, PT-34 e PT-35 (Duplicata/PT-28). }\end{array}$ & $\begin{array}{l}24 \text { poços } \\
\text { cacimbas e } \\
19 \text { poços } \\
\text { tubulares }\end{array}$ & $\begin{array}{l}\mathrm{pH}, \mathrm{Eh}, \text { condutividade } \\
\text { elétrica, temperatura, } \\
\text { cloreto, nitrato, } \\
\text { amônio, Fe } 2^{+} \text {e } \\
\text { alcalinidade. }\end{array}$ & $\begin{array}{l}\text { Série nitrogenada: } \mathrm{NO}_{3}^{-}, \mathrm{NO}_{2}{ }^{-} \\
\mathrm{NH}_{4}^{+}, \mathrm{NH}_{3} \text {. } \\
\text { lons maiores e menores: } \mathrm{Ca}^{2+} \\
\mathrm{Mg}^{2+}, \mathrm{Na}^{+}, \mathrm{K}^{+}, \mathrm{SO}_{4}^{2-}, \mathrm{F}^{-}, \mathrm{PO}_{4}^{2-}, \mathrm{Br}^{-} \\
\mathrm{Cl}^{+} \mathrm{Zn}^{-}, \mathrm{Sr}^{2+}, \mathrm{Ba}^{2+}, \mathrm{Fe}^{\text {total }}, \mathrm{Mn}^{+}, \mathrm{Al}^{+} \\
\mathrm{Cr}^{\text {total }}, \mathrm{Pb}^{+}, \mathrm{Cu}^{+}, \mathrm{Ni}^{+} \in \mathrm{Ag}^{+} \text {. }\end{array}$ \\
\hline $\begin{array}{l}3^{a} \text { campanha: } \\
05 / 02 \text { a } \\
08 / 02 / 2001\end{array}$ & $\begin{array}{l}\text { PC-02, PC-04, PC-06, PC-08, PC-17, PC-23, PC-24, PC-25, } \\
\text { PC-26, PC-27, PC-28, PC-29, PC-30, PC-32, PC-33, PC-34, } \\
\text { PC-35, PC-38, PC-40, PC-41, PC-42, PC-33, PC-44, PC-45, } \\
\text { PC-47, PT-02, PT-07, PT-11, PT-12, PT-16, PT-18, PT-19, } \\
\text { PT-21, PT-22, PT-23, PT-25, PT-27, PT-28, PT-29, PT-30, } \\
\text { PT-33, PT-34 e PT-35 (Duplicata/PT-27). }\end{array}$ & $\begin{array}{l}25 \text { poços } \\
\text { cacimbas e } \\
18 \text { poços } \\
\text { tubutares }\end{array}$ & $\begin{array}{l}\mathrm{pH}, \text { En, condutividade } \\
\text { elétrica, temperatura, } \\
\text { cloreto, nitrato, } \\
\text { amônio, nitrito, Fe } 2^{+} \\
\text {e alcalinidade. }\end{array}$ & $\begin{array}{l}\text { Série nitrogenada: } \mathrm{NO}_{3}{ }^{-}, \mathrm{NO}_{2}^{-} \\
\mathrm{NH}_{4}^{+} \text {e } \mathrm{NH}_{3} \\
\text { lons maiores e menores: } \mathrm{Ca}^{2+} \\
\mathrm{Mg}^{2+} \mathrm{Na}^{+}, \mathrm{K}^{+}, \mathrm{SO}_{4}{ }^{2-}, \mathrm{F}^{-}, \mathrm{PO}_{4}^{2-}, \mathrm{Br}^{+} \\
\mathrm{Cl}^{-}, \mathrm{Zn}^{-}, \mathrm{Sr}^{2+}, \mathrm{Ba}^{2+}, \mathrm{Fe}^{\text {total }}, \mathrm{Mn}^{+}, \mathrm{Al}^{+} \\
\mathrm{Cr}^{\text {total }}, \mathrm{Pb}^{+}, \mathrm{Cu}^{+}, \mathrm{Ni}^{+} \in \mathrm{Ag}^{+} .\end{array}$ \\
\hline
\end{tabular}

PC-04: parâmetros analisados in situ (exceto alcalinidade).

Continua...

po-02: parâmetros analisados in sĩu e em laboratório. 
Quadro 5.2 - Programa de amostragem das águas subterrâneas.

\begin{tabular}{|c|c|c|c|c|}
\hline $\begin{array}{c}\text { Data da } \\
\text { amostragem }\end{array}$ & Poços & $\begin{array}{l}\text { Tipolquantidade } \\
\text { de poços } \\
\text { amostrados }\end{array}$ & $\begin{array}{l}\text { Parâmetros } \\
\text { Analisados in situ }\end{array}$ & $\begin{array}{c}\text { Parâmetros Analisados no } \\
\text { laboratório }\end{array}$ \\
\hline $\begin{array}{l}4^{a} \text { campanha: } \\
16 / 08 \text { a } \\
20 / 08 / 2001\end{array}$ & $\begin{array}{l}\text { PC-02, PC-04, PC-06, PC-08, PC-17, PC-23, PC-24, PC-25, } \\
\text { PC-26, PC-27, PC-28, PC-20, PC-30, PC-32, PC-33, PC-34, } \\
\text { PC-35, PC-38, PC-40, PC-41, PC-42, PC-43, PC-46, PC-47, } \\
\text { PC-48, PT-02, PT-07, P- H1, PT-12, PT-16, PT-18, PT-19, } \\
\text { PT-22, PT-23, PT-25, PT.27, PT-28, PT-29, PT-30, PT-31, } \\
\text { PT-33, PT-34, PT-35 \& PT.10, (Duplicata/PC-04). }\end{array}$ & $\begin{array}{c}25 \text { poços } \\
\text { cacimbas e } \\
18 \text { poços } \\
\text { tubulares }\end{array}$ & $\begin{array}{l}\text { pH, Eh, condutividade } \\
\text { elétrica, temperatura, } \\
\text { oxigênio dissolvido, } \\
\text { cloreto, nitrato, } \\
\text { amônio, Fe } 2^{+} \mathrm{e} \\
\text { alcalinidade. }\end{array}$ & $\begin{array}{l}\text { Série nitrogenada: } \mathrm{NO}_{3}, \mathrm{NO}_{2}^{-} \text {, } \\
\mathrm{NH}_{4}^{+} \text {e } \mathrm{NH}_{3} \text {. } \\
\text { ílons maiores e menores: } \\
\mathrm{Ca}^{2+}, \mathrm{Mg}^{2+}, \mathrm{Na}^{+}, \mathrm{K}^{+}, \mathrm{SO}_{4}^{2-}, \mathrm{F}^{-} \\
\mathrm{PO}_{4}^{2-}, \mathrm{Br}^{-}, \mathrm{Cr}, \mathrm{Zn}^{-}, \mathrm{Sr}^{2+}, \mathrm{Ba}^{2+} \\
\mathrm{Fe}^{\text {total }}, \mathrm{Mn}^{+}, \mathrm{Al}^{+}, \mathrm{Cr}^{\text {total }}, \mathrm{Pb}^{+}, \mathrm{Cu}^{+} \\
\mathrm{Ni}^{+} \text {e } \mathrm{Ag}^{+} .\end{array}$ \\
\hline $\begin{array}{l}5^{\text {a }} \text { campanha: } \\
24 / 09 \text { a } \\
28 / 09 / 2001\end{array}$ & 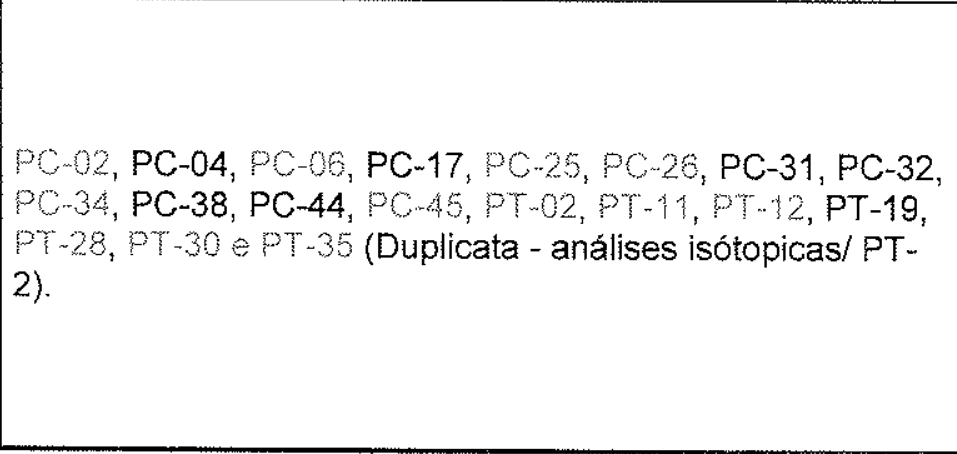 & $\begin{array}{c}12 \text { poços } \\
\text { cacimbas e } \\
07 \text { poços } \\
\text { tubulares }\end{array}$ & $\begin{array}{l}\text { pH, Eh, condutividade } \\
\text { elétrica, temperatura, } \\
\text { oxigênio dissolvido, } \\
\text { cloreto, nitrato, } \\
\text { amônio, } \mathrm{Fe} 2^{+} \mathrm{e} \\
\text { alcalinidade. }\end{array}$ & $\begin{array}{l}\text { Série nitrogenada: } \mathrm{NO}_{3}^{-}, \mathrm{NO}_{2}^{-}, \\
\mathrm{NH}_{4}^{+}, \mathrm{NH}_{3} \text { e } \mathrm{N}_{\text {org }} \\
\text { lons maiores e menores: } \mathrm{Ca}^{2+} \\
\mathrm{Mg}^{2+}, \mathrm{Na}^{+}, \mathrm{K}^{+}, \mathrm{SO}_{4}{ }^{2+}, \mathrm{F}^{-} \mathrm{PO}_{4}{ }^{2-}, \mathrm{Br}^{-}, \\
\mathrm{Cl}^{-}, \mathrm{Zn}^{-}, \mathrm{Sr}^{2+}, \mathrm{Ba}^{2+}, \mathrm{Fe}^{\text {total }} \mathrm{Mn}^{+}, \mathrm{Al}^{+}, \\
\mathrm{Cr}^{\text {total }}, \mathrm{Pb}^{+}, \mathrm{Cu}^{+}, \mathrm{Ni}^{+} \in \mathrm{Ag}^{+} . \\
{ }^{15} \mathrm{~N}_{\mathrm{NO} 3}^{-} \text {. } \\
\text { carbono orgânico dissolvido } \\
\text { (COD). }\end{array}$ \\
\hline
\end{tabular}

PC-04: parâmetros analisados in situ (exceto alcalinidade).

PC.02: parâmetros analisados in situ e em laboratório. 
Antes da realização das análises químicas no campo, foram feitas análises de soluções padrão utilizando o equipamento RQFLEX-Plus. Foram obtidos erros que variaram, em média, de $15 \%$ a $17 \%$. A faixa do percentual de erro obtido é menor do que o admitido para duplicatas pela USEPA (1995) que é de $30 \%$. A análise de parâmetros em campo, por meio de um método semi quantitativo, provou-se um método bastante eficiente para a obtenção dos dados necessários para a pesquisa.

As análises realizadas em laboratório incluíram os compostos nitrogenados (nitrato, nitrito, amônio e nitrogênio orgânico), os ions maiores e menores (cálcio, magnésio, sódio, potássio, cloreto, sulfato, fluoreto, fosfato, brometo, estrôncio, bário, ferro total, manganês, alumínio, cromo total, chumbo, cobre, zinco, cádmio, niquel, prata), o carbono orgânico dissolvido e o isótopo ${ }^{15} \mathrm{~N}$.

Os métodos analíticos utilizados nos laboratórios e os limites de detecção obtidos para cada parâmetro são apresentados nos Quadros 5.3 e 5.4 .

\section{Quadro 5.3 - Relação dos parâmetros analisados em laboratório e respectivos métodos analíticos.}

\begin{tabular}{|c|c|c|}
\hline Parâmetro & Método/Técnica & Laboratório \\
\hline $\begin{array}{c}\mathrm{Al}^{3+}, \mathrm{Ca}^{2+}, \mathrm{Cd}^{2+}, \mathrm{Fe}^{\text {total }} \\
\mathrm{Mg}^{2+}, \mathrm{Mn}^{2+}, \mathrm{Sr}^{2+}, \mathrm{Ba}^{2+}, \mathrm{Cr}^{\text {total }} \\
\mathrm{Pb}^{2+}, \mathrm{Cu}^{2+}, \mathrm{Zn}^{2+}, \mathrm{Ni}^{2+} \text { e } \mathrm{Ag}^{+}\end{array}$ & Espectrofotometria & $\begin{array}{l}\text { Laboratório de Hidroquímica do } \\
\text { CEPAS/USP }\end{array}$ \\
\hline $\mathrm{K}^{+}$e $\mathrm{Na}^{+}$ & Fotometria de chama & $\begin{array}{l}\text { Laboratório de Hidroquímica do } \\
\text { CEPAS/USP }\end{array}$ \\
\hline $\mathrm{PO}_{4}{ }^{3-}$ como $\mathrm{P}, \mathrm{Cl}, \mathrm{SO}_{4}{ }^{2-}, \mathrm{F}$ e $\mathrm{Br}^{-}$ & Cromatografia líquida & $\begin{array}{l}\text { Laboratório de Hidroquímica do } \\
\text { CEPAS/USP }\end{array}$ \\
\hline $\mathrm{N}_{\text {total }}$ & EPA 351.1 - Colorimetria & CEIMIC Análises Ambientais S/C Ltda. \\
\hline $\mathrm{NO}_{2}^{-}-\mathrm{N}$ e $\mathrm{NO}_{3}^{-}-\mathrm{N}$ & Cromatografia liquida & $\begin{array}{l}\text { Laboratório de Hidroquimica do } \\
\text { CEPAS/USP }\end{array}$ \\
\hline $\mathrm{NH}_{3}-\mathrm{N}$ & EPA 350.2 -Colorimetria & CEIMIC Análises Ambientais S/C Ltda. \\
\hline$N_{\text {org. }}$ & EPA 351.3 -Colorimetria & CEIMIC Análises Ambientais S/C Ltda. \\
\hline${ }^{*} \mathrm{COD}$ & EPA 415.1 -Combustãoa & $\begin{array}{l}\text { Laboratório de Isótopos Ambientais da } \\
\text { Universidade de Waterloo, no Canadá }\end{array}$ \\
\hline${ }^{15} \mathrm{~N}$ & Espectrofotometria & $\begin{array}{l}\text { Laboratório de Isótopos Ambientais da } \\
\text { Universidade de Waterloo, no Canadá }\end{array}$ \\
\hline
\end{tabular}

${ }^{*} \mathrm{COD}$ : carbono orgânico dissolvido. 
Quadro 5.4 - Limites de deteç̧ão obtidos para cada parâmetro.

\begin{tabular}{|c|c|c|c|c|c|}
\hline Parâmetro & $\begin{array}{c}\text { Limite de } \\
\text { detecção (mg/L) }\end{array}$ & Parâmetro & $\begin{array}{c}\text { Limite de } \\
\text { detecção (mg/L) }\end{array}$ & Parâmetro & $\begin{array}{c}\text { Limite de } \\
\text { deteç̧äo } \\
\text { (mg/L) (*) }\end{array}$ \\
\hline $\mathrm{Al}^{3+}$ & 0,550 & $\mathrm{~Pb}^{2+}$ & 0,050 & $\mathrm{SO}_{4}{ }^{2-}$ & 0,020 \\
\hline $\mathrm{Ca}^{2+}$ & 0,200 & $\mathrm{Cu}^{2+}$ & 0,025 & $\mathrm{~F}^{-}$ & 0,016 \\
\hline $\mathrm{Cd}^{2+}$ & 0,009 & $\mathrm{Zn}^{2+}$ & 0,008 & $\mathrm{Br}^{-}$ & 0,005 \\
\hline $\mathrm{Fe}^{\text {tota! }}$ & 0,050 & $\mathrm{Ni}^{2+}$ & 0,040 & $\mathrm{NO}_{2}{ }^{-2} \mathrm{~N}$ & 0,005 \\
\hline $\mathrm{Mg}^{2+}$ & 0,003 & $\mathrm{Ag}^{+}$ & 0,030 & $\mathrm{NO}_{3}{ }^{-}-\mathrm{N}$ & 0,011 \\
\hline $\mathrm{Mn}^{2+}$ & 0,020 & $\mathrm{~K}^{+}$ & 0,010 & $\mathrm{NH}_{3}-\mathrm{N}$ & 0,200 \\
\hline $\mathrm{Sr}^{2+}$ & 0,050 & $\mathrm{Na}^{+}$ & 0,010 & $\mathrm{~N}_{\text {org. }}$ & 0,400 \\
\hline $\mathrm{Ba}^{2+}$ & 0,180 & $\mathrm{HPO}_{4}{ }^{-2}$ & 0,010 & ${ }^{* *} \mathrm{COD}$ & 0,100 \\
\hline $\mathrm{Cr}^{\text {total }}$ & 0,020 & $\mathrm{Cl}^{-}$ & 0,070 & ${ }^{15} \mathrm{~N}$ & 0,3 \\
\hline
\end{tabular}

*Limite de deteç̧ăo em $\mathrm{mg} / \mathrm{L}$ exceto para a razão ${ }^{15} \mathrm{~N} /{ }^{14} \mathrm{~N}$, cuja unidade é $\%_{\text {a }}$.

${ }^{*} \mathrm{COD}$ : carbono orgânico dissolvido.

\subsection{Análise dos Resultados}

A seguir, são apresentados os métodos utilizados no tratamento dos dados.

\subsubsection{Análise Estatística}

Após a realização das análises físico-químicas, os resultados foram organizados em planilhas onde procedeu-se o seguinte tratamento estatistico:

1) determinação de estatísticas básicas [média aritmética $\overline{(x)}$ e desvio padrão $\left(s^{2}\right)$ ], para cada os parâmetros medidos no campo, $\mathrm{pH}$, Eh, condutividade elétrica, cloreto, nitrato e amônio, nas cinco campanhas realizadas, para os dois conjuntos de poços (cacimba e tubular) por meio das fórmulas:

$$
\begin{gathered}
x=\Sigma x_{i} / n \\
s^{2}=\Sigma\left(x_{i}-\bar{x}\right)^{2} / n
\end{gathered}
$$

sendo $\bar{x}=$ média aritmética, $\Sigma x_{i}=$ somatória das concentrações obtidas e $\mathrm{n}=$ número de amostras.

O objetivo desta análise foi verificar as concentraçōes médias de cada um desses compostos em cada uma das cinco campanhas realizadas. Para estas análises foram utilizados, além dos dados desta pesquisa, aqueles obtidos por ALMODOVAR (2000) no período de junho de 1998 a junho de 1999. 
Com o objetivo de verificar o tipo de distribuição dos dados, calculou-se o coeficiente de variação (CV), que é dado pela razão do desvio padrão pela média do conjunto de observações. Foram confeccionados histogramas utilizando-se o programa Statistica, versão 4.3 de 1993, da Statsoft, Inc.;

2) Elaboração de gráficos de concentração versus tempo para os compostos nitrato, cloreto e condutividade elétrica, medidos no campo;

3) Realização de uma análise multivariante por meio do cálculo dos coeficientes de correlação linear ( $r$ ) de Pearson, segundo a fórmula:

$$
(r)=\frac{\left(\sum X Y-\left(\sum X \sum Y\right)\right)^{*} n}{\sqrt{\left(\left(\mathrm{n}^{*}\left(\sum \mathrm{X}^{2}-\left(\sum \mathrm{X}^{2}\right)\right)\right)^{*}\left(\mathrm{n}^{*}\left(\sum \mathrm{Y}^{2}-\left(\sum \mathrm{Y}^{2}\right)\right)\right)\right.}}
$$

Onde $n$ é o número de pares de valores para $x$ e y. Esta análise foi feita, para os dois grupos de poços, para cada uma das campanhas, utilizando-se os dados obtidos em laboratório e os resultados de cloreto e nitrato medidos no campo. Tal procediemnto teve como objetivo avaliar o comportamento relativo entre os diferentes compostos (e suas concentrações) e suas possíveis correlações. Segundo DAVIS (1986), o teste utilizado para avaliar se uma correlação é ou não significativa é:

$$
T(r)=\frac{\sqrt[2]{n-3}}{2} \ln \left(\frac{1+r}{1-r}\right)
$$

Foi adotado um nivel de significância de $5 \%$. Neste caso, aceita-se a hipótese da existência de correlação entre dois parâmetros com $5 \%$ de significância, se o coeficiente de correlação $(r)$ entre eles for tal que $T(r)>1,96$ ou $T(r) \leq 1,00$.

Como forma de ilustrar as correlações positiva ou negativa identificadas como relevantes para o estudo, foram gerados gráficos de concentração dos compostos $A$ versus concentração do composto $B$ e ajustadas retas que melhor se encaixaram a esses pares de valores pelo método dos mínimos quadrados. Este método permite a construção de uma única reta em rélação a qual a 
somatória das diferenças ao quadrado entre os valores observados menos os correspondentes computados é mínima (LANDIM, 1997). Esses gráficos foram gerados utilizando-se o programa Statistica, versão 4.3 de 1993, da Statsoft, Inc.

4) Realização de análise espacial utilizando-se o método de krigagem ordinária. Foram confeccionados mapas de isoconcentração, para o nitrato $e$ - cloreto, para os dois grupos de poços (cacimba e tubular) e para as estações seca e úmida, nos quais foram traçadas curvas de mesmo valor. Utilizou-se, para a interpolação e confeç̧ão dos mapas, o programa SURFER, versão 7.0 da Golden Softwares, Inc. Estes mapas foram comparados com os modelos conceituais de isoconcentração para estes compostos.

A análise espacial teve como objetivo fazer uma avaliação dos padrões de distribuição dos referidos compostos (e suas concentrações) em área.

Todas as técnicas estatísticas utilizadas referem-se ao modelo estatístico definido por KRUMBEIN \& GRAYBILL (1965, apud LANDIM, 1997) como uma expressão matemática envolvendo variáveis, parâmetros, constantes e uma ou mais componentes casuais. O termo componente casual é utilizado porque representa as flutuações existentes nos dados, as quais não podem ser previstas em apenas uma observação, mas podem tornar-se previsiveis se tomado um número $n$ de observações.

\subsubsection{Classificação e Evolução Hidroquímica das Águas Subterrâneas}

A água subterrânea dos poços amostrados foi classificada, utilizando-se os resultados das concentrações dos ions maiores obtidos por meio de análises químicas em laboratório, exceto o cloreto onde foram utilizados os dados medidos no campo. Os resultados das concentrações dos ions maiores $\mathrm{Na}^{+}, \mathrm{K}^{+}, \mathrm{Ca}^{2+}$, $\mathrm{Mg}^{2+}, \mathrm{Cl}^{-}, \mathrm{HCO}_{3}{ }^{-}, \mathrm{CO}_{3}{ }^{2-}$ e $\mathrm{SO}_{4}{ }^{2-}$, obtidao em meq/L, foram tabelados e lançados em diagramas triangulares de Piper, calculando-se as porcentagens em relação a soma de cátions e ânions de cada amostra. Utilizou-se o software HydroChem, adquirido via intemet na página da Rock Ware Earth Science Software.

Os diagramas de Piper foram confeccionados para cada campanha de amostragem. O Quadro 5.5 abaixo apresenta um sumário dos dados utilizados na construção de cada diagrama. 
Quadro 5.5 - Sumário dos dados utilizados na confecção dos diagramas.

\begin{tabular}{|c|c|c|c|c|}
\hline Diagrama & Tipo de Poço & $\begin{array}{c}\text { Número de } \\
\text { dados }\end{array}$ & $\begin{array}{c}\text { Data da Coleta } \\
\text { dos Dados }\end{array}$ & Dados Utilizados \\
\hline A & cacimba e tubular & 19 & abril/00 & $\begin{array}{l}\text { PC-04, PC-06, PC-07, PC-08, } \\
\text { PC-10, PC-11, PC-12, PC-16, } \\
\text { PC-18, PC-22, PT-01, PT-02, PT- } \\
\text { O5, PT-08, PT-11, PT-12, PT-13, } \\
\text { PT-14 e PT-16. }\end{array}$ \\
\hline B & cacimba e tubular & 12 & agosto/00 & $\begin{array}{l}\text { PC-02, PC-08, PC-17, PC-29, } \\
\text { PC-33, PC-34, PC-38, PC-43, } \\
\text { PT-11, PT-27, PT-28 e PT-30 }\end{array}$ \\
\hline C & cacimba e tubular & 11 & fevereiro/01 & $\begin{array}{l}\text { PC-02, PC-08, PC-17, PC-29, } \\
\text { PC-34, PC-38, PC-43, PT-11, } \\
\text { PT-27, PT-28 e PT-30. }\end{array}$ \\
\hline D & cacimba e tubular & 17 & agosto/01 & $\begin{array}{l}\text { PC-02, PC-04, PC-06, PC-08, } \\
\text { PC-17, PC-29, PC-33, PC-34, } \\
\text { PC-38, PC-43, PC-48, PC-101, } \\
\text { PT-11, PT-27, PT-28, PT-30 e } \\
\text { PT-35. }\end{array}$ \\
\hline E & cacimba e tubular & \multirow{2}{*}{17} & setembro/01 & $\begin{array}{l}\text { PC-02, PC-06, PC-17, PC-25, } \\
\text { PC-26, PC-31, PC-32, PC-34, } \\
\text { PC-38, PC-44, PC-45, PT-02, } \\
\text { PT-11, PT-12, PT-28, PT-30 e } \\
\text { PT-35. }\end{array}$ \\
\hline
\end{tabular}




\section{APRESENTAÇÃO E DISCUSSÃO DOS RESULTADOS}

São apresentados e discutidos a seguir os resultados obtidos.

\subsection{Controle de Qualidade}

Cada um dos laboratórios utilizados possui o seu próprio controle de qualidade. Com o objetivo de verificar a exatidão dos resultados analíticos, o Laboratório CEIMIC realiza análises de soluções padrão de concentração conhecida denominada spike. Os resultados são apresentados em porcentagem de recuperação de cada ion analisado. Segundo HOUNSLOW (1994), a porcentagem de recuperação aceitável é maior que $70 \%$. Os resultados obtidos indicaram um percentual de recuperação de $97 \%$ a $110 \%$. O Laboratório de Hidroquímica do CEPAS/USP verifica a exatidão de seus resultados por meio da análise periódica de soluções padrão, porém não há procedimento de registro destes testes.

Com o objetivo de analisar a confiabilidade dos resultados das análises químicas totais, realizadas em laboratório, calculou-se a porcentagem do erro analítico, a partir das concentrações obtidas, em miliequivalentes, dos ânions e cátions (balanço iônico), segundo a equação (CUSTÓDIO \& LLAMAS, 1976):

$$
\text { Erro }(\%)=\frac{\sum \text { cátions }-\sum \hat{a} \text { nions }}{\sum \text { cátions }+\sum \text { ânions }} \times 100
$$

Segundo CUSTÓDIO \& LLAMAS (1976 modificado de ANDERSON, 1966), os erros de balanço iônico admissíveis em função da condutividade elétrica são:

$\begin{array}{lccccc}\text { Condutividade elétrica }(\mu \mathrm{s} / \mathrm{cm}) & 50 & 200 & 500 & 2000 & >2000 \\ \text { Erro admissível }(\%) & 30 & 10 & 4 & 4 & 4\end{array}$

A Tabela 6.1 abaixo apresenta os percentuais de erros abaixo de $10 \%$ e a média da condutividade elétrica para cada campanha. $O$ balanço iônico foi calculado duas vezes para cada campanha: a primeira utilizou os dados obtidos em laboratório, exceto alcalinidade que só foi determinada no campo (Anexo 2) e 
a segunda, os resultados de nitrato e cloreto obtidos no campo (Anexo 3). 0 Anexo 1 apresenta todos os resultados obtidos.

Tabela 6.1 - Percentuais de erros abaixo de 10\% e média das condutividades elétricas para cada campanha - resultados obtidos em laboratório e no campo.

\begin{tabular}{|c|c|c|c|}
\hline \multirow[b]{2}{*}{ Campanha } & \multicolumn{2}{|c|}{$\begin{array}{l}\text { Percentual de erro analítico abaixo de } \\
\qquad 10 \%(\%)\end{array}$} & \multirow{2}{*}{$\begin{array}{c}\text { Média da } \\
\text { condutividade elétrica } \\
(\mu s / \mathrm{cm})\end{array}$} \\
\hline & $\begin{array}{l}\text { Resultados de } \\
\text { laboratório }\end{array}$ & $\begin{array}{c}\text { Resultados de } \\
\text { campo para cloreto } \\
\text { e nitrato }\end{array}$ & \\
\hline abril/00 & 58 & 68 & 234 \\
\hline agosto/00 & 83 & 83 & 207 \\
\hline fevereiro/01 & 33 & 64 & 209 \\
\hline agosto/01 & 29 & 38 & 218 \\
\hline setembro/01 & 86 & 86 & 212 \\
\hline
\end{tabular}

De forma geral, os erros calculados demonstram boa confiabilidade, exceto na campanha de agosto/01, onde os percentuais de erros obtidos abaixo de $10 \%$ foram de $29 \%$ e $38 \%$. Isto se deveu à falta de precisão dos resultados de alcalinidade obtidos em virtude destes terem sido calculados utilizando-se uma seringa para a titulação e não uma bureta (esta foi danificada no percurso da viagem). Os dados de alcalinidade de agosto/01 foram utilizados com cautela, quando da análise da hidroquímica das águas subterrâneas (capítulo 6.5). Atribuem-se os maiores erros obtidos, a imprecisões na obtenção da alcalinidade que, de acordo com CUSTÓDIO \& LLAMAS (1976), é uma fonte constante de erros.

Cabe salientar que quando foram usados os resultados das técnicas de análises de campo (nitrato e cloreto), em substituição às análises de laboratório, os resultados de balanço iônico foram melhores, o que mostra uma boa confiabilidade daquela técnica. Tal resultado já foi observado por VARNIER \& HIRATA (2002) quando utilizando as mesmas técnicas analíticas em campo e em laboratório.

A Figura 6.1 abaixo apresenta um gráfico dos percentuais de erros obtidos versus número de amostras. 


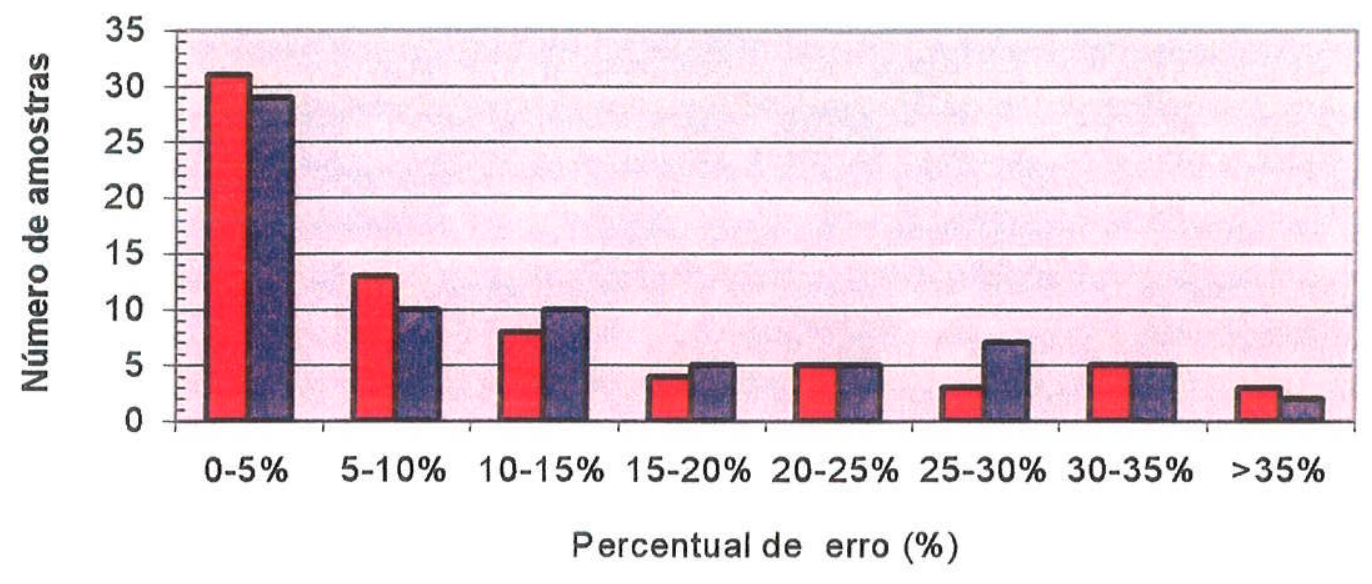

Campo $\square$ Laboratório

Figura 6.1 - Percentuais de erros analíticos obtidos versus número de amostras analisadas.

Pode-se observar que mais de $50 \%$ das amostras se restringiram a erros menores que $10 \%$, o que confirma a confiabilidade dos resultados obtidos.

Segundo USEPA (1995), o erro admissível para amostras em duplicata é de até $30 \%$. Em todas as campanhas realizadas, exceto abril/00, foram coletadas amostras em duplicata com o objetivo de verificar a precisão dos resultados obtidos em laboratório (Anexo 4). Os percentuais de erro não ultrapassaram 30\% em $88 \%$ dos compostos analisados, o que confere a estas análises boa qualidade e reprodutibilidade

\subsection{Cadastro de Poços Cacimbas e Tubulares}

Foram cadastrados 30 novos poços cacimbas e 19 tubulares (Anexo 5). A Figura 6.2 apresenta a localização de todos os poços cadastrados até 2002. Estes foram classificados em dois grupos previamente definidos por ALMODOVAR (2000): 
- Poços cacimbas: são poços privados, com diâmetros que variam de 1,2 a $1,5 \mathrm{~m}$ e profundidades de 6,0 a $21 \mathrm{~m}$. Alguns deles possuem alguns metros de acabamento em tijolos ou anéis de concreto, na base do poço. Todos possuem tampas de concreto, madeira ou telha. São equipados, na maioria, com bomba elétrica de superfície de pequena vazão (aproximadamente 1 $\mathrm{m}^{3} / \mathrm{h}$ ), e a água é utilizada para fins domésticos diversos, tais como: lavagem de áreas externas e internas das residências, irrigação de pequenas hortas e ainda como fonte de água potável (Fotos 1 e 2); e

- Poços tubulares: são poços privados ou de propriedade da prefeitura da cidade de Urânia, com diâmetro de 4 polegadas e profundidades que variam de $57 \mathrm{~m}$ a $104 \mathrm{~m}$. Todos estes poços possuem acabamento em tubo geomecânico de PVC, com comprimento de $16 \mathrm{~m}$ a 35,7 m, pedrisco (pré filtro) entre a parede do furo e o tubo e tampas de PVC. São equipados com bomba elétrica de superfície de pequena vazão (raramente possuem bomba submersa de vazão superior a $1 \mathrm{~m}^{3} / \mathrm{h}$ ), e a água é utilizada também para fins domésticos diversos. Freqüentemente serve como fonte de água potável (Fotos 3 e 4).

Não faz parte desta pesquisa um terceiro grupo de poços cadastrados e classificados por ALMODOVAR (2000) como poços profundos, de propriedade da Sabesp. Segundo ALMODOVAR (2000), existem sete poços profundos no município de Urânia denominados: PP01, PP02, PP03, PP04, PP05, PP06 e PP08, anteriormente utilizados para abastecimento público. Estes poços foram parcialmente desativados em 1995, quando a água passou a ser aduzida de Jales, pois concentraçōes de cromo acima dos limites estabelecidos pela Portaria 36 do Ministério da Saúde ( $>0,05 \mathrm{mg} / \mathrm{L}$ ) foram detectadas nas águas subterrâneas destes poços. 


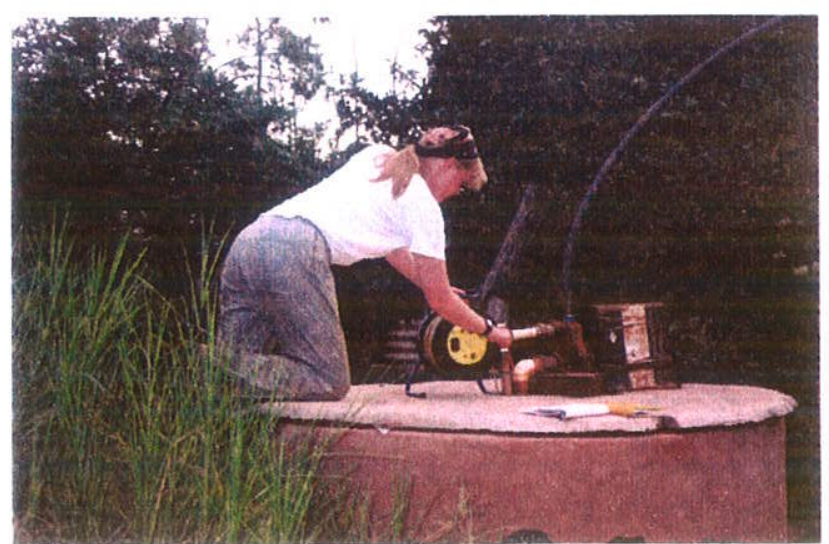

Foto 1: Medição do nível de água em poço cacimba.

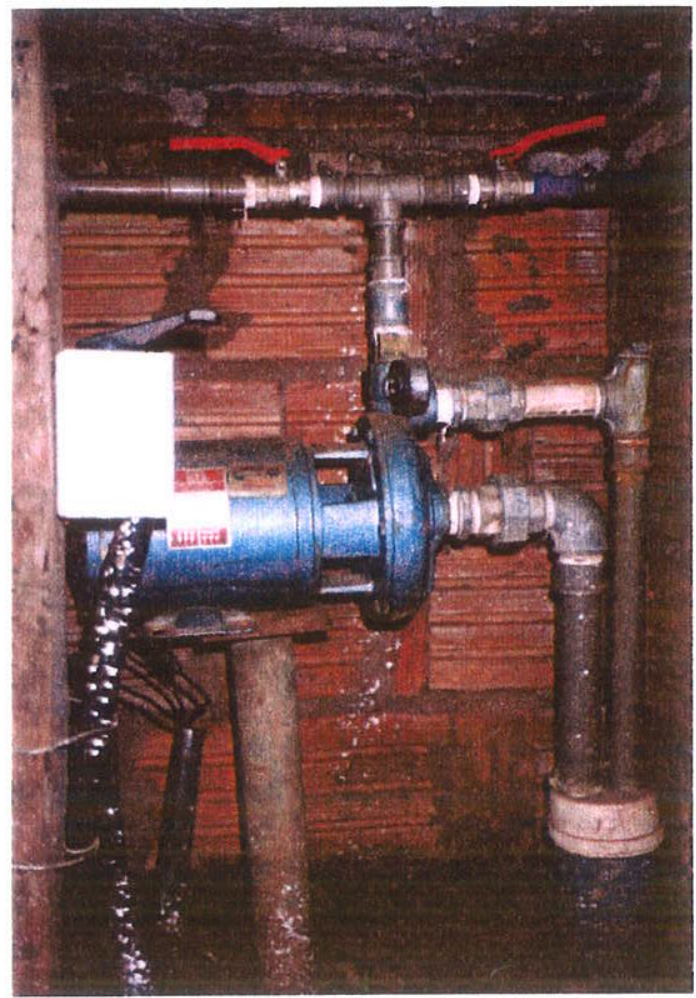

Foto 3: Bomba elétrica de superfície instalada em poço tubular.

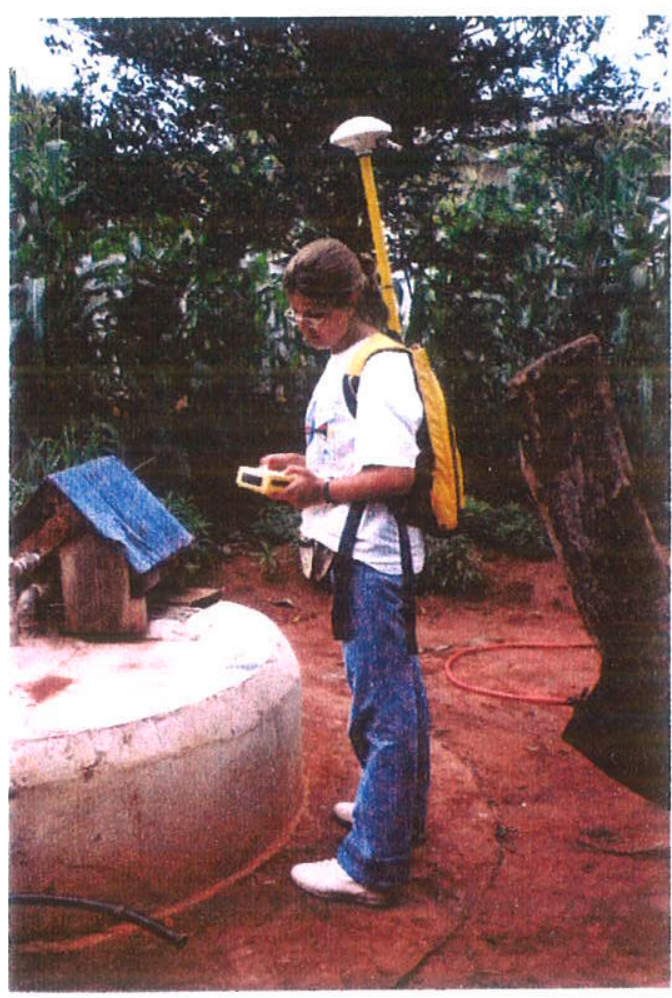

Foto 2: Levantamento topográfico de poço cacimba, utilizando GPS.

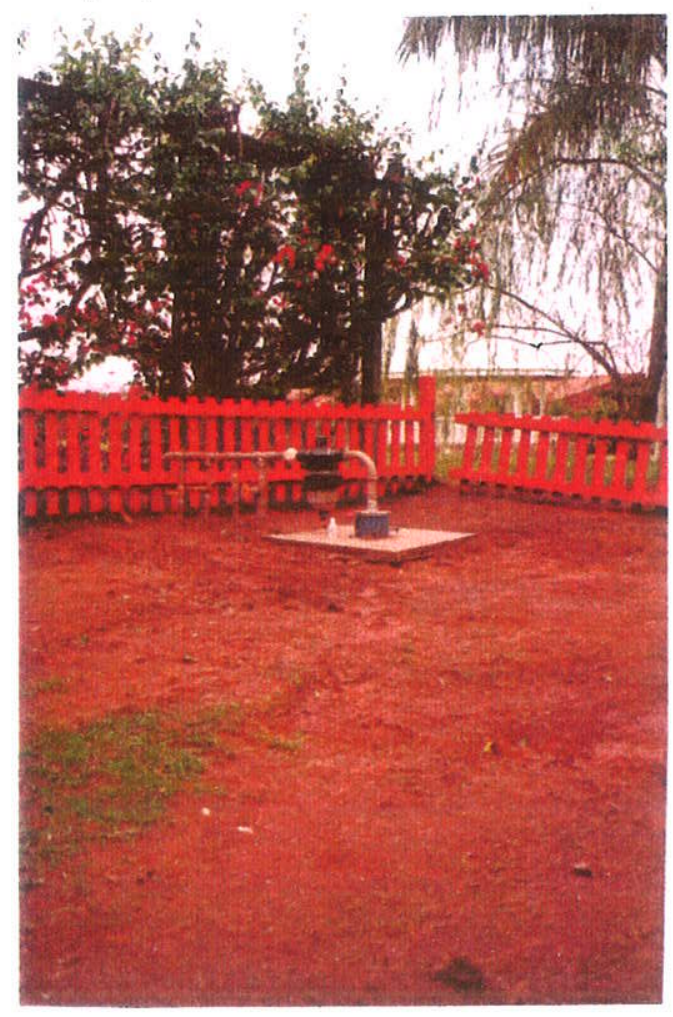

Foto 4: Poço tubular - PT-30. 


\section{LOCALIZAÇÃO DE POÇOS}

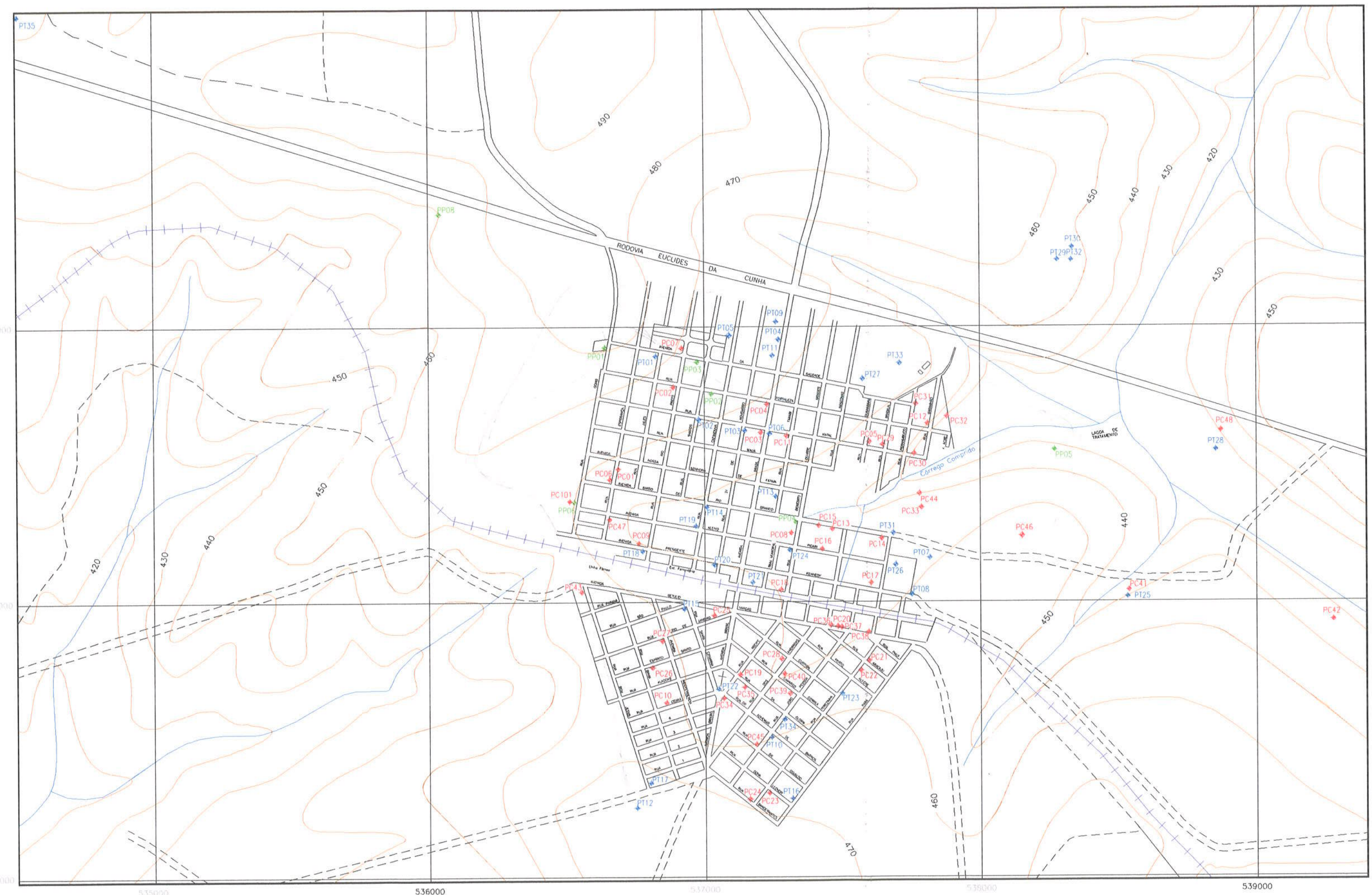

$\sum_{s}^{N}$

Curvas de nivel $(m)$

Drenagens

Rodovias principais

Estradas secundárias

+ Ferrovia

450 m Cota topográfica

Poço Profundo

Poço tubular

Poço cacimba

$\begin{array}{llll}0 & 160 & 320 & 480 \mathrm{~m}\end{array}$ $1: 16.000$ 


\subsection{Fontes Potenciais de Contaminação}

A análise do histórico do uso e ocupação do solo por meio do estudo de fotografias aéreas de diferentes datas, de uma imagem de satélite e da verificação de campo, permitiu avaliar a evolução da ocupação urbana, no município de Urânia, desde 1960 até os dias de hoje (Figura 6.3).

Década de 60: em 1963 a cidade possuia 18.000 hab. (SEADE, 1981), uma área urbana de $0,72 \mathrm{~km}^{2}$ e densidade demográfica urbana de $5.000 \mathrm{hab} . / \mathrm{km}^{2}$, se considerada uma taxa de ocupaçäo urbana de aproximadamente $20 \%$. Nesta época não existiam ruas asfaltadas e sistema de drenagem de águas pluviais. $\mathrm{A}$ cidade teve início na área hoje localizada a norte da linha do trem (área norte da cidade). $\mathrm{O}$ abastecimento de água era feito por poços privados e o sistema de saneamento in situ era constituido por fossas negras. Se considerado que, segundo BERTOLO (2001), uma moradia abriga quatro habitantes e uma fossa, a área urbana do município possuía, em 1963, aproximadamente 1.250 moradias $/ \mathrm{km}^{2}$ ou 1.250 fossas $/ \mathrm{km}^{2}$.

Década de 70: em 1971 a cidade possuía 16.829 hab. (SEADE, 1981), 1,19 $\mathrm{km}^{2}$ (área urbana) e 4.315 hab. $/ \mathrm{km}^{2}$ (taxa de ocupação urbana de $30,51 \%$, segundo SEADE, 1981). Nesta década, teve início a implementação do asfalto e do sistema de drenagem de águas pluviais, $67 \%$ da cidade era abastecida com água subterrânea captada de um poço profundo (PP01) e a coleta de efluente teve início em 1974. Em 1977, coletava-se $59 \%$ do efluente, a partir de redes localizadas na área norte/noroeste da cidade, e todo o líquido coletado era tratado em uma lagoa aeróbia. A área urbana do município, em 1971, possuía 1.079 moradias $/ \mathrm{km}^{2}$.

Década de 80: em 1985 a cidade possuía 13.510 hab. (SEADE, 2002), 1,47 $\mathrm{km}^{2}$ e $4.421 \mathrm{hab} . / \mathrm{km}^{2}$, considerando uma taxa de ocupação urbana de $48,10 \%$ (SEADE, 1999). O sistema de abastecimento público abastecia $78 \%$ da cidade com água subterrânea. Nesta época, coletava-se aproximadamente $64 \%$ do efluente o qual era $100 \%$ tratado. Teve início também a implementação do sistema de coleta de efluente nas áreas a sul e a sudoeste da cidade (localizadas a sul da linha do trem). A cidade, em 1985, consistia de 1.105 moradias $/ \mathrm{km}^{2}$. 
Década de 90: em 1990 a cidade possuía 12.280 hab. (SEADE, 2002), 1,65 $\mathrm{km}^{2}$ e $4.582 \mathrm{hab} . / \mathrm{km}^{2}$ (taxa de ocupação urbana de 61,57\%, SEADE (1999)). Ela era abastecida em $98 \%$ por água subterrânea captada dos poços PP01, PP02, PP03, PP04, PP05, PP06 e PP08. Em 1994, coletava-se 89\% do efluente na área norte/noroeste, sul e sudoeste da cidade. Em 1992 teve início a implementação do sistema de saneamento na área sul/sudeste e, em 1996, na área nordeste. A cidade, em 1990, consistia de 1.146 moradias $/ \mathrm{km}^{2}$.

Hoje a cidade possui 8.824 hab. (SEADE, 2002), 2,14 km² e 3.301 hab. $/ \mathrm{km}^{2}$, se considerada taxa de ocupação urbana de $80,06 \%$ (SEADE, 2002). Caracterizase por possuir ruas asfaltadas, sistema de drenagem de águas pluviais e sistema de saneamento público. A coleta de efluentes abrange aproximadamente $95,9 \%$ das emissōes e trata-se a totalidade deste efluente. Apenas parte da região nordeste/leste da cidade é ainda parcialmente atendida pelo sistema de saneamento público. $O$ efluente coletado segue para a estação de tratamento de efluentes (ETE) da cidade, sendo posteriormente descartado no Córrego Comprido (classe II), principal córrego do municipio. A área urbana do município possui hoje cerca de 825 moradias $/ \mathrm{km}^{2}$.

BERTOLO (2001) calculou qual seria a densidade populacional máxima necessária para que as concentrações de nitrato como nitrogênio no aqüifero fossem no máximo $10 \mathrm{mg} / \mathrm{L}$, levando-se em consideração as taxas de infiltração $e$ a recarga por chuvas. O resultado obtido foi de 48 hab./hectare (ou 48 hab/10.000 $\mathrm{m}^{2}$ ou 4.800 hab. $/ \mathrm{km}^{2}$ ), para que o aqüifero freático não seja impactado com concentrações de $\mathrm{NO}_{3}{ }^{-} \mathrm{N}$ acima de $10 \mathrm{mg} / \mathrm{L}$.

Se comparado o indice calculado por BERTOLO (2001), de $4.800 \mathrm{hab} . / \mathrm{km}^{2}$, com aquele calculado para a área urbana de Urânia no ano de 1963, de 5.000 hab. $/ \mathrm{km}^{2}$, quando não havia um sistema de saneamento público instalado, podem se concluir que as águas subterrâneas na cidade de Urânia nesta data eram vulneráveis ao impacto por sistemas de saneamento in situ.

$\mathrm{Na}$ zona rural do município, foram identificadas três categorias principais de uso do solo:

- Área de mata: ocupada por mata nativa (Fotos 5 e 7); 


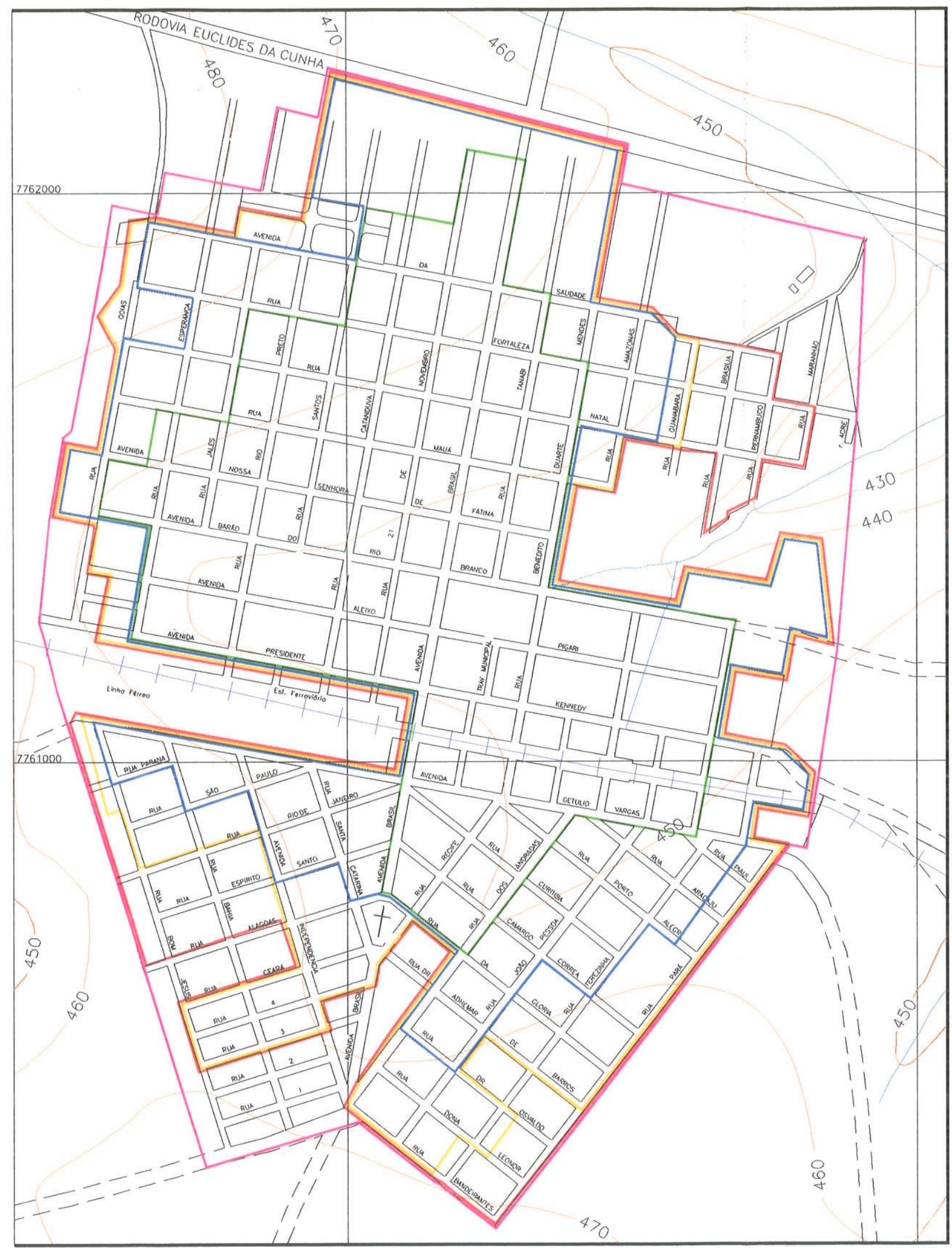

资:

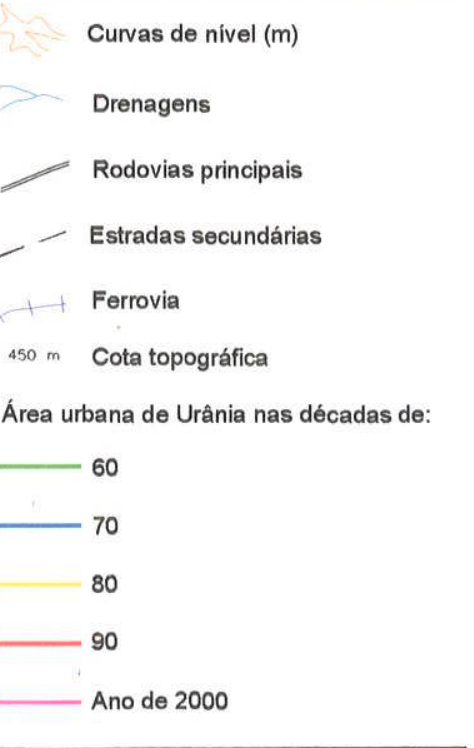

$0 \quad 100 \quad 200300 \mathrm{~m}$

$1: 10.000$ 
- Área de pastagem: cobertura de gramíneas. Eventualmente caracteriza-se por serem áreas de pousio, onde antigas áreas de cultura temporária são utilizadas para pastagem; $\mathrm{e}$

- Área agrícola: utilizada para o plantio de culturas perenes e temporárias de café, árvores frutiferas (laranja, limão, uva e pinha) e hortaliças. Nestas áreas é comum a utilização de fungicidas, pesticidas e fertilizantes orgânicos e inorgânicos (Foto 6).

A partir do estudo do histórico de uso e ocupação de solo das áreas urbana e rural e, levando-se em conta as características do composto de interesse, foram identificados dois tipos principais de fontes potenciais de contaminação por nitrato, ambas antrópicas. São elas:

Sistema de saneamento in sítu caracterizado por fossas negras: são fontes potenciais de contaminação do tipo multi pontual e possuem dimensão de até $1,5 \mathrm{~m}$ de diâmetro e aproximadamente 5 a $10 \mathrm{~m}$ de profundidade, muitas vezes tendo sua base abaixo do nível de água. Identificou-se a existência destas fossas tanto em áreas servidas como não servidas pela rede de efluente doméstico. Foram cadastradas um total de 72 fossas nas imediações dos poços monitorados. Deste total, 57 estão em atividade e 15 são inativas.

Com o objetivo de identificar a região com a maior densidade de fossas, a área de estudo foi subdividida em três áreas menores [noroeste (A), nordeste/leste (B) e sul (C) para as quais calculou-se a densidade de fossas por quilometro quadrado (Figura 6.4). Estas áreas foram subdivididas levando-se em conta dois fatores:

- tempo e forma de urbanização: as áreas norte e noroeste são as mais antigas e anteriores à instalação do sistema de saneamento público (início em 1974). Na área sul, a urbanização teve início nas décadas de 60 e 70 e o sistema de saneamento público, nos anos 80 e na área nordeste/leste a urbanização teve início nas décadas de 80 e ainda hoje possui o sistema de saneamento instalado parcialmente; $e$

- localização hidrogeológica: a área nordeste/leste, por estar localizada nas imediações do Córrego Comprido possui, do ponto de vista hidráulico, uma maior susceptibilidade ao impacto por ter os niveis de água localizados mais próximos à superficie, em contraste as áreas tipicamente de recarga (à 
noroeste e sul), onde os níveis de água são mais profundos. Os resultados obtidos foram:

- área noroeste $(\mathrm{A}): 23$ fossas $/ \mathrm{km}^{2}$;

- área nordeste/leste (B): 48 fossas $/ \mathrm{km}^{2}$; e

- área sul (C): 17 fossas $/ \mathrm{km}^{2}$.

Pode-se observar que em função de possuir um sistema de saneamento público parcialmente implementado, a área $\mathrm{B}$ é aquela com um maior número de fossas por quilometro quadrado. No entanto, a área $A$, de urbanização mais antiga e atendida na sua totalidade pelo sistema de saneamento, também apresenta um elevado número de fossas. Já a área Sul, cuja urbanização foi, em boa parte, concomitante à instalação do sistema de saneamento, possui o menor número de fossas.

Área agrícola: são consideradas fontes potenciais do tipo difusa e possuem dimensões que atingem algumas dezenas de metros quadrados. Foram identificadas 21 áreas agrícolas na região urbana e também na zona rural da cidade, sendo que a totalidade destas utilizavam adubos orgânicos e 8 delas fazem uso também de fertilizantes inorgânicos. Em nenhum dos casos houve orientação técnica do agricultor sobre a quantidade, tipo ou etapa do plantio para a aplicação de fertilizantes. Alguns dos fertilizantes inorgânicos identificados $e$ utilizados nas diversas etapas do plantio foram: Polymix, Agro-pol, Grofol e Niplocan, todos com quantidades de nitrogênio que variam de 5 a $22 \%$.

BERTOLO (2001) simulou a infiltração de nitrato de origem inorgânica (fertilizantes) e concluiu que é possivel que a água do aqüifero tenha a sua potabilidade comprometida após aproximadamente 500 dias da aplicação de uma concentração inicial de $200 \mathrm{mg} / \mathrm{L}$ de nitrato, sob regime de infiltração por meio de recarga natural por chuvas. As concentrações de nitrato no aqüifero, próximas a $45 \mathrm{mg} / \mathrm{L}$. correspondem a uma perda de fertilizantes para vários tipos de cultivo. Esses resultados indicaram que o aqüifero apresenta-se vulnerável à poluição em função da aplicação de fertilizantes. 


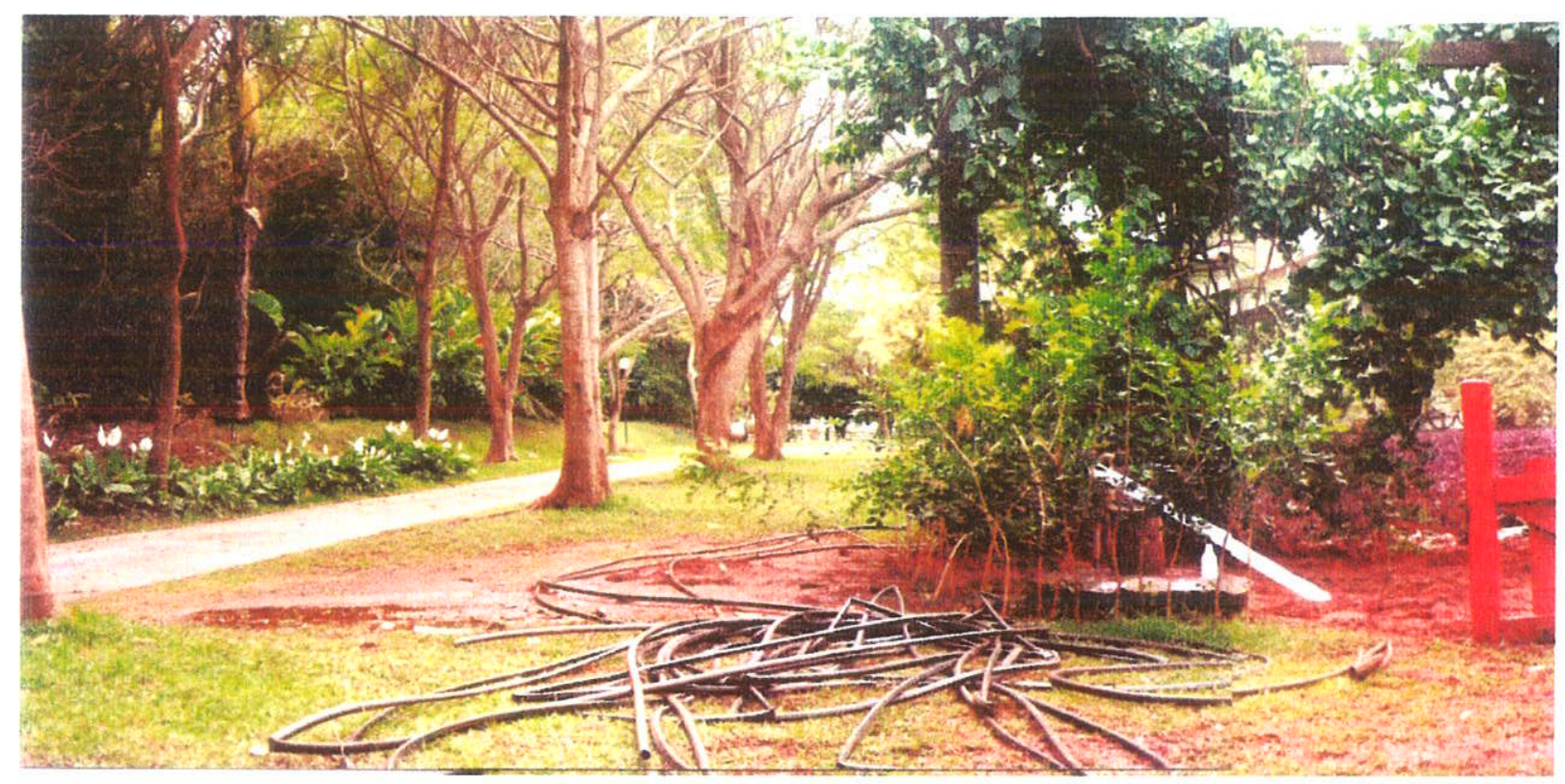

Foto 5: Poço tubular PT-29 em área de mata nativa.

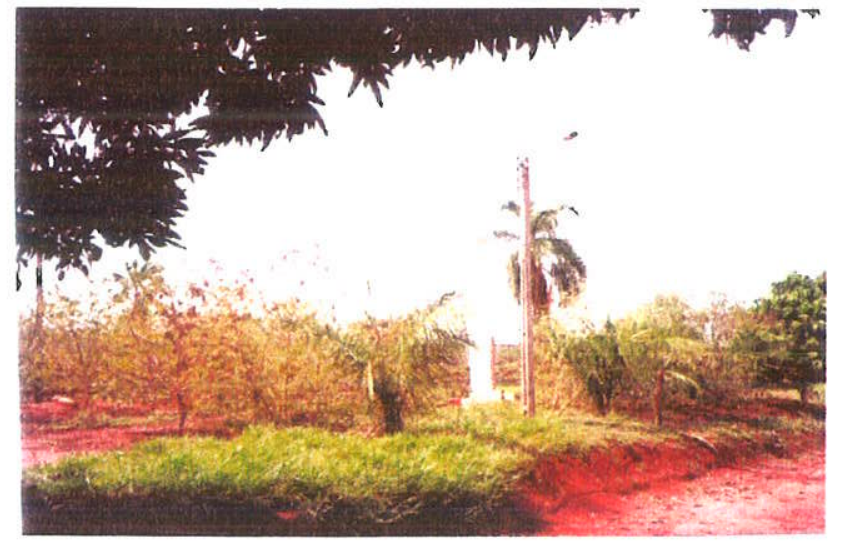

Foto 6: Poço tubular PT-28 em área agrícola.

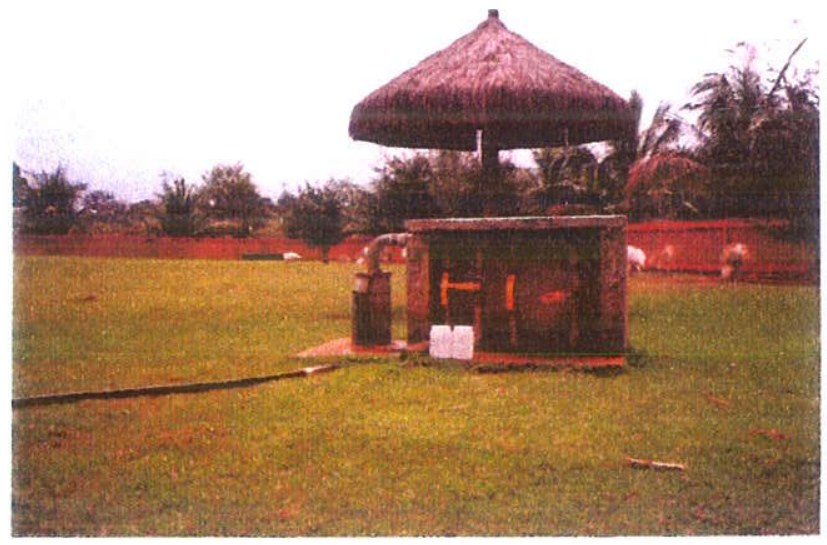

Foto 7: Coleta de água no poço tubular - PT-32. 
Os Quadros 6.1 e 6.2 apresentam o cadastro das fontes potenciais de contaminação e a Figura 6.4, o mapa de fontes potenciais de contaminação. Neste, são delimitadas as quatro áreas para as quais foram calculadas as densidades de fossas por quilômetro quadrado.

Quadro 6.1 - Cadastro das fontes potenciais de contaminação - fossas.

\begin{tabular}{|c|c|c|c|c|}
\hline Localização & $\begin{array}{l}\text { Existe fossa: } \\
\text { sim (S) ou } \\
\text { não (N)? }\end{array}$ & Quantas? & $\begin{array}{c}\text { Em atividade }(A) \\
\text { ou inativa (I)? }\end{array}$ & $\begin{array}{c}\text { Localizada à montante }(M) \text {, à } \\
\text { jusante }(J) \text { ou na mesma cota } \\
\text { topográfica (mm) do poço mais } \\
\text { próximo? }\end{array}$ \\
\hline $\mathrm{PC}-02$ & s & 1 & 1 & M \\
\hline PC-05 & $S$ & 4 & I/ $/ \mathrm{A} / \mathrm{A}$ & $\mathrm{M} / \mathrm{M} / \mathrm{J} / \mathrm{J}$ \\
\hline PC-06 & $S$ & 3 & $\mathrm{~A} / \mathrm{A} / \mathrm{A}$ & $\mathrm{M} / \mathrm{J} / \mathrm{J}$ \\
\hline PC-07 & $s$ & 2 & AVA & $\mathrm{mm}$ \\
\hline$P C-12$ & $S$ & 1 & 1 & $\mathrm{~mm}$ \\
\hline $\mathrm{PC}-14$ & $s$ & 2 & A/A & $\mathrm{mm} / \mathrm{mm}$ \\
\hline PC-18 & $S$ & 1 & A & $\mathrm{mm}$ \\
\hline $\mathrm{PC}-24$ & $S$ & 1 & 1 & $\mathrm{~mm}$ \\
\hline $\mathrm{PC}-25$ & $s$ & 1 & A & $J$ \\
\hline PC-26 & $s$ & 2 & $A / A$ & $\mathrm{Mm} / \mathrm{M}$ \\
\hline $\mathrm{PC}-30$ & $s$ & 2 & $\mathrm{~A} / \mathrm{I}$ & $2 / 7$ \\
\hline$P C-31$ & $s$ & 1 & A & $\mathrm{M}$ \\
\hline $\mathrm{PC}-32$ & S & 3 & $\mathrm{~A} / / \mathrm{A}$ & $\mathrm{M} / \mathrm{M} / \mathrm{M}$ \\
\hline $\mathrm{PC}-33$ & $s$ & 1 & A & $M$ \\
\hline PC-34 & s & 1 & A & $\mathrm{mm}$ \\
\hline PC-37 & $s$ & 1 & A & $J$ \\
\hline$P C-38$ & $s$ & 1 & 1 & M \\
\hline PC-39 & s & 1 & 1 & $\mathrm{M}$ \\
\hline $\mathrm{PC}-40$ & $s$ & 1 & A & M \\
\hline$P C-41$ & s & 1 & A & $\mathrm{mm}$ \\
\hline $\mathrm{PC}-42$ & $s$ & 1 & A & $\mathrm{M}$ \\
\hline $\mathrm{PC}-43$ & $s$ & 1 & 1 & $\mathrm{~mm}$ \\
\hline$P C-44$ & $s$ & 1 & A & M \\
\hline $\mathrm{PC}-45$ & $s$ & 1 & 1 & $\mathrm{Mm}$ \\
\hline $\mathrm{PC}-46$ & $S$ & 1 & 1 & $M$ \\
\hline PC-48 & $S$ & 2 & $A / A$ & $M / M$ \\
\hline
\end{tabular}


Quadro 6.1 - Cadastro das fontes potenciais de contaminação - fossas.

\begin{tabular}{|c|c|c|c|c|}
\hline Localização & $\begin{array}{c}\text { Existe fossa: } \\
\text { sim (S) ou } \\
\text { não (N)? }\end{array}$ & Quantas? & $\begin{array}{c}\text { Em atividade (A) } \\
\text { ou inativa (I)? }\end{array}$ & $\begin{array}{c}\text { Localizada à montante (M), à } \\
\text { jusante (J) ou na mesma cota } \\
\text { topográfica (mm) do poço mais } \\
\text { próximo? }\end{array}$ \\
\hline PC-101 & $S$ & 1 & A/A & $J$ \\
\hline PT-01 & $S$ & 4 & A/A/A/A & $\mathrm{mm} / \mathrm{mm} / \mathrm{J} / \mathrm{J}$ \\
\hline PT-02 & $S$ & 1 & A & $\mathrm{mm}$ \\
\hline PT-11 & $S$ & 1 & I & $\mathrm{mm}$ \\
\hline PT-12 & $\$$ & 1 & 1 & $\mathrm{~mm}$ \\
\hline PT-13 & $s$ & 1 & $A$ & J \\
\hline PT-14 & $S$ & 3 & AVA & $\mathrm{M} / \mathrm{J} / \mathrm{J}$ \\
\hline PT-16 & $S$ & 1 & A & $\mathrm{mm}$ \\
\hline PT-21 & $S$ & 1 & 1 & $\mathrm{~mm}$ \\
\hline PT-25 & $\$$ & 5 & $\mathrm{~A} / \mathrm{A} / \mathrm{A} / \mathrm{A} / \mathrm{A}$ & $\mathrm{mm} / \mathrm{J} / \mathrm{J} / \mathrm{J} / \mathrm{J}$ \\
\hline PT-27 & $S$ & 1 & A & $\mathrm{mm}$ \\
\hline PT-31 & $S$ & 1 & A & $M$ \\
\hline PT-33 & $S$ & 1 & A & $J$ \\
\hline PT-35 & $\$$ & 1 & A & $\mathrm{Mm}$ \\
\hline $\begin{array}{l}\text { imediações do } \\
\text { Córrego } \\
\text { Comprido }\end{array}$ & $S$ & 10 & todas ativas & - \\
\hline
\end{tabular}

Quadro 6.2 - Cadastro das fontes potenciais de contaminação - área agricola.

\begin{tabular}{|c|c|c|}
\hline Localização & $\begin{array}{c}\text { É uma área agricola, sim (S) ou não (N) ? Qual o o } \\
\text { tipo de atividade agricola ? }\end{array}$ & $\begin{array}{c}\text { Utiliza Fertilizante Orgânico } \\
(\text { O) e/ou lnorgânico (I)? }\end{array}$ \\
\hline PC-06 & S: horta & 0 \\
\hline PC-07 & S: horta & 0 \\
\hline PC-23 & S: horta & 0 \\
\hline PC-29 & S: horta & 0 \\
\hline PC-33 & S: plantação de laranja e limão & $0 / 1$ \\
\hline PC-35 & S: horta & $O / I$ \\
\hline PC-37 & S: horta & $0 / 1$ \\
\hline PC-41 & S: cultivo de plantas ornamentais & 0 \\
\hline PC-43 & S: plantação de café & $0 / 1$ \\
\hline PC-45 & S: horta & 0 \\
\hline PC-48 & S: horta & 0 \\
\hline
\end{tabular}


Quadro 6.2 - Cadastro das fontes potenciais de contaminação - área agrícola.

\begin{tabular}{|c|c|c|}
\hline Localização & $\begin{array}{c}\text { É uma área agrícola, sim (S) ou não (N) ? Qual o } \\
\text { tipo de atividade agrícola ? }\end{array}$ & $\begin{array}{c}\text { Utiliza Fertilizante Orgânico } \\
(\text { O) elou Inorgânico (I)? }\end{array}$ \\
\hline PC-101 & S: mangueiras & 0 \\
\hline PT-01 & S: horta & 0 \\
\hline PT-08 & S: horta & 0 \\
\hline PT-11 & S: horta & 0 \\
\hline PT-12 & S: horta & O/I \\
\hline PT-16 & S: horta & O/I \\
\hline PT-27 & S: plantação de café & S \\
\hline PT-28 & S: plantação de pinha e uva & O/I \\
\hline PT-33 & S: pomar de laranja e limão & S \\
\hline PT-35 & S: plantação de mudas de árvores frutíferas & O/I \\
\hline
\end{tabular}

\subsection{Hidrogeologia Local}

O aqüífero na área de estudo é do tipo livre, de porosidade primária, associado aos sedimentos da Formação Adamantina.

A Formação Adamantina é caracterizada por arenito fino a médio, vermelho arroxeado, muito homogêneo e rijo. A recarga do aqüífero ocorre pela infiltração de água de chuva, na superfície aflorante da Formação Adamantina, que perfaz toda a área de estudo. A descarga local se dá no Córrego Comprido, afluente do Córrego do Matador, o qual atravessa a cidade na região nordeste. A cidade de Urânia encontra-se sobre um divisor de águas subterrâneas.

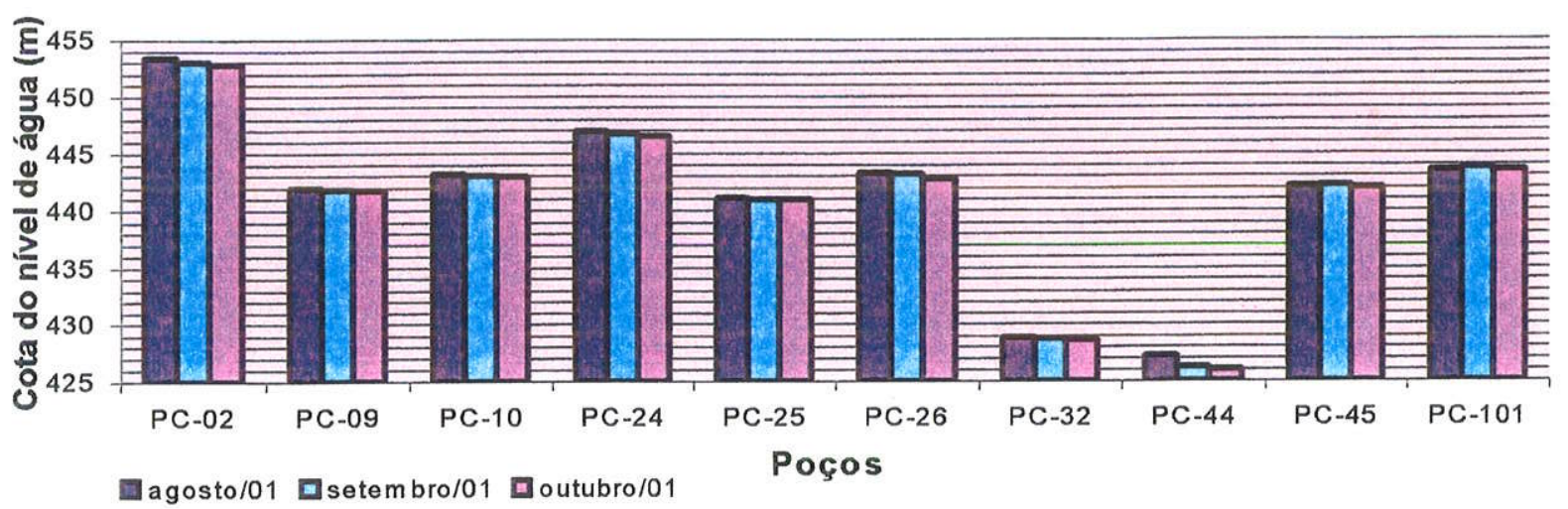

Figura 6.5 - Cota dos Níveis de Água Estáticos em Poços Cacimbas. 
FIGURA 6.4

FONTES POTENCIAIS DE CONTAMINAÇÃO

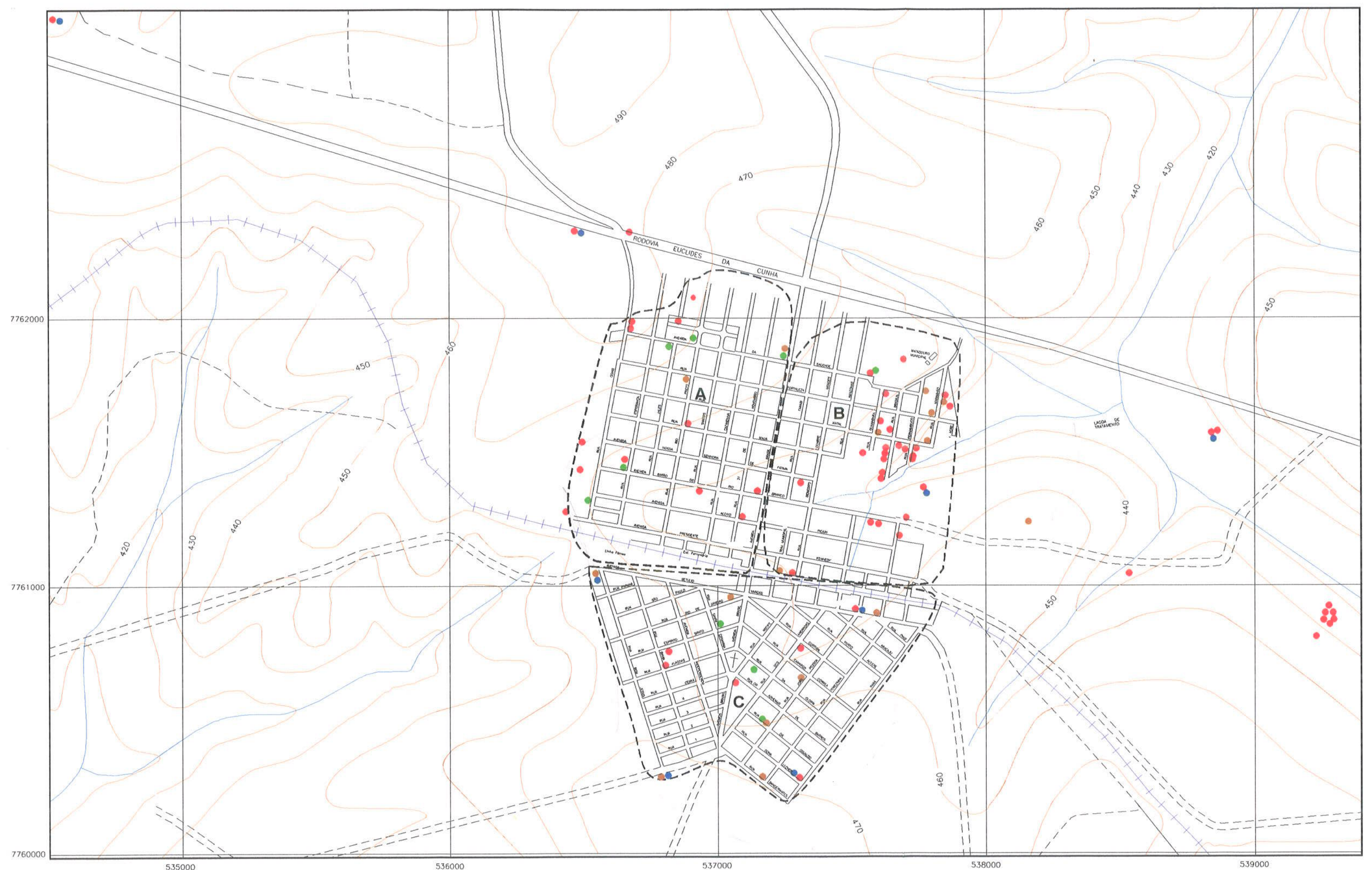

(2)

Curvas de nível (m)

Drenagens

Rodovias principais

_- Estradas secundárias

+ Ferrovia

$400 \mathrm{~m}$ Cota topográfica

- Área agrícola - uso de

fertilizantes orgânicos

Area agrícola - uso de
fertilizantes inorgânicos

- Fossa ativa

Fossa inativa

Área A (noroeste): 23 fossas $/ \mathrm{km}^{2}$ Área B (nordeste): 48 fossas $/ \mathrm{km}^{2}$ Área C (sul): 17 fossas $/ \mathrm{km}^{2}$

$\begin{array}{llll}0 & 160 & 320 & 480 \mathrm{~m}\end{array}$ 1:16.000 
De acordo com ROSSATO (1999), os níveis de água estáticos na área de estudo não variam de maneira significativa com o tempo, durante um ano hidrogeológico. Isto pode ser observado durante as medições dos níveis de água nos meses de agosto, setembro e outubro de 2001 (Figura 6.5 e Anexo 6). Observa-se que estes oscilam no máximo $0,52 \mathrm{~m}$ neste período, com exceção do poço PC-44, cuja variação máxima chega a 1,20 m. Estes dados, porém, não são representativos de uma variação sazonal, pois foram obtidos em uma única estação do ano.

Segundo HIRATA (2000), uma queda nos valores de carga hidráulica, de maio/99 para fevereiro/00, denota os efeitos da estação seca que também se reflete na posição do nível de água, que se aprofundou em torno de $1,5 \mathrm{~m}$ no periodo. De acordo com os dados obtidos, é possivel observar um aprofundamento dos níveis de água, de agosto a outubro de 2001, e as variações foram pouco menores do que aquelas observadas por HIRATA (2000).

De maneira geral, na cidade de Urânia, a profundidade do nivel de água medida nos poços cacimbas (zona rasa) variou de $0,9 \mathrm{~m}$ a $18,9 \mathrm{~m}$ abaixo da superfície, enquanto que a carga hidráulica, de $426 \mathrm{~m}$ a $453 \mathrm{~m}$ em relação ao nivel do mar. Nos poços tubulares (zona intermediária), a profundidade (aproximada) do nível de água variou de $2,9 \mathrm{~m}$ a $18 \mathrm{~m}$, enquanto que a carga hidráulica, de $451 \mathrm{~m}$ a $454 \mathrm{~m}$.

Por meio do mapa potenciométrico confeccionado com as cotas dos níveis de água estáticos medidos nos poços cacimbas, em outubro de 2001, foi possível estabelecer as direções principais de fluxo das águas subterrâneas e determinar o gradiente hidráulico. As velocidades de fluxo das águas foram calculadas utilizando-se os valores de condutividade hidráulica determinados por meio dos testes de bombeamento.

De acordo com este mapa (Figura 6.6), a direção preferencial de fluxo das águas subterrâneas, na porçāo norte da cidade, é para sudeste e na porçāo sul da cidade, para nordeste, ambas em direção ao Córrego Comprido, afluente do Córrego do Matador. 


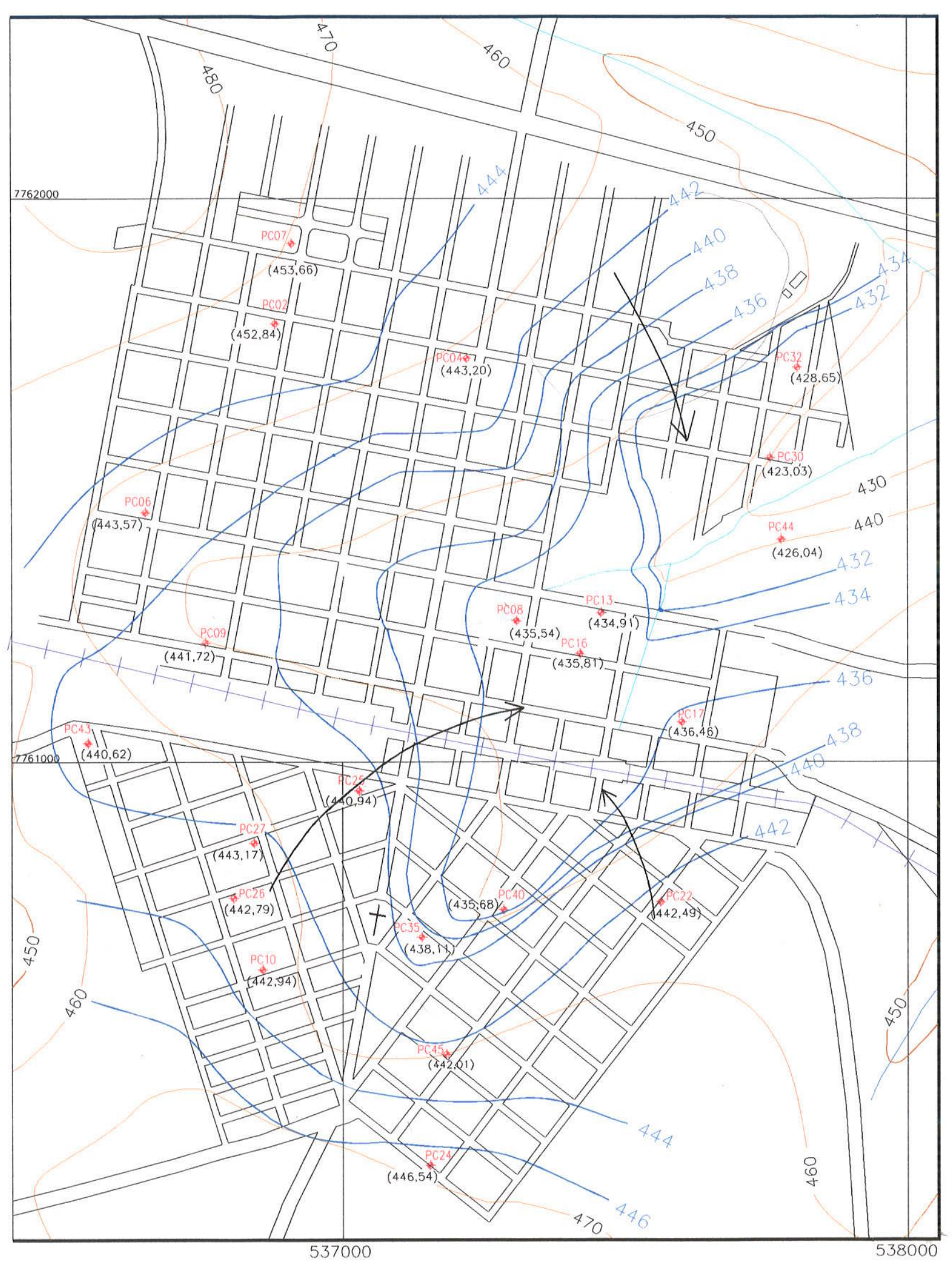

POTENCIOMÉTRICO - OUTUBRO DE 2001

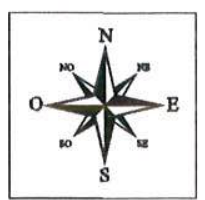

$$
\begin{aligned}
& \text { Curvas de nivel (m) } \\
& \text { Drenagens } \\
& \text { Rodovias principais } \\
& \text { Estradas secundárias } \\
& ++ \text { Ferrovia } \\
& 450 \mathrm{~m} \text { Cota topográfica } \\
& \text { PCA4 Poço cacimba } \\
& \text { (442,49) Carga hidraulica (m) } \\
& 430 \text { Linhas equipotenciométricas }(\mathrm{m}) \\
& \rightarrow \text { Linhas de Fluxo }
\end{aligned}
$$


Os ensaios de bombeamento foram realizados nos poços PT-23A e PT-26. O poço PT-23A possui $80 \mathrm{~m}$ de profundidade, filtro de $50 \mathrm{~m}$ e bomba com vazão de $5,20 \mathrm{~m}^{3} / \mathrm{h}$. O poço PT-26 tem $60 \mathrm{~m}$ de profundidade, $36 \mathrm{~m}$ de filtro e bomba com vazão de aproximadamente $1,11 \mathrm{~m}^{3} / \mathrm{h}$. Durante o teste realizado no poço PT23A, um poço de observação (PT-23), localizado a $5,49 \mathrm{~m}$ do poço de bombeamento, foi monitorado.

O valor da porosidade efetiva utilizado nos cálculos foi de 15\%. De acordo com HIRATA et al. (1997), a porosidade efetiva do Grupo Bauru varia de $5 \%$ a 15\%. A partir dos dados obtidos nos testes de bombeamento, a transmissividade do aqüifero também foi calculada.

Os resultados de condutividade hidráulica calculados foram $7,17 \times 10^{-5} \mathrm{e}$ $8,54 \times 10^{-6} \mathrm{~m} / \mathrm{s}$ e transmissividade, $7,1 \times 10^{-3}$ e $9,2 \times 10^{-4} \mathrm{~m}^{2} / \mathrm{s}$ (solução de Neuman). O gradiente hidráulico varia de 0,011 a 0,025 (ou $1,1 \%$ a $2,5 \%$ ) e a velocidade de fluxo das águas subterrâneas, de $1,20 \times 10^{-5}$ a $6,26 \times 10^{-7} \mathrm{~m} / \mathrm{s}$.

A Tabela 6.2 apresenta um sumário de parâmetros hidrogeológicos para o Aqüífero Adamantina.

Nesta pesquisa, assim como mostra a Tabela 6.2, são utilizados os conceitos de zona rasa $(Z R)$, intermediária $(Z \mathrm{l})$ e profunda $(Z P)$ definidos por ALMODOVAR (2000). Fazem parte da zona rasa as águas mais superficiais, captadas por poços cacimbas, os quais atingem até $21 \mathrm{~m}$ de profundidade, enquanto que as águas da zona intermediária são captadas por poços de até 105 $\mathrm{m}$ de profundidade. A zona profunda é caracterizada por águas captadas por poços profundos, de propriedade da Sabesp, que atingem até $270 \mathrm{~m}$ de profundidade.

De acordo com ALMODOVAR (2000) e HIRATA (2000), estes termos foram utilizados para designar três zonas hidroquímicas diferentes, identificadas na área de estudo, de acordo com a posição de amostragem dos poços.

Segundo ALMODOVAR (2000), zona rasa (ZR) é aquela caracterizada pelas águas rasas de recarga do aqüífero, representada pelos poços cacimbas. A zona intermediária (ZI) é aquela cujas águas se localizam entre a recarga e a descarga do aqüífero, representada pelos poços tubulares e a zona profunda (ZP) é composta pelas águas mais velhas e profundas do aqüífero, representada pelos poços profundos da Sabesp. A mesma terminologia será nesta dissertação. 
Tabela 6.2 - Sumário dos Parâmetros Hidrogeológicos para o Aqüífero Adamantina.

\begin{tabular}{|c|c|c|c|c|c|c|c|c|c|c|}
\hline \multirow[t]{2}{*}{ zena } & \multicolumn{3}{|c|}{ Condutivldade hidráulica $(\mathrm{m} / \mathrm{s})$} & \multicolumn{2}{|c|}{ Gradlente Hidraulleo. } & \multicolumn{2}{|c|}{ Velocitade de Fluxo $(\mathrm{m} / \mathrm{s})$} & \multicolumn{3}{|c|}{ Transmissividade $\left(\mathrm{n}^{2} / \mathrm{s}\right)$} \\
\hline & $\begin{array}{l}\text { HIRATA } \\
(2000 a)\end{array}$ & $\begin{array}{l}\text { ROCHA et } \\
\text { al. (1982) }\end{array}$ & $\begin{array}{c}\text { Teste de } \\
\text { bombeamento } \\
\text { nov/01 }\end{array}$ & $\begin{array}{l}\text { HIRATA } \\
(2000 a)\end{array}$ & $\begin{array}{c}\text { Potenciométrico } \\
\text { out } / 01\end{array}$ & $\begin{array}{l}\text { HIRATA } \\
(2000 a)\end{array}$ & $\left|\begin{array}{c}\text { Potenciométrico } \\
\text { out } / 01\end{array}\right|$ & $\begin{array}{l}\text { HIRATA \& } \\
\text { RODOLFI } \\
\text { (1993) }\end{array}$ & $\begin{array}{l}\text { ROCHA et } \\
\text { al. (1982) }\end{array}$ & $\begin{array}{c}\text { Teste de } \\
\text { bombeamento } \\
\text { nov } / 01\end{array}$ \\
\hline Zona rasa & & & $\cdots$ & & 0,011 a 0,025 & --- & & --- & --- & -- \\
\hline $\begin{array}{l}\text { Zona } \\
\text { intermediária }\end{array}$ & & & $\begin{array}{l}7,17 \times 10^{-5} \mathrm{e} \\
8,54 \times 10^{-6}\end{array}$ & & $\ldots$ & $\cdots$ & $\begin{array}{c}1,20 \times 10^{-5} \mathrm{a} \\
6,26 \times 10^{-7}\end{array}$ & --- & $\ldots$ & $\begin{array}{c}7,10 \times 10^{-3} \mathrm{e} \\
9,20 \times 10^{-4}\end{array}$ \\
\hline Zona profunda & $\begin{array}{l}1 \times 10^{-3} \mathrm{a} \\
1 \times 10^{-7}\end{array}$ & $\begin{array}{c}1,16 \times 10^{-5} \mathrm{a} \\
1,16 \times 10^{-6}\end{array}$ & --- & $\begin{array}{c}0,013 a \\
0,034\end{array}$ & --- & $\begin{array}{c}3,5 \times 10^{-8} \mathrm{a} \\
8,1 \times 10^{-7}\end{array}$ & -- & $7,3 \times 10^{-5}$ & $\left(\begin{array}{c}3,5 \times 10^{-4} \mathrm{a} \\
5,8 \times 10^{-4}\end{array}\right.$ & $\ldots$ \\
\hline
\end{tabular}


Se comparados os valores de condutividade hidráulica obtidos, por meio dos testes de bombeamento, para a Zl, com aqueles obtidos por ROCHA et al. (1982) e HIRATA (2000a), para a ZP, observa-se que os intervalos de valores obtidos por estes autores são maiores, pois são resultado de pesquisas de cunho regional e de ensaios realizados em poços profundos (ZP). Os poços profundos são normalmente caracterizados por possuírem filtros longos, tornando-os representativos de uma seção maior do aqüífero, atravessando uma ou mais zonas hidráulicas. Desta forma, as díferenças notadas podem estar associadas a heterogeneidades ao longo do perfil geológico ou, ainda, a variações regionais do aqüífero.

As velocidades de fluxo e os gradientes hidráulicos determinados são muito semelhantes àqueles apresentados por HIRATA (2000a). Da mesma forma, os valores de transmissividade calculados e aqueles obtidos por ROCHA et al. (1982) e HIRATA \& RODOLFI (1993) são muito semelhantes.

\subsection{Classificação e Evolução Hidroquímica das Águas Subterrâneas}

Para o desenvolvimento desta pesquisa, utilizou-se as definições dos termos valor de referência de qualidade, valor anômalo, poluição e contaminante, conforme apresentadas a seguir.

De acordo com CETESB (2000), um solo é considerado "limpo" quando a concentração de um elemento ou substância de interesse ambiental é menor ou igual ao valor de ocorrência natural. Nesta pesquisa, valor de referência de qualidade (VQR) é a concentração de ocorrência natural de um determinado composto ou elemento, enquanto que valor anômalo é uma concentração maior do que o valor de ocorrência natural. Desta forma, a água foi considerada poluída quando apresentou concentrações anômalas de um determinado elemento ou substância.

Ainda de acordo com CETESB (2000), uma área é considerada contaminada se, entre outras situaçōes, as concentrações de elementos ou substâncias de interesse ambiental estiverem acima de um determinado limite denominado valor de intervenção, indicando a existência de um risco potencial de efeito deletério sobre a saúde humana. Desta forma, entende-se por contaminante elementos ou 
substâncias em concentrações que indicam um risco potencial de efeito deletério sobre a saúde humana.

A Figura 6.7 apresenta os diagramas de Piper (A) a (E). Por meio destes diagramas, foi possível distinguir dois tipos hidroquímicos:

1. zona rasa (ZR): são águas bicarbonatadas nitratadas cálcicas, secundariamente cloro-nitratadas cálcicas e bicarbonatas nitratadas sódicas. Os ions predominantes nestas águas são bicarbonato, cálcio e nitrato, sendo que este último apresenta correlação positiva para cloreto e sódio.

2. zona intermediárias (ZI): são águas bicarbonatas cálcicas e bicarbonatadas nitratadas cálcicas, localizadas em maior profundidade.

De acordo com GUTIERREZ (1999), as águas da zona profunda (ZP) em Urânia, representadas pelas águas dos poços profundos de propriedade da Sabesp, são predominantemente do tipo bicarbonatadas cálcicas ou magnesianas.

Não foram observadas diferenças significativas nas quantidades dos ions maiores e menores (e, portanto, diferentes tipos hidroquímicos) entre as áreas urbanas sob influência de fossas, agrícolas com e sem aplicação de fertilizantes inorgânicos, e área ocupada por mata nativa. As diferenças identificadas estão relacionadas às zonas rasa e intermediária e às áreas poluída e não - poluída.

De maneira geral, ocorre incremento de cálcio da zona rasa (ZR) para a intermediária ( $\mathrm{Zl})$, acompanhado pelo aumento da alcalinidade e do $\mathrm{pH}$. $\mathrm{O}$ aumento da quantidade de cálcio deve estar associado a processos de dissolução de minerais de cálcio e da matriz carbonática, processo que leva ao consumo de $\mathrm{H}^{+}$ em solução (aumento do pH). Segundo CAMPOS (1987, 1993 apud BERTOLO, 2001), o carbonato de cálcio (calcrete) e os argilominerais, constituintes do cimento das litofácies, devem ser as principais fontes de enriquecimento iônico deste aqüífero. 


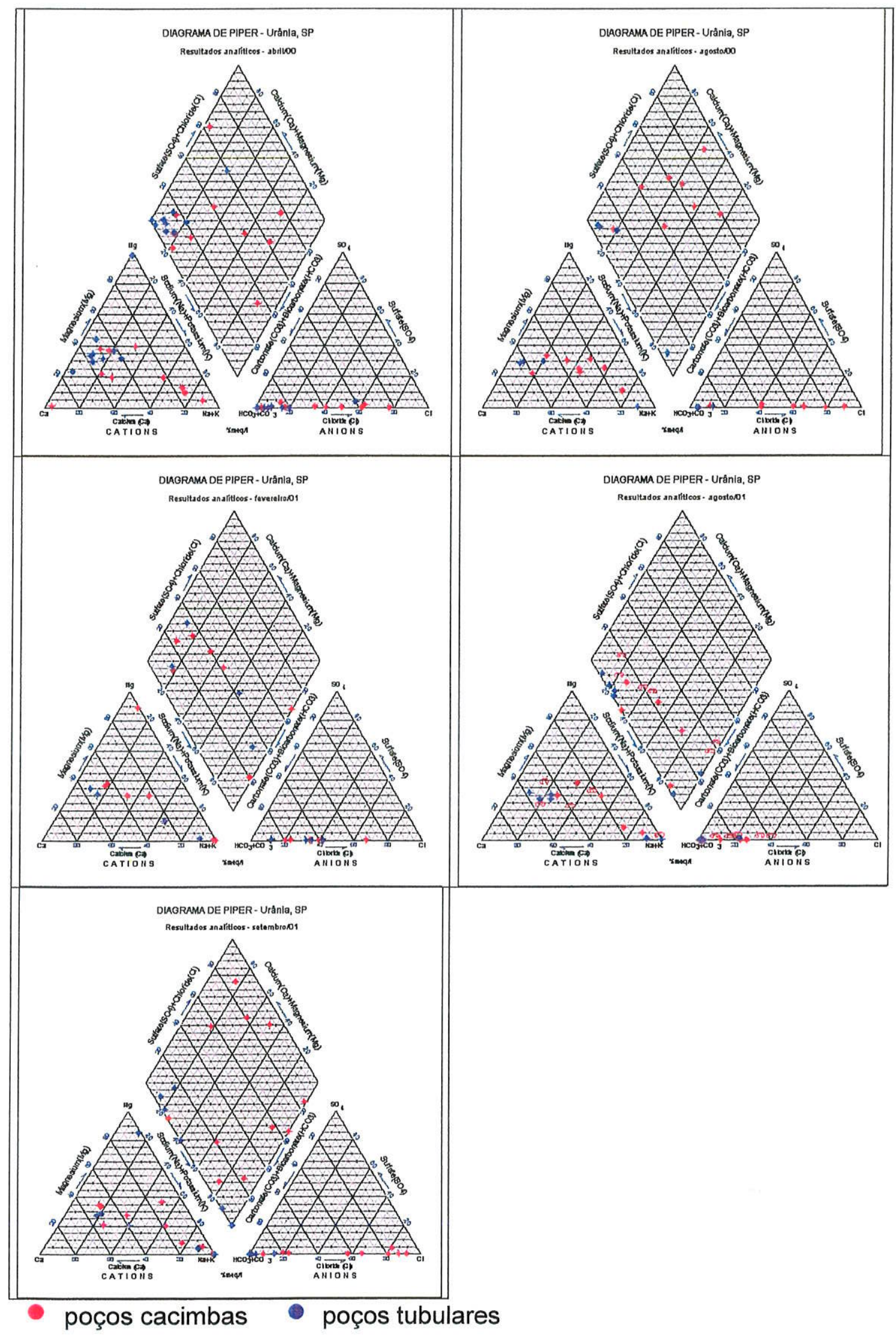

Figura 6.7 - Diagramas de Piper - (A) abril/00, (B) agosto/01, (C) fevereiro/01, (D) agosto/01 e (E) setembro/01. 
Da ZR para Zl ocorre ainda diminuição das concentrações de cloreto (até $19,68 \mathrm{mg} / \mathrm{L}$ na ZR e até $14,26 \mathrm{mg} / \mathrm{L}$, na Zl) e nitrato (até $140 \mathrm{mg} / \mathrm{L}$ na ZR e até 81 $\mathrm{mg} / \mathrm{L}$, na Zl). Estes ions devem estar sendo diluídos por dispersão mecânica. A presença de cloreto e nitrato na zona rasa e a diminuição destas concentrações em direção às águas mais profundas reforçam a hipótese de origem antrópica para estes íons.

Observa-se, ainda, ligeiro decréscimo das concentrações de potássio e sulfato de ZR para ZI, o que pode estar associado a dois mecanismos distintos: fixação do potássio na fase sólida, por troca catiônica, e redução e ou precipitação do sulfato.

Apesar de serem o bicarbonato e o cálcio os ions predominantes na $\mathrm{Zl}$, elevadas concentrações de sódio foram observadas nas águas do poço PT-28 (de 25,5 a $28 \mathrm{mg} / \mathrm{L}$ ). Neste caso, a presença de sódio em concentrações anômalas pode estar associada à dissolução de minerais de sódio e troca catiônica (a água ganha sódio e perde cálcio, que é adsorvido pelas argilas), visto que não foram detectadas concentrações anômalas de nitrato nestas águas, o que indicaria uma fonte antrópica para o sódio.

Do ponto de vista da evolução hidrogeoquímica, as águas da zona rasa (ZR) evoluiram para a intermediária (ZI) com a diminuição das concentrações de sódio, cloreto e nitrato, secundariamente sulfato e potássio, e aumento das concentrações de cálcio e bicarbonato.

Os íons menores analisados (fluoreto, ferro e estrôncio), quando detectados, apresentaram concentrações próximas aos limites de detecção. Dos constituintes traços analisados (alumínio, bário, brometo, cádmio, cromo, cobre, chumbo, zinco, níquel e prata), não foram encontrados prata e cádmio, sendo os demais detectados, próximos aos limites de detecção.

$\mathrm{Na} \mathrm{Zl,} \mathrm{a} \mathrm{correlação} \mathrm{positiva} \mathrm{observada} \mathrm{entre} \mathrm{magnésio} \mathrm{e} \mathrm{cálcio} \mathrm{reforça} \mathrm{a}$ hipótese de ocorrência de dissolução de minerais. Este processo, que está diretamente associado ao aumento na quantidade de sais dissolvidos e, portanto, ao aumento da condutividade elétrica, pode ser evidenciando pelas correlaçōes positivas entre condutividade elétrica e cálcio e condutividade elétrica e magnésio (Anexos 7 e 8). 


\subsection{Contaminação das Águas Subterrâneas por Nitrato - Distribuição Espacial e Temporal}

Neste capitulo, serão apresentados os resultados de nitrato nas águas subterrâneas e sua distribuição espacial e temporal, e ainda os resultados obtidos para os íons amônio e cloreto, cuja presença nas águas subterrâneas está diretamente relacionada ao nitrato, e para os parâmetros condutividade elétrica, Eh e $\mathrm{pH}$. Foram calculadas, para estes parâmetros, as médias aritméticas, os desvios padrão e os coeficientes de variação (CV's), Anexo 9.

Segundo BARNES (1980 apud YAMAMOTO 2001), se amostras aleatórias de tamanho fixo são retiradas de uma população, cuja distribuição teórica é de forma arbitrária, mas com média e variância finitas, a distribuição das amostras tende mais e mais a uma distribuição normal com média e variância tanto quanto o tamanho das amostras aumenta. Segundo YAMAMOTO (2001), na maioria dos casos geológicos, a aproximação é boa a partir de 40 amostras.

Apesar do número de amostras utilizadas ter sido, na maioria, menor que 40 , de forma geral, os dados possuem distribuição do tipo normal, o que pode ser observado por meio dos CVs calculados (entre 0,2 e 0,6) e dos histogramas (Figura 6.8). A exceção ficou por conta de CVs relativamente altos, por vezes maior que 0,6, obtidos para o cloreto e amônio. Para estas exceções (Figura 6.8, histograma C), a distribuiçăo é do tipo log normal, com histogramas assimétricos compostos por concentrações baixas e algumas delas excepcionalmente altas. A Figura 6.8 apresenta os histogramas confeccionados para o nitrato (ZR), condutividade elétrica (ZI) e cloreto (ZI). 
Figura 6.8 - Histogramas: (A) concentração de nitrato na zona rasa (abril/00), (B) valores de condutividade elétrica na zona intermediária (junho/99) e (C) concentração de cloreto na zona intermediária (agosto/01).

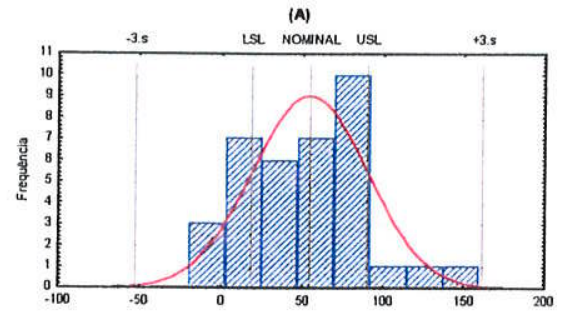

(A)

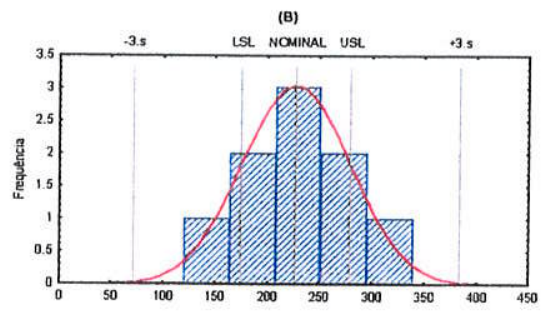

(B)

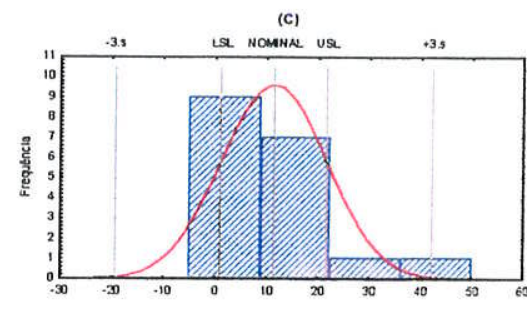

(C)

Foram identificados, como compostos que poluem as águas subterrâneas na área de estudo, o nitrato, o cloreto e o amônio. Destes, apenas o nitrato está contaminando estas águas, pois foi detectado em concentrações acima daquela estabelecida pela Portaria 1.469 do Ministério da Saúde, que é $45 \mathrm{mg} / \mathrm{L} \mathrm{NO}_{3}$.

Segundo CUSTÓDIO \& LLAMAS (1976), a concentração de nitrato nas águas doces varia de $0,1 \mathrm{mg} / \mathrm{L}$ a $10 \mathrm{mg} / \mathrm{L}$. Na área de estudo, o valor de referência de qualidade (VRQ) para nitrato considerado foi $3 \mathrm{mg} / \mathrm{L}$. Desta forma, as águas tanto das zonas rasa como intermediária, quando apresentarem concentrações acima de $3 \mathrm{mg} / \mathrm{L}$, encontram-se poluídas por nitrato. O VRQ foi definido considerando os menores valores detectados na área de estudo, a localização dos poços considerados VRQ e a baixa probabilidade de ocorrência de fonte de contaminação.

Concentrações abaixo do VRQ foram detectadas nas zonas rasa e intermediária, nos poços: PC-24, PC-42, PT-10, PT-12, PT-16, PT-22, PT-25, PT28, e PT-34, todos localizados em áreas tipicamente de recarga, com exceção dos poços PC-42, PT-25 e PT-28, estes localizados na zona rural.

Apesar de as águas dos poços PC-26 e PC-44 não estarem poluídas por nitrato, concentrações anômalas de amônio (entre 0,2 mg/L e 0,7 mg/L) foram detectadas. Três fossas foram identificadas nas imediações destes poços, o que pode ser indicativo de futura presença de nitrato nestas águas, decorrente do processo de nitrificação e da continuidade de aporte de nitrogênio proveniente destas fossas. 
Concentrações de nitrato entre $3 \mathrm{mg} / \mathrm{L}$ e $45 \mathrm{mg} / \mathrm{L}$ foram detectadas em poços distribuídos por toda a área de estudo, prioritariamente dentro dos limites da configuração da área urbana na década de 70 (ver Figura 6.3). As maiores concentrações (acima de $80 \mathrm{mg} / \mathrm{L}$ ) foram detectadas nas imediações da área de descarga local, nas proximidades do Córrego Comprido, onde os níveis de água se encontram mais próximos da superfície. Nesta área foi identificada a maior densidade de fossas por quilômetro quadrado $\left(48\right.$ fossas $\left./ \mathrm{km}^{2}\right)$ e altos valores de cloreto e condutividade elétrica.

A Figura 6.9 apresenta um gráfico de correlação entra as concentrações de nitrato e as profundidade dos niveis de água na $Z R$, monitorados em outubro de 2001.

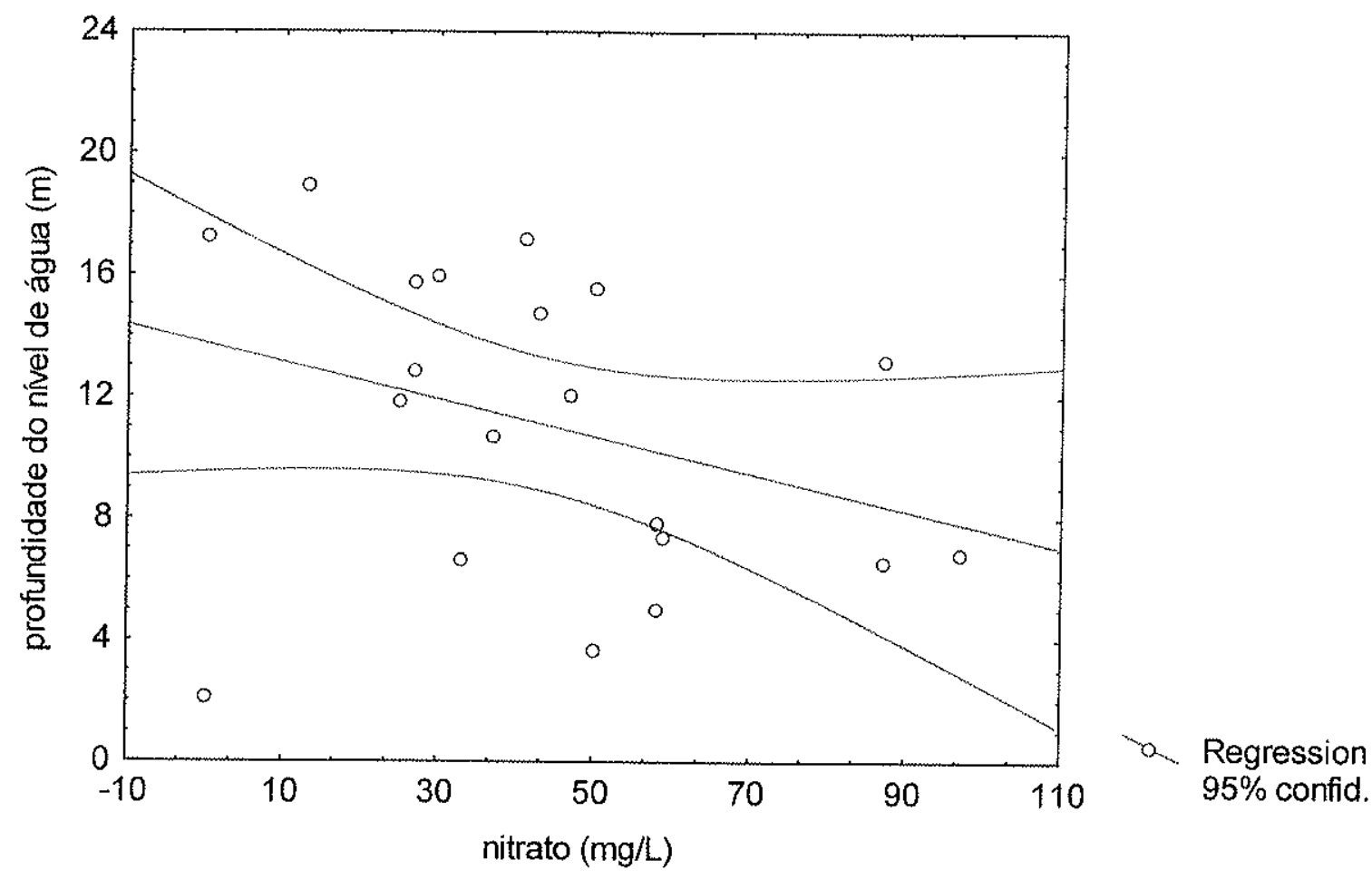

Figura 6.9 - Gráfico de correlação da concentração de nitrato (mg/L) - set/01 com as profundidades dos níveis de água $(\mathrm{m})$ - out/01.

De modo geral, é possível verificar uma boa correlação entre as profundidades dos níveis de água e as concentraçōes de nitrato. Observa-se que 
as maiores concentrações foram detectadas em águs cujos niveis de água estão mais próximos a superfície.

A partir dos mapas de isoconcentração de nitrato, para ZR e ZI, durante as estaçōes seca e úmida (Figuras 6.10 e 6.11), pode-se observar que, tanto na zona rasa como intermediária, o nitrato se distribui em formato de "ilhas" circulares.

$\mathrm{Na}$ zona rasa foi possivel identificar cinco "ilhas" principais, as quais têm como centro as concentrações detectadas nos poços PC-17, PC-23, PC-29, PC-33 e $\mathrm{PC}-43$, todos localizados nas imediações de fossas. Na zona intermediária foram identificadas duas "ilhas" principais que têm como centro os poços PT-08 e PT-19, localizados na área à norte da linha do trem. Nesta região da cidade, cuja ocupação urbana é a mais antiga, observa-se que a poluição por nitrato já atingiu as águas da zona intermediária de maneira mais severa ( $\mathrm{Zl})$.

A concentração de cloreto, detectada na área de estudo e considerada VRQ, foi $3 \mathrm{mg} / \mathrm{L}$. Desta forma, as águas subterrâneas, tanto das zonas rasa como intermediária, por apresentarem concentrações acima de $3 \mathrm{mg} / \mathrm{L}$, encontram-se poluídas por cloreto. A exemplo do nitrato, O VRQ para cloreto foi definido considerando os menores valores detectados na área de estudo e a localização dos poços considerados VRQ. As Figuras 6.12 e 6.13 apresentam os mapas de isoconcentração, de cloreto, confeccionados para a ZR e Zl, durante as estações seca e úmida.

Pode-se observar que também o cloreto se distribui de maneira a formar "ilhas" circulares, notadamente em torno dos poços PC-17, PC-28, PC-29 e PC-45 na ZR e três na ZI, em torno dos poços PT-19, PT-23 e PT-26.

Nos poços onde foram detectadas concentrações de nitrato abaixo do VRQ, também se detectou baixas concentraçōes de cloreto e baixos valores de condutividade elétrica, o que pode ser verificado pelas correlações positivas obtidas para nitrato $x$ cloreto e nitrato e condutividade elétrica (Anexos 7 e 8). A exemplo do nitrato, as concentraçōes anômalas de cloreto distribuem-se por toda a área de estudo.

Observa-se que a $Z R$, quase que na sua totalidade, está poluída por nitrato e cloreto. É nela que foram detectadas as maiores concentrações de nitrato, cloreto e os maiores valores de condutividade elétrica, se comparada à Zl (Anexo 9). 


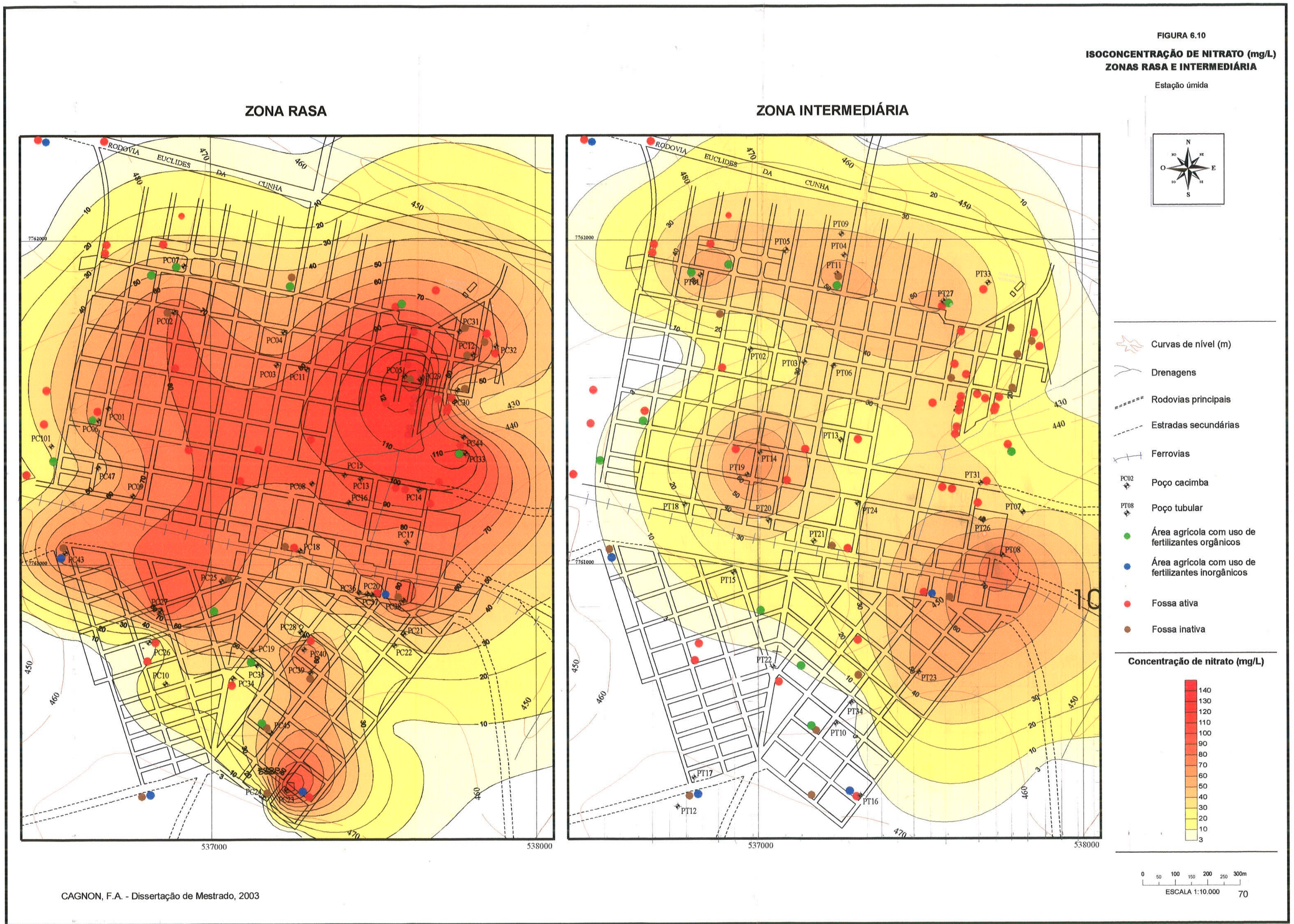




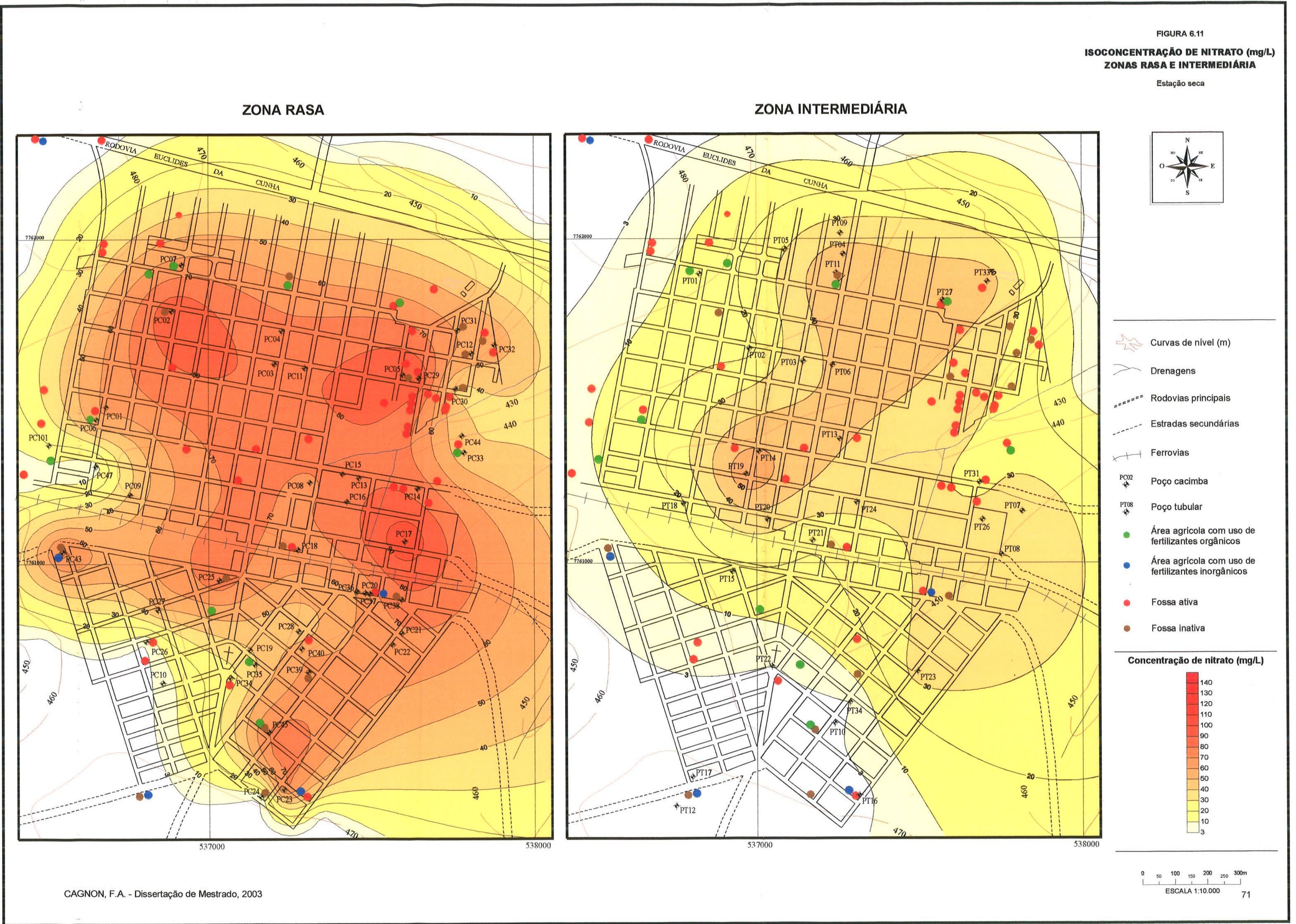


Pode-se observar que, na zona rasa, os valores de condutividade elétrica aumentam na direção norte/nordeste. É nesta área que foram detectadas os maiores valores (acima de $315 \mu \mathrm{s} / \mathrm{cm}$ ), nos poços: PC-2, PC-11, PC-17, PC-29, PC-30, PC-33, PC-45, PT-18, PT-23, PT-27 e PT-34.

A coincidente localização das "ilhas" de nitrato e cloreto reforça a hipótese de mesma origem antrópica para estes dois ions. A diminuição destas concentrações de ZR para $\mathrm{Zl}$ indica diminuição dos sais dissolvidos (ver Anexo 9). Correlações positivas entre nitrato e condutividade elétrica e cloreto e condutividade elétrica, predominantemente na zona rasa (Anexos 7 e 8), e a diminuição dos valores de condutividade elétrica de ZR para Zl evidenciam esta hipótese.

É possivel observar uma diminuição nas concentrações médias de nitrato e condutividade elétrica do período de chuvas (estação úmida) para o de estiagem (estação seca), enquanto que, para o cloreto, se observa um aumento, tanto na zona rasa como intermediária (Figuras 6.10 a 6.13 e Anexo 9). Mesmo assim, a localização das principais "ilhas" não se altera significativamente, se comparados às estações úmida e seca.

$\mathrm{Na}$ área de estudo, o VRQ para o amônio foi $0,1 \mathrm{mg} / \mathrm{L}$. Concentrações anômalas de amônio (entre $0,1 \mathrm{e} 0,7 \mathrm{mg} / \mathrm{L}$ ) foram detectadas em toda a área de estudo, sendo que no poço $\mathrm{PC}-42$ foram observadas concentrações excepcionalmente altas $(1,2$ e 1,3 mg/L).

As significativas diferenças nas concentrações de amônio observadas no período de junho/98 a junho/99 (0,00 a 0,09 mg/L) e de abril/00 a setembro/01 $(0,0$ a $1,3 \mathrm{mg} / \mathrm{L}$ ), estão associadas a mudanças de método utilizado nos dois períodos. No período de 1998 e 1999, as amostras foram analisadas em laboratório, enquanto que, no periodo de 2000 a 2001, em campo (Anexo 9).

Por meio dos diagramas de Pearson (Anexos 7 e 8), foi possível verificar correlação positiva entre os íns cloreto e nitrato, tanto na $\mathrm{ZR}$ como na $\mathrm{ZI}$, o que indica que o cloreto deve ter a mesma origem que o nitrato, já que não foi identificada outra fonte para este íon associada aos solos ou à água de recarga. 


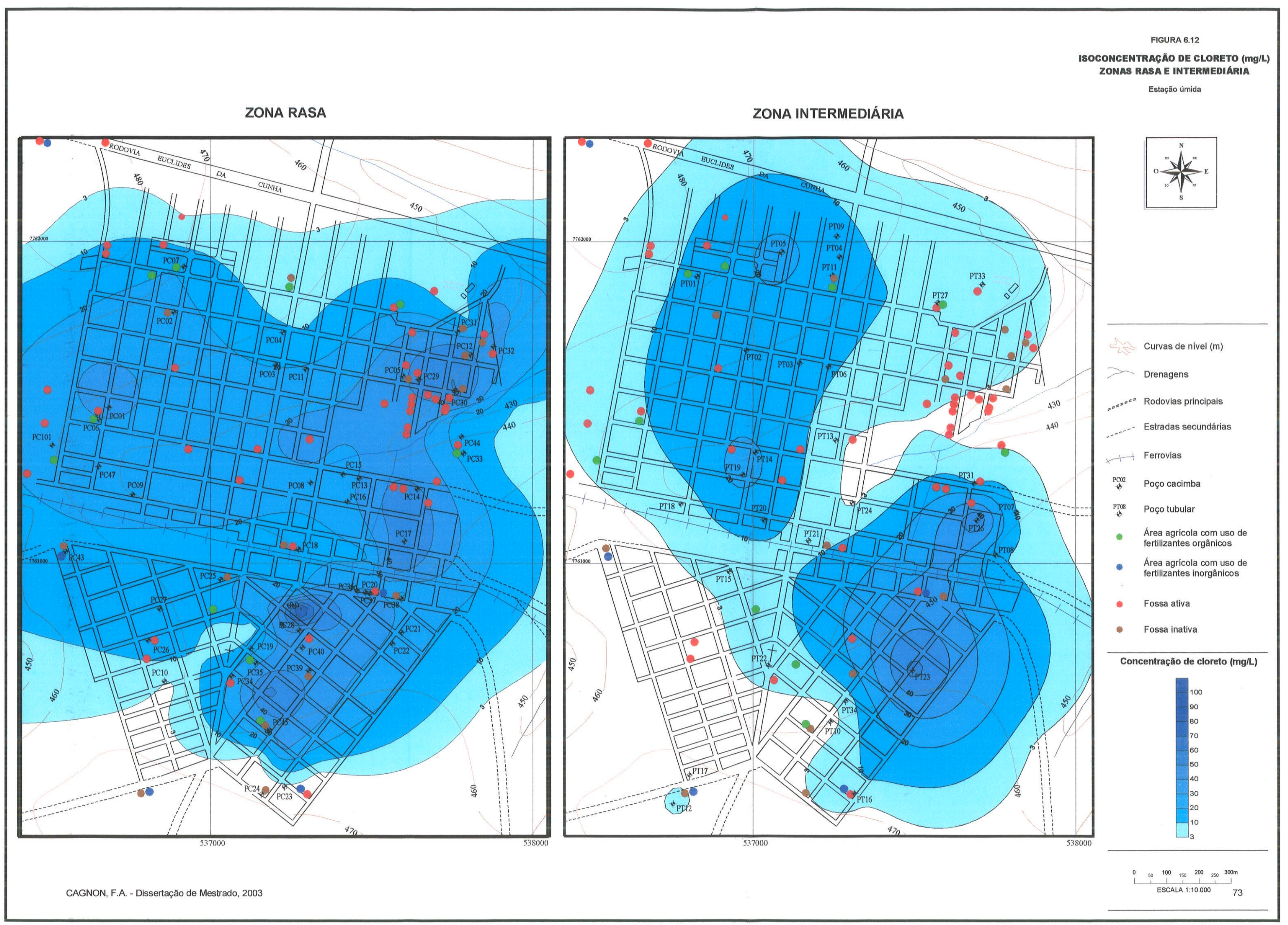




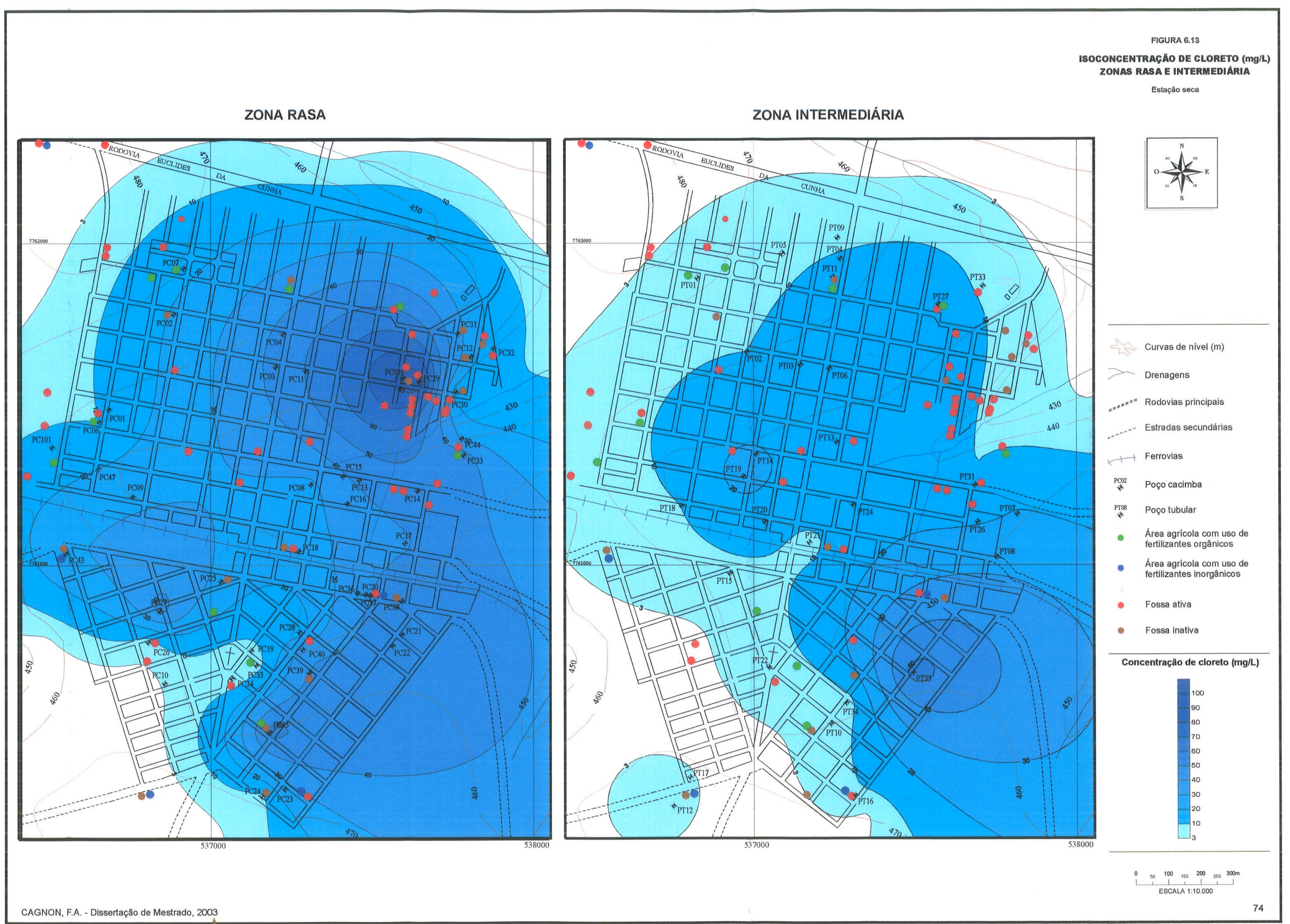


Outras correlações positivas que evidenciam a poluição antropópica das águas subterrâneas por nitrato, na zona rasa, são: cloreto $\mathrm{x}$ sódio, nitrato $\mathrm{x}$ sódio, nitrato $x$ condutividade elétrica e cloreto $x$ condutividade elétrica. Os gráficos da Figura 6.14 ilustram estas correlações nas zonas rasa e intermediária.

Correlações positivas entre nitrato $\mathrm{x}$ fluoreto, cloreto $\mathrm{x}$ fluoreto e sódio $\mathrm{x}$ fluoreto foram observadas na maioria das campanhas de amostragem; no entanto, a presença do fluoreto, que varia de 0,003 a $0,39 \mathrm{mg} / \mathrm{L}$, não está relacionado diretamente às principais fontes potenciais de poluição identificadas (fossas negras $e$ áreas agrícolas). O fluoreto pode ser proveniente da água tratada que abastece toda a cidade de Urânia e que, por sua vez, atinge as águas subterrâneas por meio do seu descarte em fossas negras. Isso explicaria as correlações positivas observadas.

A Figura 6.15 (gráficos A a F) apresenta as concentrações de nitrato, cloreto e condutividade elétrica, no periodo de junho de 1998 a setembro de 2001, para poços cacimbas e tubulares.

Foram observadas, tanto na zonas rasa quanto na intermediária, variações temporais nas concentrações destes três parâmetros, entre as estações seca $e$ úmida. $\mathrm{Na} Z \mathrm{R}$ as oscilações são mais pronunciadas do que na $\mathrm{Zl}$, como reflexo da maior proximidade dos niveis de água em relação a superficie. Não foram observadas tendências de aumento ou diminuição ao longo do tempo. As oscilações observadas, no entanto, não modificam o cenário de poluição das águas subterrâneas na área de estudo (Figuras 6.10 a 6.13). 

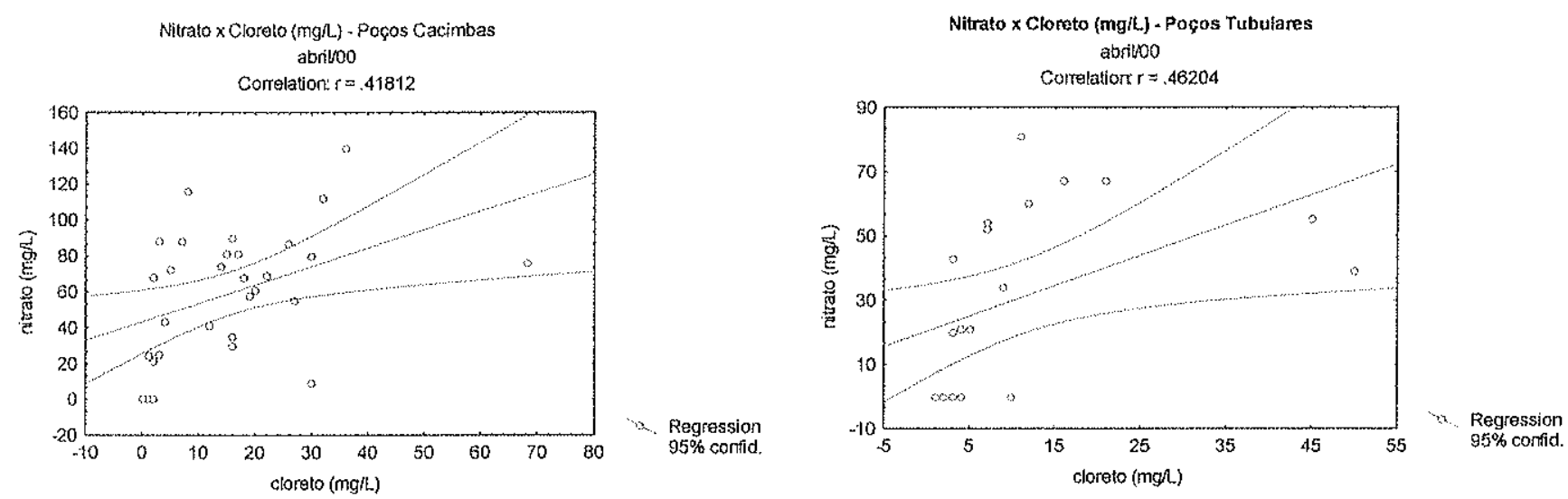

Nilrato (mgh) x Cond. elétrica (us/cm) - Poços Cacimbas abrilloo
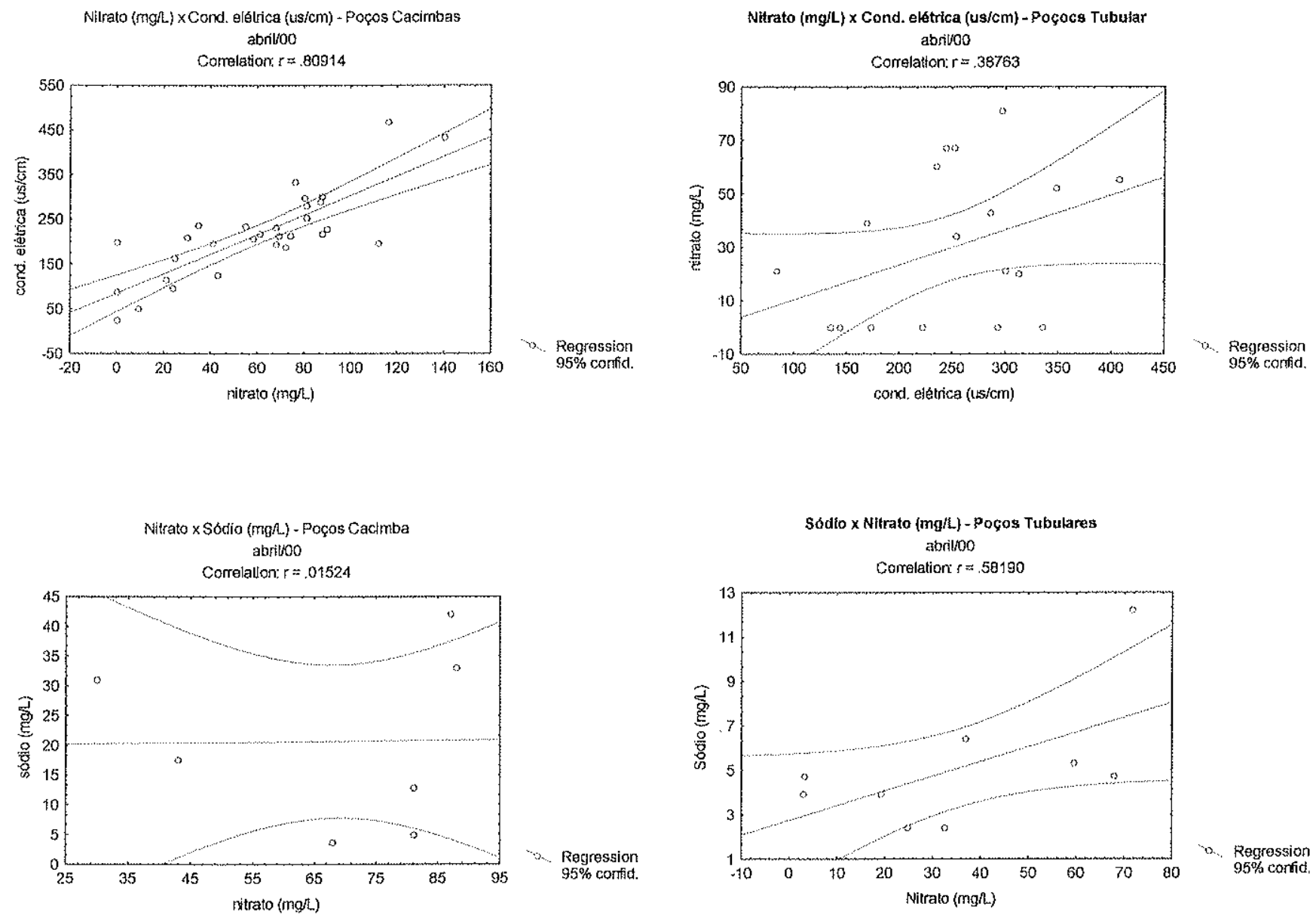

Figura 6.14 - Correlação nitrato $x$ cloreto, nitrato $x$ condutividade elétrica e nitrato x sódio. 

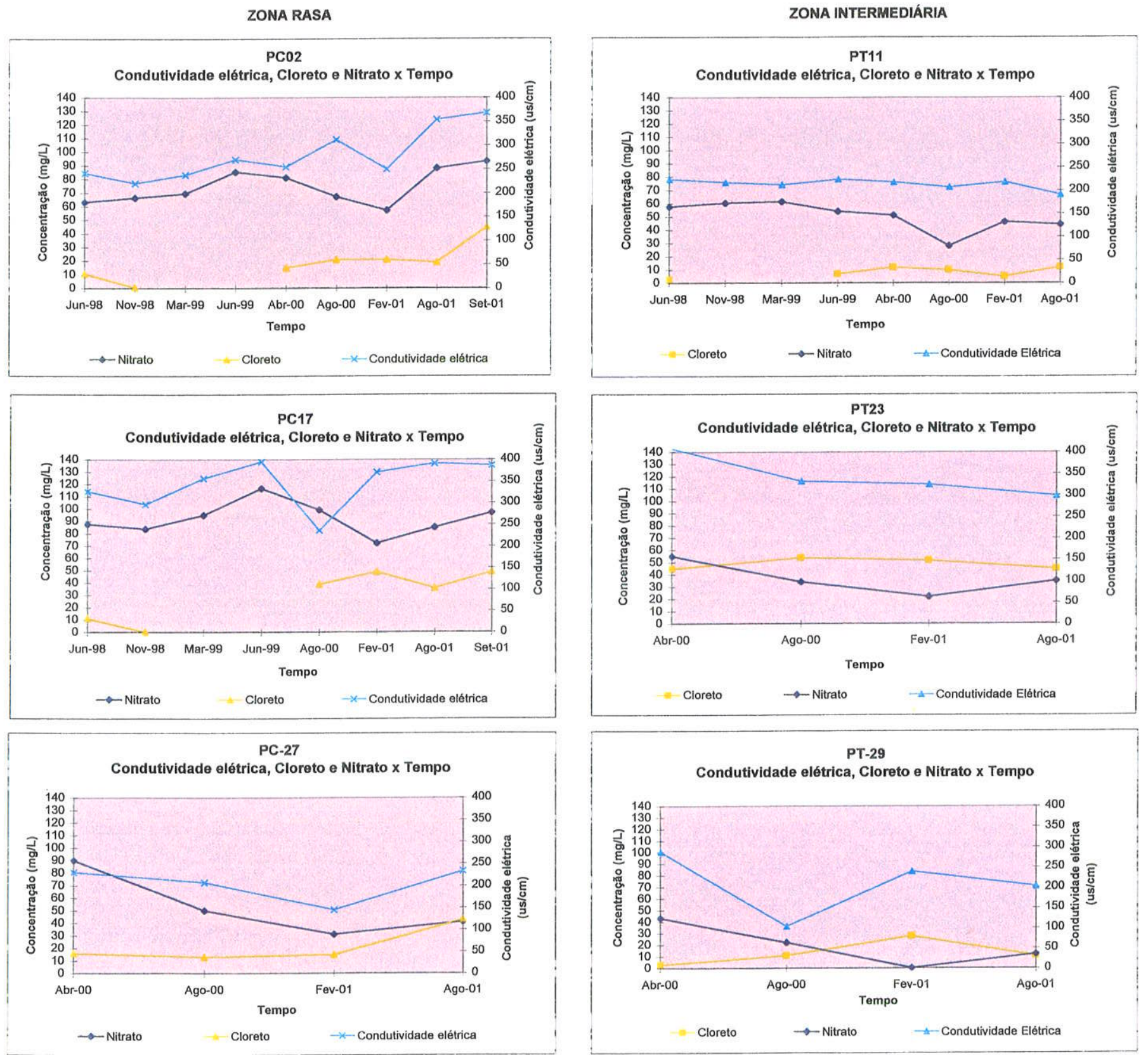

Figura 6.15 - Gráficos das concentrações de nitrato, cloreto e condutividade elétrica, no período de junho de 1998 a setembro de 2001. 


\subsection{Série Nitrogenada}

Tanto na ZR como na ZI, predomina o nitrato, o que caracteriza um ambiente oxidante, não sendo observadas zonas com predomínio de formas mais reduzidas como nitrito, amônio, amônia e nitrogênio orgânico em concentrações elevadas. Nas águas do poço PC-42, as concentrações anômalas de amônio detectadas $(>1,0 \mathrm{mg} / \mathrm{L})$ caracterizam um ambiente de formas mais reduzidas, de áreas próximas à fossas onde a degradação da matéria orgânica consome oxigênio e ocasiona a liberação de íons $\mathrm{H}^{+}$em solução, com a conseqüente queda do $\mathrm{pH}$ e presença de formas mais reduzidas do nitrogênio, tais como o amônio. Evidencia esta hipótese o fato destas águas não apresentarem concentraçōes anômalas de nitrato e de ter sido identificada uma fossa ativa à montante deste poço. Observase que a distribuiçäo dos valores de $\mathrm{pH}$ não se altera ao longo de todas as campanhas para os mesmos pontos monitorados, sendo ligeiramente mais baixos na zona rasa do que na intermediária (Anexo 9). Os únicos valores observados, pouco elevados para a área de estudo (entre 8,00 e 8,81 $\mathrm{mg} / \mathrm{L}$ ) são aqueles detectados nos poços PT-22, PT-25 e PT-28. Estes, localizam-se em área tipicamente de recarga e não poluídos por nitrato.

Os valores de Eh variaram de $290 \mathrm{mV}$ a $721 \mathrm{mV}$, de forma homogênea ao longo de todas as campanhas, não tendo sido detectadas diferenças significativas entre as zonas rasa e intermediária e entre as estaçōes seca e úmida (Anexo 9).

De acordo com FETTER (2001), as águas subterrâneas possuem um intervalo de Eh de $-290 \mathrm{mV}$ a $721 \mathrm{mV}$. Todas as leituras realizadas encontram-se dentro da faixa de normalidade estabelecida por este autor e caracterizam um ambiente hidroquímico oxidante para toda a área de estudo, o que propicia a existência de nitrato de forma abundante e estável.

As baixas concentrações de nitrogênio orgânico obtidas, entre 0,0 e 2,36 $\mathrm{mg} / \mathrm{L}$, e de carbono orgânico dissolvido (COD), entre 0,29 e 0,89 mg/L (Anexo 1), confirmam o predomínio de ambiente hidroquímico oxidante em toda a área de estudo.

As concentrações de oxigênio dissolvido (OD) obtidas variam de 2,8 a 6,1 $\mathrm{mg} / \mathrm{L}$, na ZR e de 4,4 a 5,6 mg/L, na ZI (Anexo 1). Estes dados, se analisados conjuntamente com os valores de Eh e COD, sugerem que'o processo de 
desnitrificação não opera na área de estudo, onde predomina um ambiente oxidante com pouca disponibilidade de matéria orgânica.

Estes dados são semelhantes àqueles obtidos por GIRARD \& HILLAIREMARCEL (1997). Segundo estes autores, a desnitrificação ocorre quando a baixa disponibilidade de oxigênio do meio favorece a ação de bactérias redutoras de nitrato (MARIOTTI, 1986; KOROM, 1992 apud GIRARD \& HILLAIRE-MARCEL, 1997). As concentrações de $O D$ e Eh, detectadas nas águas subterrâneas do Aqüifero Niamey, na África (GIRARD \& HILLAIRE-MARCEL, 1997) de $>1 \mathrm{mg} / \mathrm{L}$ e > $250 \mathrm{mV}$, respectivamente, indicaram que o processo de desnitrificação na área de estudo não é eficiente.

Finalmente é possivel concluir que a presença ou a coexistência de alguns compostos nas águas subterrâneas, dentre eles os da série nitrogenada, é controlada diretamente pelo $\mathrm{pH}$ e Eh, os quais determinam respectivamente quão ácido e qual é o potencial de oxi-redução do meio. Isto pode ser verificado pelas seguintes correlações identificadas nas zonas rasa e intermediária (ver Anexos $7 \mathrm{e}$ 8):

- na zona rasa o aumento do $\mathrm{pH}$ provoca o aumento da alcalinidade e consequentemente uma diminuição do potencial de oxi-redução do meio (diminuição do Eh); e

- na zona intermediária o aumento das concentrações de COD é seguido pelo aumento da alcalinidade e do Eh, aumentos do $\mathrm{pH}$ e de $O D$ ocasionam um aumento nas concentrações de nitrato e queda nas concentraçōes de amônio.

\subsection{Análises Isotópicas}

São apresentados, a seguir, os intervalos de valores de $\delta^{15} \mathrm{~N}$, obtidos em setembro de 2001, para 12 amostras de água subterrânea coletadas em poços cacimbas (ZR) e 12, coletadas em poços tubulares (ZI), conforme o tipo de ocupação da área e proximidade de fontes potenciais de contaminação:

- área urbana sob influência de fossas: $\delta^{15} \mathrm{~N}$ de $+8,74 \mathrm{a}+11,63 \%$,

- área agrícola com utilização de fertilizantes orgânicos: $\delta^{15} \mathrm{~N}$ de $+10,49$ a $+10,86 \%$, 
- área agrícola com utilização de fertilizantes inorgânico: $\delta^{15} \mathrm{~N}$ de $+8,60$ a $+11,93 \%$ o e

- mata natural: $\delta^{15} \mathrm{~N}$ de $+7,75 \mathrm{a}+9,28 \%$.

A distribuição destas concentrações, levando-se em conta as zonas rasa (ZR) e intermediária ( $\mathrm{ZI})$, é a seguinte:

- ZR: $\delta^{15} \mathrm{~N}$ de $+8,74 \mathrm{a}+11,13 \%$ o e

- Zl: $\delta^{15} \mathrm{~N}$ de $+7,75 \mathrm{a}+11,93 \%$.

A Figura 6.16 apresenta um gráfico de correlação entre as concentrações de nitrato e valores de $15 \mathrm{~N}$ obtidos para os poços monitorados.

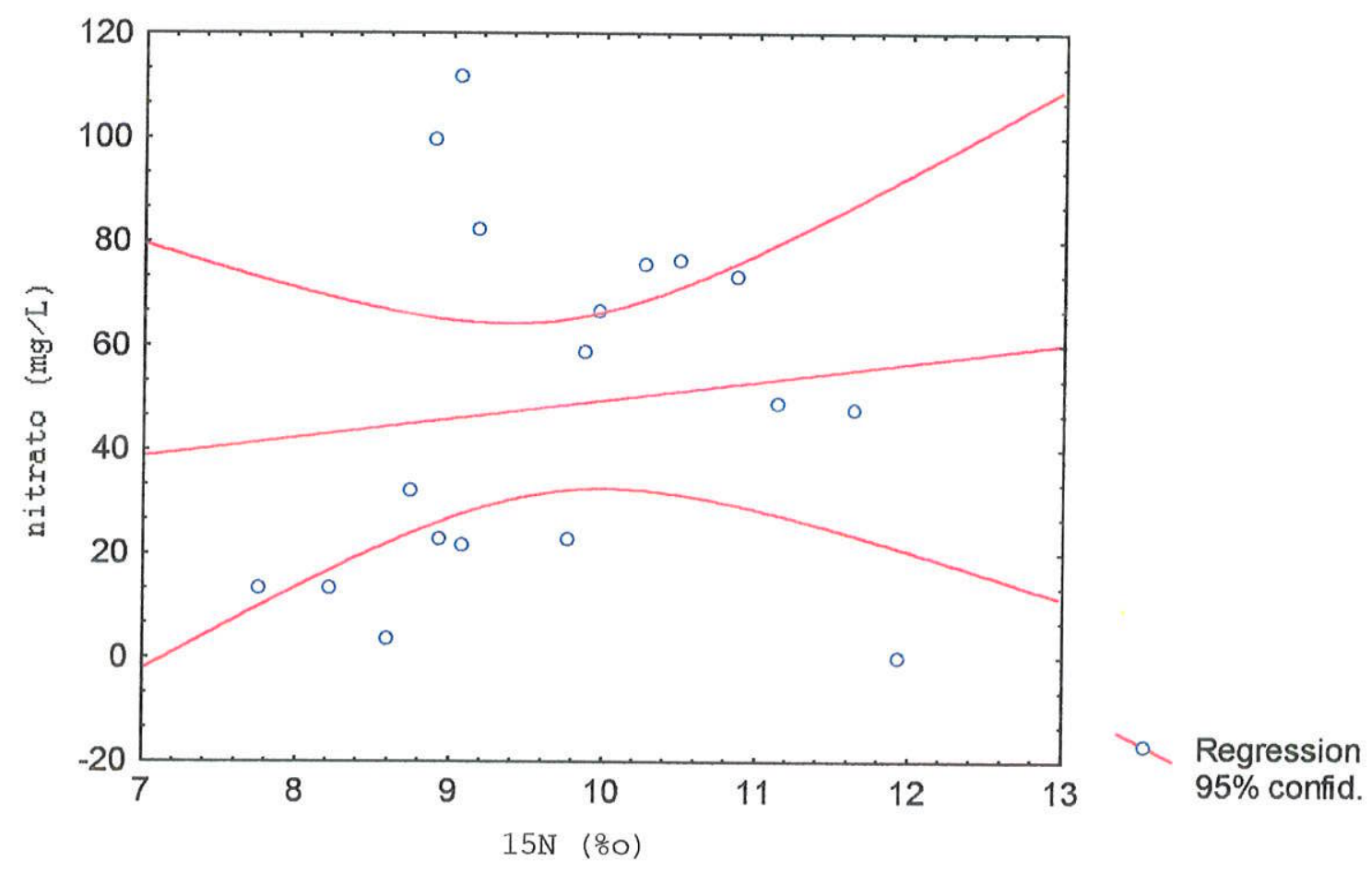

Figura 6.16 - Gráfico de correlação da concentração de nitrato (mg/L) com o os resultados de $15 \mathrm{~N}(\%)$

De acordo com a Figura 6.16 não há correlação entre as concentrações de nitrato e a assinatura isotópica.

Os resultados obtidos não demostram uma distinta separação isotópica entre o nitrato detectado nas áreas urbana, agrícola e de mata. Não são também 
observadas diferenças na assinatura isotópica entre as zonas rasa e intermediária, - que indica uma mesma origem deste composto para toda a área de estudo. De acordo com estes resultados, a origem provável do nitrato é orgânica, proveniente de dejetos humanos e animais.

No que diz respeito à área urbana de Urânia, os resultados das assinaturas isotópicas se analisados conjuntamente com os resultados da caracterização das fontes de contaminação e ainda com o estudo da hidroquímica das águas subterrânea (correlaçōes positivas de nitrato com cloreto, sódio e fluoreto), confirmam a origem no nitrato como sendo orgânica, proveniente de sistemas de saneamento in situ (fossas).

No entanto, é importante ressaltar que, o fato dos resultados das assinaturas isotópicas não indicarem a existência de outras fontes de contaminação, especialmente se considerados os pontos monitorados em áreas ágrícola $e$ de mata, não é suficiente para a afirmação de que estas não existam, visto que este fato pode estar relacionado a limitações do método.

O nitrato detectado em áreas agrícolas (tais como: PC-06, PC-45 e PT-35) e de mata (PT-29, PT-30 e PT-32) pode ser de origem natural, proveniente destas áreas anteriormente ocupadas por mata nativa, indicando que as águas subterrâneas não foram poluidas por meio da atividade agricola (fertilizantes). Esta hipótese é evidenciada pelo fato de que tanto em área agrícola como de mata foram detectadas semelhantes assinaturas isotópicas e baixas concentrações de cloreto. Outra possibilidade é que o impacto nas áreas agrícolas tenha ocorrido, porém apenas o fertilizante orgânico tenha atingido estas águas. Nenhuma evidência concreta, que comprove uma ou outra possibilidade, foi observada.

\section{CONCLUSÕES}

As águas subterrâneas do Aqüífero Adamantina, das zonas rasa (até $21 \mathrm{~m}$ de profundidade) e intermediária (de 57 a $104 \mathrm{~m}$ de profundidade), no município de Urânia, estão amplamente contaminadas por nitrato. Estas águas estão também poluídas pelos compostos cloreto e amônio;

A fonte de contaminação é do tipo antrópica e multipontual. Caracteriza-se pelo sistema de saneamento in situ do tipo fossas negras, instalado na área urbana 
do município desde a década de 50 até os dias de hoje. Esta hipótese foi confirmada por meio das seguintes comprovações:

- fossas negras foram identificadas, tanto ativas como inativas, por toda a área de estudo, localizadas nas imediações de poços cacimbas e tubulares contaminados;

- as maiores concentrações de nitrato na água subterrânea foram identificadas na porção nordeste da cidade, zona de descarga do aqüífero (Córrego Comprido), onde foi observada a maior densidade de fossas por quilômetro quadrado (48 fossas $/ \mathrm{km}^{2}$ );

- as maiores concentrações de nitrato foram identificadas na zona rasa do aqüífero, o que indica a presença de fonte de contaminação localizada em superficie;

- concentrações anômalas de nitrato estão associadas a valores anômalos de cloreto e condutividade elétrica;

- foram identificadas correlações positivas nitrato e fluoreto, cloreto e fluoreto e sódio e fluoreto, na maioria das campanhas de amostragem; e

- os resultados da razão isotópica ${ }^{15} \mathrm{~N}$ permitiram identificar a origem do nitrato como orgânica, proveniente de dejetos humanos e/ou animais. Não foram observadas evidências de outras fontes de contaminação, tais como fertilizantes inorgânicos, nem mesmo nas áreas caracterizadas como eminentemente agrícolas.

A partir dos resultados desta pesquisa e, no que diz respeito ao nitrato, foi ainda possivel concluir:

- as concentrações de nitrato e cloreto na área de estudo se distribuem de forma a compor "ilhas" de formato circular;

- na zona rasa, onde foram detectadas as maiores concentrações, foram identificadas cinco "ilhas" principais e, na zona intermediária, duas "ilhas" de nitrato;

- a exemplo do nitrato, as concentraçōes anômalas de cloreto distribuem-se por toda a área de estudo;

- a direção preferencial de fluxo das águas subterrâneas, orientada para a regiāo nordeste na qual se localiza o Córrego Comprido (área de descarga local), possibilita o transporte de poluentes (nitrato, amônio e cloreto) para esta área. Fato este que, juntamente com a elevada densidade de fossas por quilômetro quadrado 
na região nordeste, faz desta a mais poluída da cidade, com concentrações de nitrato acima de $80 \mathrm{mg} / \mathrm{L}$;

- concentrações de nitrato acima de $45 \mathrm{mg} / \mathrm{L}$ foram detectadas nas zonas rasa e intermediária, distribuídas por toda a área de estudo, prioritariamente dentro dos limites da configuração da área urbana na década de 70 ;

- a localização das principais "ilhas" de nitrato e cloreto não se altera significativamente, se comparados às estações úmida e seca; $e$

- foram observadas, tanto na zonas rasa quanto na intermediária, variações temporais nas concentrações de nitrato e cloreto e nos valores de condutividade elétrica, entre as estações seca e úmida. Estas variações no entanto, não modificam o cenário de poluição das águas subterrâneas na área de estudo.

A partir do estudo da hidroquímica e do modelo conceitual de circulação de fluxo das águas subterrâneas no município, foi possivel concluir que:

- a condutividade hidráulica na zona intermediária do Aqüífero Adamantina varia de $7,17 \times 10^{-5}$ e $8,54 \times 10^{-6} \mathrm{~m} / \mathrm{s}$, o que caracteriza sedimentos permeáveis, os quais atribuem ao aqüífero velocidade de caminhamento das águas subterrâneas de $1,20 \times 10^{-5}$ a $6,26 \times 10^{-7} \mathrm{~m} / \mathrm{s}$. O gradiente hidráulico da área varia de $1,1 \%$ a $2,5 \%$, o que demonstra que as águas têm pequena perda do potencial energético ao se deslocarem das áreas de recarga para as áreas de descarga;

- distinguem-se dois tipos hidroquímicos: as águas bicarbonatas nitratadas cálcicas, secundariamente sódicas e cloro-nitratadas, associadas à zona rasa e as águas bicarbonatadas cálcicas e nitratadas cálcicas, que são águas da zona intermediária, localizadas em maior profundidade;

- do ponto de vista da evolução hidrogeoquímica, as águas da zona rasa (ZR) evoluiram para a intermediária (ZI) com diminuição nas concentrações de sódio, cloreto e nitrato, secundariamente sulfato e potássio, e aumento das concentrações de cálcio e bicarbonato. A presença de cloreto e nitrato na zona rasa e a diminuição destas em direção às águas mais profundas reforçam a idéia de origem antrópica e superficial para estes compostos;

- os processos hidrogeoquímicos que podem estar ocorrendo na zona saturada na área de estudo são: (1) ações antropogênicas: ocorrência de elevadas concentrações de nitrato nas zonas rasa (até $140 \mathrm{mg} / \mathrm{L}$ ) e intermediária (até 81 
$\mathrm{mg} / \mathrm{L})$; (2) dispersão mecânica: diminuição nas concentrações de nitrato e cloreto (até 22,94 , na ZR e até $12,25 \mathrm{mg} / \mathrm{L}$, na ZI) da zona rasa para a intermediária e diminuição das concentrações de sódio (até 19,68, na ZR e até 14,26 mg/L, na Zl) em direção à zona profunda; (3) dissolução e/ou ou troca iônica (ainda não comprovada): aumento das concentrações de bicarbonato e cálcio da ZR para a Zl; (4) adsorção de potássio na fase sólida (ainda não comprovada): ligeiro decréscimo das quantidades relativas de potássio em direção às águas mais profundas; $e$

- predomina um ambiente hidroquímico oxidante por toda a área de estudo, onde não foram observadas evidências de processos de desnitrificação.

\section{RECOMENDAÇÕES}

Entre as ações que podem ser tomadas para a diminuição das concentrações de nitrato nas águas subterrâneas, podem-se citar diversos tipos de tratamentos da água, porém a solução mais racional para o problema é maior controle das atividades e fontes poluidoras. Este controle pode ser realizado por meio de gerenciamento do sistema de saneamento como um todo (in situ e público), que garanta a coleta e o tratamento de $100 \%$ do efluente gerado, e a completa desativação do sistema de saneamento in situ do tipo fossas negras ou sépticas. A implementação de um sistema de gerenciamento, conforme proposto, deve priorizar áreas onde ocorrem as maiores concentrações de nitrato e onde as águas subterrâneas são utilizadas para o consumo humano.

Recomenda-se ainda que sejam adotadas medidas que proporcionem um gerenciamento adequado do abastecimento de água potável à população, de forma a garantir a utilização de água de qualidade por todos os habitantes do município. Para isso, sugerem-se as seguintes medidas em ordem de prioridade: cadastro de todos os poços privados existentes; cadastro de todas as fossas ativas e inativas, restringir o uso de novas fossas, promover campanhas de conscientização da população a respeito da importância da utilização de água de qualidade como fonte de água potável e ainda utilização racional dos recursos hídricos.

Como medida emergencial, sugere-se a orientação da população a cerca dos riscos associados à ingestão de águas poluídas por nitrato, bem como a paralisação imediata do consumo de água não potável. 
No que diz respeito aos aspectos científicos desta pesquisa, sugere-se como trabalhos complementares melhor caracterização da hidrodinâmica do aqüifero com coleta de novos dados e elaboração de modelo matemático de fluxo bem como simulação do transporte de contaminantes de modo a prever a contaminação ou não dos poços profundos no aqüífero. 


\section{REFERÊNCIAS BIBLIOGRÁFICAS}

ALMODOVAR, M. L. N. (1995). Estudo da anomalia de cromo nas águas subterrâneas da região noroeste do Estado de São Paulo. São Paulo, 101 p. (Dissertação - Mestrado) - Instituto de Geociências, Universidade de São Paulo.

AMODOVAR, M.L.N. (2000). A origem natural da poluição por cromo no aqüífero Adamantina, município de Urânia (SP). São Paulo, 199 p. (Tese - Doutorado) Instituto de Geociências, Universidade de São Paulo.

AMERICAN PUBLIC HEALTH ASSOCIATION (1995). Standard methods for the examination of water and wastewater. $19^{a}$ ed. Washington DC, American Water Rocks Association and Water Environment Federation. 1268 p.

APPELO, C.A.J.; POSTMA, D. (1993). Geochemistry, groundwater and pollution. Rotterdam, A. Baalkema. $536 \mathrm{p}$.

ARAVENA, R.; EVANS, M. L.; CHERRY, J. A. (1993). Stable isotopes of oxygen and nitrogen in source identification of nitrate from septic tanks. Groundwater, v. 31, p. 180-186.

BARCHA, S.F. (1980). Aspectos Geológicos e Províncias Hidrogeológicas da Formação Bauru na Região Norte - Ocidental do Estado de São Paulo. São Paulo. 209 p. (Tese Livre-Docência) - Instituto de Biociências, Letras e Ciências Exatas da Universidade Estadual Paulista de São José do Rio Preto.

BERTOLO, R. A.; HIRATA, R. C. A. (2000). Monitoramento da zona não saturada: um estudo da hidráulica e hidroquímica na estação experimental de Urânia, São Paulo, Brasil. In: CONGRESSO MUNDIAL INTEGRADO DE ÁGUAS SUBTERRÂNEAS, 1. Fortaleza, 2000. Anais. Fortaleza, ABAS. (CD-ROM). 
BERTOLO, R. A. (2001). Hidrodinâmica e hidrogeoquímica da zona não saturada do aqüifero Adamantina em Urânia (SP). São Paulo, 218p. (Tese-Doutorado) Instituto de Geociências, Universidade de São Paulo.

BLACK, A. S.; WARING, S. A. (1979). Adsorption of nitrate, chloride and sulfate by some highly weathered soils from south-east Queensland. Australian Journal of Soil Research. v. 17, n. 2, p. 271-282.

BÖTTCHER, J. O.; STREBEL, S.; VOERKELIUS, S.; SCHMIDT, H.L. (1990). Using isotope fractionation of nitrate-nitrogen and nitrate-oxygen for evaluation of microbial denitrification in a sandy aquifer. Journal of Hydrology, v. 114, p. 413424.

BRASSINGTON, R. (1998). Field Hydrogeology. $2^{a}$ ed. Chichester, John Wiley \& Sons. $248 \mathrm{p}$.

BURT, T. P., HEATHWAITE, A. L., TRUDGILL, S. T. (1993). Nitrate: process, Patterns and Management. New York, John Wiley \& Sons Ltda. 444p.

CAMPOS, H.; HIRATA, R.; ROCHA, G.; MISTRETA, G. (1994). Origem e ocorrência de nitrato nos aqǘferos do Estado de São Paulo, Brasil. In: CONGRESSO LATINOAMERICANO DE HIDROGEOLOGIA SUBTERRÁNEA. Santiago, Alhsud. 1994. Anais. Santiago, ALHSUD. 20 p.

CAMPOS, H.C.N.S. (1987). Contribuição do estudo hidrogeoquímico do Grupo Bauru no Estado de São Paulo. São Paulo, 158 p. (Dissertação - Mestrado) Instituto de Geociências da Universidade de São Paulo.

CANDELA, L.; AURELI, A. (1998). Agricultural Threats to Groundwater Quality. In: WORKSHOP PROCEEDINGS. Zaragoza, 1996. IHP-UNESCO/IAMZCIHEAM/Geotechnical Engineering and Geosciences Department-UPC, 251 p. 
CANTER, L.W. (1997). Nitrates in Groundwater. Boca Raton, Lewis Publication. $263 p$.

CANTER, L. W.; KNOX, R. C.; FAIRCHILD, D. M. (1987). Groundwater quality protection. Michigan, Lewis Publishers. $562 \mathrm{p}$.

CANTER, L. W.; KNOX, R. C. (1988). Septic tank system effects on ground water quality. $3^{\text {a }}$ ed. Michigan, Lewis Publishers. $336 \mathrm{p}$.

CLARK, I.; FRITZ, P. (1997). Environmental isotopes in hydrogeology. New York, Lewis Publishers. $328 \mathrm{p}$.

COMPANHIA DE TECNOLOGIA DE SANEAMENTO AMBIENTAL (2000). Relatório de Estabelecimento de para Solos e Águas Subterrâneas no Estado de São Paulo. Coord. Dorothy C. P. Casarini. São Paulo, CETESB. 73 p.

COMPANHIA DE TECNOLOGIA DESANEAMENTO AMBIENTAL (1998). Relatório de qualidade das águas subterrâneas do Estado de São Paulo, 1998. São Paulo. CETESB. 106 p. (Série Relatórios).

COMPANHIA DE TECNOLOGIA DE SANEAMENTO AMBIENTAL (1988). Guia de coleta e preservação de amostras de água. São Paulo, CETESB. 150 p.

CUSTÓDIO, E. G.; LLAMAS, M. R. (1976). Hidrologia Subterrânea. Omega, Barcelona, v. 2.

DAVIS, J. C. (1986). Statistic and data analysis in geology. New York, Wiley. 646 p.

DEPARTAMENTO DE ÁGUAS E ENERGIA DO ESTAdO DE SÃO PAULO (1974). Estudo de águas subterrâneas; região administrativa 6, Ribeirão Preto SP. São Paulo, GEOPESQUISADORA. $2 v$. 
DEPARTAMENTO DE ÁGUAS E ENERGIA DO ESTADO DE SÃO PAULO (1976). Estudo de águas subterrâneas; regiões administrativas 7, 8 e 9 (Bauru, São José do Rio Preto e Araçatuba). São Paulo, ENCO. 4v.

DEPARTAMENTO DE ÁGUAS E ENERGIA DO ESTADO DE SÃO PAULO (1979). Estudo de águas subterrâneas; regiōes administrativas 10 e 11 (Presidente Prudente e Marília). São Paulo. 3v.

EXNER, M. E.; SPALDING, R. F. (1994). N-15 Identification of Non-point Sources of Nitrate Contamination beneath Cropland in the Nebraska Panhandle: two case studies. Applied Geochemistry, v. 9, p. 73-81.

FERNANDES, L. A. (1992). A cobertura cretácea suprabasáltica no Paraná e Pontal do Paranapanema (SP): os grupos Bauru e Caiuá. São Paulo, 129 p. (Dissertação -Mestrado) - Instituto de Geociências, Universidade de São Paulo.

FERNANDES, L. A.; COIMBRA, A.M. (1992). A cobertura cretácea suprabasáltica no Estado do Paraná e Pontal do Paranapanema (SP): os grupos Bauru e Caiuá. In: CONGRESSO BRASILEIRO DE GEOLOGIA, 37, São Paulo, 1992. Boletim de Resumos Expandidos. São Paulo, SBG, v.2, p. 506-508.

FERREIRA, L; HIRATA, R. (1993). Determinação dos riscos de contaminação das águas subterrâneas por sistemas de saneamento in situ. Estudo de caso: município de Campinas. In: SIMPÓSIO BRASILEIRO DE RECURSOS HíDRICOS, 10., Gramado., 1993. Anais. Gramado, IPH/ ABRH, n. 4, p.443-452.

FERREIRA, L. M. R. (1999). A prática de Disposição de Efluentes Domiciliares "in situ" e os Impactos nas Águas Subterrâneas. Estudo de Caso no Município de Campinas. São Paulo, 136 p. (Dissertação - Mestrado) - Instituto de Geociências da Universidade de São Paulo.

FETTER, C. W. (2001). Applied Hydrogeology. $4^{\mathrm{a}}$ ed. Upper Saddle River, Prentice Hall, $586 \mathrm{p}$. 
FOSTER, S. S. D.; HIRATA, R. C. A.; ROCHA, G. A. (1988). Risco de poluição das água subterrâneas: uma proposta metodológica de avaliação regional. In: CONGRESSO BRASILEIRO DE ÁGUAS SUBTERRÂNEAS, 6., São Paulo, 1988. Anais. São Paulo, ABAS. p.175-185.

FOSTER, S. S. D.; HIRATA, R. (1988). Determination del risco del contamination de aguas subterraneas: uma metodologia basada en datos existentes. $2^{a}$ ed. Perú., Centro Panamericano de Ingenieria Sanitaria y Ciencias del Ambiente CEPIS-PAHOMHO. $81 \mathrm{p}$.

FOSTER, S. S. D.; VENTURA, M.; HIRATA, R. (1987). Groundwater pollution: an executive overview of Latin America - Caribbean situation in relation to potable water-supply. CEPIS Tech. Report (WHO-PAHO-CEPIS). Lima, Peru.

FOSTER, S. S. D. ; CHILTON P. J. (1996). As the land so the water. The effects of agricultural cultivation on groundwater. In: Workshop Agricultural Threats to Groundwater Quality, Proceedings. Zaragosa, 1996. p. 15-44.

FREEZE, R. A.; CHERRY, J. A. (1979). Groundwater. Englewood Cliffs, PrenticeHall. $604 \mathrm{p}$.

FÚlfFARO, V. J.; BARCELOS, J. H. (1991). Fase Rift na Bacia do Paraná: a Formação Caiuá. In: SIMPÓSIO NACIONAL DE ESTUDOS TECTÔNICOS, 3, Rio Claro, 1991. Boletim de Resumos Expandidos. Rio Claro, SBG. p.85-87.

FÚLFARO, V. J. et al. (1982). Compartimentação e evolução tectônica da Bacia do Paraná. Revista Brasileira de Geociências, v. 12, n. 4, p. 590-610.

FUNDAÇÃo SISTEMA ESTADUAL DE ANÁLISE DE DADOS - SEADE (1999). São Paulo em Dados. Disponivel em: http://www.seade.gov.br/cgi-bin/lingcv98/spd.ksh). Acesso em: 10 de outubro de 2001. 
FUNDAÇÃO SISTEMA ESTADUAL DE ANÁLISE DE DADOS - SEADE (1981). São Paulo em Dados. Disponivel em: http://www.seade.gov.br/cgi-bin/lingcv98/spd.ksh). Acesso em: 10 de outubro de 2001.

FUNDAÇÃO SISTEMA ESTADUAL DE ANÁLISE DE DADOS - SEADE (2002). São Paulo em Dados. Disponivel em: http://www.seade.gov.br/cgi-bin/lingcv98/spd.ksh). Acesso em: 10 de outubro de 2001.

GIRARD, P.; HILLAIRE-MARCEL, C. (1997). Determining the Source of Nitrate Pollution in the Niger Discontinuous Aquifers Using the Natural ${ }^{15} \mathrm{~N} /{ }^{14} \mathrm{~N}$ Ratios. Journal of Hydrology, v. 199. n. 3-4, p. 239-251.

GORMLY, J. R.; SPALDING, R. F. (1979). Sources and concentrations of nitratenitrogen in groundwater of the central Platte region, Nebraska. Groundwater. v. 17 , n. 3, p. 291-301.

GUTIERREZ, A. S. (1999): A Hidroquímica do Sistema Aqüífero Bauru na cidade de Urânia - SP. São Paulo, 45 p. (Projeto de iniciação científica) - Instituto de Geociências da Universidade de São Paulo.

HANKE, F. (1998). Uso del refletómetro RQ FLEX en análisis de suelo. Colômbia, MERCK Colômbia S.A. 62 p.

HEATON, T. H. E. (1986). Isotopic studies of nitrogen pollution in the hydrosphere and atmosphere: A review. Chemical Geology, v. 59, p. 87-102.

HIRATA, R. ; RODOLFI, G. (1993). Presença de cromo nas águas subterrâneas em Urânia. São Paulo, Secretaria do Meio Ambiente - Instituto Geológico. (Relatório técnico). 24 p.

HIRATA, R.; BASTOS, C.; ROCHA, G. (1997). Mapeamento da vulnerabilidade das águas subterrâneas no Estado de São Paulo. São Paulo, Secretaria do Meio Ambiente do Estado de São Paulo. 95p. 
HIRATA, R. (2000a). A origem da poluição por cromo no Aqüífero Adamantina, município de Urânia (SP). São Paulo, FAPESP/IGc-USP. 333p. (Relatório finalProcesso $n^{\circ}$ 97/13879-6).

HIRATA, R. (2000b). Estudo da contaminação por nitrato no Distrito de Tibiriçá, Bauru. São Paulo, DAE/IGc-USP. 2v. (Relatório técnico)

HIRATA, R. (2000c). Nitrogênio nas águas subterrâneas: fontes antrópicas, comportamento hidrogeoquímico e manejo. São Paulo, FAPESP/IGc-USP. 150p. (Relatório final -Processo $n^{\circ}$ 97/6950-6).

HOUNSLOW, A. W. (1994). Water quality data: analysis and interpretation. Boca Raton, CRC Press/Lewis Publishers. $397 \mathrm{p}$.

INSTITUTO DE PESQUISAS TECNOLÓGICAS DO ESTADO DE SÃO PAULO (1981). Mapa Geológico do Estado de São Paulo. Escala 1:500.000. São Paulo, IPT. v. 2, (Monografias, 6).

INSTITUTO DE PESQUISAS TECNOLÓGICAS (2000). Relatório de situação dos recursos hídricos da Bacia Hidrográfica Turvo/Grande. São Paulo, IPT. Relatório zero. (CD-ROM).

INSTITUTO GEOGRÁFICO E CARTOGRÁFICO - SECRETARIA DE ECONOMIA E PLANEJAMENTO. COORDENADORIA DE PLANEJAMENTO REGIONAL (1995). Municípios e Distritos do Estado de São Paulo. São Paulo, Instituto Geográfico e Cartográfico, 208p.: il., mapas. Coordenadores: HOFFMANN, J. C. M. (SECRETARIA); CUNHA E CASTRO, L. J. da (IGc).

INSTITUTO GEOGRÁFICO E GEOLÓGICO DO ESTADO DE SÃO PAULO (1965). Mapa Topográfico. Folha Santa Albertina SF-22-D-1-2. São Paulo, IGG. (Escala 1:50.000). 
INSTITUTO GEOGRÁFICO E GEOLÓGICO DO ESTADO DE SÃO PAULO (1966). Mapa Topográfico. Folha Jales SF-22-D-I-4. São Paulo, IGG. (Escala 1:50.000).

KARR, J. D.; SHOWERS, W. J.; HINSON, T. H. (2002). Nitrate sources identification using delta ${ }^{15} \mathrm{~N}$ in a groundwater plume near a intensive swine operation. Groundwater Monitoring and Remediation. v. 22, n. 2, p. 68-75.

KEENEY, D. R. (1989). Sources of nitrate to groundwater. Nitrogen management and groundwater protection. Developments in Agricultural and Managed-forest Ecology, v. 21, p. 23-34.

KENDALL, C. (1998). Tracing sources and cycling of nitrogen in catchments. In: KENDALL, C. ; MCDONNELL, J.J. (eds) Isotopes tracers in catchment hydrology. Amsterdam, Elsevier Science, p. 519-576.

KREITLER, C. W. (1975). Determining the source of nitrate in ground water by nitrogen isotope studies. Report of Investigations. Bureau of Economic Geology. University of Texas, Austin. n. p. 83, 57.

LANDIM, P. M. B. (1997). Análise estatística de dados geológicos. São Paulo, Fundação Editora da UNESP. 226 p.

LEWIS, W.; FOSTER, S.; DRASAR, B. (1982). O risco de poluição do lençol freático por sistemas de disposição local de esgotos. Local, MDU, PNUMA. 92 p.

LEWIS, W. J.; FOSTER, S. S. D.; DRASAR, B. S. (1988). Analisis de contaminación de las aguas subterráneas por sistemas de saneamiento basico. Lima, CEPIS, OPS/OMS. $82 \mathrm{p}$.

MARIOTTI, A. (1986). Denitrification in groundwater, principes and methods for its identification: a review. Journal of Hydrology. v. 88, n. 1-2, p. 1-23. 
MARIOTTI, A.; LANDREAU, A.; SIMON, B. (1988). ${ }^{15} \mathrm{~N}$ isotope biochemistry and natural denitrification process in groundwater: Application to the chalk aquifer of northern France. Geochimica Cosmochimica Acta, v. 52, p. 549-555.

MEZZALIRA, S.; SALATI, E.; MATSUI, E.; BOTELHO, P. F.; VIEIRA, P. C. (1979). Contribuição geoquímica ao estudo das águas da Formação Bauru na bacia do rio São José dos Dourados, SP. Anais da Academia Brasileira de Ciências. v. 51, n. 4, p. 677-694.

NOMMIK, H.; VAHTRAS, K. (1982). Nitrogen in Agricultural Soil. Agronomy, v. 22, p. $123-171$.

PALMÉR RIVERA, M. I. (2002). A numerical model as a tool to understand groundwater circulation in Urânia (SP, Brazil). Suécia, 143 p. (Dissertação Mestrado) - Universidade de Tecnologia de Luleå/Suécia. (em preparação).

PINO, F. A.; FRANCISCO, V. L. F. S. dos; TORES, A. J.; LORENA NETO B.; CASER D. V.; BIRAL M. A. M. de (1997). Levantamento Censitário de Unidades de Produção Agrícola do Estado de São Paulo. São Paulo: IEA, CATI, SAA. Ed. Imprensa Oficial. v. 4, 1936 p. (Projeto LUPA).

PREFEITURA MUNICIPAL DE URÂNIA (1988). Mapa Topográfica - Projeto Urbanístico. (Escala 1:1.000). Urânia.

RAPOSO, M. I. B. (1992). Paleomagnetismo do enxame de diques do Arco de Ponta Grossa. São Paulo, 104p. (Tese - Doutorado) - Instituto Astronômico e Geofísico, Universidade de São Paulo.

RIVERS, C. N.; BARRETT, M. H.; HISCOCK, K. M.; DENNIS, P. F.; FEAST, N. A.; LERNER, D. N. (1996). Use of Nitrogen Isotopes to Identify Nitrogen Contamination of the Sherwood Sandstone Aquifer beneath the City of Nottingham, United Kingdom. Hydrogeology Journal, v. 4, p. 90-102. 
ROBERTSON, W.; CHERYY, J. A.; SUDICKY, E.A. (1991). Groundwater contamination from two small septic systems on sand aquifers. Groundwater. v. 29, n. 1, p. 82-92.

ROBERTSON, W.; CHERRY, J. (1992). Hydrogeology of an unconfined sand aquifer and its effect on the behavior of nitrogen from a large-flux septic system. Apply Hydrogeology, v. 1, p.32-44.

ROCHA, G. A.; BERTACHINI, A. C.; CAMPOS, H. C. N. S.; CAIXETA, J. B. (1982). Tentativa de zoneamento das características hidráulicas e hidroquímicas do Aqüífero Bauru. In: ENCONTRO DE GEOLOGIA E HIDROGEOLOGIA DO GRUPO BAURU NO ESTADO DE SÃO PAULO, 1., São Paulo, 1981. São Paulo, SBG - Núcleo São Paulo/ABAS, p. 37-57.

ROSS, J. L. S.; MOROZ, I. C. (1997). Mapa Geomorfológico do Estado de São Paulo. Escala 1:500 000. São Paulo. Laboratório de Geomorfologia. Departamento de Geografia - FFLCH - USP/ Laboratório de Cartografia Geotécnica - IPT/ FAPESP. v. 2.

ROSSATO, F. (1999). Modelação Matemática Bidimensional na Definição de Zonas de Captura de Poços no Aqǘfero Adamantina, Município de Urânia, Noroeste do Estado de São Paulo. São Paulo, 40 p. (Trabalho de Formatura) Instituto de Geociências, Universidade de São Paulo.

SHMIDT, L. E. (1982). Nitrification in soil in Nitrogen in agricultural soils. . Wisconsin, American Society of Agronomy Inc., p. 253-283.

STARR, J. L.; SAWHNEY, B. L. (1980). Movement of nitrogen and carbon from a septic system drain field. Water, Air and Pollution. v. 13, n. 1, p. 113-123.

STUMM, W.; MORGAN, J. J. (1996). Aquatic chemistry. $3^{\text {a }}$ ed. New York, Wiley Interscience Publication. $1022 \mathrm{p}$. 
TALTASSE, P. (1968). Os fácies hidroquímicos no Estado de São Paulo. In: CONGRESSO BRASILEIRO DE GEOLOGIA, 22., Belo Horizonte, 1968. Anais. Belo Horizonte, SBG, v. 1, p. 263-266.

TEIXEIRA, W.; TOLEDO, M. C.; FAIRCHILD, T.; TAIOLI, F. (2000). Decifrando a Terra. São Paulo. Oficina de Textos. 568 p.

UNESCO - INTERNATIONAL HYDROLOGICAL PROGRAMME. Studies and Reports in Hydrology (2001). Groundwater Contamination Inventory: A Methodological Guideline. Paris, IHP-V Project 3.1. 257 p.

UNITED STATES ENVIRONMENTAL PROTECTION AGENCY (1994). Nitrogen Control (Manual). Lancaster, Technomic Publishing Company, USEPA. p. 35-36.

UNITED STATES ENVIRONMENTAL PROTECTION AGENCY (1995). Drinking water regulations and health advisories. USEPA. Disponivel em: http: www.epa.gov.

VARNIER, C. L. (2001). O efeito do nitrogênio proveniente de sistemas de saneamento in situ na qualidade das águas subterrâneas em aqüiferos livres $e$ rasos. São Paulo. São Paulo, 150 p. .(Dissertação - Mestrado) - Instituto de Geociências da Universidade de São Paulo.

VARNIER, C. L.; HIRATA, R. (2002). Contaminação da Água Subterrânea por Nitrato no Parque Ecológico do Tietê - São Paulo, Brasil. Revista da Associação Brasileira de Águas Subterrâneas, n. 16, p.77-82.

VIRARAGHAVAN, T.; WARNOCK, R.G. (1976). Groundwater quality adjacent to a septic tank system. Journal of the American Water Works Association, v. 11, n. 68 , p.611-614. 
WALKER, W.; BOUMA, J.; KEENEY, D.; OLCOTT, P. (1973). Nitrogen transformation during subsurface disposal of septic tank effluent in sands: II Groundwater quality. Journal of Environmental Quality. v. 2, p. 521-525.

WASSENAAR, L. I. (1995). Evaluation of the origin and fate of nitrate in the Abbottsford Aquifer using the isotopes of ${ }^{15} \mathrm{~N}$ and ${ }^{18} \mathrm{O}$ in $\mathrm{NO}_{3}{ }^{-}$. Applied Geochemistry, v. 10, p. 391-405.

WOODWARD, F.; KILPATRICK, F.; JOHNSON, P. (1961). Experiences with groundwater contamination in unsewered areas in Minnesota. American Journal of Public Health, v. 51, n. 8, p. 1130-1136.

YAMAMOTO, J. K. (2001). Curso: Geoestatística Aplicada. São Paulo, IGc. 76p. (apostila). 


\section{ANEXO 1}

Sumário dos resultados analíticos das amostras de água subterrânea 

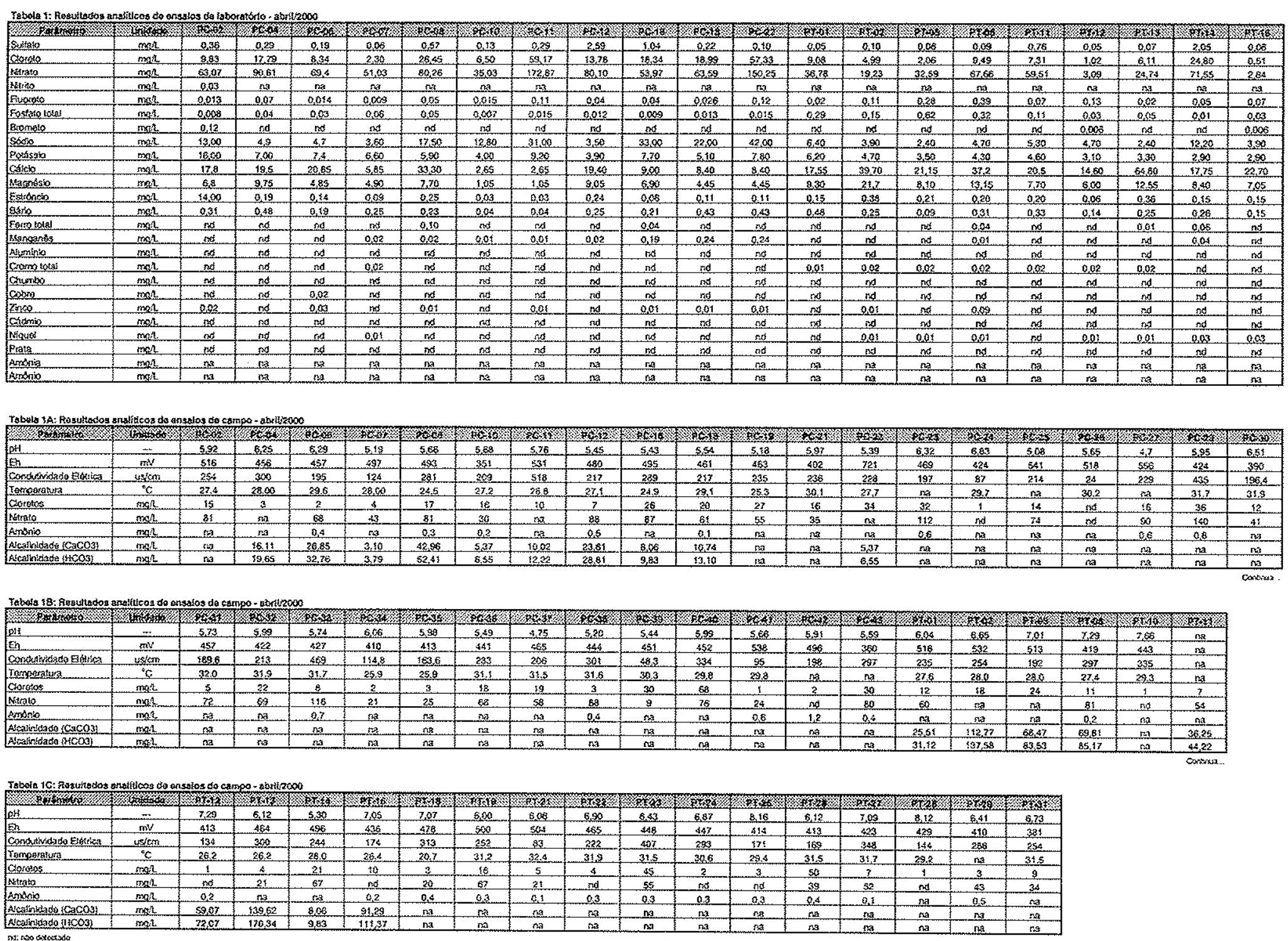


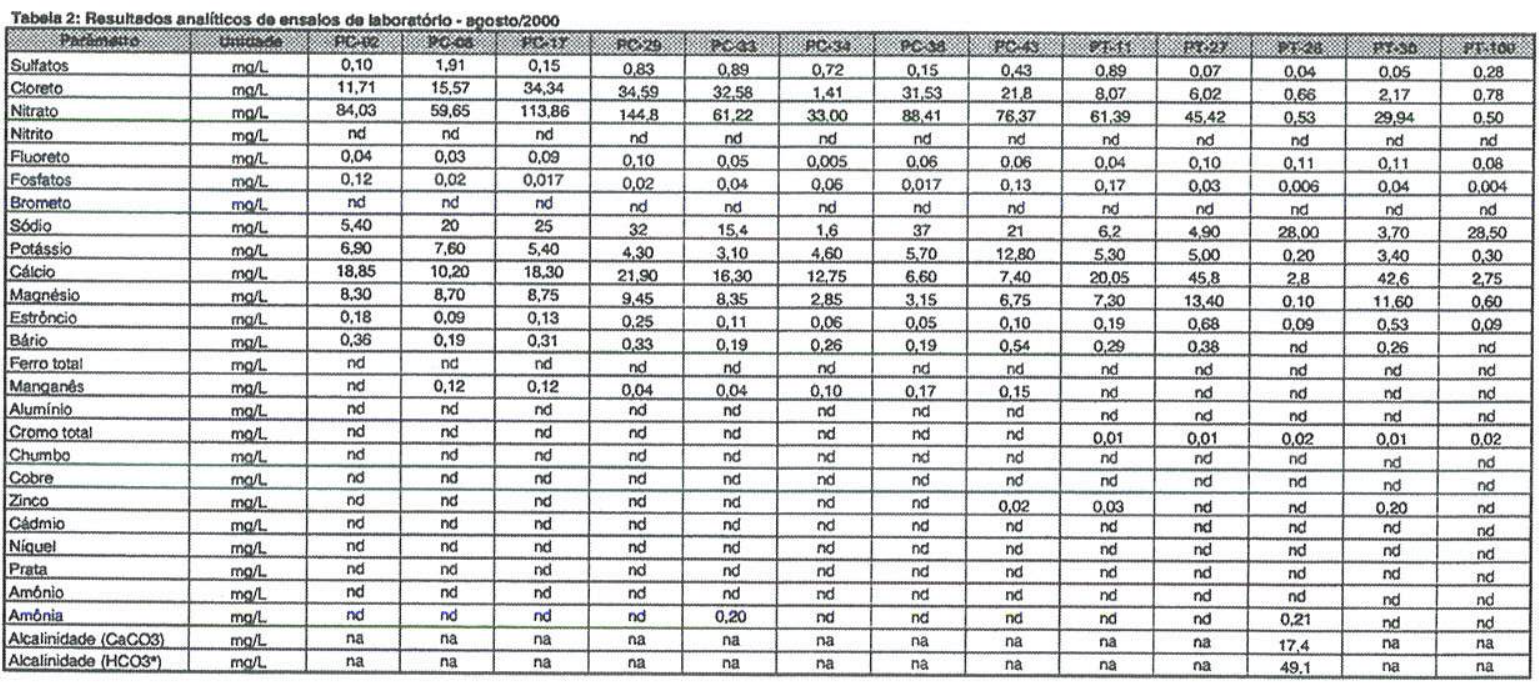
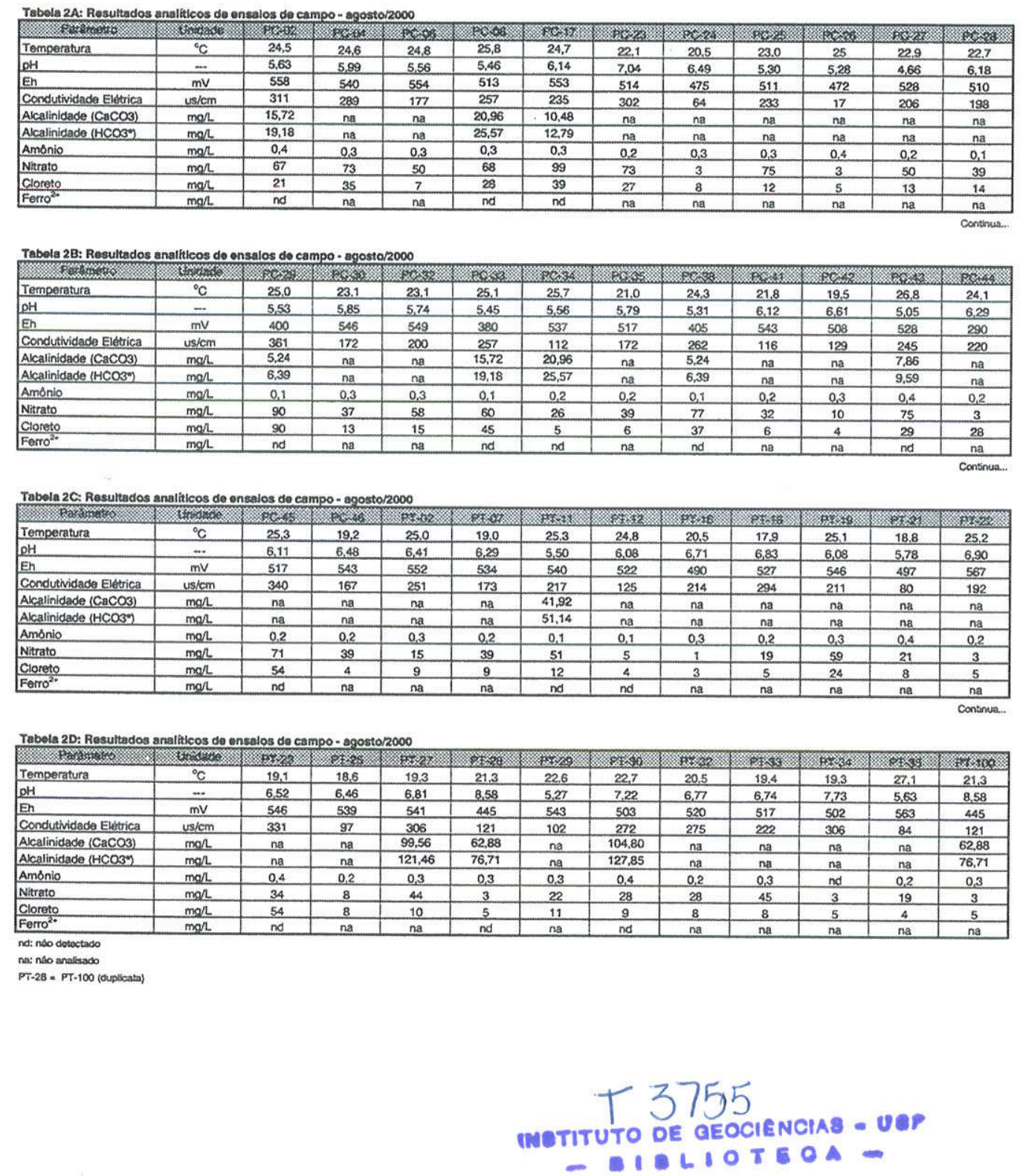

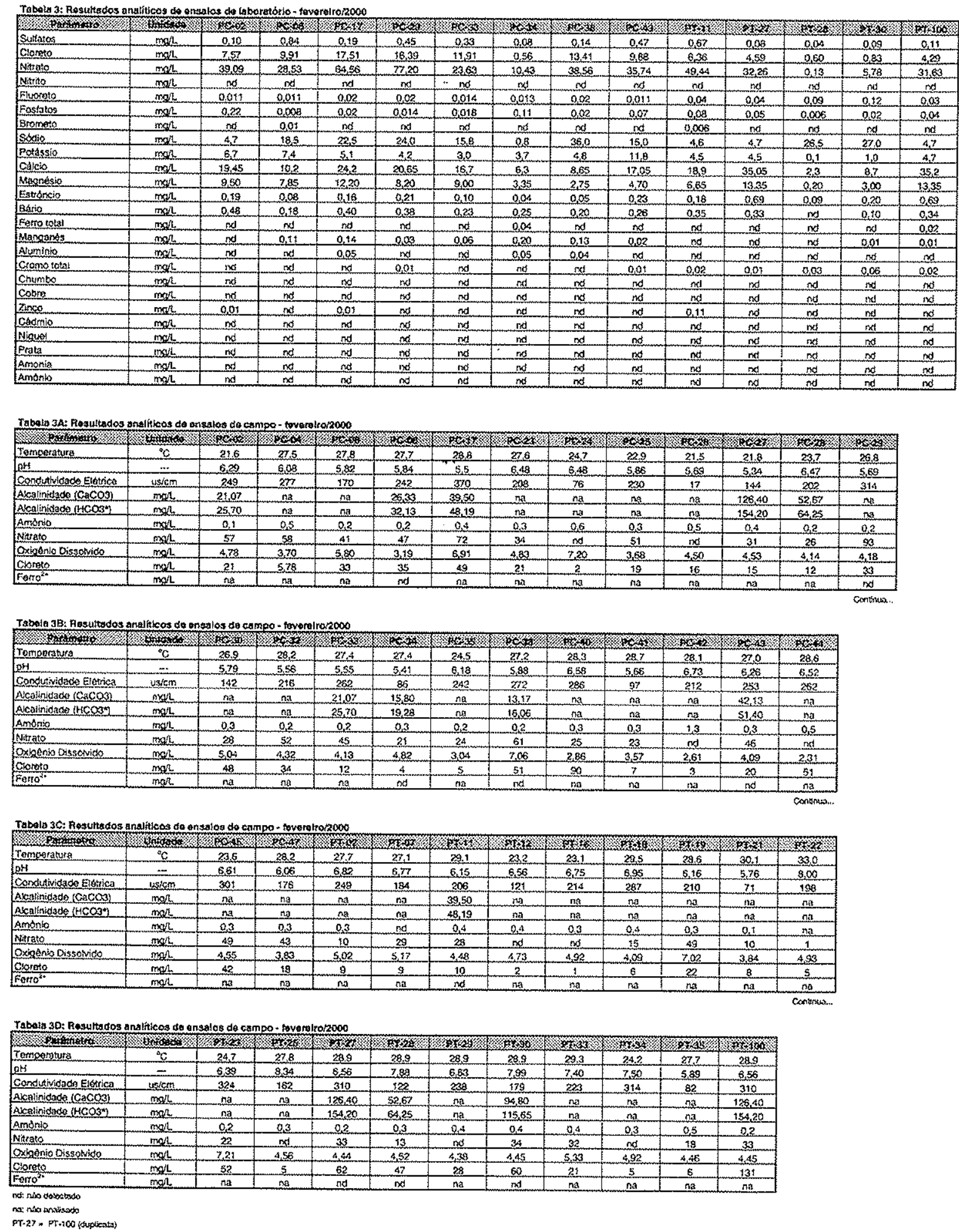

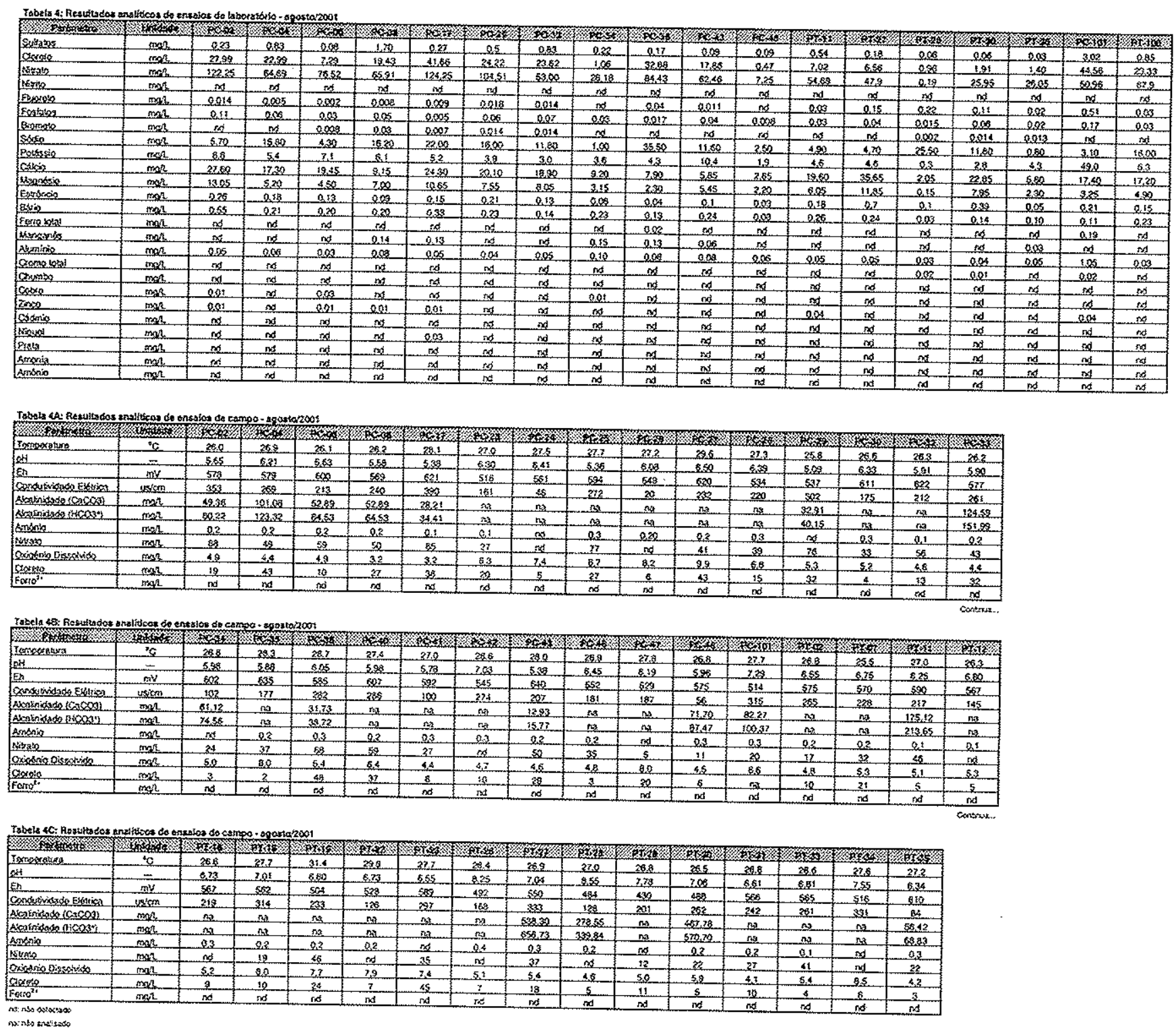

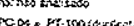




\begin{tabular}{|c|c|c|c|c|c|c|c|c|c|c|c|c|c|c|c|c|c|c|}
\hline Sulfatos & $\frac{\mathrm{m} g \mathrm{~L}}{\mathrm{~m}}$ & $\frac{1}{0.37}$ & 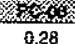 & 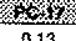 & 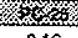 & 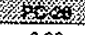 & 校 & 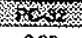 & 27. & 勧 & 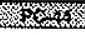 & 极 & אas & 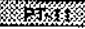 & 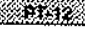 & 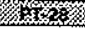 & 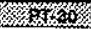 & 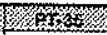 \\
\hline Closelo & $\frac{\mathrm{m} g \mathrm{~L}}{\mathrm{mg} / \mathrm{L}}$ & $\frac{0.37}{15,66}$ & 0.38 & 0.13 & 0.16 & 0,28 & 0.08 & 0.22 & 0.11 & 0.15 & 0.55 & 2,09 & 0.05 & 0.49 & 0.06 & 0,05 & 0,07 & 0.07 \\
\hline Nitralo & $\operatorname{mog} 2$ & 66.63 & $\begin{array}{l}5,35 \\
73.37 \\
\end{array}$ & $\begin{array}{l}34,04 \\
99.81 \\
\end{array}$ & $\frac{14.7}{111.7}$ & $\frac{0,41}{4,34}$ & $\frac{4.14}{48,69}$ & $\frac{13.76}{75,87}$ & $\frac{1.23}{32.04}$ & 32,14 & 0,36 & 27.83 & 5.53 & $-\frac{6,38}{6.037}$ & 1.14 & 0.95 & $\$, 15$ & 1.29 \\
\hline Nirito & $\mathrm{mol}$ & nd & $n d$ & nd & nd & 0.027 & nd & nd & $\begin{array}{l}32.04 \\
n d\end{array}$ & $\frac{82,49}{5 d}$ & $\frac{1.74}{.06}$ & 76,66 & 22.87 & 52,07 & 3.36 & 0.10 & 13.45 & 21,42 \\
\hline Fleoreto & $\mathrm{mgr}$ & 0.004 & 0,000 & 0.04 & 0.018 & nd & 0.005 & 0.013 & nd & $\begin{array}{l}\text { frd } \\
0,03 \\
\end{array}$ & nd & nd & $\frac{n d}{n+10}$ & nd & sd & nd & no & nid \\
\hline Fostatos & mgh & 46.63 & 0,093 & 0.023 & 0,017 & 0.12 & 0.011 & 0.02 & 0.012 & 0.014 & 0.03 & 0,08 & 0,10 & 0.04 & 0.16 & 0.13 & 0.09 & 0.012 \\
\hline Brometo & $\mathrm{mgl}$ & 0.009 & nd & nd & $n d$ & ind & 0,006 & $n d$ & & nd & $\frac{0.016}{0.006}$ & 0.015 & 0.03 & 0.011 & 0.014 & 0.013 & 0,02 & 0,007 \\
\hline Sódio & mol & $\hat{6}, 8$ & 4.9 & 22,5 & 17,5 & 2.2 & 2,8 & 3.9 & 1.0 & 390 & $\frac{0.008}{13.5}$ & 0.009 & 0.015 & ind & 0.003 & 0.004 & in & 0,005 \\
\hline Potássio & mor & 9.8 & 8.4 & 5.1 & 14,5 & 22 & 4.0 & 37 & 3.8 & 4,3 & $\frac{13.5}{2.0}$ & 23,0 & 3.9 & 5.1 & 4,6 & 27.0 & 19.5 & 1.0 \\
\hline Cáklo & $m g / L$ & 20.65 & 38,05 & 23.30 & 5.30 & 090 & 14,25 & 15.85 & & 7,10 & $\frac{2.0}{21.90}$ & 8.8 & 5,0 & 4,8 & 3.3 & 0.2 & 2.1 & 4.2 \\
\hline Magntísio & $\mathrm{mog}$ & 12,50 & 4,20 & 10.50 & 9,90 & 0,60 & 6,85 & & 3.25 & 2,20 & $\frac{21,90}{7.35}$ & 10.80 & 20.20 & 20.25 & 14.35 & 2.35 & 17,60 & 7.70 \\
\hline Estrôncio & $\mathrm{mgl}$ & 0,30 & 0,13 & 0,13 & 0.09 & nd & 0.18 & 0.00 & 0.04 & 0,04 & $\frac{7.35}{0.18}$ & 6,15 & 10,00 & 6,15 & 4,85 & 0.15 & 5.45 & 2.60 \\
\hline Bário & $\mathrm{migh}$ & 0.48 & 0.21 & 0.28 & 0,50 & 0.05 & 0.21 & 0.64 & 0.24 & 0.11 & 0.18 & 0,15 & 0.35 & 0.19 & 0.08 & 0,09 & 0.34 & 0.08 \\
\hline Eerrototal & $\mathrm{mgl}$ & nd & nid & nd & nd & rnd & nd & nd & nd & 0.03 & & 0.39 & 0.25 & 0.20 & 0,18 & nd & 0,11 & 0.18 \\
\hline Manganés & $\mathrm{m} g \mathrm{~h}$ & nd & nid & 0.15 & 0,19 & nnd & 0.03 & 0.05 & 0.21 & 0,11 & $\frac{\text { nd }}{0.77}$ & nd & $\mathrm{Ad}$ & $n d$ & nd & $n$ & 50 & nid \\
\hline Aluminio & malle & 0,04 & 0,04 & 0,05 & 0,09 & 0.05 & 0.04 & 0.04 & $0,0,06$ & $\frac{0.87}{0.06}$ & 0,17 & nd & nd & nd & ind & nd & $n d$ & 0.02 \\
\hline Cromo otolal & morl & nd & nd & nd & $\mathrm{nd}$ & nd & $n d$ & & $\frac{1,60}{n-1}$ & $\frac{0,06}{n d}$ & 0,03 & 0.03 & 0.04 & 0.08 & $n d$ & 0.03 & 0.05 & 0.08 \\
\hline Churnbo & moli & fid & nd & nd & nd & & nd & & ndf & for & nd & $n d$ & nd & nid & 0.01 & 0.02 & 0,02 & not \\
\hline Cobre & $\mathrm{mal}$ & $n \cdot d$ & 0.03 & $n \dot{n}$ & nd & nd & nd & no & nd & $\frac{n d}{n d}$ & nd & nd & nd & nd & $n d$ & nd & nd & nd \\
\hline Znco & $\mathrm{mgl}$ & 0.03 & 0.02 & $0.0 \mathrm{t}$ & 0.07 & $\frac{d}{n d}$ & nd & & 0,12 & $\frac{n d}{0.02}$ & nd & nd & 0.01 & nd & nod & nd & nd & nid \\
\hline Cádonio & $\mathrm{mgl}$ & nid & nd & nd & nd & $\frac{100}{n d}$ & $\begin{array}{l}n^{n} \\
\text { nd }\end{array}$ & $\frac{0.08}{n d}$ & no & $\frac{0.02}{n d}$ & nd & nd & 0.08 & 0.13 & nd & rad & nd & n. \\
\hline Niqual & $\mathrm{mglt}$ & $\mathrm{sid}$ & nd & $\mathrm{ind}$ & ind & nd & nd & ios & $n d$ & $\frac{n d}{n d}$ & nd & nd & ind & nd & ind & nd & $n d$ & nd \\
\hline Prala & mng $R$ & id & $n d$ & $n d$ & $n d$ & nod & is & nd & $\pi t^{\prime}$ & nd & nd & nd & $n d$ & nd & $n d$ & nd & $n$ & nd \\
\hline Amonia & $m g h$ & rod & $n d$ & nd & ind & ns & rod & $n d$ & not & nd & nd & nd & $n d$ & $n^{d}$ & nd & nd & $n d$ & nd \\
\hline Amónio & $\mathrm{mgl}$ & $m^{2}$ & $n d$ & $n d$ & $n d$ & 0.42 & ind & nd & nd & nd & nd & rid & nd & $\mathrm{rdf}$ & nd & nd & nid & $n d$ \\
\hline Carbono Org.Diss. $(\mathrm{COD})$ & $\operatorname{mag}$ & 0.70 & 0.46 & & & na & na & na & 0.32 & $\frac{\text { nd }}{\text { na }}$ & $\frac{\mathrm{mad}}{03}$ & nd & nd & nd & no & nd & nd & nd \\
\hline Nairogénilo orgâninico & $\mathrm{Bral}$ & 0,92 & 1.58 & 0.52 & 8.66 & nd & nd & 0,4 & 0.48 & $\frac{n a}{0.58}$ & $\frac{n a}{0,58}$ & $\frac{0.31}{0.58}$ & $\frac{\frac{m a}{1.72}}{1.72}$ & $\frac{0.26}{0,44}$ & $\frac{0,43}{1,62}$ & $\frac{\mathrm{na}}{1,72}$ & $\frac{0.43}{2.36}$ & $\frac{n a}{0,42}$ \\
\hline
\end{tabular}

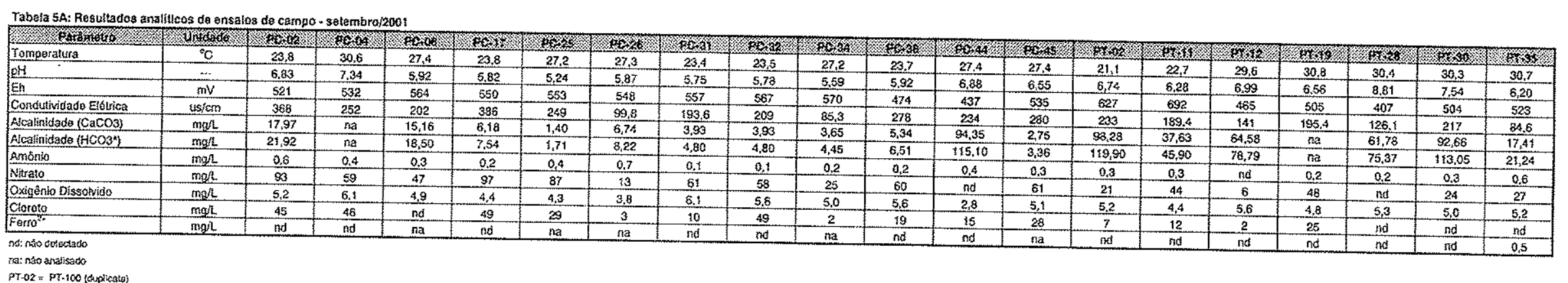




\section{ANEXO 2}

Cálculos dos percentuais de erros obtidos com o balanço iônico resultados obtidos em laboratório 
Tabela 1 - Balanço lônico - abril/00 (resultados de nitrato e cloreto medidos no laboratório)

\begin{tabular}{|c|c|c|c|c|c|c|c|c|c|c|c|c|c|c|c|c|c|c|c|c|}
\hline & Unidade & pero6 & Pe.on & 90.07 & PC. 08 & $p c-10$ & Pe-11 & $P O-12$ & $P C .16$ & PC-18 & $\mathrm{PC}-22$ & $81-01$ & PT-02 & PT-05 & PT -08 , & PT-1 1 & PT-12) & Pr-13) & PT-14] & Pr 16 \\
\hline calinidade & meq/L & 0,54 & 0,33 & 0,99 & 0,86 & 0,11 & 3,19 & 1,50 & 0,16 & 0,21 & 0,11 & 0,51 & 2,26 & 1,37 & 1,40 & 0,72 & 1,18 & 2,79 & 0,16 & 1,83 \\
\hline Sulfatos & meq/L & 0,00 & 0,01 & 0,00 & 0,01 & 0,00 & 0,01 & 0,05 & 0,02 & 0,00 & 0,00 & 0,00 & 0,00 & 0,00 & 0,00 & 0,02 & 0,00 & 0,00 & 0,04 & 0,00 \\
\hline Cloretos & meq/L & 0,24 & 0,50 & 0,06 & 0,75 & 0,18 & 1,67 & 0,39 & 0,52 & 0,54 & 1,62 & 0,26 & 0,14 & 0,06 & 0,27 & 0,21 & 0,03 & 0,17 & 0,70 & 0,01 \\
\hline Nitrato & $\mathrm{meq} / \mathrm{L}$ & 1,12 & 1,46 & 0,82 & 1,29 & 0,56 & 2,79 & 1,29 & 0,87 & 1,03 & 2,42 & 0,59 & 0,31 & 0,53 & 1,09 & 0,96 & 0,05 & 0,40 & 1,15 & 0,05 \\
\hline Nitrito & meq/L & 0,00 & 0,00 & 0,00 & 0,00 & 0,00 & 0,00 & 0,00 & 0,00 & 0,00 & 0,00 & 0,00 & 0,00 & 0,00 & 0,00 & 0,00 & 0,00 & 0,00 & 0,00 & 0,00 \\
\hline Fluoreto & $\mathrm{meq} / \mathrm{L}$ & 0,00 & 0,00 & 0,00 & 0,00 & 0,00 & 0,01 & 0,00 & 0,00 & 0,00 & 0,01 & 0,00 & 0,01 & 0,01 & 0,02 & 0,00 & 0,01 & 0,00 & 0,00 & 0,00 \\
\hline Fosfatos & meq/L. & 0,00 & 0,00 & 0,00 & 0,00 & 0,00 & 0,00 & 0,00 & 0,00 & 0,00 & 0,00 & 0,01 & 0,00 & 0,02 & 0,01 & 0,00 & 0,00 & 0,00 & 0,00 & 0,00 \\
\hline Brometo & $\mathrm{meq} / \mathrm{L}$ & 0,00 & 0,00 & 0,00 & 0,00 & 0,00 & 0,00 & 0,00 & 0,00 & 0,00 & 0,00 & 0,00 & 0,00 & 0,00 & 0,00 & 0,00 & 0,00 & 0,00 & 0,00 & 0,00 \\
\hline Sódio & meq/L. & 0,20 & 0,21 & 0,16 & 0,76 & 0,56 & 1,35 & 0,15 & 1,44 & 0,96 & 1,83 & 0,28 & 0,17 & 0,10 & 0,20 & 0,23 & 0,20 & 0,10 & 0,53 & 0,17 \\
\hline Potássio & $\mathrm{meq} / \mathrm{L}$ & 0,19 & 0,18 & 0,17 & 0,15 & 0.10 & 0.24 & 0.10 & 0,20 & 0,13 & 0,20 & 0,16 & 0,12 & 0,09 & 0,11 & 0,12 & 0,08 & 0,08 & 0,07 & 0,07 \\
\hline Cálcio & meq/L & 1,04 & 0,97 & 0,29 & 1,66 & 0,13 & 0,13 & 0,97 & 0,45 & 0,42 & 0,42 & 0,88 & 1,98 & 1,06 & 1,86 & 1,02 & 0,73 & 3,23 & 0,89 & 1,13 \\
\hline Magnésio & $\mathrm{meq} / \mathrm{L}$ & 0,40 & 0,80 & 0,40 & 0,63 & 0,09 & 0,09 & 0,74 & 0,57 & 0,37 & 0,37 & 0,77 & 1,79 & 0,67 & 1,08 & 0,63 & 0,49 & 1,03 & 0,69 & 0,58 \\
\hline Estrôncio & $\mathrm{meq} / \mathrm{L}$ & 0,00 & 0,00 & 0,00 & 0,01 & 0,00 & 0,00 & 0,01 & 0,00 & 0,00 & 0,00 & 0,00 & 0,01 & 0,00 & 0,00 & 0,00 & 0,00 & 0,01 & 0,00 & 0,00 \\
\hline Bário & $m e q / L$ & 0,00 & 0,01 & 0,00 & 0,00 & 0,00 & 0,00 & 0,00 & 0,00 & 0,01 & 0,01 & 0,01 & 0,00 & 0,00 & 0,00 & 0,00 & 0,00 & 0,00 & 0,00 & 0,00 \\
\hline Ferro total & $\mathrm{meq} / \mathrm{L}$ & 0,00 & 0,00 & 0,00 & 0,01 & 0,00 & 0,00 & 0,00 & 0,00 & 0,00 & 0,00 & 0,00 & 0,00 & 0,00 & 0,00 & 0,00 & 0,00 & 0,00 & 0,00 & 0,00 \\
\hline Manganês & meq/L & 0,00 & 0,00 & 0,00 & 0,00 & 0.00 & 0,00 & 0,00 & 0,01 & 0,01 & 0,01 & 0,00 & 0,00 & 0,00 & 0,00 & 0,00 & 0,00 & 0,00 & 0,00 & 0,00 \\
\hline Aluminio & meq/L & 0,00 & 0,00 & 0,00 & 0,00 & 0,00 & 0,00 & 0,00 & 0,00 & 0,00 & 0,00 & 0,00 & 0,00 & 0,00 & 0,00 & 0,00 & 0,00 & 0,00 & 0,00 & 0,00 \\
\hline Cromo total & $\mathrm{meq} / \mathrm{L}$ & 0,00 & 0,00 & 0,00 & 0,00 & 0,00 & 0,00 & 0,00 & 0,00 & 0,00 & 0,00 & 0,00 & 0,00 & 0,00 & 0,00 & 0,00 & 0,00 & 0,00 & 0,00 & 0,00 \\
\hline Chumbo & meq/L & 0,00 & 0,00 & 0,00 & 0,00 & 0,00 & 0,00 & 0,00 & 0,00 & 0,00 & 0,00 & 0,00 & 0,00 & 0,00 & 0,00 & 0,00 & 0,00 & 0,00 & 0,00 & 0,00 \\
\hline Cobre & $\mathrm{meq} / \mathrm{L}$ & 0,00 & 0,00 & 0,00 & 0,00 & 0,00 & 0,00 & 0,00 & 0,00 & 0,00 & 0,00 & 0,00 & 0,00 & 0,00 & 0,00 & 0,00 & 0,00 & 0,00 & 0,00 & 0,00 \\
\hline Zinco & $\mathrm{meq} / \mathrm{L}$ & 0,00 & 0,00 & 0,00 & 0,00 & 0,00 & 0,00 & 0,00 & 0,00 & 0,00 & 0,00 & 0,00 & 0,00 & 0,00 & 0,00 & 0,00 & 0,00 & 0,00 & 0,00 & 0,00 \\
\hline Cádmio & $\mathrm{meq} / \mathrm{L}$ & 0,00 & 0,00 & 0,00 & 0,00 & 0,00 & 0,00 & 0,00 & 0,00 & 0,00 & 0,00 & 0,00 & 0,00 & 0,00 & 0,00 & 0,00 & 0,00 & 0,00 & 0,00 & 0,00 \\
\hline Níquel & meq/L & 0,00 & 0,00 & 0,00 & 0,00 & 0,00 & 0,00 & 0,00 & 0,00 & 0,00 & 0,00 & 0,00 & 0,00 & 0,00 & 0,00 & 0,00 & 0,00 & 0,00 & 0,00 & 0,00 \\
\hline Prata & meq/L. & 0,00 & 0,00 & 0,00 & 0,00 & 0,00 & 0,00 & 0,00 & 0,00 & 0,00 & 0,00 & 0,00 & 0,00 & 0,00 & 0,00 & 0,00 & 0,00 & 0,00 & 0,00 & 0,00 \\
\hline $\begin{array}{l}\text { SOMA } \\
\text { CÁTIONS }\end{array}$ & $\mathrm{meq} / \mathrm{L}$ & 1,84 & 2,18 & 1,03 & 3,22 & 0,88 & 1,80 & 1,97 & 2,66 & 1,89 & 2,83 & 2,09 & 4,07 & 1,92 & 3,27 & 2,02 & 1,51 & 4,47 & 2,19 & 1,96 \\
\hline $\begin{array}{l}\text { SOMA } \\
\text { ÂNIONS } \\
\end{array}$ & meq/L & 1,90 & 2,31 & 1,88 & 2,92 & 0,86 & 7,66 & 3,24 & 1,57 & 1,78 & 4,16 & 1,37 & 2,72 & 1,99 & 2,79 & 1,91 & 1,27 & 3,37 & 2,06 & 1,89 \\
\hline Somat6ria & meq/L. & 3,74 & 4,49 & 2,91 & 6,14 & 1,74 & 9,46 & 5,21 & 4,24 & 3,67 & 6,99 & 3,46 & 6,79 & 3,91 & 6,06 & 3,93 & 2,78 & 7,84 & 4,25 & 3,85 \\
\hline $\begin{array}{l}\text { DESVIO } \\
\text { PADRÄO/ } \\
\text { ERRO }\end{array}$ & $(\%)$ & $-1,51$ & $-2,87$ & $-29,28$ & 5,00 & 1,15 & $-61,37$ & $-24,28$ & 25,74 & 2,94 & $-19,00$ & 20.76 & $\$ 9.90$ & $-1,67$ & 7,94 & 2,58 & 8,70 & 14,05 & 3,15 & 1,84 \\
\hline
\end{tabular}

Continua... 
Tabela 1 A - Balanço lônico - agosto/2000 (resultados de nitrato e cloreto medidos no laboratório)

\begin{tabular}{|c|c|c|c|c|c|c|c|c|c|c|c|c|c|}
\hline & Inidacere & PC. & $20-08$ & 2017 & $p c_{2}-2$ & $\mathrm{PC}-3$ & $\mathrm{PC} 34$. & 180.8 & $\mathrm{Pq}-48$ & $\mathrm{r}^{\mathrm{T}} \mathrm{T}$ & 7127 & $p 7+28$ & Ptra \\
\hline Alcalinidade & meq/L & 0,31 & 0,42 & 0,21 & 0,10 & 0,31 & 0,42 & 0,10 & 0,16 & 0,84 & 1,99 & 1,26 & 2,10 \\
\hline Sulfato & $\mathrm{meq} / \mathrm{L}$ & 0,01 & 0,04 & 0,00 & 0,02 & 0,02 & 0,01 & 0,00 & 0,01 & 0,02 & 0,00 & 0,00 & 0,00 \\
\hline Cloreto & meq/L & 0,33 & 0,44 & 0,97 & 0,98 & 0,92 & 0,04 & 0,89 & 0,61 & 0,23 & 0,17 & 0,02 & 0,06 \\
\hline Nitrato & meq/L & 1,36 & 0,96 & 1,84 & 2,34 & 0,99 & 0,53 & 1,43 & 1,23 & 0,99 & 0,73 & 0,01 & 0,48 \\
\hline Nitrito & meqlh & 0,00 & 0,00 & 0,00 & 0,00 & 0,00 & 0,00 & 0,00 & 0,00 & 0,00 & 0,00 & 0,00 & 0,00 \\
\hline Fluoreto & meq/L & 0,00 & 0,00 & 0,00 & 0,01 & 0,00 & 0,00 & 0,00 & 0,00 & 0,00 & 0,01 & 0,01 & 0,01 \\
\hline Fosfatos & meq/L & 0,00 & 0,00 & 0,00 & 0,00 & 0,00 & 0,00 & 0,00 & 0,00 & 0,01 & 0,00 & 0,00 & 0,00 \\
\hline Brometo & meqh & 0,00 & 0,00 & 0,00 & 0,00 & 0,00 & 0,00 & 0,00 & 0,00 & 0,00 & 0,00 & 0,00 & 0,00 \\
\hline Sódio & meq/L & 0,23 & 0,87 & 1,09 & 1,39 & 0,67 & 0,07 & 1,61 & 0,91 & 0,27 & 0,21 & 1,22 & 0,16 \\
\hline Potássio & meq/h & 0,18 & 0,19 & 0,14 & 0,11 & 0,08 & 0,12 & 0,15 & 0,33 & 0,14 & 0,13 & 0,01 & 0,09 \\
\hline Cálcio & meql & 0,94 & 0,51 & 0,91 & 1,09 & 0,81 & 0,64 & 0,33 & 0,37 & 1,00 & 2,29 & 0,14 & 2,13 \\
\hline Magnésio & meq/L & 0,68 & 0,72 & 0,72 & 0,78 & 0,69 & 0,23 & 0,26 & 0,56 & 0,60 & 1,10 & 0,01 & 0,95 \\
\hline Esstrôncio & $\mathrm{meq} / \mathrm{L}$ & 0,00 & 0,00 & 0,00 & 0,01 & 0,00 & 0,00 & 0,00 & 0,00 & 0,00 & 0,02 & 0,00 & 0,01 \\
\hline Bário & meq/L & 0,01 & 0,00 & 0,00 & 0,00 & 0,00 & 0,00 & 0,00 & 0,01 & 0,00 & 0,01 & 0,00 & 0,00 \\
\hline Ferro total & meq/L & 0,00 & 0,00 & 0,00 & 0,00 & 0,00 & 0,00 & 0,00 & 0,00 & 0,00 & 0,00 & 0,00 & 0,00 \\
\hline Manganês & meq/L & 0,00 & 0,00 & 0,00 & 0,00 & 0,00 & 0,00 & 0,01 & 0,01 & 0,00 & 0,00 & 0,00 & 0,00 \\
\hline Alumínio & meq/h. & 0,00 & 0,00 & 0,00 & 0,00 & 0,00 & 0,00 & 0,00 & 0,00 & 0,00 & 0,00 & 0,00 & 0,00 \\
\hline Cromo total & meq/L & 0,00 & 0,00 & 0,00 & 0,00 & 0,00 & 0,00 & 0,00 & 0,00 & 0,00 & 0,00 & 0,00 & 0,00 \\
\hline Chumbo & meq/L & 0,00 & 0,00 & 0,00 & 0,00 & 0,00 & 0,00 & 0,00 & 0,00 & 0,00 & 0,00 & 0,00 & 0,00 \\
\hline Cobre & meq/ & 0,00 & 0,00 & 0,00 & 0,00 & 0,00 & 0,00 & 0,00 & 0,00 & 0,00 & 0,00 & 0,00 & 0,00 \\
\hline Zinco & mea/l & 0,00 & 0,00 & 0,00 & 0,00 & 0,00 & 0,00 & 0,00 & 0,00 & 0,00 & 0,00 & 0,00 & 0,01 \\
\hline Amônio & mea $/ \mathrm{L}$ & 0,00 & 0,00 & 0,00 & 0,00 & 0,00 & 0,00 & 0,00 & 0,00 & 0,00 & 0,00 & 0,00 & 0,00 \\
\hline SOMA CÁTIONS & meq/ & 2,04 & 2,30 & 2,87 & 3,38 & 2,26 & 1,07 & 2,35 & 2,18 & 2,02 & 3,75 & 1,37 & 3,35 \\
\hline SOMA ÂNIONS & meq/L. & 2,01 & 1,86 & 3,02 & 3,44 & 2,24 & 1,01 & 2,43 & 2,02 & 2,08 & 2,90 & 1,29 & 2,65 \\
\hline Somatória & meq $/ L$ & 4,06 & 4,16 & 5,89 & 6,82 & 4,50 & 2,07 & 4,78 & 4,20 & 4,10 & 6,65 & 2,67 & 6,00 \\
\hline $\begin{array}{l}\text { DESVIO PADRÃO/ } \\
\text { ERRO }\end{array}$ & $(\%)$ & 0,77 & 10,48 & $-2,58$ & 0,80 & 0,29 & 2,82 & $-1,53$ & 3,85 & $-1,60$ & 12,78 & 3,12 & 11,72 \\
\hline
\end{tabular}


Tabela 1B - Balanço lónico - fevereiro/2001 (resultados para nitrato e cloreto medidos no laboratório)

\begin{tabular}{|c|c|c|c|c|c|c|c|c|c|c|c|c|}
\hline & Unidaco & poor & 200.08 & 30.17 & poss & $p 0 \% 4$ & $\mathrm{pos}_{3} \mathrm{x}$ & fro-4. & (2.1.1. & $P T 27$ & $\rho 7<26$ & PI: 86 \\
\hline Alcalinidade & meq/L. & 0,42 & 0,53 & 0,79 & 0,42 & 0,32 & 0,26 & 0,84 & 0,79 & 2,53 & 1,05 & 1,90 \\
\hline Sulfatos & meq/L & 0,00 & 0,02 & 0,00 & 0,01 & 0,00 & 0,00 & 0,01 & 0,00 & 0,00 & 0,00 & 0,00 \\
\hline Cloretos & mea/l & 0,21 & 0,28 & 0,49 & 0,34 & 0,02 & 0,38 & 0,28 & 0,00 & 0,13 & 0,02 & 0,02 \\
\hline Nitrato & meadh & 0,63 & 0,46 & 1,04 & 0,38 & 0,17 & 0,62 & 0,58 & 0,80 & 0,52 & 0,00 & 0,09 \\
\hline Nitrito & meqL & 0,00 & 0,00 & 0,00 & 0,00 & 0,00 & 0,00 & 0,00 & 0,00 & 0,00 & 0,00 & 0,00 \\
\hline Fluoreto & meq/L & 0,00 & 0,00 & 0,00 & 0,00 & 0,00 & 0,00 & 0,00 & 0,00 & 0,00 & 0,00 & 0,01 \\
\hline Fosfatos & meq/L & 0,01 & 0,00 & 0,00 & 0,00 & 0,00 & 0,00 & 0,00 & 0,00 & 0,00 & 0,00 & 0,00 \\
\hline Brometo & meq/h & 0,00 & 0,00 & 0,00 & 0,00 & 0,00 & 0,00 & 0,00 & 0,00 & 0,00 & 0,00 & 0,00 \\
\hline Sódio & meqL & 0,20 & 0,80 & 0,98 & 0,69 & 0,03 & 1,57 & 0,65 & 0,20 & 0,20 & 1,15 & 1,17 \\
\hline Potássio & mea/h & 0,17 & 0,19 & 0,13 & 0,08 & 0,09 & 0,12 & 0,30 & 0,08 & 0,12 & 0,00 & 0,03 \\
\hline Cálcio & mea/h & 0,97 & 0,51 & 1,21 & 0,83 & 0,31 & 0,43 & 0,85 & 0,94 & 1,75 & 0,11 & 0,43 \\
\hline Magnésio & meq/L & 0,78 & 0,65 & 1,00 & 0,74 & 0,28 & 0,23 & 0,39 & 0,55 & 1,10 & 0,02 & 0,25 \\
\hline Estrôncio & meq/L & 0,00 & 0,00 & 0,00 & 0,00 & 0,00 & 0,00 & 0,01 & 0,00 & 0,02 & 0,00 & 0,00 \\
\hline Bário & meqll. & 0,01 & 0,00 & 0,01 & 0,00 & 0,00 & 0,00 & 0,00 & 0,01 & 0,00 & 0,00 & 0,00 \\
\hline Ferro total & meqh & 0,00 & 0,00 & 0,00 & 0,00 & 0,00 & 0,00 & 0,00 & 0,00 & 0,00 & 0,00 & 0,00 \\
\hline Manganês & meq/L & 0,00 & 0,00 & 0,01 & 0,00 & 0,01 & 0,00 & 0,00 & 0,00 & 0,00 & 0,00 & 0,00 \\
\hline Alumínio & meq/L & 0,00 & 0,00 & 0,01 & 0,00 & 0,01 & 0,00 & 0,00 & 0,00 & 0,00 & 0,00 & 0,00 \\
\hline Cromo total & meq/L & 0,00 & 0,00 & 0,00 & 0,00 & 0,00 & 0,00 & 0,00 & 0,00 & 0,00 & 0,00 & 0,00 \\
\hline Chumbo & meq/L & 0,00 & 0,00 & 0,00 & 0,00 & 0,00 & 0,00 & 0,00 & 0,00 & 0,00 & 0,00 & 0,00 \\
\hline Cobre & meq/L & 0,00 & 0,00 & 0,00 & 0,00 & 0,00 & 0,00 & 0,00 & 0,00 & 0,00 & 0,00 & 0,00 \\
\hline Zinco & meq/L. & 0,00 & 0,00 & 0,00 & 0,00 & 0,00 & 0,00 & 0,00 & 0,00 & 0,00 & 0,00 & 0,00 \\
\hline Amônio & meq/L. & 0,00 & 0,00 & 0,00 & 0,00 & 0,00 & 0,00 & 0,00 & 0,00 & 0,00 & 0,00 & 0,00 \\
\hline SOMA CÁTIONS & mea/l & 2,14 & 2,16 & 3,34 & 2,35 & 0,74 & 2,36 & 2,20 & 1,79 & 3,19 & 1,29 & 1,89 \\
\hline SOMA ÂNIONS & $\mathrm{meq} / \mathrm{h}$ & 1,27 & 1,28 & 2,33 & 1,15 & 0,51 & 1,27 & 1,71 & 1,59 & 3,18 & 1,08 & 2,02 \\
\hline Somatória & meq/L & 3,41 & 3,44 & 5,67 & 3,49 & 1,24 & 3,63 & 3,91 & 3,38 & 6,37 & 2,37 & 3,91 \\
\hline $\begin{array}{l}\text { DESVIO } \\
\text { PADRÃO/ERRO }\end{array}$ & (\%) & 25,33 & 25,36 & 17,82 & 34,34 & 38,74 & 30.10 & 2,58 & 5,82 & 0,09 & 8,97 & $-3,32$ \\
\hline
\end{tabular}


Tabela 1C - Balanço lônico - agosto/2001 (resultados de nitrato e cloreto medidos no laboratório)

\begin{tabular}{|c|c|c|c|c|c|c|c|c|c|c|c|c|c|c|c|c|c|c|}
\hline & londorod & 18802 & 1000 & secos & 18008 & for & $\sqrt{1.29}$ & 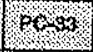 & (20) & recos & 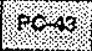 & 17048 & 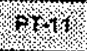 & prot? & Tro & 17730 & Plos & $97-100$ \\
\hline Alcalinidade & meq/L & 0,99 & 2,02 & 0,59 & 0,73 & 0,56 & 0,66 & 2,49 & 1,22 & 0,63 & 0,26 & 0,49 & 3,45 & 1,08 & 0,56 & 0.77 & 0,66 & 1,64 \\
\hline Sullatos & meq $/ \mathrm{h}$ & 0,00 & 0,02 & 0,00 & 0,04 & 0,01 & 0,01 & 0.02 & 0,00 & 0,00 & 0.00 & 0,00 & 0,01 & 0.00 & 0,00 & 0,00 & 0,00 & 0.06 \\
\hline Cloretos & meq/L & 0,79 & 0,65 & 0,21 & 0,55 & 1,18 & 0,68 & 0,67 & 0,03 & 0,93 & 0,50 & 0.01 & 0,20 & 0.19 & 0,03 & 0,05 & 0,04 & 1.26 \\
\hline Nitrato & meq/L & 1,97 & 1,04 & 1,23 & 1,06 & 2,00 & 1.69 & 0,85 & 0,45 & 1.36 & 1,01 & 0,12 & 0,89 & 0,77 & 0,00 & 0.42 & 0.42 & 0,82 \\
\hline Nitrito & $\mathrm{meg} / \mathrm{h}$ & 0,00 & 0,00 & 0,00 & 0.00 & 0,00 & 0.00 & 0,00 & 0,00 & 0,00 & 0,00 & 0.00 & 0,00 & 0,00 & 0,00 & 0,00 & 0,00 & 0,00 \\
\hline Fluoreto & meq/L. & 0,00 & 0,00 & 0,00 & 0,00 & 0,00 & 0.00 & 0,00 & 0,00 & 0,00 & 0,00 & 0.00 & 0,00 & 0,01 & 0,01 & 0.01 & 0,00 & 0,03 \\
\hline Fosfatos & $\mathrm{meq} / \mathrm{L}$ & 0,00 & 0,00 & 0,00 & 0,00 & 0,00 & 0,00 & 0,00 & 0,00 & 0.00 & 0,00 & 0,00 & 0.00 & 0,00 & 0,00 & 0,00 & 0,00 & 0,01 \\
\hline Brometo & mea/h. & 0,00 & 0,00 & 0,00 & 0,00 & 0,00 & 0,00 & 0.00 & 0,00 & 0,00 & 0.00 & 0.00 & 0,00 & 0,00 & 0.00 & 0.00 & 0,00 & 0,00 \\
\hline S6rdio & meq/L & 0,25 & 0,69 & 0,19 & 0,70 & 0,96 & 0,70 & 0.51 & 0,04 & 1,54 & 0,50 & 0,11 & 0.21 & 0,20 & 1.11 & 0,51 & 0,03 & 0.13 \\
\hline Potássio & meq/h & 0,23 & 0,14 & 0,18 & 0,16 & 0,13 & 0,10 & 0,08 & 0,09 & 0,11 & 0,27 & 0.05 & 0,12 & 0,12 & 0,01 & 0.07 & 0,11 & 1,25 \\
\hline Cálcio & $\mathrm{meq} / \mathrm{L}$ & 1,38 & 0,86 & 0,97 & 0,46 & $t, 21$ & 1,00 & 0,94 & 0,46 & 0,39 & 0.29 & 0,13 & 0,98 & 1,78 & 0,10 & 1,14 & 0,29 & 0,87 \\
\hline Magnésio & $\mathrm{meq} / \mathrm{L}$ & 1,07 & 0,43 & 0,37 & 0,58 & 0,88 & 0.62 & 0,66 & 0,26 & 0.19 & 0.45 & 0,18 & 0.50 & 0.97 & 0,01 & 0,65 & 0.10 & 0,27 \\
\hline Estrôncio & meq/L. & 0,01 & 0,00 & 0,00 & 0,00 & 0,00 & 0,00 & 0,00 & 0,00 & 0,00 & 0,00 & 0,00 & 0,00 & 0,02 & 0,00 & 0,01 & 0,00 & 0,00 \\
\hline Bário & meq/L. & 0,01 & 0,00 & 0,00 & 0,00 & 0,00 & 0,00 & 0,00 & 0.00 & 0,00 & 0,00 & 0,00 & 0,00 & 0,00 & 0.00 & 0,00 & 0.00 & 0,00 \\
\hline Ferro total & meq/L & 0,00 & 0,00 & 0,00 & 0,00 & 0,00 & 0,00 & 0,00 & 0,00 & 0,00 & 0,00 & 0,00 & 0,00 & 0,00 & 0,00 & 0,00 & 0,00 & 0,01 \\
\hline Mariganês & meq/L & 0,00 & 0,00 & 0,00 & 0,01 & 0.00 & 0,00 & 0,00 & 0.01 & 0,00 & 0,00 & 0,00 & 0,00 & 0,00 & 0,00 & 0.00 & 0,00 & 0,00 \\
\hline Aluminio & meq/h & 0,01 & 0,01 & 0,00 & 0,01 & 0,01 & 0,00 & 0,01 & 0,01 & 0,01 & 0.01 & 0.01 & 0.01 & 0,01 & 0,00 & 0,04 & 0,01 & 0.12 \\
\hline Cromo total & $\mathrm{meq} / \mathrm{L}$ & 0,00 & 0,00 & 0,00 & 0,00 & 0,00 & 0,00 & 0,00 & 0,00 & 0,00 & 0,00 & 0,00 & 0.00 & 0,00 & 0,00 & 0.01 & 0,00 & 0,00 \\
\hline Chumbo & meq/L & 0,00 & 0,00 & 0,00 & 0,00 & 0,00 & 0,00 & 0.00 & 0.00 & 0,00 & 0,00 & 0.00 & 0,00 & 0,00 & 0,00 & 0,00 & 0,00 & 0,00 \\
\hline Cobre & meq/L & 0,00 & 0,00 & 0,00 & 0,00 & 0.00 & 0,00 & 0,00 & 0,00 & 0,00 & 0,00 & 0,00 & 0,00 & 0,00 & 0,00 & 0,00 & 0,00 & 0,00 \\
\hline Zinco & meq/L & 0,00 & 0,00 & 0,00 & 0,00 & 0,00 & 0,00 & 0,00 & 0,00 & 0,00 & 0,00 & 0,00 & 0,00 & 0,00 & 0.00 & 0,00 & 0.00 & 0,00 \\
\hline Amônio & meq/L & 0,00 & 0,00 & 0,00 & 0,00 & 0,00 & 0,00 & 0,00 & 0,00 & 0,00 & 0,00 & 0,00 & 0,00 & 0,00 & 0,00 & 0,00 & 0,00 & 0,00 \\
\hline $\begin{array}{l}\text { SOMA } \\
\text { CÁTIONS }\end{array}$ & meq/L & 2,94 & 2,13 & 1,72 & 1,91 & 3.20 & 2,43 & 2,21 & 0,88 & 2,25 & 1.53 & 0,48 & 1,82 & 3.10 & 1.24 & 2,44 & 0.63 & 2.66 \\
\hline $\begin{array}{l}\text { SOMA } \\
\text { ÂNIONS }\end{array}$ & meq/L & 3,76 & 3,73 & 2,03 & 2,38 & 3,75 & 3,04 & 4.03 & 1,71 & 2,93 & 1,77 & 0,63 & 4,55 & 2,05 & 0,60 & 1,25 & 1,12 & 3,82 \\
\hline Somatória & meq/L & 6,70 & 5,86 & 3,75 & 4,29 & 6,95 & 5,47 & 6,24 & 2.59 & 5.18 & 3,30 & 1,10 & 6.37 & 5.15 & 1,84 & 3,69 & 1,75 & 6.48 \\
\hline $\begin{array}{l}\text { DESVIO } \\
\text { PADRÄO/ } \\
\text { ERRO }\end{array}$ & (\%) & $|-12,13|$ & $|27,32|$ & $-8,27 \mid$ & $|-10,84|$ & $.7,94$ & $-41,10$ & $-79,28$ & 32,30 & -13.003 & $-7,44$ & -13.28 & $.6 \% 84$ & 20,48 & $3 A, Z 1$ & 32,32 & ats. & $\cdot 17, \infty 0$ \\
\hline
\end{tabular}


Tabela 1D - Balanço lônico - setembro/2001 (resultados de nitrato e cloreto medidos no laboratório)

\begin{tabular}{|c|c|c|c|c|c|c|c|c|c|c|c|c|c|c|c|}
\hline & Wrighol & foroz & poros & $\mathrm{rer}$ & $(2,25$ & (20.26 & ror 31 & ro, & for 34 & 17038 & 2044 & POC $4=$ & $\mid \gamma 7 \cdot 92$ & of $x+1\}$ & $P T=28$ \\
\hline Alcalinidade & mea/L & 0,36 & 0,30 & 0,12 & 0,03 & 0,13 & 0,08 & 0,08 & 0,07 & 0,11 & 1,89 & 0,06 & 1,96 & 0,75 & 1,24 \\
\hline Sulfatos & meq/L & 0,01 & 0,01 & 0,00 & 0,00 & 0,01 & 0,00 & 0,00 & 0,00 & 0,00 & 0,01 & 0,04 & 0,00 & 0,01 & 0,00 \\
\hline Cloretos & meq $/$ & 0,44 & 0,18 & 0,96 & 0,41 & 0,01 & 0,12 & 0,39 & 0,03 & 0,91 & 0,24 & 0,79 & 0,16 & 0,18 & 0,03 \\
\hline Nitrato & meq/L & 1,07 & 1,18 & 1,61 & 1,80 & 0,07 & 0,79 & 1,22 & 0,52 & 1,33 & 0,03 & 1,24 & 0,37 & 0,84 & 0,00 \\
\hline Nitrito & meq/L. & 0,00 & 0,00 & 0,00 & 0,00 & 0,00 & 0,00 & 0,00 & 0,00 & 0,00 & 0,00 & 0,00 & 0,00 & 0,00 & 0,00 \\
\hline Fluoreto & meq/h & 0,00 & 0,00 & 0,00 & 0,00 & 0,00 & 0,00 & 0,00 & 0,00 & 0,00 & 0,00 & 0,00 & 0,01 & 0,00 & 0,01 \\
\hline Fosfatos & meq/L & 1,47 & 0,00 & 0,00 & 0,00 & 0,00 & 0,00 & 0,00 & 0,00 & 0,00 & 0,00 & 0,00 & 0,00 & 0,00 & 0,00 \\
\hline Brometo & meq/L & 0,00 & 0,00 & 0,00 & 0,00 & 0,00 & 0,00 & 0,00 & 0,00 & 0,00 & 0,00 & 0,00 & 0,00 & 0,00 & 0,00 \\
\hline Sódio & meqlL & 0,30 & 0,21 & 0,98 & 0,76 & 0,10 & 0,12 & 0,17 & 0,04 & 1,70 & 0,59 & 1,00 & 0,17 & 0,22 & 1,17 \\
\hline Potássio & meq/L & 0,25 & 0,21 & 0,13 & 0,37 & 0,08 & 0,10 & 0,09 & 0,10 & 0,11 & 0,05 & 0,25 & 0,13 & 0,12 & 0,01 \\
\hline Cálcio & $\mathrm{meq} / \mathrm{L}$ & 1,48 & 0,90 & 1,16 & 0,26 & 0,04 & 0,74 & 0,80 & 0,22 & 0,35 & 1,09 & 0,94 & 1,46 & 1,01 & 0,12 \\
\hline Magnésio & mea/L & 1,03 & 0,35 & 0,86 & 0,81 & 0,05 & 0,56 & 0,56 & 0,27 & 0,18 & 0,60 & 0,51 & 0,82 & 0,51 & 0,01 \\
\hline Estrôncio & $\mathrm{meq} / \mathrm{L}$ & 0,01 & 0,00 & 0,00 & 0,00 & 0,00 & 0,00 & 0,00 & 0,00 & 0,00 & 0,00 & 0,00 & 0,01 & 0,00 & 0,00 \\
\hline Bário & $\mathrm{meq} / \mathrm{L}$ & 0,01 & 0,00 & 0,00 & 0,01 & 0,00 & 0,00 & 0,00 & 0,00 & 0,00 & 0,00 & 0,01 & 0,00 & 0,00 & 0,00 \\
\hline Ferro total & meq/L & 0,00 & 0,00 & 0,00 & 0,00 & 0,00 & 0,00 & 0,00 & 0,00 & 0,00 & 0,00 & 0,00 & 0,00 & 0,00 & 0,00 \\
\hline Manganês & meq/L & 0,00 & 0,00 & 0,01 & 0,01 & 0,00 & 0,00 & 0,00 & 0,01 & 0,00 & 0,01 & 0,00 & 0,00 & 0,00 & 0,00 \\
\hline Aluminio & mea/L & 0,00 & 0,00 & 0,01 & 0,01 & 0,01 & 0,00 & 0,00 & 0,01 & 0,01 & 0,00 & 0,00 & 0,00 & 0,01 & 0,00 \\
\hline Cromo total & $\mathrm{meq} / \mathrm{L}$ & 0,00 & 0,00 & 0,00 & 0,00 & 0,00 & 0,00 & 0,00 & 0,00 & 0,00 & 0,00 & 0,00 & 0,00 & 0,00 & 0,00 \\
\hline Chumbo & meq/L & 0,00 & 0,00 & 0,00 & 0,00 & 0,00 & 0,00 & 0,00 & 0,00 & 0,00 & 0,00 & 0,00 & 0,00 & 0,00 & 0,00 \\
\hline Cobre & meq/L & 0,00 & 0,00 & 0,00 & 0,00 & 0,00 & 0,00 & 0,00 & 0,00 & 0,00 & 0,00 & 0,00 & 0,00 & 0,00 & 0,00 \\
\hline Zinco & meq/L & 0,00 & 0,00 & 0,00 & 0,00 & 0,00 & 0,00 & 0,00 & 0,00 & 0,00 & 0,00 & 0,00 & 0,00 & 0,00 & 0,00 \\
\hline Amônio & mea/l & 0,00 & 0,00 & 0,00 & 0,00 & 0,00 & 0,00 & 0,00 & 0,00 & 0,00 & 0,00 & 0,00 & 0,00 & 0,00 & 0,00 \\
\hline $\begin{array}{l}\text { SOMA } \\
\text { CÁTIONS }\end{array}$ & meq/L. & 3,07 & 1,69 & 3,16 & 2,24 & 0,25 & 1,54 & 1,63 & 0,65 & 2,36 & 2,35 & 2,71 & 2,60 & 1,88 & 1,32 \\
\hline SOMA ÂNIONS & meq/L & 3,36 & 1,67 & 2,70 & 2,25 & 0,22 & 0,99 & 1,70 & 0,63 & 2,35 & 2,16 & 2,12 & 2,50 & 1,78 & 1,27 \\
\hline Somatória & meq/L & 6,42 & 3,36 & 5,85 & 4,49 & 0,47 & 2,53 & 3,33 & 1,28 & 4,71 & 4,52 & 4,83 & 5,09 & 3,66 & 2,59 \\
\hline \begin{tabular}{|l|} 
DESVIO \\
PADRÄO/ERRO
\end{tabular} & $\%$ & $-4,48$ & 0,41 & 7,79 & $-0,21$ & 7,97 & 21,37 & $-1,90$ & 1,80 & 0,18 & 4,15 & 12,06 & 1,94 & 2,61 & 1,70 \\
\hline
\end{tabular}


ANEXO 3

Cálculo dos percentuais de erros obtidos com o balanço iônico resultados obtidos no campo (cloreto e nitrato) 
Tabela 1 - Balanço lônico - abril/00 (resultados de nitrato e cloreto obtidos no campo)

\begin{tabular}{|c|c|c|c|c|c|c|c|c|c|c|c|c|c|c|c|c|c|c|c|c|}
\hline & 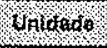 & e.8. & $1+0=04$ & (For) & \% & Wro & 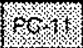 & Sor & 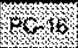 & ( & $\int$ & 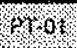 & $17-0.2$ & Troos & $8 \%$ & $87 \%$ & Pr 72 & 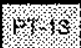 & 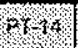 & 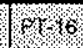 \\
\hline Icalinidade & mequl & 0,54 & 0,33 & 0,99 & 0,86 & 0,11 & 3,19 & 1,50 & 0,16 & 0.21 & 0.11 & 0.51 & 2,26 & 1,37 & 1,40 & 0,72 & 1,18 & 2.79 & 0,16 & 1,83 \\
\hline Hatos & nead & 0,00 & 0,01 & 0.00 & 0,01 & 0,00 & 0,01 & 0,05 & 0,02 & 0.00 & 0,00 & 0,00 & 0,00 & 0,00 & 0,00 & 0,02 & 0.00 & 0.00 & 0,04 & 0,00 \\
\hline oretos & neq/L & 0,06 & 0,08 & 0,71 & 0,48 & 0.45 & 0.28 & 0.20 & 0,73 & 0,56 & 0,96 & 0,34 & 0.51 & 0,68 & 0,31 & 0,20 & 0,03 & 0,011 & 0,59 & 0.28 \\
\hline itrato & meq/L & 1,10 & 1,46 & 0,69 & 1,31 & 0,48 & 0,56 & 1,42 & 1,40 & 0,98 & 2,42 & 0,97 & 0.31 & 0,53 & 1,31 & 0,87 & 0.00 & 0,34 & $t .08$ & 0.00 \\
\hline itrito & meq/L & 0.00 & 0,00 & 0,00 & 0,00 & 0,00 & 0,00 & 0,00 & 0.00 & 0.00 & 0,00 & 0,00 & 0,00 & 0.00 & 0.00 & 0,00 & 0,00 & 0,00 & 0,00 & 0.00 \\
\hline uoreto & neqfh & 0.00 & 0,00 & 0,00 & 0,00 & 0,00 & 0,01 & 0,00 & 0.00 & 0.00 & 0,01 & 0,00 & 0,01 & 0,01 & 0,02 & 0,00 & 0.01 & 0,00 & 0.00 & 0,00 \\
\hline Fosfatos & neq/L & 00 & 0,00 & 0.00 & 0,00 & 0,00 & 0,00 & 0.00 & 0.00 & 0,00 & 0,00 & 0,01 & 0,00 & 0,02 & 0.01 & 0.00 & 0.00 & 0,00 & 0,00 & 0,00 \\
\hline ometo & neq/L & 00 & 0.00 & 0.00 & 0,00 & 0.00 & 0,00 & 0,00 & 0,00 & 0,00 & 0,00 & 0,00 & 0,00 & 0.00 & 0,00 & 0.00 & 0.00 & 0,00 & 0,00 & 0.00 \\
\hline Sódio & neqlh & 0,20 & 0.21 & 0,16 & 0.76 & 0,56 & 1,35 & 0,15 & 1.44 & 0,96 & 1,83 & 0.28 & 0.17 & 0,10 & 0.20 & 0,23 & 0,20 & 0,10 & 0,53 & 0,17 \\
\hline tassi & neq $/ L$ & 0,19 & 0.18 & 0,17 & 0,15 & 0.10 & 0,24 & 0,10 & 0,20 & 0,13 & 0,20 & 0.16 & 0.12 & 0.09 & 0,11 & 0,12 & 0.08 & 0.08 & 0.07 & 0,07 \\
\hline Cálcio & eq/L & 1,04 & 0,97 & 0,29 & 1,66 & 0.13 & 0,13 & 0,97 & 0,45 & 0,42 & 0,42 & 0.88 & 1,98 & $\{, 06$ & 1,86 & 1,02 & 0,73 & 3,23 & 0,89 & 1,13 \\
\hline Magnéste & eq/L & 40 & 0,80 & 0,40 & 0,63 & 0,09 & 0,09 & 0.74 & 0,57 & 0,37 & 0,37 & 0,77 & 1,79 & 0,67 & $t, 08$ & 0,63 & 0,49 & 1,03 & 0,69 & 0,58 \\
\hline Estrôncio & $e q / 2$ & 0,00 & 0,00 & 0,00 & 0.01 & 0,00 & 0,00 & 0,01 & 0,00 & 0,00 & 0,00 & 0,00 & 0.01 & 0,00 & 0,00 & 0,00 & 0,00 & 0.01 & 0,00 & 0,00 \\
\hline Eário & meqh & 0,00 & 0.01 & 0,00 & 0,00 & 0,00 & 0,00 & 0,00 & 0,00 & 0,01 & 0,01 & 0,01 & 0,00 & 0,00 & 0,00 & 0,00 & 0,00 & 0.00 & 0,00 & 0,00 \\
\hline Ferro total & meqh & 0.00 & 0,00 & 0,00 & 0,01 & 0,00 & 0,00 & 0,00 & 0,00 & 0,00 & 0,00 & 0,00 & 0,00 & 0,00 & 0,00 & 0,00 & 0.00 & 0.00 & 0,00 & 0,00 \\
\hline Manganês & $m \in q / h$ & 0,00 & 0,00 & 0,00 & 0,00 & 0,00 & 0.00 & 0,00 & 0,01 & 0,01 & 0.01 & 0,00 & 0,00 & 0,00 & 0,00 & 0,00 & 0,00 & 0.00 & 0,00 & 0,00 \\
\hline Aluminio & meq/L & 0,00 & 0,00 & 0,00 & 0,00 & 0.00 & 0,00 & 0,0 & 0.0 & 0. & 0,00 & 0,00 & 0,00 & 0,00 & 0,00 & 0,00 & 0.00 & 0,00 & 0.00 & 0,00 \\
\hline Cromo total & mea/h. & 0,00 & 0,00 & 0,00 & 0,00 & 0,00 & 0,00 & 0, & 0. & 0. & 0,00 & 0,00 & 0,00 & 0,00 & 0,0 & 0,00 & 0,00 & 0,00 & 0,00 & 0.00 \\
\hline Chumbo & $\mathrm{meq} / \mathrm{L}$ & 0,00 & 0,00 & 0 & 0 & 0 & 0.00 & 0. & 0,0 & 0. & 0,00 & 0,00 & 0,00 & 0,8 & 0,0 & 0,00 & 0,00 & 0,00 & 0,00 & 0,00 \\
\hline Cobre & eqh & 0 & 0.0 & 0 & 0 & 0 & 0.00 & 0,0 & 0.0 & 0,0 & 0,00 & 0.00 & 0,00 & 0.00 & 0,00 & 0,00 & 0.00 & 0,00 & 0.00 & 0.00 \\
\hline$c$ & meqh & 0,00 & 0 & 0,00 & 0 & 0 & 0,00 & 0,0 & 0,0 & 0,00 & 0.00 & 0,00 & 0,00 & 0,00 & 0,00 & 0,00 & 0,00 & 0.00 & 0,00 & 0,00 \\
\hline domio & meq/L & 0,00 & 0.0 & 0 & $0_{1}$ & 0,00 & 0.00 & 0,00 & 0,00 & 0,00 & 0.00 & 0,00 & 0,00 & 0,00 & 0,00 & 0,00 & 0,00 & 0,00 & 0,00 & 0,00 \\
\hline Niquel & MequL & 0 & 0,00 & 0.0 & 0,00 & 0,00 & 0,00 & 0.00 & 0.00 & 0,00 & 0,00 & 0,00 & 0,00 & 0.00 & 0,00 & 0.00 & 0.00 & 0,00 & 0.00 & 0,00 \\
\hline Thet & $\mathrm{eq} / \mathrm{s}$ & 0,00 & 0,00 & 0,00 & 0,00 & 0,00 & 0.00 & 0,00 & 0,00 & 0,00 & 0,00 & 0,00 & 0,00 & 0,00 & 0,00 & 0,00 & 0,00 & 0,00 & 0.00 & 0,00 \\
\hline $\begin{array}{l}\text { SOMA } \\
\text { CATIONS }\end{array}$ & leq & 1,84 & 2.18 & 1,03 & 3,22 & 0,88 & 1.80 & 1,97 & 2,66 & 1,89 & 2,83 & 2,09 & 4.07 & 1.92 & 3,27 & 2,02 & 1,51 & 4,47 & 2,19 & 1,96 \\
\hline $\begin{array}{l}\text { SOMA } \\
\text { ÂNIONS }\end{array}$ & $100 / \mathrm{h}$ & 1,7 & 1,85 & 1,80 & 2,66 & 1,05 & 4,05 & 3,18 & 2,3 & 1,77 & 3,50 & 1,83 & 3,09 & 2,61 & 3,05 & 1,82 & 1,22 & 3,25 & 1,88 & 2,11 \\
\hline Somatória & mea/L & 3,54 & 4,07 & 2.83 & 5,88 & 1,93 & 5,85 & 5,15 & 4,98 & 3,66 & 33 & 92 & 36 & 53 & 31 & 83 & 73 & 72 & 4.07 & 4,08 \\
\hline $\begin{array}{l}\text { PESVIO } \\
\text { PADRAOO/ } \\
\text { ERRO }\end{array}$ & (\%) & 4 & 7,09 & 24 & 9 & $\cdot 8,67$ & .35 & 34 & 6 & 3,32 & .57 & 6.67 & 13.36 & 5.70 & 3.53 & 5.19 & 10.71 & 15,32 & 7,72 & $\cdot 3.71$ \\
\hline
\end{tabular}

25,74 : erro superior a $10 \%$. 
Tabela 1A - Balanço lônico - agosto/00 (resultados de nitrato e cloreto obtidos no campo)

\begin{tabular}{|c|c|c|c|c|c|c|c|c|c|c|c|c|c|}
\hline & Urios 6 & $\mathrm{PC} \cdot 2$ & 2808 & 18077 & $p<-2 \%$ & 19633 & Po 74 & PC 38 & 16648 & $P(1 / x$ & 27127 & PI 28 & 171.80 \\
\hline Alcalinidade & $\mathrm{meq} / \mathrm{L}$ & 0,31 & 0,42 & 0,21 & 0,10 & 0,31 & 0,42 & 0,10 & 0,16 & 0,84 & 1,99 & 1,26 & 2,10 \\
\hline Sulfato & mea/h & 0,01 & 0,04 & 0,00 & 0,02 & 0,02 & 0,01 & 0,00 & 0,01 & 0,02 & 0,00 & 0,00 & 0,00 \\
\hline Cloreto & meq/L & 0,59 & 0,79 & 1,10 & 2,54 & 1,27 & 0,14 & 1,04 & 0.82 & 0,34 & 0,28 & 0,14 & 0,25 \\
\hline Nitrato & mea/l & 1,08 & 1,10 & 1,60 & 1,45 & 0,97 & 0,42 & 1,24 & 1,21 & 0,82 & 0,71 & 0,05 & 0,45 \\
\hline Nitrito & mea/h & 0,00 & 0,00 & 0,00 & 0,00 & 0,00 & 0,00 & 0,00 & 0,00 & 0,00 & 0,00 & 0,00 & 0,00 \\
\hline Fluoreto & meq/L. & 0,00 & 0,00 & 0,00 & 0,01 & 0,00 & 0,00 & 0,00 & 0,00 & 0,00 & 0,01 & 0,01 & 0,01 \\
\hline Fosfatos & $\mathrm{mea} / \mathrm{L}$ & 0,00 & 0,00 & 0,00 & 0,00 & 0,00 & 0,00 & 0,00 & 0,00 & 0,01 & 0,00 & 0,00 & 0,00 \\
\hline Brometo & meq/L & 0,00 & 0,00 & 0,00 & 0,00 & 0,00 & 0,00 & 0,00 & 0,00 & 0,00 & 0,00 & 0,00 & 0,00 \\
\hline Sódio & meqh & 0,23 & 0,87 & 1,09 & 1,39 & 0,67 & 0,07 & 1,61 & 0,91 & 0,27 & 0,21 & 1,22 & 0,16 \\
\hline Potássio & mea/L. & 0,18 & 0,19 & 0,14 & 0,11 & 0,08 & 0,12 & 0,15 & 0,33 & 0,14 & 0,13 & 0,01 & 0,09 \\
\hline Cálcio & meq/L & 0,94 & 0,51 & 0,91 & 1,09 & 0,81 & 0,64 & 0,33 & 0,37 & 1,00 & 2,29 & 0,14 & 2,13 \\
\hline Magnésio & meq/L & 0,68 & 0,72 & 0,72 & 0,78 & 0,69 & 0,23 & 0,26 & 0,56 & 0,60 & 1,10 & 0,01 & 0,95 \\
\hline Estrôncio & meq/L & 0,00 & 0,00 & 0,00 & 0,01 & 0,00 & 0,00 & 0,00 & 0,00 & 0,00 & 0,02 & 0,00 & 0,01 \\
\hline Bário & meq/L & 0,01 & 0,00 & 0,00 & 0,00 & 0,00 & 0,00 & 0,00 & 0,01 & 0,00 & 0,01 & 0,00 & 0,00 \\
\hline Ferro total & meq/L. & 0,00 & 0,00 & 0,00 & 0,00 & 0,00 & 0,00 & 0,00 & 0,00 & 0,00 & 0,00 & 0,00 & 0,00 \\
\hline Manganês & meq/L & 0,00 & 0,00 & 0,00 & 0,00 & 0,00 & 0,00 & 0,01 & 0,01 & 0,00 & 0,00 & 0,00 & 0,00 \\
\hline Alumínio & meq/L & 0,00 & 0,00 & 0,00 & 0,00 & 0,00 & 0,00 & 0,00 & 0,00 & 0,00 & 0,00 & 0,00 & 0,00 \\
\hline Cromo total & $\mathrm{meq} / \mathrm{L}$ & 0,00 & 0,00 & 0,00 & 0,00 & 0,00 & 0,00 & 0,00 & 0,00 & 0,00 & 0,00 & 0,00 & 0,00 \\
\hline Chumbo & meq/L & 0,00 & 0,00 & 0,00 & 0,00 & 0,00 & 0,00 & 0,00 & 0,00 & 0,00 & 0,00 & 0,00 & 0,00 \\
\hline Cobre & meq/L & 0,00 & 0,00 & 0,00 & 0,00 & 0,00 & 0,00 & 0,00 & 0,00 & 0,00 & 0,00 & 0,00 & 0,00 \\
\hline Zinco & meq/L & 0,00 & 0,00 & 0,00 & 0,00 & 0,00 & 0,00 & 0,00 & 0,00 & 0,00 & 0,00 & 0,00 & 0,01 \\
\hline Amônio & meq/L & 0,00 & 0,00 & 0,00 & 0,00 & 0,00 & 0,00 & 0,00 & 0,00 & 0,00 & 0,00 & 0,00 & 0,00 \\
\hline $\begin{array}{l}\text { SOMA } \\
\text { CÁTIONS }\end{array}$ & $\mathrm{meq} / \mathrm{L}$ & 2,04 & 2,30 & 2,87 & 3,38 & 2,26 & 1,07 & 2,35 & 2,18 & 2,02 & 3,75 & 1,37 & 3,35 \\
\hline $\begin{array}{l}\text { SOMA } \\
\text { ÂNIONS }\end{array}$ & meq $/ \mathrm{h}$ & 2,01 & 1,86 & 3,02 & 3,44 & 2,24 & 1,01 & 2,43 & 2,02 & 2,08 & 2,90 & 1,29 & 2,65 \\
\hline Somatória & $\mathrm{meq} / \mathrm{L}$ & 4,06 & 4,16 & 5,89 & 6,82 & 4,50 & 2,07 & 4,78 & 4,20 & 4,10 & 6,65 & 2,67 & 6,00 \\
\hline $\begin{array}{l}\text { DESVIO } \\
\text { PADRÃO/ } \\
\text { ERRO }\end{array}$ & $(\%)$ & 0,77 & 10.48 & $-2,58$ & $-0,80$ & 0,29 & 2,82 & $-1,53$ & 3,85 & $-1,60$ & 12,78 & 3,12 & 11.72 \\
\hline
\end{tabular}

25.74: erro superior a $10 \%$. 
Tabela 1B * Balanço lônico - fevereiro/01 (resultados de nitrato e cloreto obtidos no campo)

\begin{tabular}{|c|c|c|c|c|c|c|c|c|c|c|c|c|}
\hline & hidatsen & $\mathrm{Tc}-02$ & 6008 & $\mathrm{FO}+7$ & $P 8,83$ & 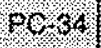 & 20,58 & $68=49$ & $197-1$ & $P T 27$ & PT.28 & $P T=30$ \\
\hline Alcalinidade & meq/L & 0,42 & 0,53 & 0,79 & 0,42 & 0,32 & 0,26 & 0,84 & 0,79 & 2,53 & 1,05 & 1,90 \\
\hline Sulfatos & $\mathrm{meq} / \mathrm{L}$ & 0,00 & 0,02 & 0,00 & 0,01 & 0,00 & 0,00 & 0,01 & 0,00 & 0,00 & 0,00 & 0,00 \\
\hline Cloretos & meq/L. & 0,59 & 0,99 & 1,38 & 0,34 & 0,11 & 1,44 & 0,56 & 0,28 & 1,75 & 1,33 & 1,69 \\
\hline Nitrato & meo/l & 0,92 & 0,76 & 1,16 & 0,73 & 0,34 & 0,98 & 0,74 & 0,45 & 0,53 & 0,21 & 0,55 \\
\hline Nitrito & mea/l. & 0,00 & 0,00 & 0,00 & 0,00 & 0,00 & 0,00 & 0,00 & 0,00 & 0,00 & 0,00 & 0,00 \\
\hline Fluoreto & meqll & 0,00 & 0,00 & 0,00 & 0,00 & 0,00 & 0,00 & 0,00 & 0,00 & 0,00 & 0,00 & 0,01 \\
\hline Fosfatos & meall. & 0,01 & 0,00 & 0,00 & 0,00 & 0,00 & 0,00 & 0,00 & 0,00 & 0,00 & 0,00 & 0,00 \\
\hline Brometo & meq $/ \mathrm{L}$ & 0,00 & 0,00 & 0,00 & 0,00 & 0,00 & 0,00 & 0,00 & 0,00 & 0,00 & 0,00 & 0,00 \\
\hline Sódio & meq/L & 0,20 & 0,80 & 0,98 & 0,69 & 0,03 & 1,57 & 0,65 & 0,20 & 0,20 & 1,15 & 1,17 \\
\hline Potássio & meq/L. & 0,17 & 0,19 & 0,13 & 0,08 & 0,09 & 0,12 & 0,30 & 0,08 & 0,12 & 0,00 & 0,03 \\
\hline Cálcio & meq/L & 0,97 & 0,51 & 1,21 & 0,83 & 0,31 & 0,43 & 0,85 & 0,94 & 1,75 & 0,11 & 0,43 \\
\hline Magnésio & mea/l. & 0,78 & 0,65 & 1,00 & 0,74 & 0,28 & 0,23 & 0,39 & 0,55 & 1,10 & 0,02 & 0,25 \\
\hline Estrôncio & meq/L & 0,00 & 0,00 & 0,00 & 0,00 & 0,00 & 0,00 & 0,01 & 0,00 & 0,02 & 0,00 & 0,00 \\
\hline Bário & $\mathrm{eq} / \mathrm{L}$ & 0,01 & 0,00 & 0,01 & 0,00 & 0,00 & 0,00 & 0,00 & 0,01 & 0,00 & 0,00 & 0,00 \\
\hline Ferro total & neq/L. & 0,00 & 0,00 & 0,00 & 0,00 & 0,00 & 0,00 & 0,00 & 0,00 & 0,00 & 0,00 & 0,00 \\
\hline Manganès & meql & 0,00 & 0,00 & 0,01 & 0,00 & 0,01 & 0,00 & 0,00 & 0,00 & 0,00 & 0,00 & 0,00 \\
\hline Alumínio & meq $/ \mathrm{L}$ & 0,00 & 0,00 & 0,01 & 0,00 & 0,01 & 0,00 & 0,00 & 0,00 & 0,00 & 0,00 & 0,00 \\
\hline Cromo total & meq/L & 0,00 & 0,00 & 0,00 & 0,00 & 0,00 & 0,00 & 0,00 & 0,00 & 0,00 & 0,00 & 0,00 \\
\hline Chumbo & meq/L & 0,00 & 0,00 & 0,00 & 0,00 & 0,00 & 0,00 & 0,00 & 0,00 & 0,00 & 0,00 & 0,00 \\
\hline Cobre & meq/ & 0,00 & 0,00 & 0,00 & 0,00 & 0,00 & 0,00 & 0,00 & 0,00 & 0,00 & 0,00 & 0,00 \\
\hline Zinco & meqh & 0,00 & 0,00 & 0,00 & 0,00 & 0,00 & 0,00 & 0,00 & 0,00 & 0,00 & 0,00 & 0,00 \\
\hline Amônio & $\mathrm{meq} / \mathrm{h}$ & 0,00 & 0,00 & 0,00 & 0,00 & 0,00 & 0,00 & 0,00 & 0,00 & 0,00 & 0,00 & 0,00 \\
\hline $\begin{array}{l}\text { SOMA } \\
\text { CÁTIONS }\end{array}$ & meq/L & 2,14 & 2,16 & 3,34 & 2,35 & 0,74 & 2,36 & 2,20 & 1,79 & 3,19 & 1,29 & 1,89 \\
\hline $\begin{array}{l}\text { SOMA } \\
\text { ÂNIONS } \\
\end{array}$ & meq/L & 1,94 & 2,29 & 3,34 & 1,49 & 0,77 & 2,69 & 2,16 & 1,53 & 4,81 & 2,59 & 4,14 \\
\hline Somatória & (\%) & 4,08 & 4,45 & 6,68 & 3,84 & 1,51 & 5,05 & 4,36 & 3,32 & 8,00 & 3,88 & 6,04 \\
\hline $\begin{array}{l}\text { DESVIO } \\
\text { PADRÃO/ } \\
\text { ERRO }\end{array}$ & & 4,83 & $-2,99$ & 0,03 & 22,19 & $-2,27$ & $-6,54$ & 0,94 & 7,85 & $-20,32$ & $-33,57$ & $-37,35$ \\
\hline
\end{tabular}

25.74: erro superior a $10 \%$. 
Tabela 1C - Balanço lônico - agosto/01 (resultados de nitrato e cloreto obtidos no campo)

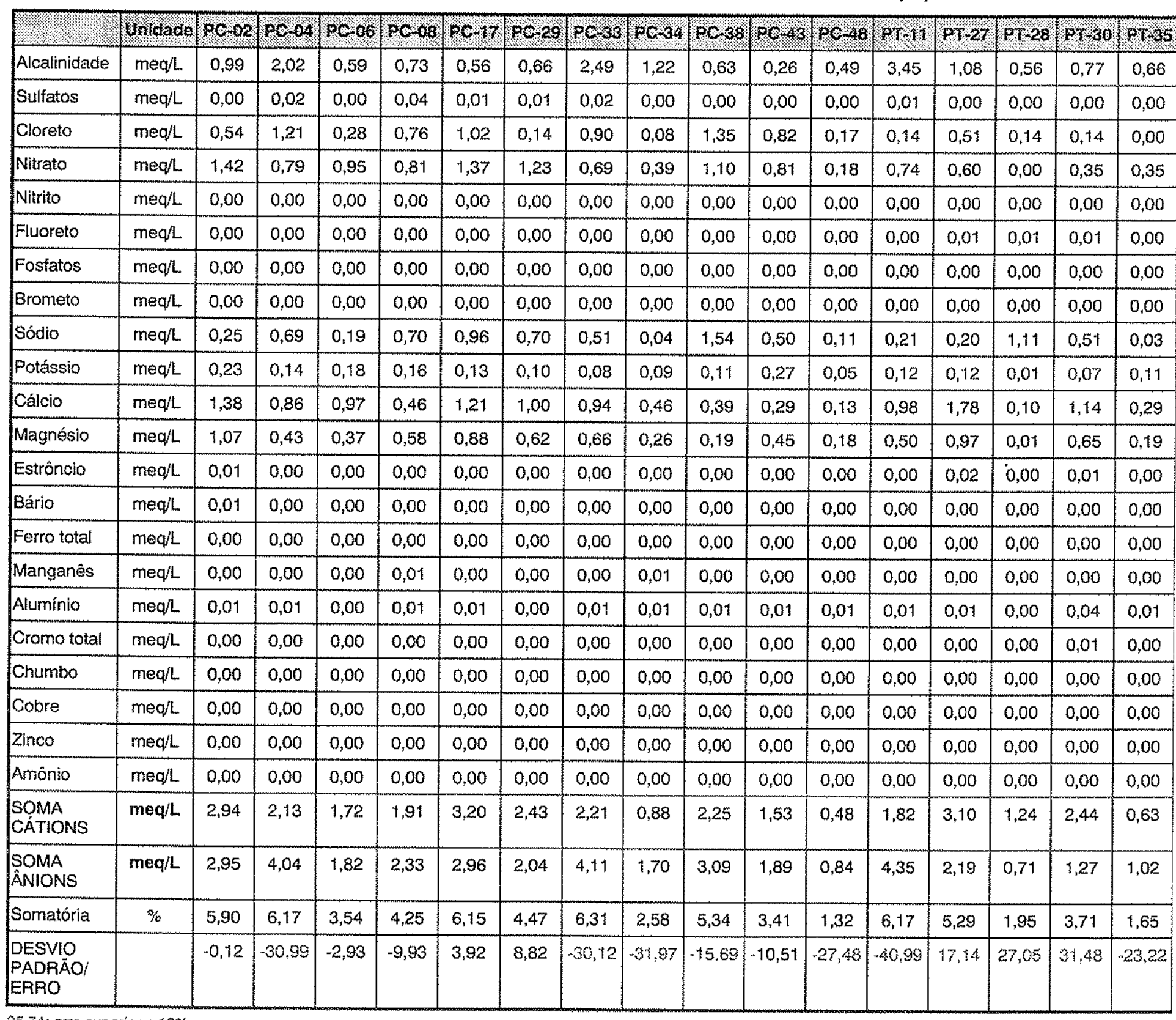

25.74: erro superior a $10 \%$. 
Tabela 1D - Balanço lônico - setembro/01 (resultados de nitrato e cloreto obtidos no campo)

\begin{tabular}{|c|c|c|c|c|c|c|c|c|c|c|c|c|c|c|c|}
\hline & e & $8+12$ & pcos. & per.1) & 2625 & $\mathrm{PC}_{26}$ & ne.si & 2032 & PC.34) & $\mathrm{PC}-38$ & $\mathrm{PC}-14$ & $p<.45$ & FT.02! & $P r / 1 / 4$ & 9728 \\
\hline Alcalinidade & $\mathrm{meq} / \mathrm{L}$ & 0,36 & 0,30 & 0,12 & 0,03 & 0,13 & 0,08 & 0,08 & 0,07 & 0,11 & 1,89 & 0,06 & 1,96 & 0,75 & 1,24 \\
\hline Sulfatos & $\mathrm{meq} / \mathrm{L}$ & 0,01 & 0,01 & 0,00 & 0,00 & 0,01 & 0,00 & 0,00 & 0,00 & 0,00 & 0,01 & 0,04 & 0,00 & 0,01 & 0,00 \\
\hline Cloreto & meq/L & 3,27 & 0,00 & 1,38 & 0,82 & 0,08 & 0,28 & 1,38 & 0,06 & 0,54 & 0,42 & 0,79 & 0,20 & 0,34 & 0,06 \\
\hline Nitrato & meq/L & 1,50 & 0,76 & 1,56 & 1,40 & 0,21 & 0,98 & 0,94 & 0,40 & 0,97 & 0,00 & 0,98 & 0,34 & 0,71 & 0,10 \\
\hline Nitrito & mea/l & 0,00 & 0,00 & 0,00 & 0,00 & 0,00 & 0,00 & 0,00 & 0,00 & 0,00 & 0,00 & 0,00 & 0,00 & 0,00 & 0,00 \\
\hline Fluoreto & meq/L & 0,00 & 0,00 & 0,00 & 0,00 & 0,00 & 0,00 & 0,00 & 0,00 & 0,00 & 0,00 & 0,00 & 0,01 & 0,00 & 0,01 \\
\hline Fosfatos & meol & 1,47 & 0,00 & 0,00 & 0,00 & 0,00 & 0,00 & 0,00 & 0,00 & 0,00 & 0,00 & 0,00 & 0,00 & 0,00 & 0,00 \\
\hline Brometo & meq/L & 0,00 & 0,00 & 0,00 & 0,00 & 0,00 & 0,00 & 0,00 & 0,00 & 0,00 & 0,00 & 0,00 & 0,00 & 0,00 & 0,00 \\
\hline Sódio & meq/L & 0,30 & 0,21 & 0,98 & 0,76 & 0,10 & 0,12 & 0,17 & 0,04 & 1,70 & 0,59 & 1,00 & 0,17 & 0,22 & 1,17 \\
\hline Potássio & meall. & 0,25 & 0,21 & 0,13 & 0,37 & 0,06 & 0,10 & 0,09 & 0,10 & 0,11 & 0,05 & 0,25 & 0,13 & 0,12 & 0,01 \\
\hline Cálcio & meq/L & 1,48 & 0,90 & 1,16 & 0,26 & 0,04 & 0,74 & 0,80 & 0,22 & 0,35 & 1,09 & 0,94 & 1,46 & 1,01 & 0,12 \\
\hline Magnésio & meq/L & 1,03 & 0,35 & 0,86 & 0,81 & 0,05 & 0,56 & 0,56 & 0,27 & 0,18 & 0,60 & 0,51 & 0,82 & 0,51 & 0,01 \\
\hline Estrôncio & mea/h. & 0,01 & 0,00 & 0,00 & 0,00 & 0,00 & 0,00 & 0,00 & 0,00 & 0,00 & 0,00 & 0,00 & 0,01 & 0,00 & 0,00 \\
\hline Bário & meq/L. & 0,01 & 0,00 & 0,00 & 0,01 & 0,00 & 0,00 & 0,00 & 0,00 & 0,00 & 0,00 & 0,01 & 0,00 & 0,00 & 0,00 \\
\hline Ferro total & mequl & 0,00 & 0,00 & 0,00 & 0,00 & 0,00 & 0,00 & 0,00 & 0,00 & 0,00 & 0,00 & 0,00 & 0,00 & 0,00 & 0,00 \\
\hline Manganês & mea/l & 0,00 & 0,00 & 0,01 & 0,01 & 0,00 & 0,00 & 0,00 & 0,01 & 0,00 & 0,01 & 0,00 & 0,00 & 0,00 & 0,00 \\
\hline Aluminio & mea/l & 0,00 & 0,00 & 0,01 & 0,01 & 0,01 & 0,00 & 0,00 & 0,01 & 0,01 & 0,00 & 0,00 & 0,00 & 0,01 & 0,00 \\
\hline Cromo total & meq/L & 0,00 & 0,00 & 0,00 & 0,00 & 0,00 & 0,00 & 0,00 & 0,00 & 0,00 & 0,00 & 0,00 & 0,00 & 0,00 & 0,00 \\
\hline Chumbo & meq/L & 0,00 & 0,00 & 0,00 & 0,00 & 0,00 & 0,00 & 0,00 & 0,00 & 0,00 & 0,00 & 0,00 & 0,00 & 0,00 & 0,00 \\
\hline Cobre & mea/L & 0,00 & 0,00 & 0,00 & 0,00 & 0,00 & 0,00 & 0,00 & 0,00 & 0,00 & 0,00 & 0,00 & 0,00 & 0,00 & 0,00 \\
\hline Zinco & $\mathrm{meq} / \mathrm{L}$ & 0,00 & 0,00 & 0,00 & 0,00 & 0,00 & 0,00 & 0,00 & 0,00 & 0,00 & 0,00 & 0,00 & 0,00 & 0,00 & 0,00 \\
\hline Amônio & meaph & 0,00 & 0,00 & 0,00 & 0,00 & 0,00 & 0,00 & 0,00 & 0,00 & 0,00 & 0,00 & 0,00 & 0,00 & 0,00 & 0,00 \\
\hline $\begin{array}{l}\text { SOMA } \\
\text { CÁTIONS } \\
\end{array}$ & $\mathrm{meq} / \mathrm{L}$ & 3,07 & 1,69 & 3,16 & 2,24 & 0,25 & 1,54 & 1,63 & 0,65 & 2,36 & 2,35 & 2,71 & 2,60 & 1,88 & 1,32 \\
\hline $\begin{array}{l}\text { SOMA } \\
\text { ANIONS }\end{array}$ & meq/L & 3,36 & 1,67 & 2,70 & 2,25 & 0,23 & 0,99 & 1,70 & 0,63 & 2,35 & 2,16 & 2,12 & 2,50 & 1,78 & 1,27 \\
\hline Somatoria & $\%$ & 6,42 & 3,36 & 5,85 & 4,49 & 0,48 & 2,53 & 3,33 & 1,28 & 4,71 & 4,52 & 4,83 & 5,09 & 3,66 & 2,59 \\
\hline $\begin{array}{l}\text { DESVIO } \\
\text { PADRAAO/ } \\
\text { ERRO }\end{array}$ & & $.4,48$ & 0,41 & 7,79 & $-0,21$ & 5,44 & 21,97 & $-1,90$ & 1,80 & 0,18 & 4,15 & 12,06 & 1,94 & 2,61 & 1,70 \\
\hline
\end{tabular}

25.74: erro superior a $10 \%$. 


\section{ANEXO 4}

Resultados analíticos e cálculo dos percentuais de erros para as amostras em duplicata 
Tabela 1 - Sumárto dos Resujtados Analíticos das Amostra em Dupilcatas e Respectivos Percentuais de Erros.

\begin{tabular}{|c|c|c|c|c|c|c|c|c|c|c|c|}
\hline (3) & (x) & 28 & 等 & vidy & 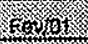 & - & 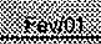 & ris & 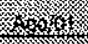 & 45 & 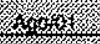 \\
\hline r & 14 & (3) & E & Arstia & 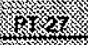 & - & E.t. & ( & 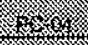 & 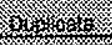 & - \\
\hline 3. & (1) & 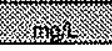 & (.) & 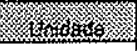 & S & 1 Itiz & 1. & S & . & $2 x_{14}$ & 经 \\
\hline Sulfato & 0,04 & 0.28 & $.75,00$ & Sulfato & 0.08 & 0,11 & $-15,79$ & Sulfato & 0.83 & 0.85 & $-1,19$ \\
\hline Cloreto & 0.66 & 0.78 & $.8,33$ & Cloreto & 4,59 & 4,29 & 3,38 & Cloreto & 22.99 & 23,33 & .0 .73 \\
\hline Nilrato & 0,53 & 0.50 & 2.91 & Nitrato & 32,26 & 31,63 & 0,99 & Nitrato & 64.69 & 57,90 & -2.42 \\
\hline Nitito & 0.00 & 0,00 & 0,00 & Nitrito & 0,00 & 0,00 & 0.00 & Nitrito & 0,00 & 0,00 & 0,00 \\
\hline Fuoreto & 0,11 & 0.08 & 15,79 & Fuoreto & 0.04 & 0.03 & 14,29 & Fituoreta & 0.01 & 0.03 & .71 .43 \\
\hline Fosialos & 0,01 & 0,00 & 20,00 & Fosfates & 0.05 & 0.04 & 11,11 & Fosfatos & 0.06 & 0,03 & 33,33 \\
\hline Bromelo & 0,00 & 0,00 & 0,00 & Brometo & 0.00 & 0,00 & 0.00 & Brometo & 0,00 & 0,00 & 0,00 \\
\hline Sódia & 28,00 & 28.50 & $-0,88$ & Sódio & 4.70 & 4,70 & 0.00 & Sodio & 15,80 & 16,00 & $-0,63$ \\
\hline Potássio & 0.20 & 0.30 & $-20,00$ & Potássio & 4.50 & 4,70 & $-2,17$ & Potássio & 5.40 & 5,30 & 0.93 \\
\hline cálicia & 2,80 & 2,75 & 0.90 & Cácio & 35,05 & 35.20 & -0.21 & Cálcio & 17,30 & 17.20 & 0,29 \\
\hline Magrésio & 0,10 & 0,60 & $.71,43$ & Magnésio & 13,35 & 13,35 & 0,00 & Magnésio & 5.20 & 4,90 & 2.97 \\
\hline Estrôncio & 0,09 & 0,09 & 0,00 & Estrôncio & 0,69 & 0,69 & 0,00 & Estróncio & 0.18 & 0.15 & 9.09 \\
\hline Bário & 0,00 & 0.00 & 0,00 & Bártio & 0.33 & 0,34 & -1.49 & Bastio & 0,21 & 0.23 & $-4,55$ \\
\hline Ferro total & 0,00 & 0.00 & 0,00 & Farfo total & 0,00 & 0,02 & $-100,00$ & Fetro total & 0,00 & 0,00 & 0.00 \\
\hline Manganess & 0,00 & 0.00 & 0,00 & Manganès & 0.00 & 0.01 & $-100,00$ & Manganês & 0,00 & 0,00 & 0,00 \\
\hline Aluminio & 0,00 & 0.00 & 0.00 & Aluminto & 0.00 & 0,00 & 0,00 & Altuminio & 0.06 & 0.03 & 33,33 \\
\hline Cromo total & 0.02 & 0.02 & 0.00 & Cromo totat & 0.01 & 0.02 & $-33,33$ & Cromo totat & 0,00 & 0,00 & 0,00 \\
\hline Chumbo & 0.00 & 0.00 & 0,00 & Chumbo & 0,00 & 0,00 & 0,00 & Chumbo & 0,00 & 0,00 & 0,00 \\
\hline Cosre & 0,00 & 0,00 & 0,00 & Cobre & 0,00 & 0.00 & 0,00 & Cobre & 0.00 & 0,00 & 0.00 \\
\hline Znico & 0.00 & 0,00 & 0,00 & Znco & 0,00 & 0,00 & 0,00 & Zinco & 0.00 & 0,00 & 0.00 \\
\hline Cadmio & 0.00 & 0,00 & 0,00 & Cádmio & 0.00 & 0,00 & 0,00 & Cánio & 0.00 & 0.00 & 0.00 \\
\hline Niquel & 0,00 & 0.00 & 0.00 & Nique: & 0,00 & 0,00 & 0.00 & Niquel & 0,00 & 0.00 & 0,00 \\
\hline Prata & 0,00 & 0.00 & 0.00 & Prata & 0.00 & 0,00 & 0,00 & Prata & 0,00 & 0,00 & 0,00 \\
\hline Amönio & 0.00 & 0.00 & 0,00 & Amônio & 0,00 & 0,00 & 0.00 & Annônio & 0.00 & 0,00 & 0,00 \\
\hline Amônia & 0,21 & 0.00 & 100,00 & Ámb́nia & 0,00 & 0,00 & 0,00 & Amonia & 0,00 & 0,00 & 0,00 \\
\hline
\end{tabular}

33,33: Erro malor que 30\%

Tabela 1 A - Sumário dos Resultados Anaíticos das Amostra em Duplicatas e Respectivos Percentuals de Erros (isótopos).

\begin{tabular}{|c|c|c|c|c|c|}
\hline 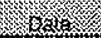 & s. & $S$ & s. & 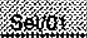 & 58 \\
\hline Atastio & 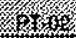 & 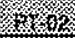 & bit & 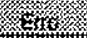 & $z_{i}$ \\
\hline 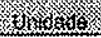 & 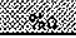 & (s) & 263. & 2 - & in \\
\hline Istápoo & 9,76 & 8,94 & 8,20 & 2,95 & -1.43 \\
\hline
\end{tabular}




\section{ANEXO 5}

Cadastros de poços cacimbas e tubular 
Tabela 1: Cadastro de Poços Cacimba $€$ Tubular - Urânia (SP).

\begin{tabular}{|c|c|c|c|c|c|c|c|c|c|c|}
\hline Poro & Propriezárlo & Enderego & $\begin{array}{c}\text { Diametro } \\
(\mathrm{n})\end{array}$ & $\begin{array}{c}\text { Prolundidade } \\
\text { (mi) }\end{array}$ & $\begin{array}{c}\text { Nivel } \\
\text { de agua } \\
(\mathrm{m})\end{array}$ & $\begin{array}{l}\text { Acabamento } \\
(\mathrm{m})\end{array}$ & $\begin{array}{l}\text { Protecáo } \\
\text { Sanitaria }\end{array}$ & Usos da agua & $\begin{array}{l}\text { Equipado com } \\
\text { bomba ? qual? }\end{array}$ & $\begin{array}{l}\text { Provavel ano } \\
\text { de Perfuraça }\end{array}$ \\
\hline PC-19 & Particular & R. da Glória, 1783 & 1,5 & 8,0 & $\cdots$ & $\begin{array}{c}8 \text { anéis de } \\
\text { concreto de } \\
0,5 \mathrm{~m} .\end{array}$ & $\begin{array}{l}\text { Tampa de } \\
\text { concreto. }\end{array}$ & $\begin{array}{c}\text { Doméstico - não } \\
\text { bebem. }\end{array}$ & $\begin{array}{l}\text { Sim: bomba } \\
\text { elétrica de } \\
\text { superfície. }\end{array}$ & 1999 \\
\hline PC-20 & Particular & $\begin{array}{l}\text { R. Getúlio Vargas, } \\
1169\end{array}$ & 1,5 & $\ldots$ & $\cdots$ & $-\cdots$ & $\begin{array}{l}\text { Tampa de } \\
\text { concreto. }\end{array}$ & Doméstico. & $\begin{array}{l}\text { Sim: bomba } \\
\text { elétrica de } \\
\text { superficie. }\end{array}$ & $\cdots$ \\
\hline PC-21 & Particular & R. Terezinha, 51 & 1,5 & 14,0 & 10,54 & $\begin{array}{c}5 \text { anéis de } \\
\text { concreto de } 1 \mathrm{~m} \\
\text { e } 2 \text { fileiras de } \\
\text { tijolos. }\end{array}$ & $\begin{array}{l}\text { Tampa de } \\
\text { concreto. }\end{array}$ & $\begin{array}{c}\text { Doméstico- } \\
\text { lavagem de } \\
\text { áreas externas e } \\
\text { roupas. }\end{array}$ & $\begin{array}{l}\text { Sim: bomba } \\
\text { elétrica de } \\
\text { superfície. }\end{array}$ & 1999 \\
\hline $\mathrm{PC}-22$ & Particular & & 1,5 & 13,00 & 11,32 & $\cdots$ & $\begin{array}{l}\text { Tampa de } \\
\text { concreto. }\end{array}$ & Doméstico. & $\begin{array}{l}\text { Sim: bomba } \\
\text { elétrica de } \\
\text { superficie. }\end{array}$ & $\cdots$ \\
\hline $\mathrm{PC}-23$ & Particular & R. Leonor, n.2095 & 1,5 & $\cdots$ & -- & $\ldots$ & $\begin{array}{l}\text { Tampa de } \\
\text { concreto. }\end{array}$ & $\begin{array}{c}\text { Doméstico - não } \\
\text { bebem. }\end{array}$ & $\begin{array}{l}\text { Sim: bomba } \\
\text { elétrica de } \\
\text { superfície. }\end{array}$ & $\cdots$ \\
\hline $\mathrm{PC}-24$ & Particular & $\begin{array}{l}\text { R. Bandeirantes, } \\
\text { n.158 }\end{array}$ & 1,5 & 21,0 & 17,21 & $\begin{array}{c}7 \text { anéis de } \\
\text { concreto de } 1 \mathrm{~m} \\
\text { na base do } \\
\text { poço. }\end{array}$ & $\begin{array}{l}\text { Tampa de } \\
\text { concreto. }\end{array}$ & $\begin{array}{c}\text { Doméstico- } \\
\text { lavagem de } \\
\text { áreas externas. }\end{array}$ & $\begin{array}{l}\text { Sim: bomba } \\
\text { elétrica de } \\
\text { superície. }\end{array}$ & 1993 \\
\hline PC-25 & Particular & $\begin{array}{l}\text { R. Rio de Janeiro, } \\
\text { n. } 24\end{array}$ & 1,5 & $\cdots$ & 11,86 & Tijolos. & $\begin{array}{l}\text { Tampa de } \\
\text { madeira. }\end{array}$ & $\begin{array}{c}\text { Doméstico - } \\
\text { bebem }\end{array}$ & Não & 1966 \\
\hline PC-26 & Particular & $\begin{array}{l}\text { R. Espirito Santo, } \\
\text { n. } 1420\end{array}$ & 1,5 & $\ldots$ & 15,00 & Tijolos. & $\begin{array}{l}\text { Tampa de } \\
\text { concreto. }\end{array}$ & $\begin{array}{l}\text { Doméstico - } \\
\text { bebem. }\end{array}$ & $\begin{array}{l}\text { Sim: bomba } \\
\text { elétrica de } \\
\text { superfície. }\end{array}$ & $\ldots$ \\
\hline
\end{tabular}


Tabela 1A: Cadastro de Poços Cacimba e Tubular - Urânia (SP).

\begin{tabular}{|c|c|c|c|c|c|c|c|c|c|c|}
\hline paco & proprietario & mencos & planoro & frortindadade & $\begin{array}{l}\text { Noel } \\
\text { de agua } \\
(\mathrm{m}) \text {. }\end{array}$ & $\begin{array}{l}\text { Acabamento } \\
(\mathrm{f})\end{array}$ & Srotecalo & Jsos da agua & 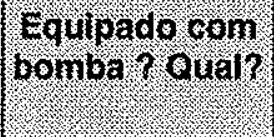 & $\begin{array}{l}\text { frovavel ano } \\
\text { de Periuracao }\end{array}$ \\
\hline $\mathrm{PC}-27$ & particular & $\begin{array}{l}\text { Av. } \\
\text { independência, }\end{array}$ & 1,5 & $\ldots$ & 17,15 & Tijolo & $\begin{array}{l}\text { Tampa de } \\
\text { concreto }\end{array}$ & $\begin{array}{c}\text { Doméstico - } \\
\text { bebem }\end{array}$ & $\begin{array}{l}\text { Sim: bomba } \\
\text { elétrica de } \\
\text { superfície. }\end{array}$ & $\ldots$ \\
\hline PC-28 & particular & $\begin{array}{l}\text { Av. dos Andrades, } \\
\text { n.1288 }\end{array}$ & 1,5 & $\ldots$ & 5,30 & $\cdots$ & $\begin{array}{l}\text { Tampa de } \\
\text { concreto. }\end{array}$ & Doméstico. & $\begin{array}{l}\text { Sim: bomba } \\
\text { elétrica de } \\
\text { superficie. }\end{array}$ & $\ldots$ \\
\hline PC-29 & Particular & $\begin{array}{l}\text { R. Natal - em } \\
\text { frente a n. } 2024\end{array}$ & 1,5 & $\sim 12$ & 8,15 & $\begin{array}{c}\text { Anéis de } \\
\text { concreto e tijolos }\end{array}$ & $\begin{array}{l}\text { Tampa de } \\
\text { concreto }\end{array}$ & $\begin{array}{c}\text { Doméstico - } \\
\text { bebem }\end{array}$ & $\begin{array}{l}\text { Sim: bomba } \\
\text { elétrica de } \\
\text { superficie. }\end{array}$ & 1997 \\
\hline PC-30 & Particular & R. Natal, n. 2185 & 1,2 & $\sim 12$ & 6,60 & Tijolos & $\begin{array}{l}\text { Tampa de } \\
\text { concreto }\end{array}$ & $\begin{array}{c}\text { Doméstico - } \\
\text { bebem }\end{array}$ & $\begin{array}{l}\text { Sim: bomba } \\
\text { elétrica de } \\
\text { superfície. }\end{array}$ & 1995 \\
\hline PC-31 & Particular & $\begin{array}{l}\text { R. Pernambuco, } \\
\text { n. } 263\end{array}$ & 1,2 & 11 & 8,00 & $\begin{array}{c}\text { Anéis de } \\
\text { concreto e } \\
\text { tijolos, de } 7 \text { a } 11 \\
m .\end{array}$ & $\begin{array}{l}\text { Tampa de } \\
\text { concreto }\end{array}$ & $\begin{array}{c}\text { Doméstico - } \\
\text { bebem }\end{array}$ & $\begin{array}{l}\text { Sim: bomba } \\
\text { elétrica de } \\
\text { superficie. }\end{array}$ & 1985 \\
\hline PC-32 & Particular & $\begin{array}{l}\text { R. Maranhão, n. } \\
274\end{array}$ & 1,2 & 7,62 & 6,28 & $0,4 \mathrm{~m}$ de tijolos & $\begin{array}{l}\text { Tampa de } \\
\text { madeira }\end{array}$ & Doméstico. & $\begin{array}{l}\text { Sim: bomba } \\
\text { elétrica de } \\
\text { superficie. }\end{array}$ & $>1990$ \\
\hline $\mathrm{PC}-33$ & Particular & $\begin{array}{l}\text { R. R. Branco, n. } \\
1271\end{array}$ & 1,2 & 10 & 8,00 & $\begin{array}{c}\text { Tijolos de } 9 \text { a } 10 \\
\mathrm{~m} .\end{array}$ & $\begin{array}{l}\text { Tampa de } \\
\text { madeira }\end{array}$ & $\begin{array}{c}\text { Doméstico - } \\
\text { bebem }\end{array}$ & $\begin{array}{l}\text { Sim: bomba } \\
\text { elétrica de } \\
\text { superficie. }\end{array}$ & 1998 \\
\hline PC-34 & Particular & $\begin{array}{l}\text { R. Ademar de } \\
\text { Barros, n. } 1541\end{array}$ & 1,2 & 11,73 & 10,40 & $0,5 \mathrm{~m}$ de tijolo. & $\begin{array}{l}\text { Tampa de } \\
\text { concreto }\end{array}$ & $\begin{array}{c}\text { Doméstico - } \\
\text { bebem }\end{array}$ & $\begin{array}{l}\text { Sim: bomba } \\
\text { elétrica de } \\
\text { superficie. }\end{array}$ & 1996 \\
\hline
\end{tabular}


Tabela 1B: Cadastro de Poços Cacimba e Tubular - Urânia (SP).

\begin{tabular}{|c|c|c|c|c|c|c|c|c|c|c|}
\hline Pogo & Proprietario & (1. Enderego & $\begin{array}{l}\text { blametro } \\
(\mathrm{m})\end{array}$ & $\begin{array}{l}\text { Profundidade } \\
(\mathrm{m})\end{array}$ & $\begin{array}{l}\text { Nivel } \\
\text { de aqua } \\
(\mathrm{m})\end{array}$ & Acabamento & $\begin{array}{l}\text { Proteçáo } \\
\text { Sanitaria }\end{array}$ & Usos da agua & Eoguipacio com & $\begin{array}{l}\text { Provavel ano. } \\
\text { de Perfuracáo }\end{array}$ \\
\hline PC-35 & Particular & $\begin{array}{l}\text { R. da Glória, n. } \\
1820 / 530\end{array}$ & 1,2 & 10,71 & 6,00 & $\begin{array}{c}\text { Anéis de } \\
\text { concreto }-2 \mathrm{~m} \text {. }\end{array}$ & $\begin{array}{l}\text { Tampa de } \\
\text { concreto }\end{array}$ & $\begin{array}{l}\text { Irrigação - } \\
\text { jardim }\end{array}$ & $\begin{array}{l}\text { Sim: bomba } \\
\text { elétrica de } \\
\text { superficie. }\end{array}$ & 1998 \\
\hline PC-36 & Particular & $\begin{array}{l}\text { R. Getúlio Vargas, } \\
\text { n. } 1157\end{array}$ & 1,2 & & & $\begin{array}{l}\text { Anéis de } \\
\text { concreto no } \\
\text { fundo }\end{array}$ & $\begin{array}{l}\text { Tampa de } \\
\text { concreto }\end{array}$ & $\begin{array}{l}\text { Doméstico - } \\
\text { bebem }\end{array}$ & $\begin{array}{l}\text { Sim: bomba } \\
\text { elétrica de } \\
\text { superficie. }\end{array}$ & 1997 \\
\hline $\mathrm{PC}-37$ & Particular & $\begin{array}{l}\text { R. Getúlio Vargas, } \\
\text { n. } 1131\end{array}$ & 1,0 & 6 & 4,87 & $\begin{array}{c}\text { Anéis de } \\
\text { concreto }-2 \mathrm{~m} \text {. }\end{array}$ & $\begin{array}{l}\text { Tampa de } \\
\text { concreto }\end{array}$ & Irrigação - horta & $\begin{array}{l}\text { Sim: bomba } \\
\text { elétrica de } \\
\text { superfície. }\end{array}$ & 1996 \\
\hline PG-38 & Particular & $\begin{array}{l}\text { R. Getúlio Vargas, } \\
\text { n. } 2039\end{array}$ & 1,5 & --- & 6,97 & $-\cdots$ & $\begin{array}{l}\text { Tampa de } \\
\text { concreto. }\end{array}$ & $\begin{array}{l}\text { Doméstico - } \\
\text { bebem }\end{array}$ & $\begin{array}{l}\text { Sim: bomba } \\
\text { elétrica de } \\
\text { superficie. }\end{array}$ & 1987 \\
\hline PC-39 & Particular & $\begin{array}{l}\text { R. Camargo } \\
\text { Correia, n. } 256\end{array}$ & 1,2 & & 8,07 & Tijolos $-2 m$ & Sem proteçäo & Não utilizam & Não & 1970 \\
\hline$P C-40$ & Particular & $\begin{array}{l}\text { R. dos Andrades, } \\
\text { n. } 243 / 1313\end{array}$ & 1,2 & $\ldots$ & 17,22 & Tijolos $-2,5 \mathrm{~m}$ & $\begin{array}{l}\text { Tampa de } \\
\text { madeira }\end{array}$ & $\begin{array}{l}\text { Irrigação - } \\
\text { jardim }\end{array}$ & $\begin{array}{l}\text { Sim: bomba } \\
\text { elétrica de } \\
\text { superfície. }\end{array}$ & 1995 \\
\hline PC-41 & Particular & $\begin{array}{l}\text { R. R. Branco, s/n - } \\
\text { Chác. Limoeiro }\end{array}$ & 1,2 & -.. & 12,82 & $\begin{array}{l}\text { Anéis de } \\
\text { concreto }\end{array}$ & $\begin{array}{l}\text { Tampa de } \\
\text { concreto }\end{array}$ & $\begin{array}{c}\text { Doméstico - } \\
\text { bebem e } \\
\text { Irrigaçāo - horta }\end{array}$ & $\begin{array}{l}\text { Sim: bomba } \\
\text { elétrica de } \\
\text { superfície. }\end{array}$ & 1950 \\
\hline PC-42 & Particular & Recinto & 1,2 & & 8,29 & $\begin{array}{c}5 \text { anéis de } \\
\text { concreto na } \\
\text { base }\end{array}$ & $\begin{array}{l}\text { Tampa de } \\
\text { madeira }\end{array}$ & $\begin{array}{c}\text { Doméstico: } \\
\text { bebiam (poço foi } \\
\text { fechado em } \\
2001 \text { ). }\end{array}$ & Não & $\ldots$ \\
\hline
\end{tabular}


Tabela 1C: Cadastro de Poços Cacimba e Tubular - Urânia (SP).

\begin{tabular}{|c|c|c|c|c|c|c|c|c|c|c|}
\hline Poco & Proprietario: & Enderego & Diametro & $\begin{array}{l}\text { Profundidade } \\
(\mathrm{m})\end{array}$ & $\begin{array}{l}\text { Nuvel } \\
\text { deagual }\end{array}$ & Acabamento & $\begin{array}{l}\text { Proteçao } \\
\text { Sanitaria }\end{array}$ & Usos da agua & $\begin{array}{l}\text { Equipado com } \\
\text { bomba ? Qual }\end{array}$ & $\begin{array}{l}\text { provavel ano } \\
\text { de periuracao }\end{array}$ \\
\hline PC-43 & Particular & $\begin{array}{l}\text { R. Bom Jesus, } \\
\text { n. } 1062\end{array}$ & 1,2 & 16,58 & 15,58 & $\begin{array}{l}\text { Anéis de } \\
\text { concreto }\end{array}$ & $\begin{array}{l}\text { Tampa de } \\
\text { concreto }\end{array}$ & Irrigação & $\begin{array}{l}\text { Sim: bomba } \\
\text { elétrica de } \\
\text { superfície. }\end{array}$ & $\cdots$ \\
\hline$P C-44$ & Particular & $\begin{array}{l}\text { R. Pio Branco, } \\
n .1271\end{array}$ & 1,5 & 5,64 & 0,86 & $4 \mathrm{~m}$ de tijolos & $\begin{array}{l}\text { Tampa de } \\
\text { madeira. }\end{array}$ & $\begin{array}{l}\text { Irrigação e } \\
\text { Criação de } \\
\text { animais. }\end{array}$ & $\begin{array}{l}\text { Sim: bomba } \\
\text { elétrica de } \\
\text { superfície. }\end{array}$ & 1994 \\
\hline$P C-45$ & Particular & $\begin{array}{l}\text { R. João } \\
\text { Pessoa/R. } \\
\text { Osvaldo Cruz, n. } \\
171\end{array}$ & $1,5 \mathrm{~m}$ & 17,50 & 13,60 & $\begin{array}{c}7 \text { anéis de } \\
\text { concreto de } \\
0,5 \mathrm{~m} .\end{array}$ & $\begin{array}{l}\text { Tampa de } \\
\text { telhas } \\
\text { quebradas. }\end{array}$ & $\begin{array}{c}\text { Doméstico - } \\
\text { lavagem de } \\
\text { áreas externas, } \\
\text { bebem e } \\
\text { Irrigação - } \\
\text { hortaliças. }\end{array}$ & $\begin{array}{l}\text { Sim: bomba } \\
\text { elétrica de } \\
\text { superficie. }\end{array}$ & 1999 \\
\hline$P C-46$ & Particular & $\begin{array}{l}\text { R. Rio Branco, } \\
\text { n. } 1271 \text { - Chácara } \\
\text { Boa Vista }\end{array}$ & 4 & 64 & 36,00 & $\begin{array}{l}36 \mathrm{~m} \text { de tubo de } \\
\text { PVC geom. Liso } \\
\text { com pedrisco } \\
\text { em volta }\end{array}$ & Tampa de PVC & $\begin{array}{c}\text { Criação de } \\
\text { animais - gado. }\end{array}$ & $\begin{array}{l}\text { Sim: bomba } \\
\text { elétrica de } \\
\text { superficie. }\end{array}$ & 2000 \\
\hline$P C-47$ & Particular & $\begin{array}{l}\text { R. Esperança, } \\
n .773\end{array}$ & 1,5 & 9 & $\cdots$ & $\begin{array}{c}10 \text { anéis de } \\
\text { concreto e tijolos } \\
\text { até o solo }\end{array}$ & $\begin{array}{l}\text { Tampa de } \\
\text { concreto }\end{array}$ & $\begin{array}{c}\text { Doméstico - não } \\
\text { bebem. }\end{array}$ & $\begin{array}{l}\text { Sim: bomba } \\
\text { elétrica de } \\
\text { superficie. }\end{array}$ & 2000 \\
\hline PC-48 & Particular & $\begin{array}{l}\text { SP320, km 592,5 } \\
\text { Sítio Ouro Verde }\end{array}$ & $1,8 \mathrm{~m}$ & $\ldots$ & 11,80 & $\begin{array}{l}\text { Anéis de } \\
\text { concreto }\end{array}$ & $\begin{array}{l}\text { Tampa de } \\
\text { concreto }\end{array}$ & Irrigação & $\begin{array}{l}\text { Sim: bomba } \\
\text { elétrica de } \\
\text { superficie. }\end{array}$ & $>1995$ \\
\hline
\end{tabular}


Tabela 1D: Cadastro de Poços Cacimba e Tubular - Urânia (SP).

\begin{tabular}{|c|c|c|c|c|c|c|c|c|c|c|}
\hline Pogo & Proprietario & $\int$ & olametro & orofundoldo & $\begin{array}{l}\text { Nuve } \\
\text { de agua }\end{array}$ & $\begin{array}{l}\text { Acabamento } \\
\text { (m) }\end{array}$ & Srotegâ & Usos da agua & $\begin{array}{l}\text { Equipado com } \\
\text { bomba }\end{array}$ & $\begin{array}{l}\text { Provavel ano } \\
\text { de perturacáo }\end{array}$ \\
\hline PT-18 & Público & $\begin{array}{l}\text { Av. Pres. } \\
\text { Kennedy - } \\
\text { rodoviária }\end{array}$ & 4 & 60 & -- & $\begin{array}{l}16 \mathrm{~m} \text { de tubo de } \\
\text { PVC geom. liso } \\
\text { com pedrisco } \\
\text { em volta }\end{array}$ & Tampa de PVC & $\begin{array}{c}\text { Doméstico - não } \\
\text { bebem }\end{array}$ & $\begin{array}{l}\text { Sim: bomba } \\
\text { elétrica de } \\
\text { superficie. }\end{array}$ & 2000 \\
\hline PT-19 & Público & $\begin{array}{l}\text { R. Catanduva, } \\
123 \text { - Centro de } \\
\text { Saúde }\end{array}$ & 4 & 60 & 2,90 & $\begin{array}{l}23,69 \mathrm{~m} \text { de tubo } \\
\text { de PVC geom. } \\
\text { liso com } \\
\text { pedrisco em } \\
\text { volta }\end{array}$ & Sem proteçāo & Não utilizada & Não & 2000 \\
\hline PT-20 & Público & $\begin{array}{l}\text { R. Pres. Kenedy, } \\
277 \text { - Centro } \\
\text { Comunitário } \\
\text { municipal }\end{array}$ & 4 & 60 & $+\infty$ & $\begin{array}{c}24,00 m \text { de tubo } \\
\text { de PVC geom. } \\
\text { liso com } \\
\text { pedrisco em } \\
\text { volta }\end{array}$ & Tampa de PVC & Não utilizada & $\begin{array}{l}\text { Sim: bomba } \\
\text { elétrica de } \\
\text { superfície. }\end{array}$ & 2000 \\
\hline PT-21 & Público & $\begin{array}{l}\text { Av. Brasil, } 108- \\
\text { Delegacia }\end{array}$ & 4 & 60 & 10,19 & $\begin{array}{c}23,70 m \text { de tubo } \\
\text { de PVC geom. } \\
\text { liso com } \\
\text { pedrisco em } \\
\text { volta }\end{array}$ & Tampa de PVC & $\begin{array}{c}\text { Doméstico - não } \\
\text { bebem }\end{array}$ & $\begin{array}{l}\text { Sim: bomba } \\
\text { elétrica de } \\
\text { superficie. }\end{array}$ & 2000 \\
\hline PT-22 & Público & $\begin{array}{l}\text { Av. Brasil s/n - } \\
\text { lgreja N. S. } \\
\text { Fátima }\end{array}$ & 4 & 60 & $\cdots$ & $\begin{array}{c}\text { 24,00m de tubo } \\
\text { de PVC geom. } \\
\text { liso com } \\
\text { pedrisco em } \\
\text { volta }\end{array}$ & Tampa de PVC & $\begin{array}{c}\text { Doméstico - } \\
\text { bebem }\end{array}$ & $\begin{array}{l}\text { Sim: bomba } \\
\text { elétrica de } \\
\text { superfície. }\end{array}$ & 2000 \\
\hline PT-23A & Público & $\begin{array}{l}\text { R. Dona } \\
\text { Terezinha, s/n }- \\
\text { Centro de lazer } \\
\text { municipal }\end{array}$ & 4 & 80 & 13,27 & $\begin{array}{c}30 \mathrm{~m} \text { de tubo de } \\
\text { PVC geom. liso } \\
\text { com pedrisco } \\
\text { em volta. }\end{array}$ & Tampa de PVC & $\begin{array}{c}\text { Doméstico - não } \\
\text { bebem }\end{array}$ & $\begin{array}{l}\text { Sim: bomba } \\
\text { elétrica de } \\
\text { superficie. }\end{array}$ & 2001 \\
\hline
\end{tabular}


Tabela 1E: Cadastro de Poços Cacimba e Tubular - Urânia (SP).

\begin{tabular}{|c|c|c|c|c|c|c|c|c|c|c|}
\hline Pogo & Proprietario & Enderego & (plametro & Profundidade & $\begin{array}{l}\text { Nivel de } \\
\text { agua (m) }\end{array}$ & $\begin{array}{c}\text { acaloamento } \\
(\mathbf{m})\end{array}$ & $\begin{array}{l}\text { Protegáo } \\
\text { Sanitaria }\end{array}$ & usos ca aqua & $\begin{array}{l}\text { Eqquipado com } \\
\text { bomba ? oualh }\end{array}$ & $\begin{array}{l}\text { Provavel ano } \\
\text { de perturacaso }\end{array}$ \\
\hline PT-23 & Público & $\begin{array}{l}\text { R. Dona } \\
\text { Terezinha, s/n - } \\
\text { Centro de lazer } \\
\text { municipal }\end{array}$ & 4 & 50 & 13,31 & $\begin{array}{c}20 \mathrm{~m} \text { de tubo } \\
\text { de PVC geom. } \\
\text { liso com } \\
\text { pedrisco em } \\
\text { volta. }\end{array}$ & Tampa de PVC & Não utillizada. & Não & 2000 \\
\hline PT-24 & Público & $\begin{array}{l}\text { R. Aleixo x R. } \\
\text { Benedita Duarte } \\
\text { - Grupo Escolar }\end{array}$ & 4 & 60 & 15,50 & $\begin{array}{l}\sim 30,0 \mathrm{~m} \text { de } \\
\text { tubo de PVC } \\
\text { geom. Liso } \\
\text { com pedrisco } \\
\text { em volta. }\end{array}$ & Tampa de PVC & Não utilizada & não & 2000 \\
\hline PT-25 & Público & $\begin{array}{l}\text { Parque de } \\
\text { Exposições } \\
\text { Municipal }\end{array}$ & 4 & 80 & 10,69 & $\begin{array}{c}23,60 \mathrm{~m} \text { de } \\
\text { tubo de PVC } \\
\text { geom. liso com } \\
\text { pedrisco em } \\
\text { volta. }\end{array}$ & Tampa de PVC & $\begin{array}{c}\text { Doméstico - } \\
\text { bebem }\end{array}$ & $\begin{array}{l}\text { Sim: bomba } \\
\text { elétrica de } \\
\text { superficie. }\end{array}$ & 2000 \\
\hline РТ-26 & Público & $\begin{array}{l}\text { R. Pres. Kenedy } \\
x \text { R. Guadalajara } \\
\text { Estádio } \\
\text { municipal }\end{array}$ & 4 & 60 & 12,24 & $\begin{array}{c}24,00 m \text { de } \\
\text { tubo de PVC } \\
\text { geom. liso com } \\
\text { pedrisco em } \\
\text { volta. }\end{array}$ & Tampa de PVC & $\begin{array}{c}\text { Doméstico - } \\
\text { bebem }\end{array}$ & $\begin{array}{l}\text { Sim: bomba } \\
\text { elétrica de } \\
\text { subsuperfície. }\end{array}$ & 2000 \\
\hline PT-27 & Público & $\begin{array}{l}\text { R. da Saudade } \\
\text { s/n Cemitério }\end{array}$ & 4 & 60 & $\ldots$ & $\begin{array}{c}24,00 m \text { de } \\
\text { tubo de PVC } \\
\text { geom. liso com } \\
\text { pedrisco em } \\
\text { volta. }\end{array}$ & Tampa de PVC & $\begin{array}{c}\text { Doméstico - } \\
\text { bebem }\end{array}$ & $\begin{array}{l}\text { Sim: bomba } \\
\text { elétrica de } \\
\text { superficie. }\end{array}$ & 2000 \\
\hline PT-28 & Particular & $\begin{array}{l}\text { Rod. Euclides da } \\
\text { Cunha/SP } 320, \\
590 \mathrm{~km}\end{array}$ & 4 & 60 & $\cdots$ & $\begin{array}{c}30,00 \mathrm{~m} \text { de } \\
\text { tubo de PVC } \\
\text { geom. liso com } \\
\text { pedrisco em } \\
\text { volta. }\end{array}$ & Tampa de ferro & $\begin{array}{c}\text { Doméstico e } \\
\text { Irrigação }\end{array}$ & $\begin{array}{l}\text { Sim: bomba } \\
\text { elétrica de } \\
\text { superficie. }\end{array}$ & 1998 \\
\hline
\end{tabular}

Continua... 
Tabela 1F: Cadastro de Poços Cacimba e Tubular - Urânia (SP).

\begin{tabular}{|c|c|c|c|c|c|c|c|c|c|c|}
\hline Pocos & moprofurto & moregr & polamerso: & profundidade & Hover & 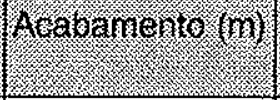 & proverats. & 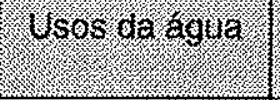 & 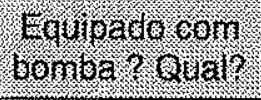 & mopervelano \\
\hline PT-29 & Particular & $\begin{array}{l}\text { Rod. Euclides da } \\
\text { Cunha/SP } 320, \\
\mathrm{Km} 593 .\end{array}$ & 4 & $\sim 80$ & $\cdots$ & $\begin{array}{l}\text { tubo de PVC } \\
\text { geom. liso com } \\
\text { pedrisco em } \\
\text { volta }\end{array}$ & Tampa de ferro & $\begin{array}{c}\text { Doméstico - não } \\
\text { bebem e } \\
\text { Irrigação }\end{array}$ & $\begin{array}{l}\text { Sim: bomba } \\
\text { elétrica de } \\
\text { superfície. }\end{array}$ & 1993 \\
\hline PT-30 & Particular & $\begin{array}{l}\text { Rod. Euclides da } \\
\text { Cunha/SP } 320, \\
\mathrm{Km} 593 .\end{array}$ & 4 & $\sim 80$ & $-\cdots$ & $\begin{array}{l}\text { tubo de PVC } \\
\text { geom. liso com } \\
\text { pedrisco em } \\
\text { volta }\end{array}$ & Tampa de ferro & $\begin{array}{c}\text { Doméstico - não } \\
\text { bebem e } \\
\text { Irrigação }\end{array}$ & $\begin{array}{l}\text { Sim: bomba } \\
\text { elétrica de } \\
\text { superficie. }\end{array}$ & $\cdots$ \\
\hline PT-31 & Particular & $\begin{array}{l}\text { Av, Rio Branco, } \\
2169 .\end{array}$ & 4 & $\cdots$ & $\cdots$ & $\begin{array}{l}\text { tubo de PVC } \\
\text { geom. liso com } \\
\text { pedrisco em } \\
\text { volta }\end{array}$ & Tampa de PVC & $\begin{array}{c}\text { Doméstico - } \\
\text { bebem }\end{array}$ & $\begin{array}{l}\text { Sim: bomba } \\
\text { elétrica de } \\
\text { superficie. }\end{array}$ & $>1996$ \\
\hline PT-32 & Particular & $\begin{array}{l}\text { Rod. Euclides da } \\
\text { Cunha/SP } 320, \\
\mathrm{Km} 593 .\end{array}$ & 4 & $\sim 104$ & $\cdots$ & $\begin{array}{l}\text { tubo de PVC } \\
\text { geom. liso com } \\
\text { pedrisco em } \\
\text { volta }\end{array}$ & Tampa de ferro & $\begin{array}{c}\text { Doméstico - nāo } \\
\text { bebem e } \\
\text { Irrigação }\end{array}$ & $\begin{array}{l}\text { Sim: bomba } \\
\text { elétrica de } \\
\text { superficie. }\end{array}$ & 2001 \\
\hline PT-33 & Particular & $\begin{array}{l}\text { Av. da Saudade } \\
\text { sin-Chácara } \\
\text { Santo Antônio. }\end{array}$ & 4 & 65 & $\ldots$ & $\begin{array}{l}24,00 m \text { de tubo } \\
\text { de PVC geom. } \\
\text { liso com } \\
\text { pedrisco em } \\
\text { volta }\end{array}$ & Tampa de PVC & $\begin{array}{c}\text { Doméstico - } \\
\text { bebem }\end{array}$ & $\begin{array}{l}\text { Sim: bomba } \\
\text { elétrica de } \\
\text { superficie. }\end{array}$ & 2000 \\
\hline PT-34 & Público & $\begin{array}{l}\text { R. da Glória s/n } \\
\text { Santa Casa }\end{array}$ & 4 & 60 & $\cdots$ & $\begin{array}{l}\text { tubo de PVC } \\
\text { geom. Liso com } \\
\text { pedrisco em } \\
\text { volta }\end{array}$ & Tampa de PVC & $\begin{array}{c}\text { Doméstico - não } \\
\text { bebem }\end{array}$ & $\begin{array}{l}\text { Sim: bomba } \\
\text { elétrica de } \\
\text { superfície. }\end{array}$ & 2000 \\
\hline PT-35 & Particular & $\begin{array}{l}\text { Rod. Euclides da } \\
\text { Cunha/SP } 320, \\
597 \mathrm{~km} .\end{array}$ & 4 & 57 & -18 & $\begin{array}{l}30,00 \mathrm{~m} \text { de tubo } \\
\text { de PVC geom. } \\
\text { liso com } \\
\text { pedrisco. }\end{array}$ & Tampa de PVC & $\begin{array}{l}\text { Doméstico- } \\
\text { bebem e } \\
\text { Irrigação }\end{array}$ & $\begin{array}{l}\text { Sim: bomba } \\
\text { elétrica de } \\
\text { superfície. }\end{array}$ & 1995 \\
\hline
\end{tabular}


ANEXO 6

Medidas dos níveis de água e carga hidráulica nos meses de agosto, setembro outubro de 2001 
Tabela 1 - Sumário das cotas topográficas, nível de água e carga hidráulica (m) - agosto/01

\begin{tabular}{|c|c|c|c|c|c|c|}
\hline Pogfo & Data & Coordenada & Coordenada & Coordenada & $\begin{array}{c}\text { Nivel de Agua } \\
\text { Estático } \\
(\mathbf{m})\end{array}$ & $\begin{array}{c}\text { Cota do Nivel de } \\
\text { Aqua } \\
(\mathbf{m})\end{array}$ \\
\hline PC-02 & $17 / 08 / 01$ & 536,88 & 7761,78 & 467,51 & 14,15 & 453,36 \\
\hline PC-09 & $20 / 08 / 01$ & 536,76 & 7761,21 & 448,82 & 6,82 & 442,00 \\
\hline PC-10 & $20 / 08 / 01$ & 536,86 & 7760,63 & 458,93 & 15,74 & 443,19 \\
\hline PC-101 & $19 / 08 / 01$ & 536,55 & 7761,37 & 455,08 & 11,57 & 443,51 \\
\hline PC-24 & $19 / 08 / 01$ & 537,15 & 7760,29 & 463,81 & 16,90 & 446,91 \\
\hline PC-25 & $19 / 08 / 01$ & 537,03 & 7760,95 & 454,11 & 13,00 & 441,11 \\
\hline PC-26 & $19 / 08 / 01$ & 536,81 & 7760,76 & 461,69 & 18,42 & 443,27 \\
\hline PC-28 & $19 / 08 / 01$ & 537,25 & 7760,78 & 444,16 & 6,27 & 437,89 \\
\hline PC-29 & $17 / 08 / 01$ & 537,65 & 7761,57 & 441,$5 ; 5$ & 8,03 & 433,52 \\
\hline PC-32 & $18 / 08 / 01$ & 537,87 & 7761,74 & 436,50 & 7,69 & 428,81 \\
\hline PC-37 & $20 / 08 / 01$ & 537,49 & 7760,91 & 448,09 & 4,87 & 443,22 \\
\hline PC-44 & $20 / 08 / 01$ & 537,66 & 7761,33 & 428,16 & 0,90 & 427,26 \\
\hline PC-45 & $20 / 08 / 01$ & 537,19 & 7760,48 & 455,81 & 13,71 & 442,10 \\
\hline
\end{tabular}


Tabela 2 - Sumário das cotas topográficas, nível de água e carga hidráulica ( $\mathrm{m}$ ) - setembro/01

\begin{tabular}{|c|c|c|c|c|c|c|}
\hline Poço & Data & Coordenada & Coordenada & Coordenada & $\begin{array}{c}\text { Nivel de Agua } \\
\text { Estatico } \\
(\mathbf{m})\end{array}$ & $\begin{array}{c}\text { Cota do Nivel de } \\
\text { Agua } \\
(\mathbf{m})\end{array}$ \\
\hline PC-02 & $26 / 09 / 01$ & 536,88 & 7761,78 & 467,51 & 14,47 & 453,04 \\
\hline PC-06 & $26 / 09 / 01$ & 537,31 & 7761,25 & 455,62 & 11,89 & 443,73 \\
\hline PC-09 & $26 / 09 / 01$ & 536,76 & 7761,21 & 448,82 & 6,97 & 441,85 \\
\hline PC-10 & $26 / 09 / 01$ & 536,86 & 7760,63 & 458,93 & 15,87 & 443,06 \\
\hline PC-101 & $26 / 09 / 01$ & 536,55 & 7761,37 & 455,08 & 11,38 & 443,70 \\
\hline PC-22 & $26 / 09 / 01$ & 537,58 & 7760,75 & 453,90 & 11,32 & 442,57 \\
\hline PC-24 & $26 / 09 / 01$ & 537,15 & 7760,29 & 463,81 & 17,02 & 446,79 \\
\hline PC-25 & $26 / 09 / 01$ & 537,03 & 7760,95 & 454,11 & 13,14 & 440,97 \\
\hline PC-26 & $26 / 09 / 01$ & 536,81 & 7760,76 & 461,69 & 18,48 & 443,21 \\
\hline PC-27 & $26 / 09 / 01$ & 536,84 & 7760,87 & 460,33 & 17,15 & 443,18 \\
\hline PC-28 & $26 / 09 / 01$ & 537,25 & 7760,78 & 444,16 & 6,41 & 437,75 \\
\hline PC-29 & $26 / 09 / 01$ & 537,65 & 7761,57 & 441,55 & 8,15 & 433,40 \\
\hline PC-32 & $26 / 09 / 01$ & 537,87 & 7761,74 & 436,50 & 7,76 & 428,74 \\
\hline PC-34 & $26 / 09 / 01$ & 537,06 & 7760,64 & 457,93 & 11,80 & 446,13 \\
\hline PC-35 & $26 / 09 / 01$ & 537,14 & 7760,69 & 448,79 & 10,57 & 438,23 \\
\hline PC-38 & $26 / 09 / 01$ & 537,59 & 7760,89 & 457,93 & 6,97 & 450,97 \\
\hline PC-40 & $26 / 09 / 01$ & 537,29 & 7760,74 & 443,03 & 7,22 & 435,81 \\
\hline PC-44 & $26 / 09 / 01$ & 537,66 & 7761,33 & 428,16 & 1,93 & 426,23 \\
\hline PC-45 & $26 / 09 / 01$ & 537,19 & 7760,48 & 455,81 & 13,63 & 442,18 \\
\hline & & & & & & \\
\hline
\end{tabular}


Tabela 3 - Sumário das cotas topográficas, nível de água e carga hidráulica (m) - outubro/01

\begin{tabular}{|c|c|c|c|c|c|c|}
\hline Poco & Data & Coordenada & Coordenada & Coordenada & $\begin{array}{c}\text { Nivel de Agua } \\
\text { Estático }\end{array}$ & $\begin{array}{c}\text { Cota do Nivel de } \\
\text { Agua }\end{array}$ \\
\hline PC-02 * & $11 / 07 / 01$ & 536,88 & 7761,78 & 467,51 & 14,67 & $(\mathbf{m})$ \\
\hline PC-04* & $11 / 06 / 01$ & 537,23 & 7761,72 & 459,29 & 16,00 & 452,84 \\
\hline PC-06 & $31 / 10 / 01$ & 537,31 & 7761,25 & 455,62 & 12,05 & 443,29 \\
\hline PC-07 & $31 / 10 / 01$ & 536,91 & 7761,92 & 468,42 & 14,76 & 453,66 \\
\hline PC-08 & $30 / 10 / 01$ & 537,31 & 7761,25 & 439,19 & 3,65 & 435,54 \\
\hline PC-09 & $29 / 10 / 01$ & 536,76 & 7761,21 & 448,82 & 7,10 & 441,72 \\
\hline PC-10 & $29 / 10 / 01$ & 536,86 & 7760,63 & 458,93 & 15,99 & 442,94 \\
\hline PC-13 & $30 / 10 / 01$ & 537,41 & 7761,25 & 439,11 & 4,20 & 434,91 \\
\hline PC-16 & $29 / 10 / 01$ & 537,42 & 7761,21 & 442,36 & 6,55 & 435,81 \\
\hline PC-17 & $30 / 10 / 01$ & 537,60 & 7761,07 & 443,32 & 6,86 & 436,46 \\
\hline PC-101 * & $06 / 11 / 01$ & 536,55 & 7761,37 & 455,08 & 11,65 & 443,43 \\
\hline PC-22 & $29 / 10 / 01$ & 537,58 & 7760,75 & 453,90 & 11,41 & 442,49 \\
\hline PC-23 & $29 / 10 / 01$ & 537,00 & 7760,84 & 463,20 & 15,78 & 447,42 \\
\hline PC-24 & $29 / 10 / 01$ & 537,15 & 7760,29 & 463,81 & 17,27 & 446,54 \\
\hline PC-25 & $29 / 10 / 01$ & 537,03 & 7760,95 & 454,11 & 13,17 & 440,94 \\
\hline PC-26 & $29 / 10 / 01$ & 536,81 & 7760,76 & 461,69 & 18,90 & 442,79 \\
\hline PC-27 & $29 / 10 / 01$ & 536,84 & 7760,87 & 460,33 & 17,16 & 443,17 \\
\hline PC-30 & $30 / 10 / 01$ & 537,76 & 7761,54 & 429,63 & 6,60 & 423,03 \\
\hline PC-32 & $30 / 10 / 01$ & 537,87 & 7761,74 & 436,50 & 7,85 & 428,65 \\
\hline PC-34 & $30 / 10 / 01$ & 537,06 & 7760,64 & 457,93 & 11,80 & 446,13 \\
\hline PC-35 & $30 / 10 / 01$ & 537,14 & 7760,69 & 448,79 & 10,68 & 438,11 \\
\hline PC-37 & $30 / 10 / 01$ & 537,49 & 7760,91 & 448,09 & 4,98 & 443,11 \\
\hline PC-40 & $29 / 10 / 01$ & 537,29 & 7760,74 & 443,03 & 7,35 & 435,68 \\
\hline PC-43 & $30 / 10 / 01$ & 536,55 & 7761,03 & 456,20 & 15,58 & 440,62 \\
\hline PC-44 & $29 / 10 / 01$ & 537,66 & 7761,33 & 428,16 & 2,12 & 426,04 \\
\hline PC-45 & $29 / 10 / 01$ & 537,19 & 7760,48 & 455,81 & 13,80 & 442,01 \\
\hline (5) & & & & \\
\hline
\end{tabular}

(*) Dados não utilizados na confecção do mapa potenciométrico. 
ANEXO 7

Diagramas de Pearson - zona rasa 


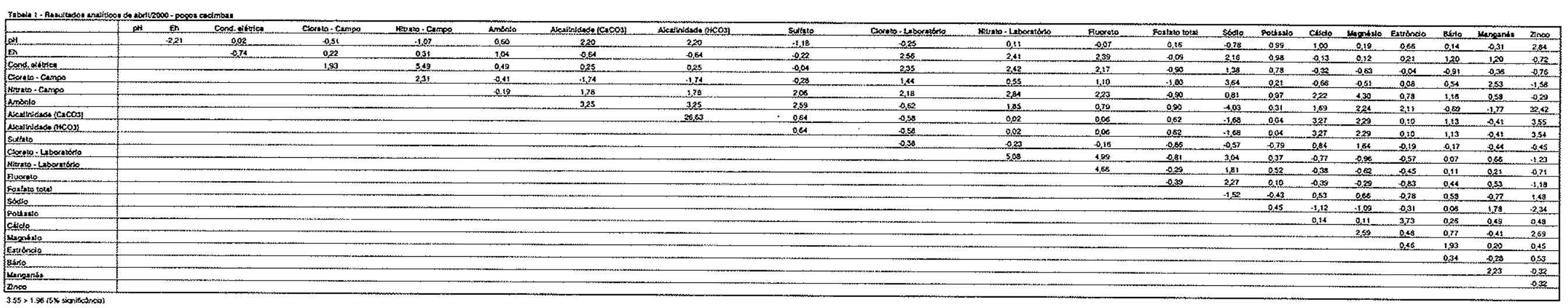




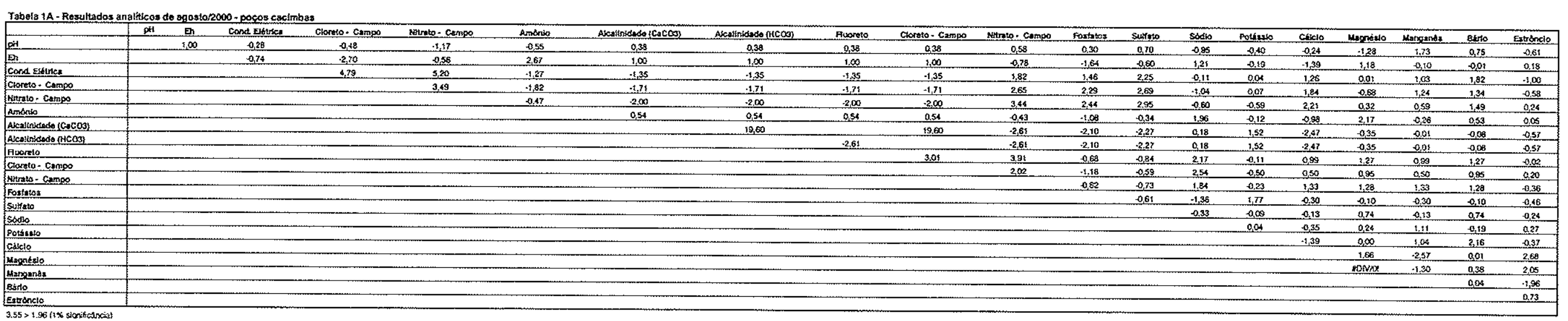




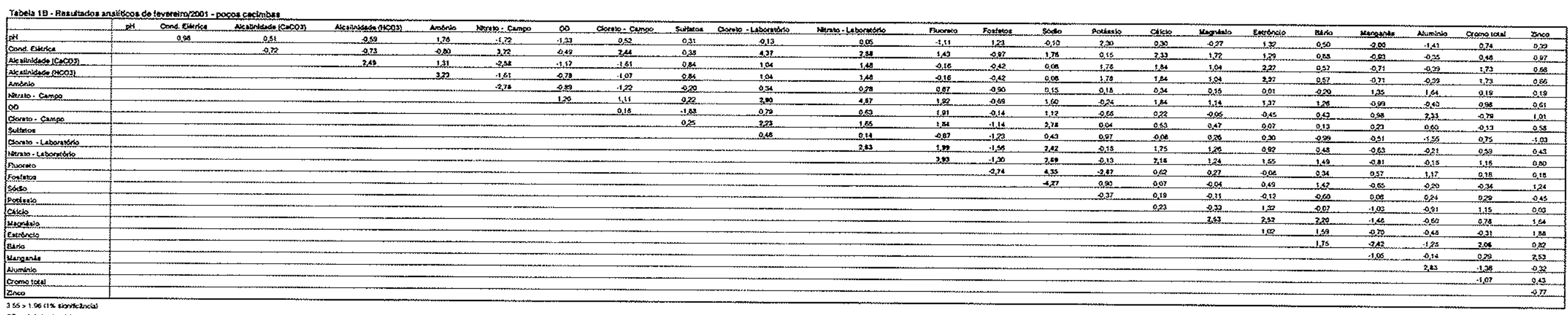

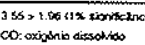




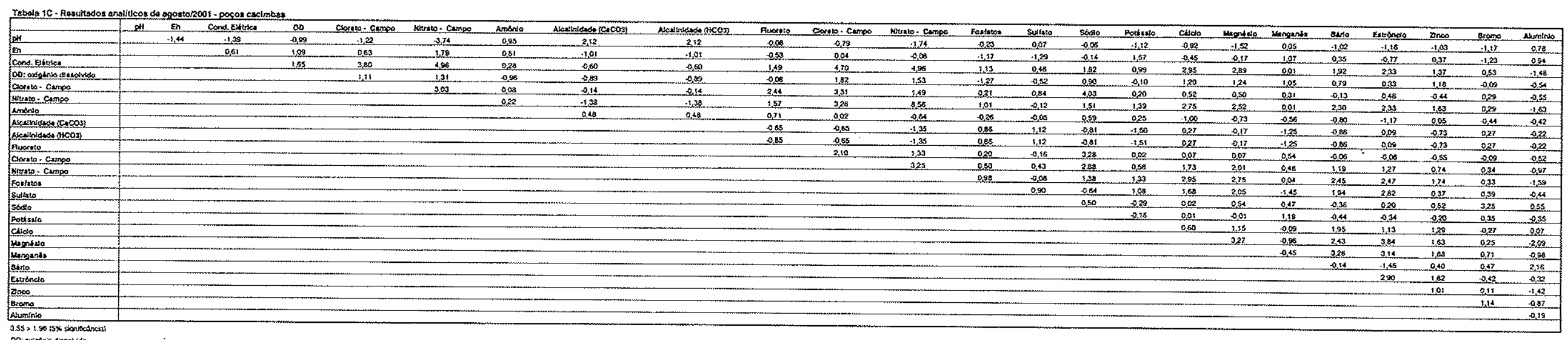




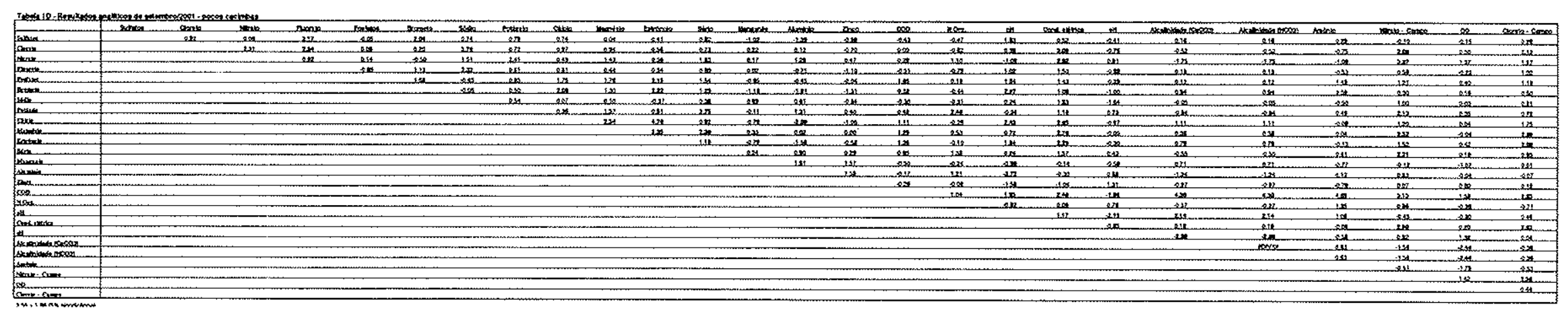


ANEXO 8

Diagramas de Pearson - zona intermediária 


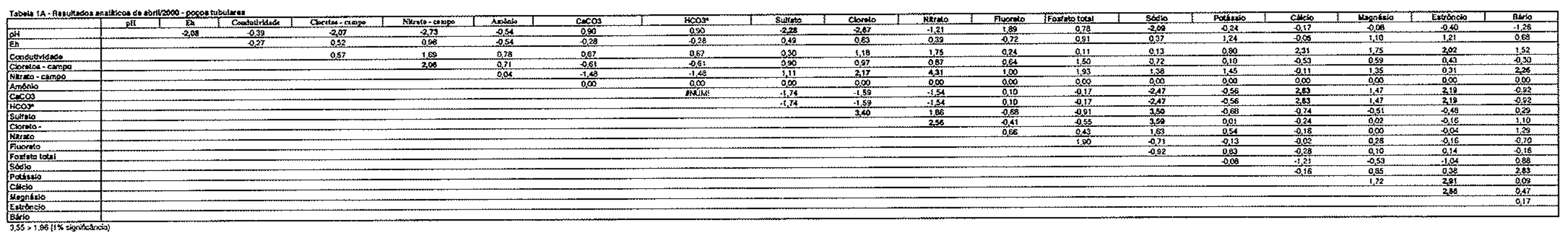




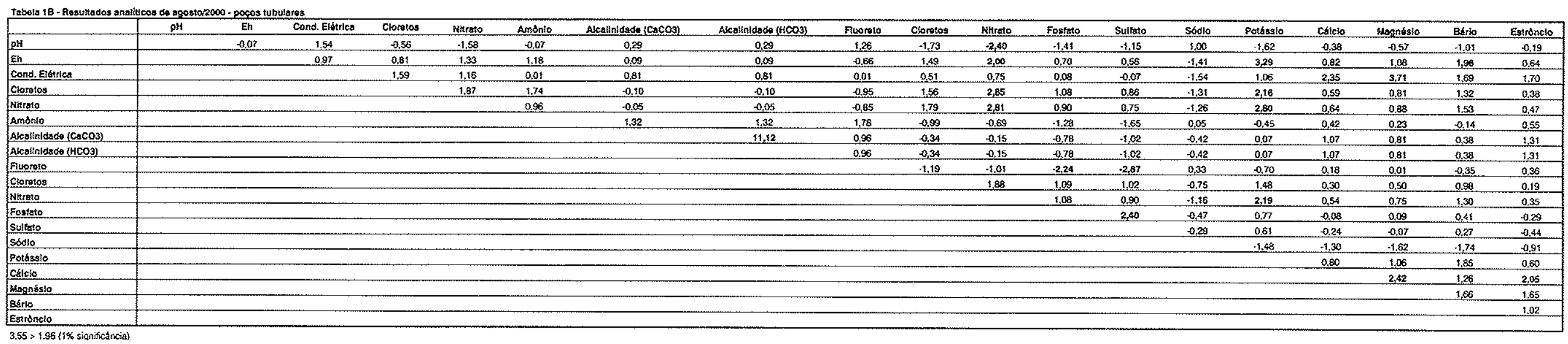




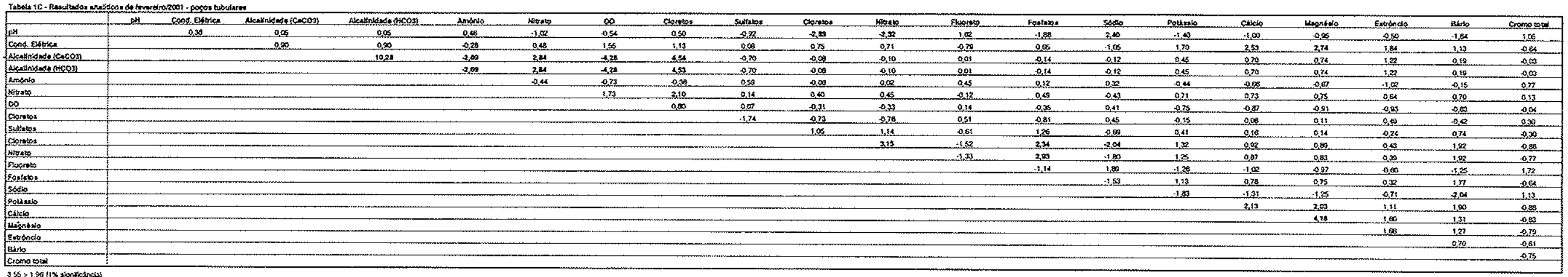




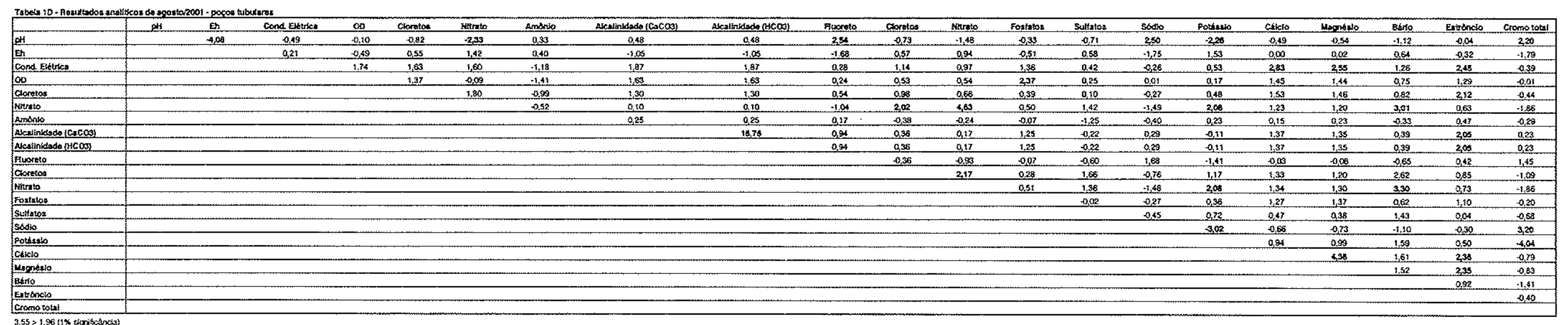




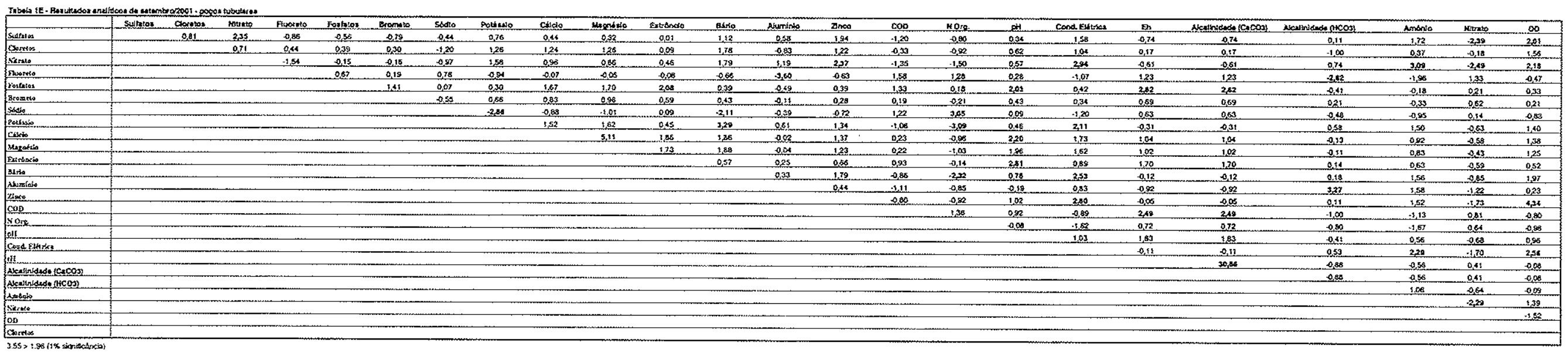




\section{ANEXO 9}

Sumário dos intervalos de concentração, médias aritméticas, desvios padrão, coeficiente de variação (CV's) e número de amostras utilizadas nos cálculos, para os compostos nitrato, cloreto, amônio, pH e Eh 
Tabela 1 - Sumário dos intervalos de concentração de nitrato, médias aritméticas e desvios padrão (mg/L), o número de amostras utilizadas nos cálculos e os CV's obtidos para cada conjunto de dados.

\begin{tabular}{|c|c|c|c|c|c|c|c|c|c|c|}
\hline \multirow{2}{*}{$\begin{array}{l}\text { pala } \\
\text { jun/98 } \\
\end{array}$} & \multirow{2}{*}{ 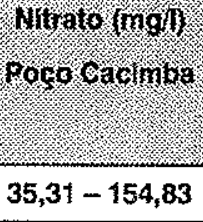 } & \multirow{2}{*}{ 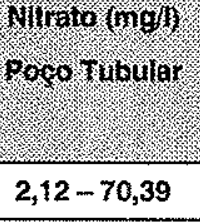 } & \multirow{2}{*}{ 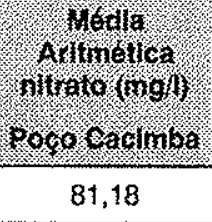 } & \multirow{2}{*}{ 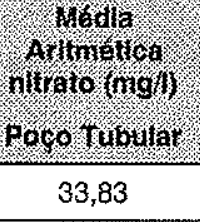 } & \multirow{2}{*}{ 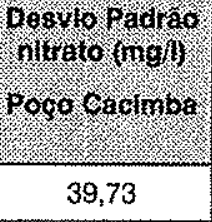 } & \multirow{2}{*}{ 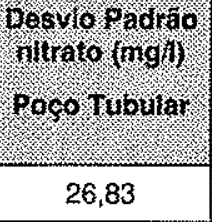 } & \multicolumn{2}{|c|}{ 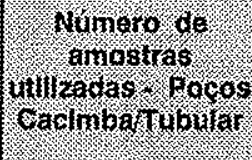 } & \multicolumn{2}{|c|}{ 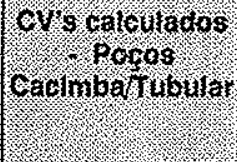 } \\
\hline & & & & & & & 12 & 8 & 0,49 & 0,79 \\
\hline nov/98 & $27,92-113,24$ & $24,86-69,31$ & 67,69 & 43,94 & 23,55 & 19,02 & 7 & 4 & 0,41 & 0,43 \\
\hline $\operatorname{mar} / 99$ & $37,35-163,19$ & $1,46-69,04$ & 77,82 & 36,17 & 35,74 & 27,09 & 10 & 8 & 0,48 & 0,75 \\
\hline Jun/99 & $37,22-160,45$ & $18,60-69,40$ & 85,76 & 48,75 & 36,45 & 21,93 & 11 & 7 & 0,42 & 0,45 \\
\hline$a b r / 00$ & $\mathrm{Nd}-140,00$ & $\mathrm{Nd}-81,00$ & 59,73 & 30,70 & 35,80 & 27,86 & 30 & 20 & 0,60 & 0,91 \\
\hline ago/00 & $3,00-99,00$ & $1,00-59,00$ & 50,71 & 23,53 & 27,90 & 17,89 & 24 & 19 & 0,55 & 0,76 \\
\hline fev/01 & $\mathrm{Nd}-93,00$ & $\mathrm{Nd}-49,00$ & 36,67 & 16,33 & 23,80 & 15,14 & 25 & 18 & 0,65 & 0,93 \\
\hline ago/01 & $N d-88,00$ & $\mathrm{Nd}-46,00$ & 41,56 & 19,78 & 26,24 & 17,12 & 25 & 18 & 0,63 & 0,87 \\
\hline set/01 & $\mathrm{Nd}-97,00$ & $\mathrm{Nd}-48,00$ & 55,08 & 24,29 & 30,31 & 17,76 & 12 & 18 & 0,55 & 0,73 \\
\hline
\end{tabular}

nd: năo detectado 
Tabela $1 \mathrm{~A}$ - Sumário dos intervalos de concentração de cloreto, médias aritméticas e desvios padrão (mg/L), 0 número de amostras utilizadas nos cálculos e os CV's obtíclos para cada conjunto de dados.

\begin{tabular}{|c|c|c|c|c|c|c|c|c|c|c|}
\hline \multirow{2}{*}{$\frac{b^{3}}{\text { bala }}$} & \multirow{2}{*}{ 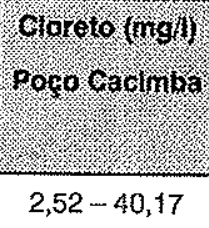 } & \multirow{2}{*}{$\begin{array}{l}\text { pororo (moin) } \\
\text { poco Tubular } \\
0,65-17,32\end{array}$} & \multirow{2}{*}{ 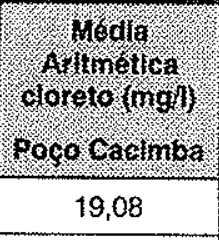 } & \multirow{2}{*}{ 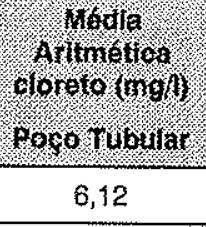 } & \multirow{2}{*}{ 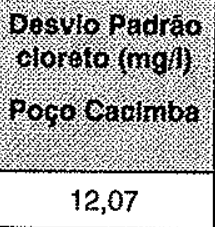 } & \multirow{2}{*}{ 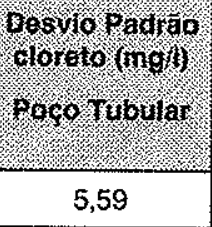 } & \multicolumn{2}{|c|}{ 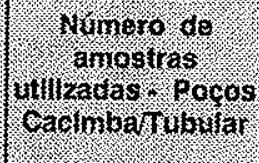 } & \multicolumn{2}{|c|}{ 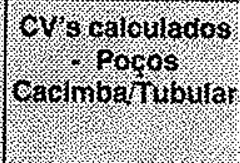 } \\
\hline & & & & & & & 12 & 9 & 0,63 & 0,91 \\
\hline nov $/ 98$ & $3,19-22,23$ & $3,78-23,29$ & 13,68 & 10,92 & 7,73 & 8,64 & 7 & 4 & 0,56 & 0,79 \\
\hline $\operatorname{mar} / 99$ & $2,36-44,00$ & $0,36-20,94$ & 17,79 & 6,62 & 12,56 & 6,69 & 10 & 9 & 0,71 & 1,01 \\
\hline Jun/99 & $2,55-48,65$ & $2,53-23,74$ & 22,47 & 9,68 & 15,13 & 6,94 & 11 & 7 & 0,67 & 0,72 \\
\hline$a b r / 00$ & nd $-68,00$ & $1,00-50,00$ & 15,41 & 11,68 & 14,29 & 13,37 & 22 & 22 & 0,89 & 1,10 \\
\hline ago/00 & $4,00-90,00$ & $4,00-54,00$ & 22,71 & 10,58 & 20,35 & 11,48 & 19 & 19 & 0,54 & 0,81 \\
\hline fev/01 & $2,00-90,00$ & $2,00-62,00$ & 25,87 & 19,89 & 20,89 & 20,90 & 18 & 18 & 0,49 & 0,92 \\
\hline ago/01 & $2,00-43,00$ & $3,00-45,00$ & 19,84 & 11,39 & 14,58 & 10,27 & 18 & 18 & 0,64 & 1,63 \\
\hline set/01 & nd $-49,00$ & $\mathrm{Nd}-25,00$ & 24,58 & 6,57 & 19,10 & 9,31 & 7 & 7 & 0,84 & 0,92 \\
\hline
\end{tabular}

nd: nâo detectado 
Tabela $1 \mathrm{~B}$ - Sumário dos intervalos de valores de condutividade elétrica, médias aritméticas e desvios padrão $(\mu \mathrm{s} / \mathrm{cm})$, o número de amostras utilizadas nos cálculos e os CV's obtidos para cada conjunto de dados.

\begin{tabular}{|c|c|c|c|c|c|c|c|c|c|c|}
\hline \multirow{2}{*}{ 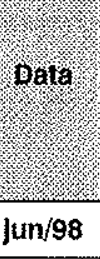 } & 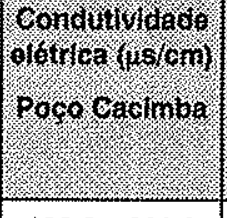 & 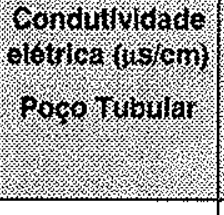 & 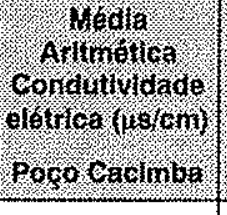 & 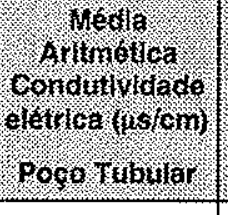 & 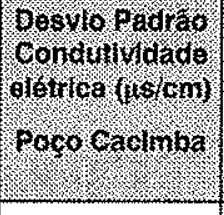 & \multirow{2}{*}{ 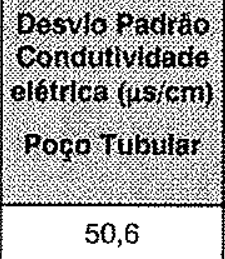 } & \multicolumn{2}{|c|}{ 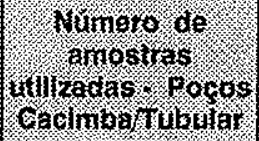 } & \multicolumn{2}{|c|}{ 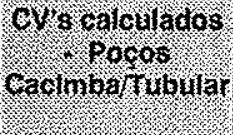 } \\
\hline & $126,6-390,0$ & $157,1-318,0$ & 280,5 & 240,9 & 101,7 & & 12 & 9 & 0,36 & 0,21 \\
\hline nov/9B & $120,8-332,0$ & $137,3-265,0$ & 234,0 & 217,8 & 78,9 & 40,8 & 12 & 9 & 0,34 & 0,19 \\
\hline $\operatorname{mar} / 99$ & $124,0-512,0$ & $93,3-279,0$ & 265,2 & 213,6 & 107,0 & 58,7 & 12 & 9 & 0,40 & 0,27 \\
\hline Jun/99 & $121,0-486,0$ & $140,3-266,0$ & 268,1 & 227,3 & 110,8 & 51,9 & 12 & 9 & 0,41 & 0,23 \\
\hline$a b r / 00$ & $24,0-518,0$ & $83,0-407,0$ & 228,7 & 243,2 & 105,2 & 80,0 & 34 & 21 & 0,46 & 0,33 \\
\hline ago/00 & $17,0-361,0$ & $80,0-331,0$ & 210,1 & 203,8 & 84,4 & 82,8 & 24 & 19 & 0,40 & 0,41 \\
\hline fev/01 & $17,0-370,0$ & $71,0-324,0$ & 212,2 & 205,2 & 82,9 & 75,6 & 25 & 18 & 0,39 & 0,37 \\
\hline ago/01 & $20,0-390,0$ & $84,0-331,0$ & 208,7 & 229,9 & 92,3 & 73,7 & 25 & 18 & 0,44 & 0,32 \\
\hline set/01 & $85,3-386,0$ & $84,6-233,0$ & 236,4 & 169,5 & 89,9 & 53,6 & 12 & 7 & 0,38 & 0,32 \\
\hline
\end{tabular}

nd: näo detectado 
Tabela 1C - Sumário dos intervalos de concentração de amônio, médias aritméticas e desvios padrăo (mg/L), 0 número de amostras utilizadas nos cálculos e os CV's obtidos para cada conjunto de dados.

\begin{tabular}{|c|c|c|c|c|c|c|c|c|c|c|}
\hline pata & 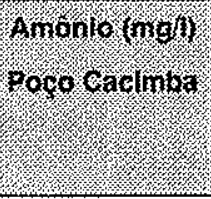 & Anonoringul & 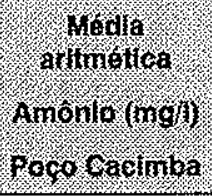 & 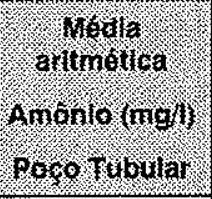 & 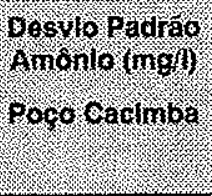 & 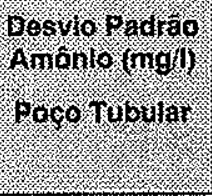 & 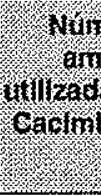 & 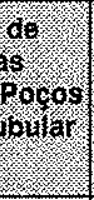 & evs sa & 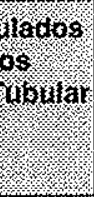 \\
\hline jun/98 & $0,02-0,08$ & $n d-0,03$ & 0,04 & 0,01 & 0,02 & 0,01 & 12 & 9 & 0,53 & 1,43 \\
\hline nov/98 & $0,01-0,11$ & nd $-0,08$ & 0,04 & 0,02 & 0,03 & 0,03 & 12 & 8 & 0,71 & 1,46 \\
\hline mari99 & $0,01-0,07$ & nd $-0,09$ & 0,03 & 0,03 & 0,02 & 0,03 & 12 & 9 & 0,60 & 1,06 \\
\hline$a b r / 00$ & $0,10-1,20$ & $0,10-0,50$ & 0,52 & 0,28 & 0,28 & 0,12 & 13 & 13 & 0,54 & 0,42 \\
\hline ago/00 & $0,10-0,40$ & nd $-0,40$ & 0,25 & 0,24 & 0,09 & 0,11 & 24 & 18 & 0,38 & 0,45 \\
\hline fev/01 & $0,10-1,30$ & $0,10-0,50$ & 0,35 & 0,31 & 0,24 & 0,12 & 24 & 17 & 0,67 & 0,41 \\
\hline agolo1 & nd $-0,30$ & $n d-0,40$ & 0,18 & 0,18 & 0,10 & 0,11 & 25 & 18 & 0,56 & 0,63 \\
\hline set/ot & $0,10-0,70$ & $n d-0,60$ & 0,33 & 0,27 & 0,19 & 0,18 & 12 & 7 & 0,57 & 0,66 \\
\hline
\end{tabular}

nd: nāo detectado 
Tabela 1D - Sumário dos intervalos de valores de Eh, médias aritméticas e desvios padrão (mV), o número de amostras utilizadas nos cálculos e os CV's obtidos para cada conjunto de dados.

\begin{tabular}{|c|c|c|c|c|c|c|c|c|c|c|}
\hline Dara & pocosolong & 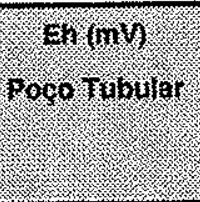 & 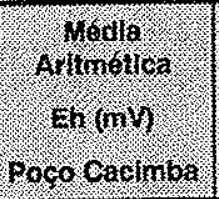 & 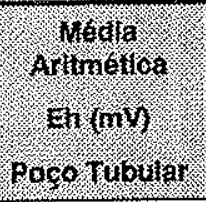 & 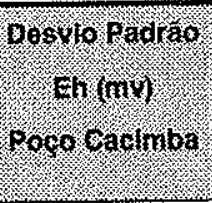 & 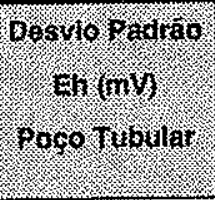 & 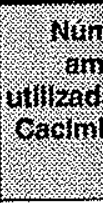 & 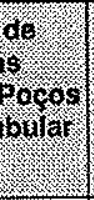 & $\begin{array}{l}\text { crisca } \\
\text { cacting }\end{array}$ & $\begin{array}{l}\text { Madros } \\
\text { os } \\
\text { provial }\end{array}$ \\
\hline jun/98 & $471-513$ & $488-514$ & 490 & 495 & 16 & 17 & 12 & 9 & 0,03 & 0,03 \\
\hline nov/98 & $513-595$ & $410-547$ & 556 & 496 & 27 & 44 & 12 & 9 & 0,05 & 0,09 \\
\hline $\operatorname{mar} / 99$ & $490-535$ & $453-502$ & 513 & 483 & 17 & 15 & 12 & 9 & 0,03 & 0,03 \\
\hline jun/99 & $474-568$ & $462-537$ & 509 & 512 & 56 & 25 & 12 & 9 & 0,11 & 0,05 \\
\hline abr/00 & $360-721$ & $381-535$ & 467 & 454 & 67 & 42 & 33 & 21 & 0,14 & 0,09 \\
\hline ago/00 & $290-558$ & $445-567$ & 500 & 526 & 66 & 29 & 24 & 19 & 0,13 & 0,06 \\
\hline ago/01 & $516-640$ & $484-610$ & 581 & 542 & 35 & 47 & 25 & 19 & 0,06 & 0,09 \\
\hline setor & $437-570$ & $407-692$ & 534 & 532 & 40 & 97 & 12 & 7 & 0,08 & 0,18 \\
\hline
\end{tabular}


Tabela IE - Sumário dos intervalos de valores de pH, médias aritméticas e desvios padrão, o número de amostras utilizadas nos cálculos e os CV's obtidos para cada conjunto de dados.

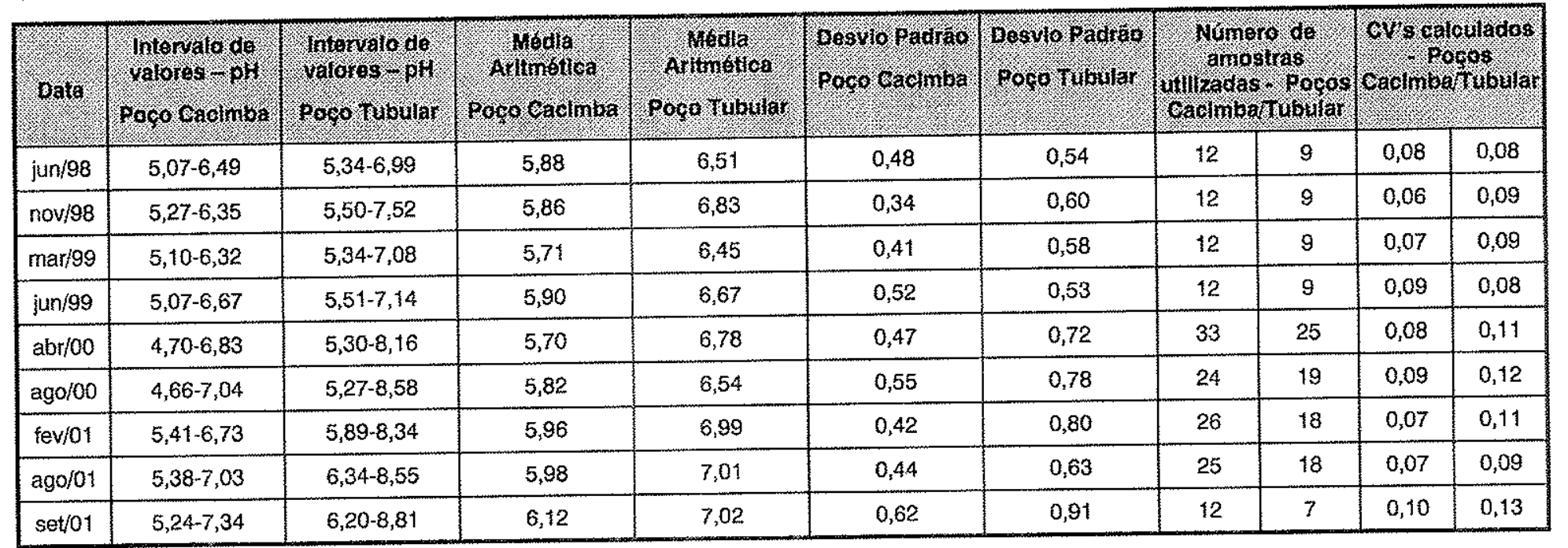

